\title{
Improving maternal and neonatal health: Measuring the impact of the PAIMAN project in ten districts in Pakistan-Comparing baseline and end-line household survey findings (2005-2010)
}

Arshad Mahmood

Population Council

Follow this and additional works at: https://knowledgecommons.popcouncil.org/departments_sbsr-rh

Part of the International Public Health Commons, Maternal and Child Health Commons, Social and Behavioral Sciences Commons, and the Women's Health Commons How does access to this work benefit you? Let us know!

\section{Recommended Citation}

Mahmood, Arshad. 2010. "Improving maternal and neonatal health: Measuring the impact of the PAIMAN project in ten districts in Pakistan-Comparing baseline and end-line household survey findings (2005-2010)." Islamabad: The PAIMAN Project, JSI Research and Training Institute. 


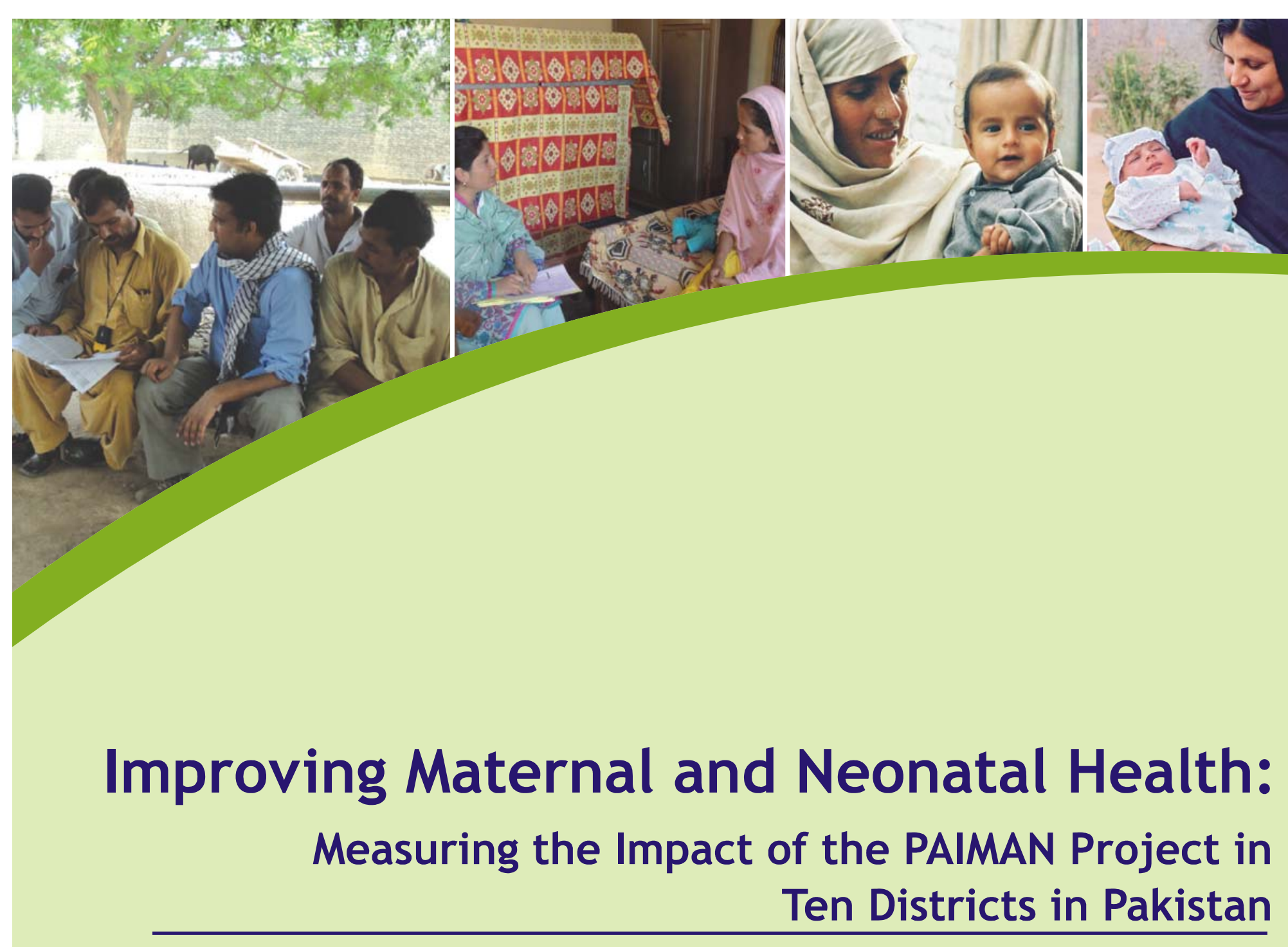

Comparing Baseline and Endline Household Survey Findings (2005-2010) 



\section{Improving Maternal and Neonatal Health:}

Measuring the Impact of the PAIMAN Project in Ten Districts in Pakistan

Comparing Baseline and Endline Household Survey Findings (2005-2010)

Dr. Arshad Mahmood 
Copyright (C) 2010 by The PAIMAN Project, JSI Research and Training Institute, Inc.- All Rights Reserved Any part of this publication may be reproduced or translated by duly acknowledging the source.

The PAIMAN Project is funded by the United States Agency for International Development and implemented by JSI Research \& Training Institute, Inc. in conjunction with Aga Khan University, Contech International, Save the Children, US, The Population Council, and Johns Hopkins University/CCP

This report was prepared by the Population Council, an international, non-profit, non-governmental organization established in 1952, seeks to improve the well-being and reproductive health of current and future generations around the world and to help achieve a humane, equitable, and sustainable balance between people and resources.

The Council analyzes population issues and trends; conducts research in the reproductive sciences; develops new contraceptives; works with public and private agencies to improve the quality and outreach of family planning and reproductive health services; helps governments design and implement effective population policies; communicates the results of research in the population field to diverse audiences; and helps strengthen professional resources in developing countries through collaborative research and programs, technical exchange, awards, and fellowships.

\section{For inquiries, please contact:}

Population Council

\# 7, Street 62, F-6/3, Islamabad, Pakistan

Tel: 92518445566

Fax: 92512821401

Email: pcpak@popcouncil.org

Web: http://www.popcouncil.org

http://www.paiman.org.pk

Published: October 2010

\section{Disclaimer}

"This study/report is made possible by the generous support of the American people through the United States Agency for International Development (USAID). The contents are the responsibility of JSI Research \& Training Institute, Inc and do not necessarily reflect the views of USAID or the United States Government." 


\section{Table of Contents}

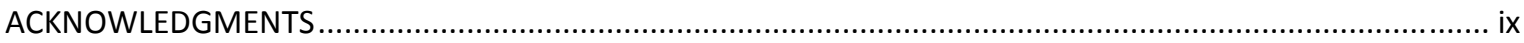

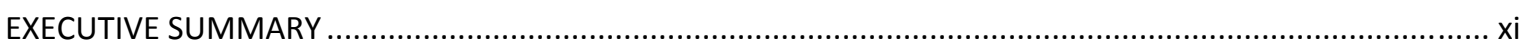

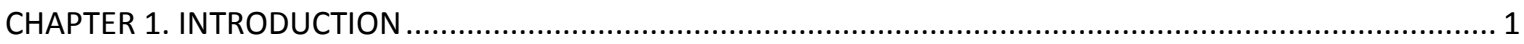

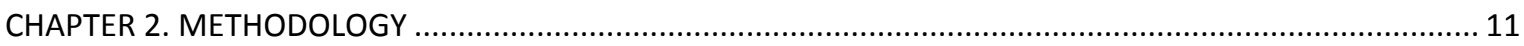

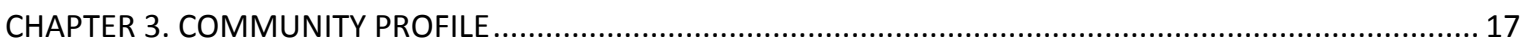

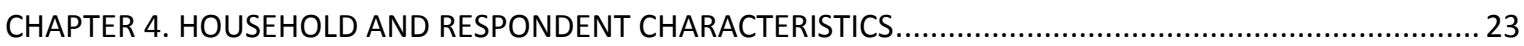

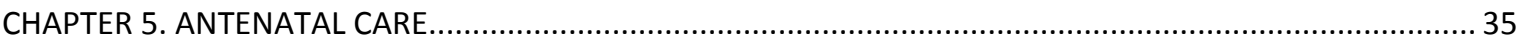

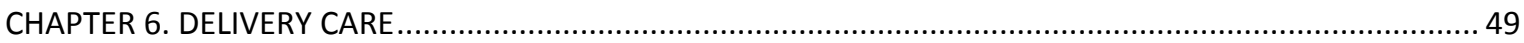

CHAPTER 7. POSTPARTUM CARE AND CONTRACEPTIVE KNOWLEDGE AND USE......................................59

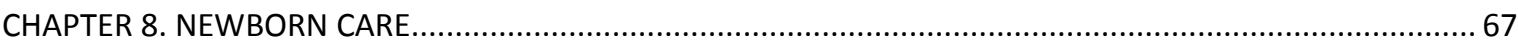

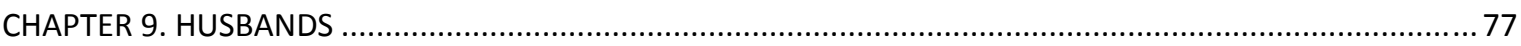

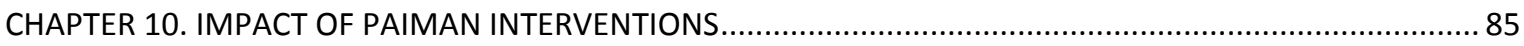

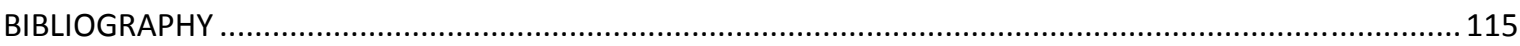

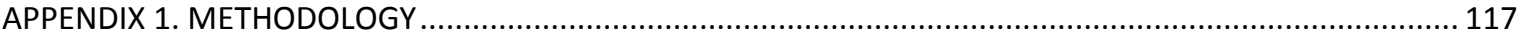

\section{List of Boxes}

KNOWLEDGE OF AT LEAST THREE DANGER SIGNS DURING PREGNANCY ........................................... 37

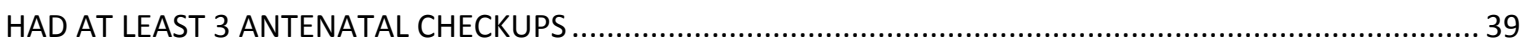

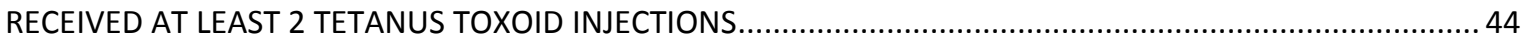

KNOWLEDGE OF AT LEAST THREE DANGER SIGNS DURING DELIVERY ..............................................50

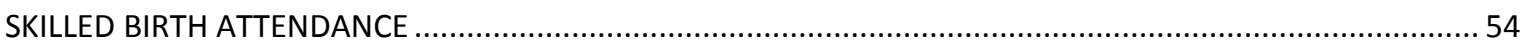

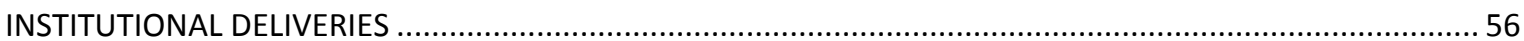

DECISIONMAKING AND THE THREE DELAYS IN OBSTETRIC EMERGENCIES .........................................57

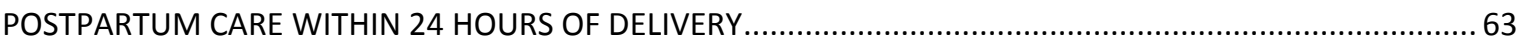

KNOWLEDGE OF AT LEAST THREE DANGER SIGNS IN NEWBORNS WITHIN ONE HOUR AFTER BIRTH..........73

\section{List of Tables}

Table 2.1: Number of PSUs in each district, by area, according to coverage

Table 2.2: Distribution of households and currently married women of reproductive age, by interview

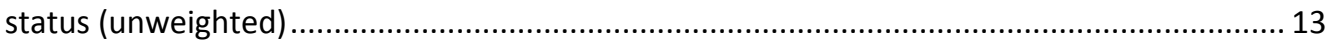

Table 3.1: Community health facilities used most frequently, by selected variables..................................20

Table 4.1: Percentage distribution of household population, by age, sex and education............................24

Table 4.2: Percentage of households, by selected household characteristics.........................................25

Table 4.3: Percentage distribution of household population, by age and marital status............................27

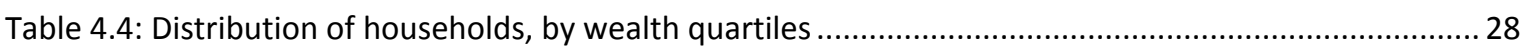

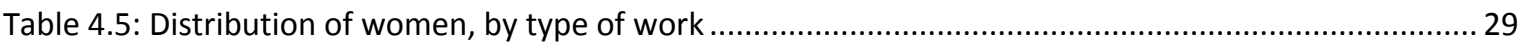

Table 5.1: Percentage of women, by attitude toward ANC and use of ANC during last pregnancy..............38

Table 7.1: Percentage distribution of women, by attitude toward and use of postpartum services after

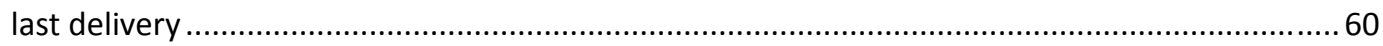


Table 7.2: Percentage of women reporting spontaneous knowledge, ever use and current use of family planning methods, by method.

Table 7.3: Percentage of women who discontinued contraceptive use, by reasons*....

Table 8.1: Percentage of women whose newborns were examined after birth, by selected variables ......... 70

Table 9.1: Percentage distribution of husbands of currently married women of reproductive age, by occupation.

Table 9.2: Percentage of husbands of currently married women of reproductive age, by attitude toward ANC, skilled birth attendance and postpartum care

Table 9.3: Percentage of husbands, by source of knowledge about danger signs in pregnancy, delivery, postpartum and newborn .

Table 10.1: Percentage of women who were exposed to any PAIMAN communication and behavior change intervention, by district and specific intervention ....

Table 10.2: Percentage of different types of deliveries conducted in within $15 \mathrm{kms}$. of upgraded and non-upgraded RHCs.

Table 10.3: Percentage of women, by clean delivery practices used by TBAs during last home delivery, with 95 percent confidence intervals and $p$-values, baseline and endline

Table 10.4: Percentage of women in rural areas who had knowledge of at least 3 danger signs during pregnancy, delivery and postpartum period, with 95 percent confidence intervals and $\mathrm{p}$ values, by exposure to WSG meeting

Table 10.5: Percentage of women who had at least 3 ANC checkups, with 95 percent confidence intervals and p-values, by residence, for survey, presence of LHW and WSG attendance .........98

Table 10.6: Percentage of women who had at least 2 TT injections, with 95 percent confidence intervals and $\mathrm{p}$-values, by residence, for survey, presence of LHW and WSG attendance

Table 10.7: Percentage of women who used skilled birth assistance, with 95 percent confidence intervals and p-values, by residence, for survey, presence of LHW and WSG attendance

Table 10.8: Percentage of women who received postpartum care within 24 hours after delivery, 95 percent confidence intervals and p-values, by residence, presence of LHW and WSG attendance

Table 10.9: Percentage of women in rural and urban areas who had knowledge of at least 3 danger signs of pregnancy, delivery and postpartum period, with 95 percent confidence intervals and $\mathrm{p}$-values, by exposure to PAIMAN interventions

Table 10.10: Percentage of women who had at least 3 ANC checkups, with 95 percent confidence intervals and $p$-values, by residence and exposure to at least one PAIMAN communication and behavior change intervention.

Table 10.11: Percentage of women who had at least 2 TT injections, with 95 percent confidence intervals and $p$-values, by residence and exposure to at least one PAIMAN communication and behavior change intervention.

Table 10.12: Percentage of women who used skilled birth assistance, with 95 percent confidence intervals and $p$-values, by residence and exposure to at least one PAIMAN communication and behavior change intervention

Table 10.13: Percentage of women who received postpartum care within 24 hours after delivery, with 95 percent confidence intervals and $p$-values, by residence and exposure to at least one PAIMAN communication and behavior change intervention

Table 10.14: Estimated neonatal, early neonatal and perinatal mortality rates, with 95 percent confidence intervals and p-values, by exposure to at least one PAIMAN communication and behavior change interventions 


\section{List of Figures}

Figure 3.1: Percentage distribution of communities, by area and distance to main road.......................... 17

Figure 3.2: Percentage of communities, by area and availability of transport..........................................18

Figure 3.3: Percentage distribution of communities, by area and distance to nearest health facility at baseline.

Figure 3.4: Percentage of communities, by area and availability of selected community health providers.

Figure 3.5: Percentage distribution of communities, by area and type of drainage/sewerage system .........21

Figure 4.1a: Percent distribution of household population by age and sex, baseline survey, 2005.............23

Figure 4.1b: Percent distribution of household population by age and sex, endline survey, $2010 \ldots \ldots \ldots \ldots . . . .23$

Figure 4.2: Percentage of households, by selected household possessions..............................................26

Figure 4.3: Percentage distribution of households, by number of bedrooms .............................................26

Figure 4.4: Percentage distribution of women, by age group .................................................................28

Figure 4.5: Percentage distribution of women, by education ...............................................................29

Figure 4.7: Percentage of women who listened to the radio, by type of program ....................................32

Figure 4.8: Percentage distribution of women, by how often they read newspapers .................................32

Figure 4.9: Percentage of women who watched/read/heard a maternal/newborn health-related program in the three months preceding the survey..................................................... 33

Figure 5.1: Percentage distribution of women, by knowledge of danger signs during pregnancy................36

Figure 5.2: Percentage of women, by knowledge of specific danger signs during pregnancy .......................36

Figure 5.3: Percentage of women, by attitude toward ANC and use of ANC during last pregnancy.............38

Figure 5.4: Percentage distribution of women, by timing of first ANC checkup during last pregnancy .........40

Figure 5.5: Percentage of women, by place or provider of ANC checkups during last pregnancy (for four main reported sources)

Figure 5.6: Percentage of women, by specific services given by healthcare provider during last pregnancy.

Figure 5.7: Percentage of women, by type of advice given by healthcare provider during last pregnancy.

Figure 5.8: Percentage of women, by duration of use of iron supplements during last pregnancy..............42

Figure 5.9: Percentage of women, by awareness and use of TT injections during last pregnancy ...............43

Figure 5.10: Percentage of women who experienced complications during last pregnancy, by specific complications

Figure 5.11: Percentage distribution of women who had complications during their last pregnancy, by source of treatment

Figure 5.12: Percentage distribution of women who did not seek treatment for complications during last pregnancy, by reason . . 46

Figure 5.13: Percentage of women who made preparations for last delivery, by type of preparations........47

Figure 6.1: Percentage distribution of women, by knowledge of danger signs during delivery....................49

Figure 6.2: Percentage distribution of women, by knowledge of specific danger signs during delivery........51

Figure 6.3: Percentage of women, by type of delivery and presence of skilled birth attendant at last delivery...

Figure 6.4: Percentage distribution of women, by place of last delivery ..................................................52

Figuer 6.5: Percentage distribution of women who delivered at home, by skill of birth attendant .............52

Figure 6.6: Percentage distribution of women who delivered at home, by type of birth attendant ..... 
Figure 6.7: Percentage of women who experienced complications on the day of last delivery, by specific complications.

Figure 6.8: Percentage of women who sought treatment for complications on the day of last delivery, by source of treatment

Figure 6.9: Percentage distribution of women who did not seek treatment for their complication(s) during last delivery, by reason

Figure 7.1: Percentage distribution of women, by knowledge of danger signs during postpartum period.

Figure 7.2: Percentage of women, by knowledge of specific danger signs during postpartum period..........60

Figure 7.3: Percentage of women, by attitude toward and use of postpartum services after last delivery.

Figure 7.4: Percentage of women who experienced complications during postpartum period after last delivery, by specific complications......

Figure 7.5: Percentage distribution of women who experienced complication in postpartum period after last delivery, by source of treatment .

Figure 7.6: Percentage distribution of women who did not seek treatment for complications in postpartum period during last delivery, by reasons

Figure 8.1: Percentage distribution of women, by knowledge of danger signs in newborns within one hour after birth

Figure 8.2: Percentage of women, by knowledge of specific danger signs in newborns within one hour after birth.

Figure 8.3: Percentage of women, by knowledge of specific danger signs in newborns within the first week after birth

Figure 8.4: Percentage of women, by clean delivery practices used by attendant during last home delivery......

Figure 8.5: Percentage of women whose last delivery was at home, by safe delivery practices used by birth attendant.

Figure 8.6: Percentage of women who reported at least one danger sign/symptom in newborns within one hour of birth, by specific signs/symptoms

Figure 8.7: Percentage of women who reported at least one danger sign/symptom in newborns within one week of birth, by specific danger signs/symptoms.....

Figure 8.8: Percentage of women who sought treatment for their newborns with danger signs/symptoms within one hour of birth at last home delivery, by source of treatment.....

Figure 8.9: Percentage of women who sought treatment for their newborns with danger signs/symptoms within the first week of life after last home delivery, by source of treatment

Figure 8.10: Percentage of women whose children under 3 years of age had diarrhea in the two weeks prior to the survey, by treatment given at home

Figure 8.11: Percentage of women whose children under 3 years of age were treated for diarrhea in the two weeks prior to the survey, by treatment facility

Figure 8.12: Percentage of women whose children under 3 years of age had symptoms of ARI, by symptoms.....

Figure 8.13: Percentage of women whose children under 3 years of age had ARI symptoms in the two weeks prior to the survey and were given something at home, by treatment .

Figure 8.14: Percentage of women whose children under 3 years of age had symptoms of ARI in the two weeks prior to the survey and were taken for treatment, by treatment facility

Figure 9.1: Percentage distribution of husbands of currently married women of reproductive age, by age group 
Figure 9.2: Percentage distribution of husbands of currently married women of reproductive age, by education.

Figure 9.3: Percentage of husbands of currently married women of reproductive age, by exposure to mass media

Figure 9.4: Percentage of husbands of currently married women of reproductive age, by hearing/seeing/ reading maternal and newborn health messages and the source of interpersonal communication

Figure 9.5: Percentage of husbands of currently married women of reproductive age, by their perceptions of their responsibilities during childbirth

Figure 9.6: Percentage of husbands of currently married women of reproductive age, by knowledge of specific danger signs during pregnancy....

Figure 9.7: Percentage of husbands of currently married women of reproductive age, by knowledge of specific danger signs during delivery

Figure 9.8: Percentage of husbands of currently married women of reproductive age, by knowledge of specific danger signs during postpartum period.

Figure 9.9: Percentage of husbands of currently married women of reproductive age, by knowledge of specific danger signs in newborns

Figure 9.10: Percentage distribution of husbands of currently married women of reproductive age, by attitudes about antenatal care, skilled birth assistance and postpartum care, according to exposure to PAIMAN interventions

Figure 10.1: Percentage distribution of women, by awareness of and exposure to PAIMAN interventions according to number of interventions

Figure 10.2: Percentage of women who were exposed to at least one PAIMAN intervention, by district .... 87

Figure 10.3: Percentage of women, by exposure to specific interventions. .88

Figure 10.4: Percentage of women who had attended WSG meetings, by recall of specific message received about maternal health

Figure 10.5: Percentage of women who attended WSG meetings, by recall of specific messages given on newborn care.

Figure 10.6: Percentage of women who watched TV drama/advertisements about maternal health, by recall of specific messages

Figure 10.7: Percentage of women who watched TV drama/advertisements about newborn care, by recall of specific messages received

Figure 10.8: Percentage of deliveries conducted in public-sector health facilities, by type of delivery.........93

Figure 10.9: Percentage of deliveries conducted in public sector health facilities among women living within $15 \mathrm{kms}$. of upgraded RHCs.

Figure 10.10: Percentage of deliveries conducted in public health sector facilities among women living within $15 \mathrm{kms}$. of non-upgraded RHCs....

Figure 10.11: Percentage of women who were of aware of a CMW in their community, by knowledge of the tasks a CMW can perform.

Figure 10.12: Percentage of women, by clean delivery practices used by TBAs during last home delivery

Figure 10.13: Percentage of women who had at least 3 ANC checkups, by residence, presence of LHW and WSG attendance

Figure 10.14: Percentage of women who received at least 2 TT injections, by residence, presence of LHW and WSG attendance

Figure 10.15: Percentage of women who utilized skilled birth assistance, by residence, presence of LHW and WSG attendance

Figure 10.16: Percentage of women who received postpartum care within 24 hours after delivery, by residence, presence of LHW and WSG attendance 
Figure 10.17: Percentage of women in rural areas, by impact of PAIMAN communication and behavioral change intervention of women's support groups on four maternal health indicators

Figure 10.18: Percentage of women who had at least 3 ANC checkups, by residence, survey and exposure to at least one PAIMAN communication and behavior change intervention ......... 106

Figure 10.19: Percentage of women who had at least 2 TT injections, by residence, according to survey and exposure to at least one PAIMAN communication and behavior change intervention

Figure 10.20: Percentage of women who used skilled birth assistance, by residence and exposure to at least one PAIMAN communication and behavior change intervention 108

Figure 10.21: Percentage of women who utilized postpartum care within 24 hours, by residence and exposure to at least one PAIMAN intervention

Figure 10.22: Percentage of women in rural areas by exposure to at least one PAIMAN communication and behavior change intervention, by change over time in selected maternal health indicators

Figure 10.23: Percentage of women in urban areas by exposure to at least one PAIMAN communication and behavior change intervention, by change over time in selected maternal health indicators

Figure 10.24: Perinatal mortality, by exposure status of women to at least one PAIMAN communication and behavior change intervention 


\section{Acknowledgments}

The PAIMAN endline survey was a collaborative effort involving many partners. As the baseline survey (2005) formed the foundation for the PAIMAN project as a whole, the endline documents the impact of the six-year effort by the PAIMAN partners in the original ten PAIMAN districts. Without the funding provided by the United States Agency for International Development (USAID), this project would not have come into being. Dr. Nabeela Ali, Chief of Party for PAIMAN, has steered the project's course for six years, and she and her staff were responsible for the coordination of the consortium and the design and implementation of all of the PAIMAN activities.

The endline survey followed the design of the baseline survey, which was developed in consultation with the PAIMAN partners. The National Institute of Population Studies (NIPS) carried out the fieldwork for both the baseline and endline surveys and was responsible for the clean data sets. The Population Council, a PAIMAN partner, had primary responsibility for designing the study, overseeing the data collection, analyzing the data, and writing the reports.

It is not possible to thank everyone who was involved in the endline survey. However, special appreciation goes to the staff of the National Institute of Population Studies for their valuable fieldwork, and most especially to the Executive Director, Dr. Sajid Ahmad, and to Computer Programmer, Mr. Fateh-ud-din, who managed the data entry and cleaning.

The author is grateful to Dr. Zeba Sathar, Country Director, Population Council, Islamabad office, and to Dr. Anrudh Jain, Distinguished Scholar, Population Council, New York office, for their help in designing the questionnaire and analyzing the impact of PAIMAN interventions. The author also recognizes Mr. Mehboob Sultan, a consultant, for his participation in data analysis and drafting the report. Mr. Muhammad Ashraf, Mr. Irfan Masood and Ms. Saman Naz are appreciated for their assistance in preparing the tables and figures. Finally, thanks to Ms. Pamela Ledbetter for final editing and Mr. Ali Ammad for designing and formatting the report.

The women, men and key informants who gave their time to the interviewers deserve special thanks for their willingness to cooperate in this effort to improve maternal and neonatal health services in Pakistan.

Dr. Arshad Mahmood

Director of Research, Monitoring and Evaluation

Population Council

Islamabad 


\section{Abbreviations/Acronyms}

\begin{tabular}{|c|c|}
\hline AKU & Aga Khan University \\
\hline AMTSL & Active Management of the Third Stage of Labor \\
\hline ANC & Antenatal Care \\
\hline ARI & Acute Respiratory Infection \\
\hline $\mathrm{BCC}$ & Behavior Change Communication \\
\hline $\mathrm{BP} / \mathrm{CR}$ & Birth Preparedness/Complications readiness \\
\hline $\mathrm{BHU}$ & Basic Health Unit \\
\hline $\mathrm{CBO}$ & Community Based Organization \\
\hline CMW & Community Midwife \\
\hline CMWRA & Currently Married Women of Reproductive Age \\
\hline DHDC & District Health Development Center \\
\hline DHIS & District Health Information System \\
\hline ENNMR & Early Neonatal Mortality Rate \\
\hline FATA & Federally Administered Tribal Areas \\
\hline FALAH & Family Advancement for Life and Health \\
\hline FP & Family Planning \\
\hline FWC & Family Welfare Center \\
\hline GoP & Government of Pakistan \\
\hline GSM & Greenstar Social Marketing Pakistan Ltd. \\
\hline HCP & Healthcare Providers \\
\hline IEC & Information, Education and Communication \\
\hline IMR & Infant Mortality Rate \\
\hline JSI & John Snow, Inc. \\
\hline JHUCCP & Johns Hopkins University Center for Communication Programs \\
\hline LHV & Lady Health Visitor \\
\hline LHW & Lady Health Worker \\
\hline LQAS & Lot Quality Assurance Sampling \\
\hline $\mathrm{MCH}$ & Maternal and Child Health (also used to refer to Maternal and Child Health Centers) \\
\hline MMR & Maternal Mortality Rate \\
\hline $\mathrm{MNCH}$ & Maternal, Newborn and Child Health; Maternal, Neonatal and Child Health \\
\hline $\mathrm{MNH}$ & Maternal and Newborn Health; Maternal and Neonatal Health \\
\hline MO & Medical Officer \\
\hline NDF & National Research and Development Foundation \\
\hline NGO & Nongovernmental Organization \\
\hline NIPS & National Institute of Population Studies \\
\hline NNMR & Neonatal Mortality Rate \\
\hline NPFPPHC & National Programme for Family Planning and Primary Health Care \\
\hline ORT & Operating Room/Theater or Oral Rehydration Therapy \\
\hline PAIMAN & Pakistan Initiative for Mothers and Newborns \\
\hline PAVHNA & Pakistan Voluntary Health and Nutrition Association \\
\hline PCO & Public Call Office \\
\hline PNC & Postnatal Care \\
\hline PSU & Primary Sampling Unit \\
\hline $\mathrm{RHC}$ & Rural Health Centers \\
\hline SMART & Safe Motherhood Applied Research and Training \\
\hline TBA & Traditional Birth Attendant \\
\hline TT & Tetanus Toxoid \\
\hline USAID & United States Agency for International Development \\
\hline WMO & Women Medical Officers \\
\hline WSG & Women's Support Group \\
\hline
\end{tabular}




\section{Executive Summary}

The Pakistan Initiative for Mothers and Newborns (PAIMAN) project was a USAID-funded project that focused on improving maternal and newborn health in Pakistan. The project was implemented by a consortium led by John Snow Inc. (JSI), with partners from Pakistani and international organizations, including Aga Khan University (AKU); Contech International Health Consultants; Greenstar Social Marketing (GSM); Johns Hopkins University Bloomberg School of Public Health Center for Communication Programs (JHUCCP); Pakistan Voluntary Health and Nutrition Association (PAVHNA); Population Council; and Save the Children USA. The involvement of both GSM and PAVHNA did not continue when the project was expanded and extended in 2009.

PAIMAN strategized specific interventions designed to improve awareness and promote positive maternal and neonatal health behaviors; to increase access to maternal and child health services; to improve service quality in the public and private sectors to manage obstetric and neonatal complications; to increase the capacity of healthcare system managers and providers in maternal and neonatal health; and to improve management and integration of services at all levels.

The project, which lasted for six years beginning in 2004 and ending in 2010, had a mandate to assist the Government of Pakistan to improve the status of maternal and newborn health in ten districts. In 2007, two Agencies of FATA, two Frontier regions, and Swat district were added. In September 2008, USAID awarded the consortium an expansion of the project, adding 13 more districts and increasing the scope of work to include child health and child spacing. The baseline survey was conducted in 2005 to measure selected maternal and neonatal health indicators in the ten original project districts. The endline survey was conducted in $\mathbf{2 0 1 0}$ in the original ten districts where the baseline survey had been conducted and where the project had been operating for the longest duration.

The ten original PAIMAN districts in which the baseline and endline surveys were conducted were Upper Dir and Buner districts in Khyber Pakhtunkhwa province; Rawalpindi, Jhelum, Khanewal and Dera Ghazi Khan in Punjab province; Sukkur and Dadu in Sindh province; and Jaffarabad and Lasbela in Balochistan province. Both surveys used comparable randomized sample designs and standardized research tools for the assessment of indicators of interest.

\section{Findings}

\section{Community profile}

Key informants were interviewed in the communities where the surveys were conducted in order to obtain community-wide information: essentially, this was a panel from the same communities for baseline and endline surveys (baseline - 391; endline - 385). For the most part, these key informants reported similar characteristics as the same communities were selected in the endline and baseline surveys. Because of the importance of transport when obstetrical emergencies occur, the increase between baseline and endline in the availability of transport during daytime (from 49 to 74 percent) and at night (from 43 to 63 percent) was important 


\section{Household characteristics}

Information regarding household characteristics came from 9,384 baseline household interviews and 11,501 endline household interviews. The socioeconomic conditions of the communities surveyed improved slightly over the project period. Ownership of a television, which can be a major resource for creating awareness of maternal and neonatal health issues, increased by 9 percentage points. Broader access to multiple TV channels probably contributed to the 14 percentage point decline in possession of radios. Possession of other valued items (e.g., car, refrigerator, etc.) increased from 3 to 12 percentage points depending on the item. Electricity was found to be the major source of lighting in both surveys (increasing from 88 to 94 percent).

Household ownership of agricultural land remained constant at 36 percent; however, agriculture declined as a major source of livelihood, from 18 percent in the baseline to 16 percent in the endline survey, reflecting a shift from agriculture to other sectors in the economy.

\section{Respondents' characteristics}

Currently married women of reproductive age (from 15 to 49 years) were interviewed in both surveys: 9,242 in the baseline survey and 12,357 in the endline survey. The mean age of these women was higher in the endline survey, from 31.3 to 32.2 years, as was their level of education. In the endline survey, there was a small increase in women who were housewives (from 71 to 76 percent), while the proportion engaged in agriculture fell by 6 percentage points. Exposure to television increased from 54 to 60 percent between the two surveys. A majority of the women watched PTV, a public channel accessible in many rural areas in addition to urban areas. The proportion of radio listeners declined (from 12 to 9 percent). Since a majority of the women were illiterate, it is not surprising that only 2-3 percent of women reported reading newspapers regularly, though those saying they were casual readers increased slightly (from 19 to 22 percent).

\section{PAIMAN interventions}

In keeping with the strategic objectives, key interventions were implemented to achieve PAIMAN project goals within the PAIMAN districts. The interventions fell into two broad areas: 1) health systems upgradation and 2) behavior change communication/community mobilization.

The health system upgradation had a number of components. Facility upgradation was carried out in 31 health facilities in the original PAIMAN districts, ensuring that these facilities were equipped to provide emergency obstetric care at all times; in some cases, ambulances were also provided for obstetric emergencies. Facility personnel, providers and managers received training to improve the quality of maternal and newborn care provided and the service delivery outcomes. Public and private healthcare providers also received training to enhance provision of maternal, neonatal and child healthcare, and family planning services. Upgradation of the health system included training for traditional birth attendants to improve home-delivery outcomes; this training included early identification of danger signs, making timely referrals, improving use of clean delivery practices, and raising knowledge of maternal and neonatal health and family planning, etc. PAIMAN funds were also used to train and mobilize the new cadre of community midwives in PAIMAN districts through an 18-month national training program and deployment to their home communities; these community midwives are expected to greatly increase the coverage of skilled birth attendance at home deliveries, especially in rural areas. 
The second broad intervention category was behavior change communication/community mobilization at different levels. A number of activities -- women's support group meetings (WSGs); training and involvement of community midwives; dramas and advertisements on TV and radio on maternal and newborn health; puppet shows in rural and remote areas; and involvement of ulama and religious scholars for creating awareness about maternal and newborn healthcare in light of the teachings of Islam -- were part of this intervention strategy undertaken by the PAIMAN project in selected areas.

Findings show that dramas and advertisements on TV were the most known intervention (26 percent), followed by women's support group meetings held by lady health workers (LHWs) (12 percent overall and 18 percent in LHW-covered areas) and, finally, by nongovernmental and community-based organizations' engagements in maternal and neonatal health education activities ( 6 percent). Other individual interventions that were implemented on a limited scale reached fewer women in the communities, and their impact on the entire project was naturally limited as well.

The impact of the PAIMAN communication and behavior change interventions is described below for different stages of the birthing process, from pregnancy to the postnatal period, for husbands and for mortality rates.

\section{Pregnancy care}

Knowledge of three or more danger signs during pregnancy increased from 31 percent in the baseline to 38 percent in the endline survey. The proportion of women who could not name a single danger sign declined from 23 percent to 19 percent in the corresponding period. Women who were exposed to PAIMAN behavior change communication interventions had significantly higher knowledge of danger signs during pregnancy compared to the women who were not exposed to these interventions ( $45 \mathrm{vs} .34$ percent).

There was a substantial increase in the proportion of women having at least one antenatal care visit during their last pregnancy, from 58 to 72 percent. The proportion of women who had three or more antenatal care visits increased significantly from 34 percent to 44 percent. In PAIMAN districts, women who were exposed to PAIMAN behavior change communication interventions were significantly more likely to receive antenatal checkups compared to women who had not been exposed to these interventions.

More women visited a provider for their first antenatal care visit in the first trimester of pregnancy than other trimesters: the proportion of first-trimester visits increased from 47 to 52 percent during the duration of the project. The proportion of those who had their first antenatal care visit in the third trimester declined from 24 to 19 percent. Of those who had antenatal checkups, a majority preferred to use the private sector, increasing from 52 to 71 percent, while seeking antenatal care from the public sector declined.

Awareness about tetanus toxoid (TT) injections increased from 87 to 92 percent during the project. There continues to be a substantial gap between awareness and action, though the proportion of those who had $\pi T$ injections in their last pregnancy increased from 53 to 62 percent. The proportion of those who had at least two TT injections increased by 8 percentage points (from 48 to 56 percent). An increase of 20 percentage points (from 48 to 68 percent) was observed among women exposed to any PAIMAN behavior change communication intervention, while for women who had no exposure the increase was minimal (from 48 to 49 percent) 


\section{Delivery care}

Knowledge of three or more danger signs during delivery increased from 16 to 23 percent between the two surveys; however, the proportion of women who had no knowledge of any danger signs remained the same (around 27 percent) during the project period. Women who were exposed to PAIMAN behavior change communication interventions had significantly higher knowledge of danger signs during delivery compared to the women who were not exposed to these interventions ( 28 vs. 19 percent).

Indicators of birth preparedness improved during the project period. There was an increase in the proportions of women who now had information about the nearest facility where obstetric emergencies could be treated (from 51 to 71 percent) and who had arranged money for a normal delivery (from 60 to 74 percent).

Eighty-eight percent of the total births were normal deliveries in the baseline compared to 82 percent in the endline. The number of Caesarean sections was higher (from 6 to 11 percent) in the endline compared to the baseline.

Overall, skilled birth assistance increased between the two surveys from 41 to 52 percent. An increase of 20 percentage points (from 41 to 61 percent) was observed among women who were exposed to any one of the PAIMAN behavior change communication interventions compared to a much smaller change for women who were not exposed to any of these interventions (from 41 to 47 percent).

Deliveries at home declined by 12 percentage points (from 62 to 50 percent). These changes were captured by the increase in institutional deliveries in the private sector, while deliveries in public-sector facilities declined slightly (2 percentage points).

Clean delivery practices improved in the PAIMAN project areas in comparison with the baseline findings. The largest increase for maternal care was in the use of a clean surface for the delivery (22 percentage points).

Women reporting at least one complication during their last delivery decreased between the two surveys, from 37 to 32 percent. The proportions of women reporting specific complications were higher in the baseline compared to the endline. Among those who had any complication and received treatment, a majority went to private hospitals/clinics. Though the proportion declined, there were still many women who did not get any treatment for their complications.

Changes in maternal health indicators (2005-2010)

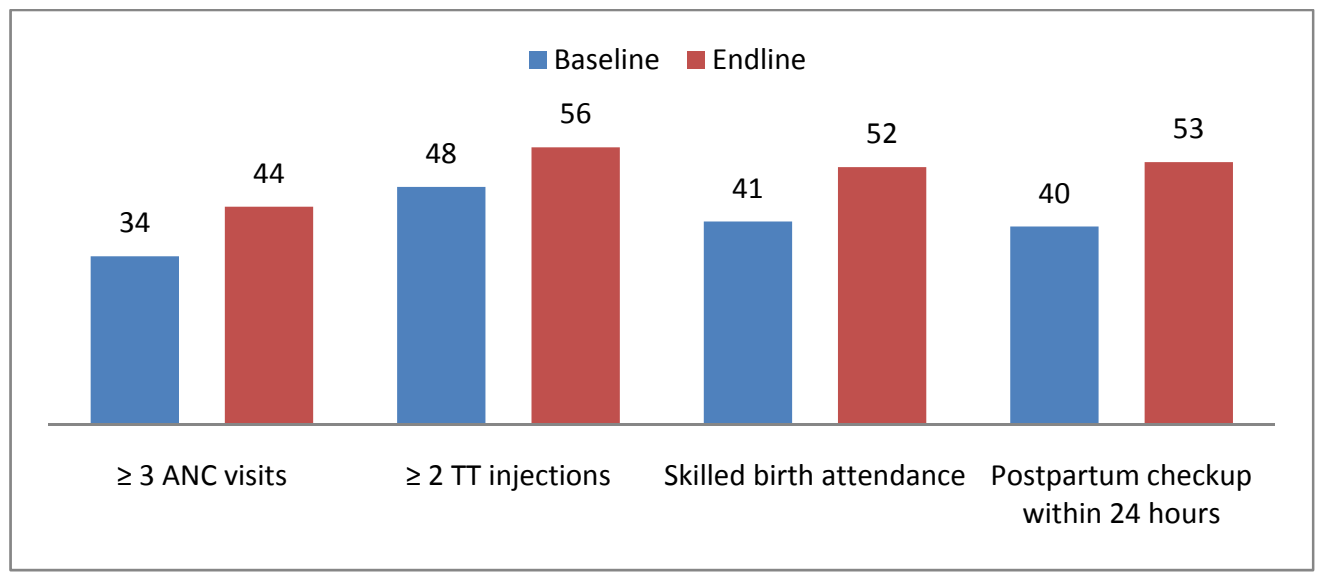




\section{Postpartum care}

The proportion of those who knew about three or more postpartum danger signs increased slightly from 11 to 14 percent between baseline and endline. However, in both surveys 28 percent of the women reported having no knowledge of postpartum danger signs. Only one-third of the women were aware of only one danger sign and a quarter knew about two signs; these proportions remained the same during the project period. Importantly, women who were exposed to PAIMAN behavior change communication interventions had significantly higher knowledge of danger signs during the postpartum period compared to women who were not exposed to these interventions (18 vs. 11 percent).

An increasing proportion of the women believed that postpartum care was essential (from 47 to 64 percent), and postpartum checkups within 40 days of delivery increased by 11 percentage points (from 45 to 56 percent), reflecting an important change. The proportion of those who received postpartum care within the first 24 hours after delivery increased by 13 percentage points (from 40 to 53 percent) between baseline and endline. A significantly higher proportion of women who were exposed to PAIMAN behavior change communication interventions received postpartum care within 24 hours after delivery as compared to women who had no exposure to these interventions. The increase from baseline to endline for women with exposure was from 40 to 54 percent, while for women with no exposure it was from 40 to 44 percent.

Nearly one out of five women had at least one complication following her last delivery. High fever and low abdominal pain were the two most-reported postpartum complications. However, a substantial proportion of these women did not get treatment (32 percent in the baseline; 28 percent in the endline). Among those who sought some treatment, an increasing proportion went to private-sector hospitals/clinics (rising from 34 to 44 percent). Utilization of public-sector facilities showed a decline. The proportion of women who did not seek outside treatment and used traditional methods instead increased from 19 to 30 percent.

\section{Newborn care}

Clean delivery practices are instrumental in reducing newborn and maternal morbidity and mortality. In both surveys, it was assumed that institutional deliveries were performed by trained healthcare personnel observing clean delivery practices; therefore, only women who had delivered at home were asked about the newborn-care practices adopted by their delivery attendants. Among other improvements over the duration of the project, was an increase in the use of a new blade or sterilized instrument to cut the cord ( 9 percentage points).

Women's knowledge of three danger signs in newborns within one hour of birth increased from 34 to 40 percent, while knowledge of danger signs in newborns within a week of birth remained about the same. For a majority of the women who knew specific danger signs in newborns within both an hour of birth and the first week after birth, the knowledge level was higher in the endline compared to the baseline survey. Five healthy newborn-care practices within the first hour after birth all showed some level of improvement. The highest improvements were seen for bathing the newborn six or more hours after birth (from 23 to 53 percent); getting a physical/medical examination of the newborn within three days of birth (from 36 to 55 percent); and wrapping the newborn in a clean cloth after birth (from 64 to 75 percent).

The proportions of newborns reported to have danger signs within an hour after birth and within the first week after birth were lower for the endline as compared to the baseline survey. An increasing proportion of newborns with danger signs within an hour after birth (from 38 to 55 percent) or within a week (from 45 to 60 percent) were taken to private hospitals/clinics for treatment. 


\section{Husbands}

There were 3,017 husbands interviewed in the baseline survey and 3,203 interviewed in the endline survey to get a better assessment of men's knowledge and attitudes toward the maternal and neonatal health of their wives and children. PAIMAN behavior change communication interventions targeting men were designed to increase their supportive role in preparing for childbirth and post-birth care.

The proportion of husbands who thought that women should seek antenatal checkups during pregnancy increased between baseline and endline (from 82 to 94 percent), as did the proportion who thought women should seek antenatal care in the first trimester of pregnancy (from 41 to 61 percent). A high percentage of husbands at both endline and baseline thought that deliveries should be assisted by skilled birth attendants (90 percent baseline; 96 percent endline). There was an increase in the proportion of husbands who thought that postpartum care was necessary (from 57 to 65 percent).

One-third of the husbands reported that they had heard maternal and neonatal health messages through at least one of the PAIMAN behavior change communication interventions. Twenty-seven percent of the husbands had heard maternal and neonatal messages through TV dramas/advertisements. The findings show that husbands who were exposed to at least one behavior change communication intervention had a better attitude about critical maternal and neonatal care practices compared to husbands who had no exposure.

\section{Mortality estimates}

The main objective of the PAIMAN project was to demonstrate through evidence that a certain package of interventions can lead to reduced maternal and neonatal mortality in districts across Pakistan. The project's key outcome indicator was selected to be neonatal mortality, since it is almost impossible to measure maternal mortality with high levels of accuracy. All PAIMAN interventions were collectively expected to have an impact on reducing neonatal mortality, also reflecting changes in maternal mortality. The results of the endline survey are very encouraging and reinforce the positive overall impact of PAIMAN on reducing neonatal mortality.

The endline survey results show a decline both in perinatal and neonatal mortality rates. The neonatal mortality rate declined from 31 deaths to 24 deaths per 1,000 live births (a decline of 24 percent), whereas the early neonatal mortality rate declined from 27 deaths to 19 deaths per 1,000 live births (a decline of 29 percent). It is observed that the reduction in NNMR is mainly due to the decline in early neonatal mortality. It should be pointed out that perinatal mortality is probably the most sensitive indicator of improvements in pregnancy and delivery care, and most closely related to maternal mortality as well. Between

Changes in perinatal, neonatal and early neonatal mortality rates (2005-2010)

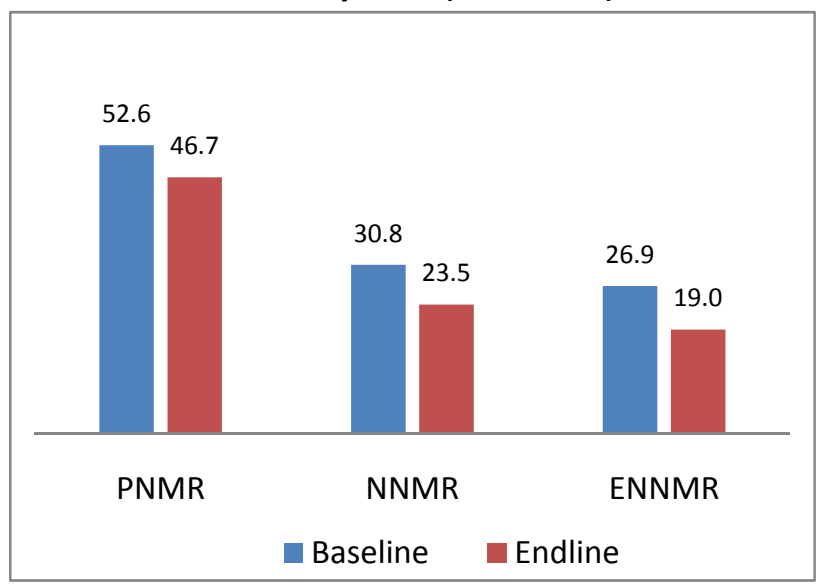
baseline and endline, perinatal mortality declined from 53 perinatal deaths per 1,000 births to 47 . 
A further encouraging result is that the reduction in the perinatal mortality rate (stillbirths and early neonatal mortality per 1,000 births) for women who were exposed to at least one PAIMAN behavior change communication intervention is significantly greater than for women who were not exposed to such interventions: perinatal mortality in the endline is 37 for women who were exposed to at least one PAIMAN intervention, while it is 53 for women who were not exposed. Indeed, we can safely conclude that, while some interventions probably had greater influences than others, some of which we cannot measure individually because of their limited geographical spread, overall, being exposed to an intervention of the PAIMAN project certainly improved the chances of survival of newborns, and most likely their mothers as well, in Pakistan.

\section{Conclusion}

In conclusion, PAIMAN has been successful in impacting positively on overall maternal and neonatal health indicators in these mainly rural districts of PAIMAN in a short period of six years. The thrust of PAIMAN efforts were aimed at reducing the health risk to mothers and newborns by increasing knowledge of danger signs, risks and birth preparedness and, most importantly, improving antenatal and delivery practices. Success has been recorded in almost all areas, albeit with varying degrees of coverage and impact.

Two of the most notable changes in the six-year period are improvements in skilled birth assistance and declines in neonatal and perinatal mortality in the PAIMAN project districts. The majority of the increase in skilled birth attendance is due to institutional deliveries that occurred in private institutions, not surprisingly, given the growth in the private sector in the past decade. The upgrading of facilities carried out by PAIMAN in the public sector, particularly in terms of human resources, most likely played a catalytic role.

The other important finding, the decline in perinatal as well as early neonatal mortality in the PAIMAN districts during the project period, is an outstanding achievement given that Pakistan continues to struggle with stagnant neonatal mortality rates. PAIMAN findings, when analyzed further, can offer real solutions to this national challenge. PAIMAN has succeeded in reducing perinatal mortality in a period of six years in the project districts through a combination of improved knowledge of pregnant women on maternal and newborn health issues, and increased ANC checkups, TT injections, skilled delivery attendance, and postpartum care utilization.

In general, women who were exposed to PAIMAN behavior change communication interventions were significantly more likely to obtain maternal health services during pregnancy, delivery and postpartum period, and to know about danger signs during these times, compared to women who did not have exposure to these interventions. PAIMAN behavior change communication interventions had a greater impact in rural areas compared to urban areas. This is not surprising since the room for improvement in maternal and neonatal healthcare practices is also greater in rural areas, where opportunities for getting information and accessing services are scarcer. It is important to point out that the focus of the major PAIMAN behavior change communication interventions was in the rural areas, where women were more likely to be exposed to the women's support groups (WSGs) conducted by LHWs and mobilization of the local NGOs/CBOs. Maternal health also improved in the urban areas, but the major impact was mainly due to mass media campaigns initiated by PAIMAN.

The set of interventions designed to improve health services, particularly the upgradation of selected facilities in the PAIMAN districts, had some impact on maternal health. Closer vicinity to an upgraded facility increased Caesarean section deliveries and reduced vaginal deliveries in public-sector health 
facilities. This trend was also noted, but to a much lesser extent, in the vicinity of non-upgraded facilities. In contrast to BCC interventions, urban women are more likely to have benefitted from the upgradation of public facilities and the expansion of choices of maternal care in the private sector. An important contribution of PAIMAN is the improvement in care provided at home deliveries through the training of dais in many rural communities, which was carried out by selected NGOs/CBOs. Improved healthcare practices at home deliveries were observed, and it is expected that these contributed to reduced neonatal mortality among deliveries by unskilled birth attendants.

The PAIMAN project activities that led to the improvements described above are available for scaling up for use at the national level. At the same time, it is important to point out that a period longer than the duration of the PAIMAN project is required for changes in maternal health behavior to become more widespread and integrated into national programs and internalized in personal behavior. There are still many obstetrical and neonatal complications that are not detected or not treated, and the overall coverage of at least three ANC checkups, postpartum care within 24 hours, and institutional deliveries are still far from satisfactory, despite the tremendous improvements achieved. The challenge now is to take the opportunity to scale up those interventions that had the greatest impact on maternal and neonatal indicators, and create the sustainable framework that will allow women and newborns across the country to reap the benefit of the PAIMAN project's successes. 


\section{Chapter 1. Introduction}

\section{PAIMAN}

The Pakistan Initiative for Mothers and Newborns (PAIMAN) project was a six-year project designed to improve the health of mothers and neonates in Pakistan by reducing maternal, neonatal and child morbidity and mortality. The vision of the project was similar to that of the Government of Pakistan in recognizing that it is the basic right of every woman and child to access essential healthcare and that no family should suffer the loss of a mother or child due to preventable or treatable causes. The PAIMAN project sought to realize this vision through viable and demonstrable initiatives and capacity building of existing programs and structures, both within the health system and within communities, to ensure improvements and supportive linkages in the continuum of healthcare for women from home to hospital.

The overall project goals, set in order to achieve the project vision, were to:

- $\quad$ reduce neonatal mortality and

- reduce maternal mortality.

The Pakistan Initiative for Mothers and Newborns (PAIMAN) (2005-2010) was funded by the United States Agency for International Development (USAID). The project was implemented through a consortium, led by JSI Research \& Training Institute, Inc. (JSI), which included Aga Khan University (AKU); Contech International Health Consultants; Greenstar Social Marketing (GSM); Johns Hopkins University, Bloomberg School of Public Health, The Center for Communication Programs (JHUCCP); Pakistan Voluntary Health \& Nutrition Association (PAVHNA); Population Council; and Save the Children, USA. The involvement of both GSM and PAVHNA did not continue when the project was expanded and extended in 2009.

PAIMAN's initial mandate was to assist the Government of Pakistan to improve the status of maternal and newborn health in ten districts (see Table 2.1). In 2007, two agencies of the Federally Administered Tribal Areas (FATA), two Frontier regions, and the district of Swat were added. In September 2008, USAID awarded the consortium an expansion of the PAIMAN project, adding 13 more districts and increasing the scope of work to include child health and child spacing.

\section{Strategic objectives}

There were five strategic objectives of the PAIMAN project; these were to:

\section{Increase awareness and promote positive maternal and neonatal health behaviors.}

Increasing the knowledge and awareness of women and their families about harmful practices and issues surrounding maternal, newborn and child health and family planning was one of the primary objectives of the PAIMAN project. The expectation was that greater knowledge and awareness would lead to increased demand for health services and improved health-seeking behavior. Interventions were integrated with cultural norms and traditional beliefs that support healthy behaviors, while countering harmful traditional practices. Among the strategies to improve knowledge and awareness were various communication channels, such as information-education-communication (IEC) packages in local languages and goodwill ambassadors. Because of the important role that men plan in decisionmaking within families, some interventions sought to improve their awareness and knowledge of maternal and child health issues. 
The program created a pool of professionals capable of designing communication strategies/campaigns to address local communication needs by conducting capacity building of managers and health providers. Additionally, the interpersonal communication skills of public and private-sector health providers, including doctors, lady health visitors (LHVs), lady health workers (LHWs), staff of nongovernmental organizations (NGOs) and community based organizations (CBOs), and other healthcare providers (HCPs), were improved.

2. Increase access to and community involvement in maternal and child health services (including emergency obstetric and newborn care) and ensure services are delivered through health and ancillary health services.

Given the social and cultural context of Pakistan, the community-based interventions were key to sustainable solutions to reducing maternal and newborn mortality. In order to circumvent the cultural constraints limiting the mobility of pregnant women, obstetrical and neonatal service delivery needs were brought closer to the community. PAIMAN fully supported the National Skilled Birth Attendant (SBA) strategy, endorsed by the provinces, as reflected in the National Maternal, Neonatal and Child Health (NMNCH) strategy document. As part of this effort, traditional birth attendants (TBAs) were given orientation courses in safe delivery practices. As trained skilled birth attendants (the new cadre of community midwives) become widely available, the role of birth attendant should shift from TBAs to SBAs, and TBAs will then function primarily as a liaison between the women in the household and the professional health worker.

Increased awareness and proximity to services were expected to lead to higher use of antenatal and postpartum care services and contraception, more births attended by skilled birth attendants, greater tetanus toxoid coverage, enhanced basic and emergency obstetric care, and reduced maternal and newborn fatalities. Innovative solutions were adopted by PAIMAN to resolve transport problems between the home and the health facilities, which addressed cost, time and distance involved in obtaining basic emergency care, ultimately saving maternal and newborn lives. Furthermore, public-private partnerships were encouraged to enable better access to care.

\section{Improve service quality in both the public and private sectors, particularly related to the management of obstetrical and neonatal complications.}

In order to provide the full "continuum of care," the community-based obstetrical and newborn care system needed to be backed up by a strong, high-quality referral system at the tehsil and district levels to ensure management of life-threatening obstetrical complications. In this regard, PAIMAN upgraded 79 referral health facilities and provided support for minor renovations of rural health centers (RHCS), supplying essential equipment for maternal and newborn health (MNH) interventions. In addition, PAIMAN, with the Government of Pakistan (GoP), established MNH norms, standards of care, protocols, prevailing supervision, and provider practices for consistency with the latest best practices. Quality improvement mechanisms were also put into place to regulate practices, along with effective supervisory systems to ensure quality care, according to the established protocols and guidelines.

PAIMAN introduced a client-centered approach to service delivery and quality improvement, focusing on the ability of providers to identify and meet client needs. Within the client-centered approach, interpersonal communication between providers and clients received particular focus.

In addition, PAIMAN supported health facilities to prepare and implement infection prevention control measures and established 10 indigenous efficient low-cost incinerators at health facilities. 


\section{Increase capacity of MNH managers and care providers.}

The capacity of community-based providers (LHVs, LHWs, TBAs, and now CMWs [community midwives]) as well as facility-based providers (medical officers [MOs], women medical officers [WMOs], LHVs, midwives and obstetricians) was strengthened to implement a continuum of care, from the normal delivery at home to the management of emergency obstetrical and neonatal complications in the hospital. Furthermore, follow-up of trainees, as well as strengthening of individual performance monitoring and supervisory systems (including management and leadership training) was conducted. Additionally, development of district-specific training content, specifically for lower-level health workers, such as LHWs and TBAs, was ensured.

\section{Improve management and integration of services at all levels.}

PAIMAN worked closely with the Government of Pakistan at all levels for integration of MNH services within the devolved environment, with particular focus on the health system at the district level.

\section{Interventions}

In keeping with the strategic objectives, PAIMAN implemented packages of need-based interventions matching the wide diversity of its audiences and the complexity of the task at hand. The intervention packages for each district were carefully selected in view of the socioeconomic and cultural conditions as well as the knowledge and behavioral needs of key audiences identified through baseline and formative studies and other research carried out by PAIMAN and its partners. PAIMAN did not have a one-size-fits-all strategy for the districts. Excluding some of the key interventions that were implemented for overall maximum reach (for example, the media campaigns), many PAIMAN communication and behavior change interventions (for example, the puppet shows) were designed for people in specific areas of selected district who were unlikely to receive PAIMAN's MNH messages without these special intervention activities.

Overall, PAIMAN interventions were divided into two basic categories, 1) demand generation or communication and behavior change interventions that were focused on household and community health behaviors and 2) systems strengthening designed to meet the healthcare needs of the communities, primarily through the public healthcare system. The presentation here does not describe every individual activity carried out by PAIMAN, its partners and grantees; these activities were numerous and touched on a wide variety of aspects of maternal and newborn healthcare and service delivery.

The PAIMAN project estimates that information about maternal and newborn healthcare issues reached 7.3 million individuals in 24 PAIMAN districts. It is impossible to judge the accuracy of this estimate, though there is no doubt that many women and their families were exposed to one or more of the PAIMAN interventions, whether this meant exposure to a media message or having received healthcare from a PAIMAN-upgraded public health facility.

\section{Upgrading health systems}

\section{A. Facility upgradation}

The PAIMAN project did an assessment of the public health facilities (RHCs, THQs and DHQs) in the ten original project districts to determine what needs these facilities required to provide better maternal and newborn health services. These findings, overall and by district, are available on the PAIMAN website (www.paiman.org.pk). Most of these facilities did not have the full complement of needed supplies, drugs, 
equipment or personnel to provide basic or emergency obstetric and newborn care. Upgrading of public health facilities was carried out in all 24 PAIMAN districts and areas, as follows:

- 79 public health facilities were upgraded and equipped to provide emergency obstetric care services across all PAIMAN areas.

- 31 of these public health facilities were in the 10 original PAIMAN districts.

Upgradation included providing a wide range of needs, from providing basic supplies and equipment to setting up operating theaters and birthing centers. Some of these activities were carried out through the $\mathrm{NGO/CBO}$ grantees (described below).

In addition, to support women's access to healthcare during obstetric emergencies, PAIMAN provided the following:

- 76 purpose-built ambulances for emergency OB cases (and other emergencies).

- 50 Suzuki vans converted to ambulances for use by communities in five districts to transport patients to health facilities.

Other PAIMAN activities that were designed to improve the effectiveness of public health facilities included:

- Functional integration of services between health and population welfare departments and integration of family planning services at the district level (initiated in selected districts).

In a number of ways, public-private partnerships were also encouraged, including sharing of information to give a better picture of health indicators, such as:

- 189 private healthcare providers signed agreements to regularly provide data on key $\mathrm{MNCH}$ performance indicators.

\section{B. Trainings for healthcare providers and administrators}

The PAIMAN project engaged in an extensive effort to upgrade the knowledge and skills of healthcare providers and administrators. While the focus was on public providers, capacity building of private providers was included in specific areas of healthcare. In all PAIMAN areas, training was carried out for:

- 2,204 public healthcare providers, who were trained in essential maternal and newborn care.

As part of its partnership role in PAIMAN, the Population Council carried out leadership training for 143 district health and population managers, service providers, and district administrators to transform them into effective leaders and change agents who will be instrumental in improving reproductive health services by planning and implementing innovative intervention strategies.

PAIMAN's website presents the details of all of the trainings provided to different levels of mostly public, but also private, healthcare providers and administrators, ranging from very specific healthcare issues (e.g., infection prevention, AMTSL and use of partographs) to specific health system management and capacitybuilding efforts (e.g., strategic annual and operational planning, financial management and data management). In addition to the training given to CMWs and TBAs (described below), various trainings were given to doctors, LHVs, LHWs, nurses, and health officials in national, provincial and district 
departments on other topics as well, including the client-centered approach to providing healthcare, lot quality assurance sampling (LQAS), behavior change communication (BCC), etc.

In an effort to promote better maternal and newborn care in remote areas, the PAIMAN project also provided educational support for:

- 80 women from remote areas of Khyber Pakhtunkhwa and Balochistan to attain a matriculate education in order to qualify to be enrolled as LHWs.

\section{CMW trainings}

Skilled birth attendance is considered to be a critical intervention for reducing maternal and neonatal mortality. In the 2006-07 Pakistan Demographic and Health Survey, at the national level, nearly two-thirds (65 percent) of all deliveries took place at home (NIPS, 2008). The majority of these women (57 percent) did not think it necessary to go to a hospital for the delivery, and, for 38 percent, the cost of delivering at a hospital was considered to be unaffordable (PDHS, 2008). Despite the current increase in facility deliveries within the private sector, it is expected that most women in Pakistan will continue to deliver at home for some time to come using the assistance of traditional birth attendants who are not trained to handle complicated cases. To reduce maternal and infant death risks, the availability of skilled birth attendants at the community level is, therefore, an essential part of the national $\mathrm{MNCH}$ program.

As the new cadre of CMWs was being introduced by the Government of Pakistan, PAIMAN provided the funding for the training and mobilization of the CMWs in PAIMAN program districts. These CMWs were trained to conduct home-based deliveries, with the expectation that their efforts will, in time, as enough CMWs are trained and deployed, significantly increase the proportion of births assisted by skilled birth attendants in the country and will decrease the maternal mortality (MMR) and infant mortality (IMR) rates through the use of clean delivery practices and the early detection and timely referral of obstetric and newborn complications.

Not only did PAIMAN work to help establish training and deployment systems for this new cadre of community midwives, so they could provide skilled birth assistance at homebirths, PAIMAN also helped the deployed CMWs establish their own health houses by providing supplies and equipment. PAIMAN trained a core group of master trainers and developed training material and ran training courses for midwifery tutors. The upgradation of health facilities to provide EmOC care 24/7 was part of this effort given that CMWs (and TBAs) were trained to recognize and refer cases of obstetric complications to appropriate facilities, requiring that facilities be prepared to receive emergency OB cases $24 / 7$. For CMWs, PAIMAN carried out the following:

- 28 District Health Development Centers (DHDCs) (training centers) and 29 midwifery schools were upgraded and equipped.

- 1,623 students were supported for CMW training.

- 1,600 CMW homes were supplied with essential equipment and furnishings.

In the ten original PAIMAN districts, the following numbers apply:

- Over $900 \mathrm{CMWs}$ were trained and deployed in 328 out of the 632 union councils in the 10 original PAIMAN districts. 
These CMWs are in the process of establishing themselves in their communities, but it will take time for them to make their presence felt. Unfortunately, there have also been problems in the training and deployment of the CMWs, and efforts are being made to address these problems.

\section{TBA trainings}

Because most births in Pakistan continue to be attended by traditional birth attendants, and this will probably continue for some time, until a transition to facility-based deliveries and/or deliveries conducted by the newly trained community midwives accounts for more deliveries, it was important for reducing maternal and neonatal mortality that TBAs were trained in safe and clean delivery practices. Additionally, behavior change and knowledge enhancement trainings in $\mathrm{MNCH}$ and family planning issues were also conducted. TBAs were taught to identify danger signs during pregnancy, delivery, postpartum and for the neonate, and they were encouraged to make timely referrals to health facilities that provide emergency obstetric services. They were also trained to encourage women to seek antenatal checkups and tetanus vaccinations. In addition, many clean delivery kits were distributed to TBAs in PAIMAN districts and the TBAs were trained in the use of these kits. TBA training and clean delivery kit distribution, both by PAIMAN and by PAIMAN partners, included:

- 2,275 TBAs oriented on clean delivery practices, etc., in all PAIMAN districts.

- 176,910 clean delivery kits distributed in all PAIMAN districts; most distributed to TBAs.

\section{Demand generation: PAIMAN communication and behavior change interventions}

The following are the basic set of communication and behavior change interventions carried out by the PAIMAN project.

\section{A. Support groups for women formed by lady health workers}

The endline survey collected information from the currently married women of reproductive age about their awareness of and participation in women's support group meetings formed by the lady health workers. Training the lady health workers to organize these women's support groups was a key PAIMAN activity. The project worked with the LHW program to support and counsel women on $\mathrm{MNCH}$ and family planning. By working with the LHW program in 24 PAIMAN districts:

- 47,653 support groups were organized by trained LHWs.

- 437,396 support group meetings were held by these trained LHWs.

- 4,686,036 women were provided with information and support through WSG meetings.

Under this intervention, the following activities were carried out in the 10 original PAIMAN districts:

- 8,322 lady health workers of the National Program for Family Planning and Primary Health Care trained in how to conduct meetings to sensitize women on maternal and newborn health issues.

LHWs were trained to create a cordial environment where women could discuss their issues/problems/experiences and be given information about maternal and neonatal health through open discussions with other women and interaction with the LHW. Role models within the community were also invited to share their experiences. Each support group for women comprised 8 to 15 women; these women could be pregnant, lactating, mothers-in-law, traditional birth attendants, formal healthcare providers, 
elected councilors, and unmarried women of reproductive age. Each LHW was to organize two WSG meetings a month.

Proponents of this model for communication within communities leading to behavioral change believe that WSGs provide a persuasive environment for all women who attend. This includes influencing mothers-inlaw who, armed with better information, would be more supportive of their daughters-in-law when decisions are being made about pregnancy and childbirth, for example, in the decision to use a skilled birth attendant for the delivery, an area in which mothers-in-law have strong influence.

\section{B. Mass media interventions: dramas, advertisements and print}

In view of its wide reach and popularity, mass media was used as a strategic tool to reach out to people with $\mathrm{MNCH}$ messages. PAIMAN used a variety of media products for a better message-media fit. The mass media communication and behavioral change intervention using television and radio programming to inform the viewing and listening audiences about $\mathrm{MNCH}$ issues was, by its very nature, a nationwide intervention. Subtle messages were given through a 13-episode TV drama series and two music videos that educated viewers on key themes of mother and child health. The messages presented in these forms were reinforced through television commercials and magazine shows giving direct instructions to viewers on key $\mathrm{MNCH}$ issues. For soliciting support of decisionmakers, special district-based TV talk shows were produced to advocate for mother and child health issues. The project produced a number of other products to promote $\mathrm{MNCH}$, including flyers and brochures.

Journalists were included in the communication and behavioral change interventions so that they could better understand the importance of $\mathrm{MNCH}$ issues for individual families and for the nation, thereby expanding both coverage and accuracy of reporting on $\mathrm{MNCH}$. Journalists were encouraged to publish articles on $\mathrm{MNCH}$ and to initiate discussions in the media relating to $\mathrm{MNCH}$ issues.

- PAIMAN produced more than 40 hours of diverse film, television and radio productions on $\mathrm{MNCH}$ issues, a commercial feature film, a drama series, television commercials and magazine shows, and radio talk shows.

- In all, it is estimated that 8.1 million women of reproductive age were reached through the PAIMAN TV drama series.

- In addition, over 400 journalists were trained on reporting on $\mathrm{MNCH}$ issues.

\section{Ulama involvement}

The involvement of ulama was carried out in the relatively conservative Khyber Pakhtunkhwa province and in selected rural union councils of districts in Punjab having low reach from mass media and community health workers. Ulama play an important role in the daily lives of a majority of the people, who look up to them for guidance on various issues, including health and wellbeing. In this intervention, ulama were sensitized on $\mathrm{MNCH}$ issues and their prospective role in light of the teachings of Islam, and they were encouraged to advocate for $\mathrm{MNCH}$ issues and to promote positive behaviors in their sermons and lectures, especially with the Friday congregations.

Friday congregations are mostly attended by men only, however, the project assumed that men would carry the maternal, newborn and child health messages home and discuss these with their wives and other family members. In addition, as Pakistan is a patriarchal society, improving awareness and knowledge of 
men about maternal, newborn and child health is one avenue for improving the family and community response to $\mathrm{MNCH}$ issues.

PAIMAN started its work with ulama in 2007 with a pilot project, which was expanded twice after evaluating its success and potential. The National Research and Development Foundation (NRDF), a Peshawar-based nonprofit organization specializing in working with ulama, was the implementing partner of the ulama intervention. The PAIMAN project produced a report on this communication and behavioral change intervention, entitled "Ulama -- Agents for Social Change: Muslim Scholars Speak for Mothers' Rights" in 2010 (Johns Hopkins Bloomberg School of Public Health, 2010). That report provides the details of the intervention itself and information gathered from exit interviews after Friday prayers and from focus group discussions with ulama. The reach of this intervention involved:

- 1,000 ulama sensitized and networked on $\mathrm{MNCH}$ issues and their role in spreading $\mathrm{MNCH}$ messages during Friday sermons and through other channels.

\section{Video on wheels}

Maternal and neonatal health and family planning messages were communicated by showing PAIMAN dramas and music videos on a screen set up in special tents in selected remote union councils of Punjab and Sindh, having limited TV and mass media reach. PAIMAN experimented with an innovative intervention called video-on-wheels. In areas where a lack of electricity or other problems meant limited access to radio and television, a large screen mounted on a pick-up truck was used to show selected episodes of the drama series Paiman, its music video, and other information that lent itself to this form of presentation. Men and women were shown these screenings separately.

- $\quad 300,000$ delivered PAIMAN messages in remote areas via mobile TV vans.

\section{E. Puppet shows}

PAIMAN project adopted a media-mix approach employing different forms of communication, including traditional media, to disseminate $\mathrm{MNCH}$ and family planning messages. Puppet shows, putlee tamasha, are a centuries-old traditional way of communicating messages on different issues; they are a useful approach for health behavior change communication, especially in rural and remote areas, where modern communication channels are not operative or are severely limited. Since setting up of a puppetry counter takes only a few minutes and uses simple sheets of cloth and a couple of bedsteads to hang them, items readily available in every home, it is extremely mobile and can be held within the four walls of homes in areas where women are in seclusion.

Specific MNCH messages that targeted men and women of reproductive age were entwined into the stories and characters of the puppet shows, effectively combining storytelling with songs and dances. Public announcements were made a day before the show by loudspeaker and word of mouth with the help of community mobilizers and local health workers who went door-to-door to invite villagers. Shows were held separately for men and women. Each puppet show lasted 30 to 40 minutes and was followed by a quiz on health messages delivered during the performance to reinforce desired behavior change. 
In the limited geographical areas of the six districts in Punjab and Sindh provinces where the puppet shows were conducted, their coverage included:

- 662 puppet shows were held.

- Approximately 40,000 people were exposed to $\mathrm{MNCH}$ messages through the puppet shows.

\section{F. Involvement of community based organizations and nongovernmental organizations}

PAIMAN designed an NGO/CBO grants mechanism to implement community-based interventions to promote $\mathrm{MNH}$ and to increase the capacities of local organizations to provide such services. The role of the local NGOS/CBOs was to provide services in areas not covered by the government-supported LHW program. These sub-grantees worked with the local communities to develop community-based plans that addressed unique issues within those communities. Additionally, the sub-grant recipients worked toward increasing awareness and promoting positive maternal and neonatal health behaviors. Since 2006, the NGOs/CBOs in all 24 of the PAIMAN districts at provincial and district/community levels promoted MNCH education through a variety of mechanisms. For example, they organized free health camps, established birthing centers, mobilized women for safe maternal and health educational activities and arranged other local events.

Other NGOs/CBOs played a role in many aspects of PAIMAN activities, including enabling students to complete their education in preparation for CMW training, providing orientation sessions for new CMWs, communicating $\mathrm{MNCH}$ messages in remote areas, and aiding with linkages among healthcare providers of all sectors/levels. It was a Pakistani nonprofit NGO, the National Research and Development Foundation, based in Peshawar, that carried out the ulama intervention. In addition to the local NGOs, as part of its NGO allocation, PAIMAN provided a grant to Mercy Corps, an international NGO that worked locally in two districts of Balochistan (Lasbela and Jaffarabad).

For the selected NGOS/CBOs, PAIMAN organized training workshops on program and financial management and communication skills to improve their capacity. In all, the following numbers of grants were awarded to NGOs and CBOs:

- 96 grants were awarded to local NGOs/CBOs to reach non-covered populations.

- $36 \mathrm{NGOs/CBOs,} \mathrm{out} \mathrm{of} \mathrm{these} \mathrm{96,} \mathrm{were} \mathrm{given} \mathrm{grants} \mathrm{in} \mathrm{the} 10$ original PAIMAN districts.

- These NGOs/CBOs reached 2.1 million beneficiaries in non-LHW areas. 



\section{Chapter 2. Methodology}

\section{Baseline and endline household survey}

To ensure that the outcomes of the PAIMAN project were properly documented and that the lessons learned were based on sound evidence, PAIMAN developed a monitoring and evaluation plan. Included in this plan was the establishment of baseline measures for a set of indicators to be used for the evaluation of the success of the project. The baseline, midline and endline surveys were planned accordingly. The baseline household survey was conducted in 2005 in order to establish the foundations for identifying maternal and newborn priorities. This survey was carried out in the original 10 PAIMAN project districts in Pakistan's four provinces, namely: Rawalpindi, Jhelum, Khanewal, and DG Khan in Punjab; Dadu and Sukkur in Sindh; Jaffarabad and Lasbela in Balochistan; and Upper Dir and Buner in Khyber Pakhtunkhwa. After the baseline results, the district-wise indicators were reviewed and the decisions about the nature and type of interventions and process indicators were developed. In 2007-2008, as part of the Family Advancement for Life and Health (FALAH) project, for which the Population Council is leading a consortium of organizations, a baseline study was carried out. Because there was overlap with the FALAH baseline, the FALAH data were used as the PAIMAN midline.

In the final year of the project, an endline household survey was conducted in the original 10 PAIMAN districts, as part of the initial monitoring and evaluation plan, to measure changes that occurred over the course of the project's implementation, from 2004-2010, and to assess the achievement of project goals, objectives and output indicators.

\section{Objectives}

In line with the overall objectives of the PAIMAN project, the baseline survey was designed to measure selected maternal and neonatal health indicators that were needed for setting rationalized targets for the project to achieve. The information was also required for designing district-specific strategies for improving maternal and neonatal health conditions. The baseline survey also provided useful information for structuring a detailed design for the project, particularly including behavior change communication, publicprivate partnerships, and strengthening the health system.

The endline survey was designed to assess the achievements of the project in terms of its stated objectives and to identify the initiatives that were successful and could be replicated in other districts and areas of the country. 


\section{Sampling design}

A similar sampling design was used for the baseline and endline surveys. The surveys covered community residents, both mothers and prospective mothers, in order to understand and measure general knowledge and practice about pregnancy, delivery, and obstetric and neonatal emergencies. Thus, both surveys focused on currently married women of reproductive age (15-49 years) (CMWRA) living in the original 10 PAIMAN districts. Women who had experienced a pregnancy in the three years prior to each of the surveys were specifically questioned about their attitude, behavior and practice during their latest reproductive process (pregnancy, delivery and postpartum period).

Table 2.1: Number of PSUs in each district, by area, according to coverage

\begin{tabular}{|c|c|c|c|c|c|c|c|c|}
\hline \multirow[b]{3}{*}{ District } & \multicolumn{4}{|c|}{ Coverage in baseline } & \multicolumn{4}{|c|}{ Coverage in endline } \\
\hline & \multirow[b]{2}{*}{ Planned } & \multicolumn{3}{|c|}{ Covered } & \multirow[b]{2}{*}{ Planned } & \multicolumn{3}{|c|}{ Covered } \\
\hline & & Rural & Urban & Total & & Rural & Urban & Total \\
\hline Upper Dir & 40 & 32 & 2 & 34 & 40 & 32 & 2 & 34 \\
\hline Buner & 40 & 40 & 0 & 40 & 40 & 40 & 0 & 40 \\
\hline Rawalpindi & 40 & 19 & 21 & 40 & 40 & 19 & 21 & 40 \\
\hline Jhelum & 40 & 29 & 11 & 40 & 40 & 29 & 10 & 39 \\
\hline Khanewal & 40 & 33 & 7 & 40 & 40 & 33 & 7 & 40 \\
\hline DG Khan & 40 & 33 & 6 & 39 & 40 & 30 & 7 & 37 \\
\hline Dadu & 40 & 32 & 8 & 40 & 40 & 32 & 8 & 40 \\
\hline Sukkur & 40 & 20 & 20 & 40 & 40 & 20 & 20 & 40 \\
\hline Lasbela & 40 & 25 & 15 & 40 & 40 & 23 & 13 & 36 \\
\hline Jaffarabad & 40 & 30 & 8 & 38 & 40 & 31 & 8 & 39 \\
\hline Total & 400 & 293 & 98 & 391 & 400 & 289 & 96 & 385 \\
\hline
\end{tabular}

The sample design adopted for both surveys was a stratified, systematic sample of households. The universe consisted of all urban and rural areas of the district. The PSUs (rural villages and urban blocks) remained the same for both the baseline and the endline surveys. However, independent samples of households were drawn in the two surveys. The status of the number of primary sampling units (PSUs) sampled and enumerated by residence are presented in Table 2.1 and the status of number of households and currently married women of reproductive age interviewed for baseline and endline is presented in Table 2.2. The findings presented in the report are based on weighted samples. 
Table 2.2: Distribution of households and currently married women of reproductive age, by interview status (unweighted)

\begin{tabular}{|c|c|c|c|c|c|c|c|c|}
\hline \multirow[b]{3}{*}{ Interview status } & \multicolumn{4}{|c|}{ Household } & \multicolumn{4}{|c|}{ Women } \\
\hline & \multicolumn{2}{|c|}{ Baseline } & \multicolumn{2}{|c|}{ Endline } & \multicolumn{2}{|c|}{ Baseline } & \multicolumn{2}{|c|}{ Endline } \\
\hline & Percent & Number & Percent & Number & Percent & Number & Percent & Number \\
\hline Completed & 97.5 & 9,150 & 99.4 & 11,431 & 96.9 & 9,242 & 98.9 & 12,357 \\
\hline Incomplete & 0.3 & 31 & 0.2 & 23 & 1.5 & 145 & 0.6 & 76 \\
\hline Refused & 1.9 & 174 & 0.4 & 44 & 1.4 & 130 & 0.5 & 64 \\
\hline Other & 0.3 & 29 & 0.0 & 3 & 0.3 & 24 & 0.0 & 0 \\
\hline Total & 100.0 & 9,384 & 100.0 & 11,501 & 100.0 & 9,541 & 100.0 & 12,497 \\
\hline
\end{tabular}

\section{Urban sample}

The enumeration circle was the smallest unit available in the 1998 Population District Census Reports as demarcated by the Population Census Organization of Pakistan. The required numbers of enumeration blocks were selected with probability proportional to size (number of circles). The maps of these circles were obtained from the Population Census Organization. The circles were already divided into blocks of approximately 250-300 households, depending on the number of households in each circle. Later, blocks were randomly selected with probability proportional to size from the list of total blocks in that circle. The listing of each block was then prepared by the enumeration teams before selecting the sampled households. A fixed number of 24 households in the baseline survey and 30 households in the endline survey were drawn from each sampled enumeration block using the systematic random sampling technique.

\section{Rural sample}

The 1998 Population Census list of villages was used as the sampling frame for the selection of the rural sample. Villages in rural areas were treated as primary sampling units. Sampled PSUs were selected with probability proportional to size (number of households). Households within the sample PSU were considered secondary sampling units. The enumeration teams then prepared the listing of each village before selecting the sampled households. A fixed number of 24 households in the baseline survey and 30 households in the endline survey were drawn from each sampled enumeration village by the systematic random sampling technique.

\section{Questionnaire}

The baseline questionnaire was developed by the Population Council. It was based on a combination of current general demographic and health survey methodologies and the questionnaire developed by the Population Council for the Safe Motherhood Applied Research and Training (SMART) project. For the endline survey, the same questionnaire was used, but additional questions were added to collect information on specific interventions of the PAIMAN project.

The following areas were the focus of the PAIMAN questionnaires (for both baseline and endline surveys, with the addition of the last item for the endline survey):

- Household information

- Socioeconomic status of women 
- Fertility, pregnancy history, and reproductive intentions

- Attitude toward, as well as knowledge and practice of, contraceptive methods

- Attitude toward pregnancy, delivery and the postpartum period

- Health-seeking behavior

- $\quad$ Facilities for birth preparedness and complication readiness (BP/CR) available in the community

- Current birth preparedness, complication readiness and knowledge of newborn care

- $\quad$ Future birth preparedness and complication readiness intentions

- Factors that facilitate or hinder behaviors related to birth preparedness and complication readiness

- Media habits

- Knowledge of PAIMAN interventions (endline survey only)

\section{Pretest}

The questionnaires were reviewed by the PAIMAN monitoring and evaluation thematic group as well as by other interested stakeholders, and they were pre-tested in non-PAIMAN districts. The main objective of the pretesting was to examine the suitability and effectiveness of questions in eliciting adequate responses, and to find out if there were any linguistic problems faced by interviewers or respondents. Pretesting also helped determine the approximate time required to complete a questionnaire. The pre-tests were carried out by the Population Council's female staff members, who recorded their experiences with regard to each question. These records were then used to revise and finalize the questionnaire.

\section{Field teams}

Hiring: Since the respondents in the baseline and endline surveys were to be currently married women of reproductive age and married men, it was decided that female interviewers would be used to interview women and male interviewers for men. Based on the constitution of each team, the required numbers of female and male interviewers were hired by the National Institute of Population Studies (NIPS), according to its own internal procedures.

Training: In order to ensure that interviewers were of a uniformly high quality and understood the definitions and concepts behind the language of the questions, training was conducted by NIPS, in collaboration with the Population Council. Interviewers were extensively trained with regard to survey procedures. It was very important for the interviewers to thoroughly understand the methodology and statistical importance of the sampled households, therefore, experts provided training in the importance of the criteria for the selection of primary sampling units, mapping and listing procedures, field operation procedures, and the selection of the particular households and respondents. The training took place over a two-week period in Islamabad. During the training, interviewers visited 3-4 households to conduct practice interviews.

\section{Data processing}

\section{Management}

Data processing was started in the field with the checking of questionnaires. Each team leader completed on-the-spot checks and preliminary editing of the questionnaires during the enumeration period. Editing instructions were provided to the team leaders; emphasis was placed on the importance of completing 
each questionnaire, correctly identifying each eligible respondent, and the completeness of the household composition.

\section{Quality assurance}

To ensure the quality of the data, staff from the Population Council and NIPS monitored the fieldwork by accompanying the field teams. While supervising the fieldwork, they were available to provide immediate

guidance to interviewers in the event that any part of the questionnaire was unclear. This ensured the completeness and accuracy of each questionnaire. 



\section{Chapter 3. Community Profile}

In Pakistan, challenges in defining community relate largely to its diversity in terms of geographical boundaries, culture, language, and ethnicity. However, from the perspective of research and program, there is a need to measure certain common characteristics that people living in a geographical vicinity share, such as access to services, communications, and other social networks.

PSUs in rural areas yielded a realistic assessment about the proximity and availability of various services, such as schools. However, in urban PSUs, which are usually more densely populated and located over a few streets or a mohallah (a cluster of households), several reported no primary schools in their immediate vicinity though they had access to schools located outside the survey's definition of their community or neighborhood. Care has been taken in the analysis of the data to reflect a more realistic sense of a community's access to services. In this chapter, any reference to a facility that is "inside" a community includes those that are within one kilometer of the community's border.

The community information collected by the PAIMAN baseline and endline surveys is based on structured, guided group discussions. In each of the communities, four to five reliable key informants were asked questions about their community in neutral group settings. Key informants included teachers, village leaders, shopkeepers and moulvi (religious leaders). Group consensus was reached regarding the various aspects of their community's profile.

\section{Access to roads and transport}

The degree of access of communities to roads and transport is an important reflection of their development status. Road and transport access is an important mark of mobility, education, employment and health. It also indicates connections to the outside world. In those communities where access to roads and transportation is poor or non-existent, it is very difficult to deal with health emergencies, especially for childbearing women and children. Endline survey findings show that there was a slight change in community access to a main road compared to baseline findings (Figure 3.1).

Figure 3.1: Percentage distribution of communities, by area and distance to main road

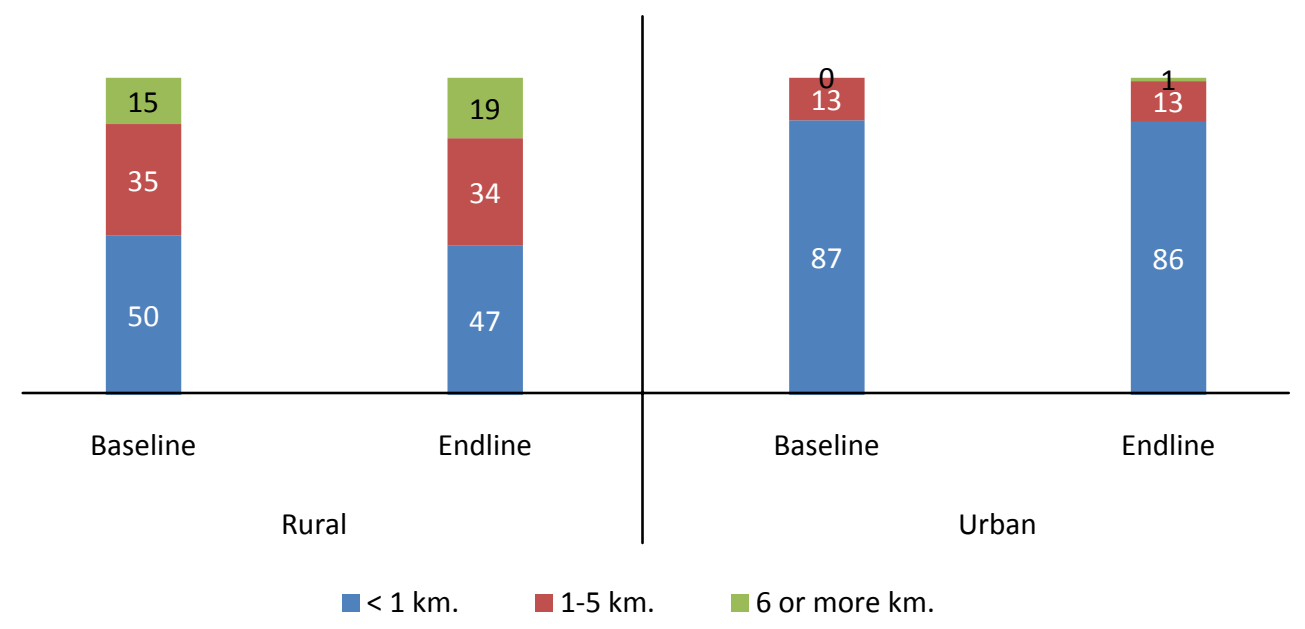


In rural areas, for both baseline and endline surveys, 20 percent of community representatives reported that 24-hour public transport was available in their communities. The endline survey in rural areas showed that there was much improvement in availability of transport for emergencies both in the day (67 percent) and at night ( 55 percent) when compared to the baseline of 44 percent for day and 38 percent for night.

The urban community representatives reporting in the baseline that 24-hour public transport was available in their communities was 62 percent as compared to the endline of 72 percent. In urban communities, the availability of transport in case of emergencies, both day and night, was much better in the endline as compared to the baseline (Figure 3.2).

Figure 3.2: Percentage of communities, by area and availability of transport

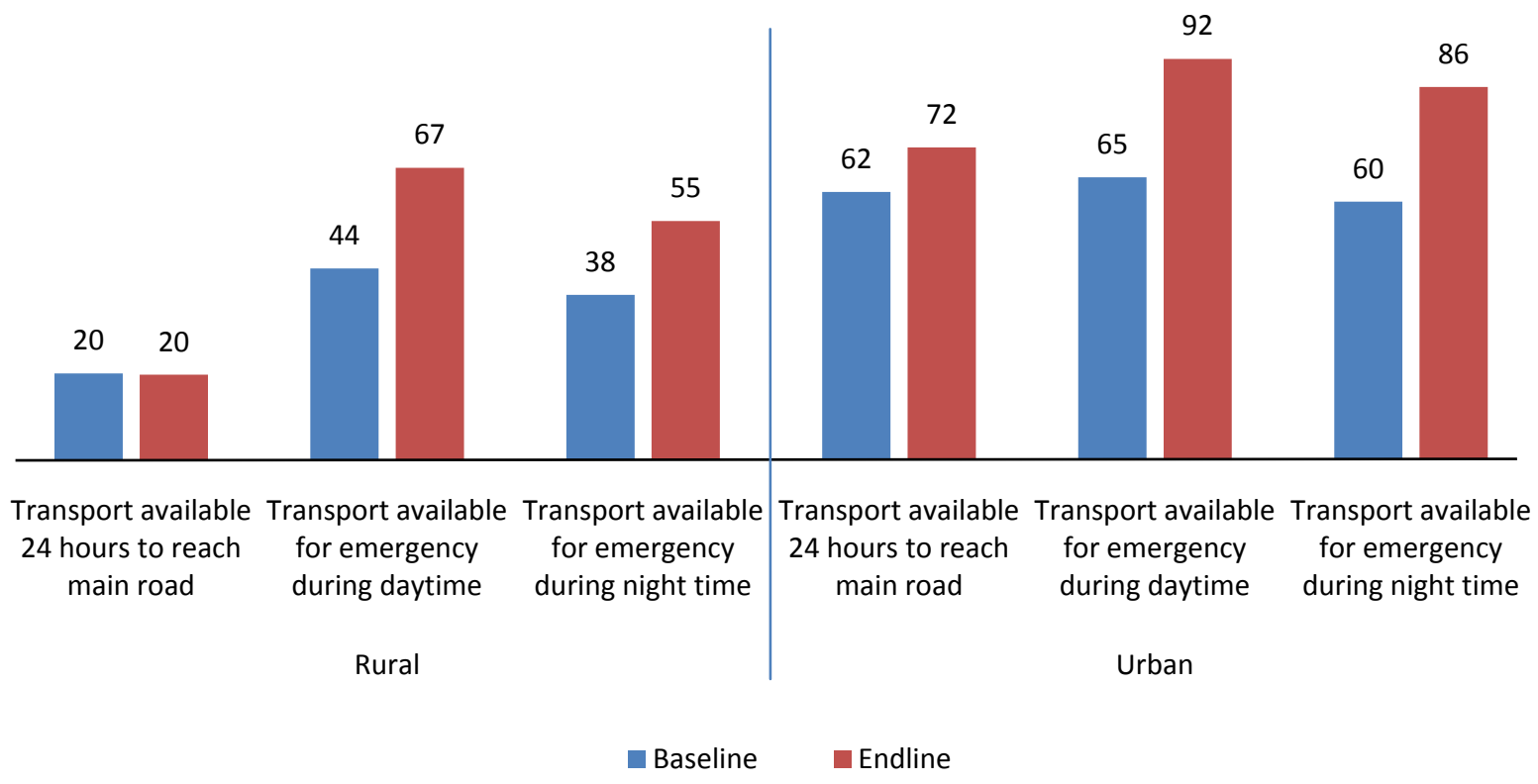

\section{Access to health facilities and services}

Community key informants were asked about available health services and facilities. Where no facilities were immediately available, key informants estimated the distance to the nearest available facility. The availability of a health facility within proximity of the communities makes accessing services much easier, otherwise women think twice about whether or not they can afford the time and the travel costs to reach services. Table 3.3 shows the distances as reported in the baseline report. 
Figure 3.3: Percentage distribution of communities, by area and distance to nearest health facility at baseline

\begin{tabular}{c|c|c}
28 & 26 or more km. & 11 \\
& & 9 \\
15 & $16-25 \mathrm{~km}$. & 42 \\
21 & $6-15 \mathrm{~km}$. & \\
18 & $\square-5 \mathrm{~km}$. & 37 \\
19 & $\square 1 \mathrm{~km}$. & \\
\hline Rural & & Urban
\end{tabular}

Figure 3.4 shows that in the endline survey there was a slight increase in the presence of lady heath workers in both rural and urban communities, as reported by community representatives. There was no incremental change in the availability of midwives. According to the baseline, 49 percent of the community representatives mentioned the availability of traditional birth attendants in rural communities, while in the endline this was mentioned by 54 percent. It is interesting to note that the presence of LHWs, TBAs or midwives is much higher in urban PSUs compared to rural PSUs.

Figure 3.4: Percentage of communities, by area and availability of selected community health providers

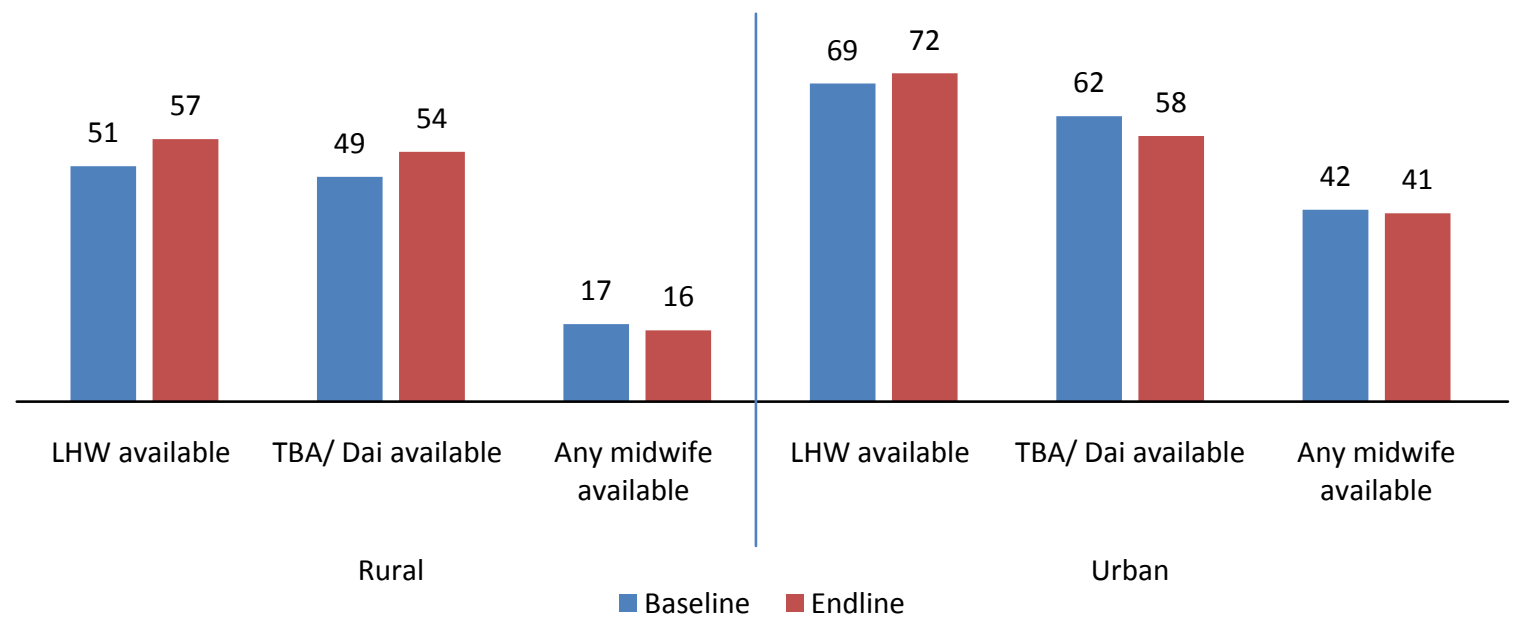

In addition to questions regarding the availability of health services, the key informants were also asked about the healthcare facilities that were most frequently utilized by members of the community (Table 3.1). The majority of the communities reported that residents seek advice from more than one source. The average distance to different facilities from the communities was almost the same. There was a significant change in availability of medicine at facilities and in behavior of service providers in both public and private facilities. According to the baseline survey, only 50 percent of the government hospitals had medicines; however, in the endline this was 85 percent. Private hospitals also showed improvement in availability of medicine as well as in the attitude of providers. 
Table 3.1: Community health facilities used most frequently, by selected variables

\begin{tabular}{lrr|rr|rr} 
& \multicolumn{2}{c}{$\begin{array}{c}\text { Average estimated distance } \\
\text { from community (in kms.) }\end{array}$} & \multicolumn{2}{c|}{$\begin{array}{c}\text { Medicine available } \\
\text { (percent of facilities) }\end{array}$} & \multicolumn{2}{c}{$\begin{array}{c}\text { Good attitude of provider } \\
\text { (percent of facilities) }\end{array}$} \\
\cline { 2 - 8 } Type of facility & Baseline & Endline & Baseline & Endline & Baseline & $\begin{array}{r}\text { Endline } \\
\text { RHC }\end{array}$ \\
\hline BHU & 19 & 15 & 25 & 68 & 38 & 67 \\
\hline MCH center & 5 & 6 & 33 & 66 & 46 & 69 \\
\hline Dispensary & 17 & 17 & 29 & 73 & 33 & 69 \\
\hline Government hospital & 8 & 8 & 31 & 72 & 41 & 73 \\
\hline Private hospital /clinic & 13 & 15 & 50 & 85 & 52 & 74 \\
\hline Dispenser/compounder & 10 & 8 & 71 & 92 & 78 & 96 \\
\hline Nurse/LHV & 3 & 3 & 55 & 78 & 65 & 86 \\
\hline Hakeem/homeopath & 7 & 7 & 42 & 63 & 51 & 79 \\
\hline FWC & 7 & 8 & 58 & 89 & 59 & 87 \\
\hline
\end{tabular}

\section{Access to other infrastructure}

In urban areas, there are much greater levels of access to essential facilities than in rural areas. The community profile provides details on access to key facilities, which reflects the development status of the area.

In the baseline, 60 percent of the rural communities reported no sewerage system; in the endline, 49 percent reported no sewerage system (Figure 3.5). In the baseline, one-quarter of the rural communities had open cemented drains, while in the endline 45 percent of rural communities had the same type of sewerage facility. Underground cemented drains remained the same between the two surveys. For urban communities, 19 percent of the urban communities reported no sewerage system in the baseline; in the endline, only 8 percent mentioned the same. For open cemented drains in urban communities, there was a change from 46 percent to 75 percent between baseline and endline surveys. Covered cemented drains remained the same. 
Figure 3.5: Percentage distribution of communities, by area and type of drainage/sewerage system

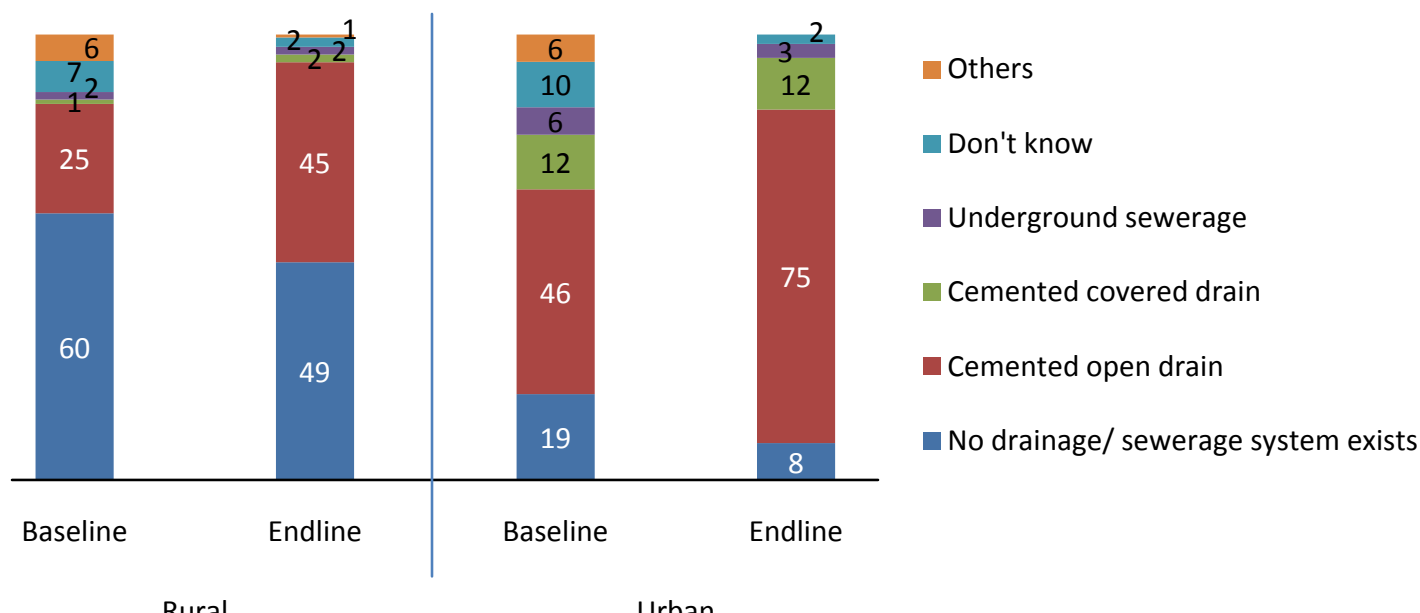

Mobile phone connections, home telephones, public call offices (PCOs) and post offices reveal to what extent communities are connected to the outside world. Banks indicate the potential of the communities for saving as well as for loans. Most communities had access to one or more of the facilities described in Figure 3.6. There was improvement in most of the facilities both in rural and urban communities between the baseline and endline surveys. Endline results show improvement in cell phone connectivity at the community level in both urban and rural communities and a decline in the number of public call centers in rural communities. There was also an increase in the number of medical stores at the community level in rural communities.

Figure 3.6: Percentage of communities, by area and selected community infrastructure

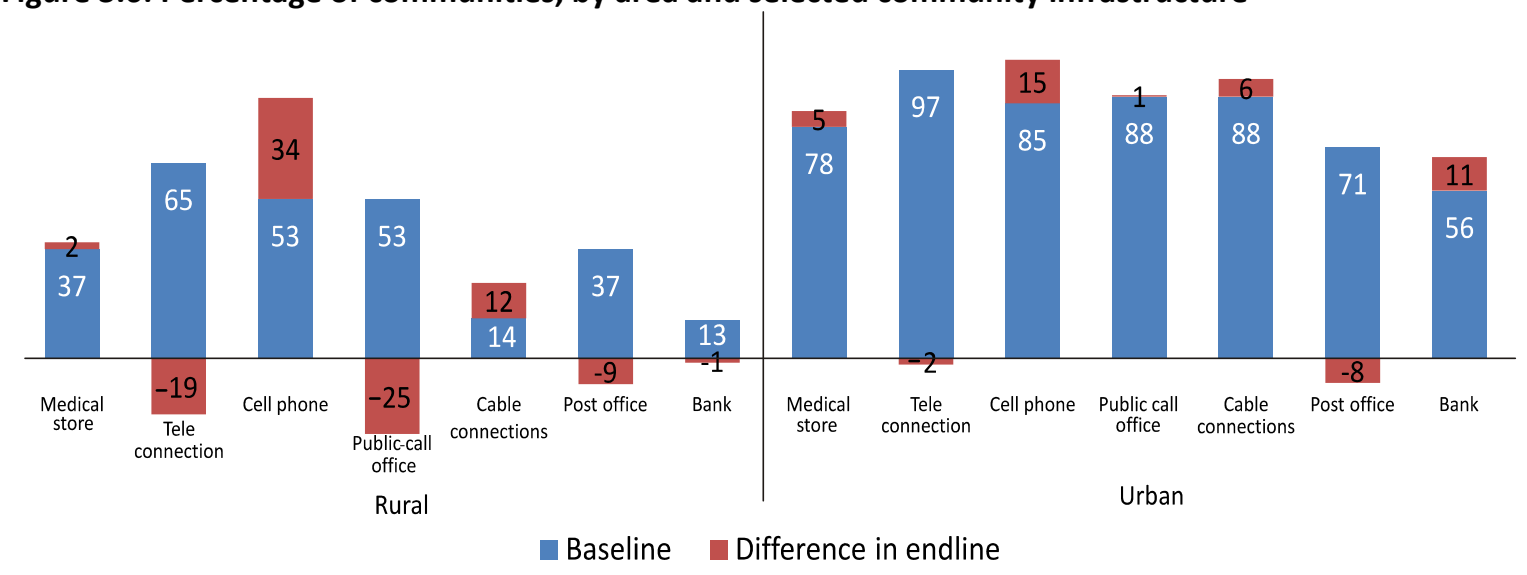





\section{Chapter 4. Household and Respondent Characteristics}

This chapter provides a summary of the socioeconomic and demographic characteristics of the study population, according to the baseline and endline surveys. Both surveys collected information about the household population: age structure, educational attainment, availability of water and sanitation facilities, and fuel used for cooking and lighting purposes. In addition, household possessions were also listed as a proxy for economic condition and standard of living of the subject population. Currently married women of reproductive age were interviewed in greater detail through questions about their literacy, level of education and work status.

\section{Household characteristics}

The analysis of the age structure of the sample population from the baseline and endline surveys suggests a fair degree of resemblance in terms of age distribution, mean age of women, occupational background, and literacy and education.

Age

The age distribution of the household population indicates many similarities between the baseline and endline findings: the proportion of children under 15 years of age (42.2 vs. 43.6 percent); proportion of working age adults $15-59$ years (50.7 vs. 51.7 percent); and proportion of older adults $\geq 60$ years (5.8 vs. 6.0 percent) (Figures 4.1a and 4.1b).

Figure 4.1a: Percent distribution of household population by age and sex, baseline survey, 2005

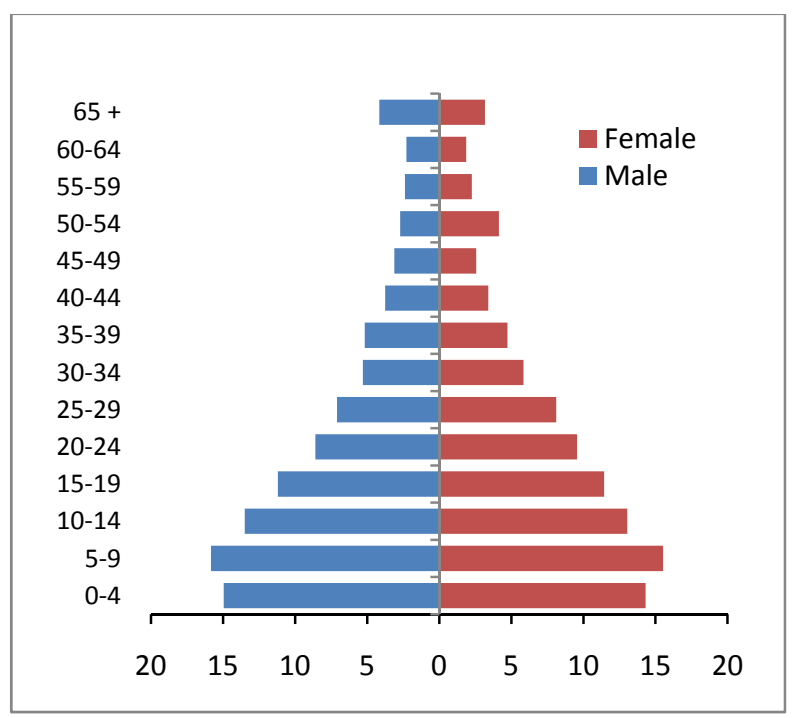

Figure 4.1b: Percent distribution of household population by age and sex, endline survey, 2010

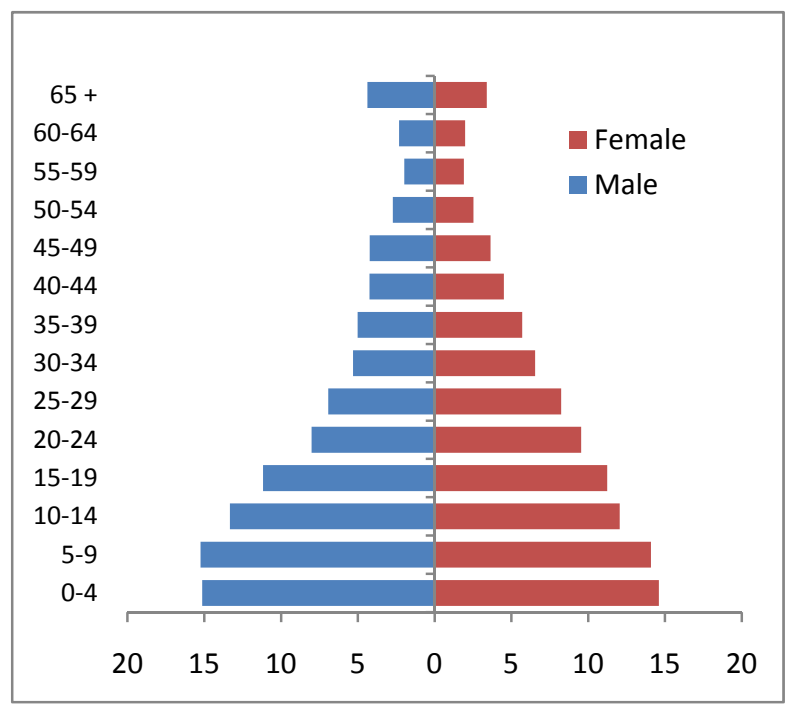


Table 4.1: Percentage distribution of household population, by age, sex and education

\begin{tabular}{|c|c|c|c|c|c|c|c|c|c|c|}
\hline \multirow[b]{2}{*}{ Age group } & \multicolumn{5}{|c|}{ Male (Baseline) } & \multicolumn{5}{|c|}{ Male (Endline) } \\
\hline & $\begin{array}{r}\text { No } \\
\text { education }\end{array}$ & $\begin{array}{r}\text { Class } \\
1-5\end{array}$ & $\begin{array}{r}\text { Class } \\
6-10\end{array}$ & $\begin{array}{r}\text { Class } \\
11+\end{array}$ & (N) & $\begin{array}{r}\text { No } \\
\text { education }\end{array}$ & $\begin{array}{r}\text { Class } \\
1-5\end{array}$ & $\begin{array}{r}\text { Class } \\
6-10\end{array}$ & $\begin{array}{r}\text { Class } \\
11+\end{array}$ & (N) \\
\hline $10-14$ & 21.2 & 55.9 & 22.9 & 0.0 & 5,127 & 19.7 & 53.0 & 27.2 & 0.1 & 5,703 \\
\hline $15-19$ & 17.9 & 17.9 & 54.7 & 9.4 & 4,658 & 18.0 & 17.0 & 55.5 & 9.5 & 5,164 \\
\hline $20-24$ & 17.5 & 14.6 & 44.2 & 23.8 & 3,565 & 18.7 & 13.9 & 42.2 & 25.2 & 3,994 \\
\hline $25-29$ & 19.8 & 14.0 & 41.3 & 25.0 & 2,898 & 20.6 & 14.8 & 41.1 & 23.6 & 3,290 \\
\hline $30-34$ & 25.2 & 13.8 & 36.5 & 24.5 & 2,101 & 22.6 & 14.0 & 37.5 & 25.9 & 2,319 \\
\hline $35-39$ & 31.5 & 13.3 & 35.5 & 19.7 & 2,088 & 27.2 & 13.6 & 34.3 & 24.8 & 2,080 \\
\hline $40-44$ & 33.2 & 14.4 & 37.4 & 15.0 & 1,578 & 32.1 & 14.2 & 30.5 & 23.1 & 1,760 \\
\hline $45-49$ & 33.1 & 16.2 & 35.4 & 15.3 & 1,328 & 32.9 & 15.6 & 34.4 & 17.0 & 1,761 \\
\hline $50-54$ & 37.0 & 16.6 & 29.5 & 17.0 & 1,166 & 35.6 & 14.2 & 30.1 & 20.1 & 1,263 \\
\hline $55-59$ & 43.1 & 19.6 & 22.3 & 15.0 & 961 & 39.0 & 15.3 & 30.9 & 14.7 & 1,101 \\
\hline $60-64$ & 46.0 & 14.2 & 29.8 & 10.0 & 938 & 47.0 & 15.7 & 25.4 & 12.0 & 1,211 \\
\hline $65+$ & 55.5 & 18.3 & 21.8 & 4.5 & 1,703 & 54.9 & 14.6 & 22.3 & 8.2 & 2,275 \\
\hline \multirow[t]{2}{*}{ Total } & 26.6 & 23.0 & 36.5 & 13.8 & 28,114 & 26.4 & 21.8 & 36.7 & 15.2 & 31,920 \\
\hline & \multicolumn{5}{|c|}{ Female (Baseline) } & \multicolumn{5}{|c|}{ Female (Endline) } \\
\hline Age group & $\begin{array}{r}\text { No } \\
\text { education }\end{array}$ & $\begin{array}{r}\text { Class } \\
1-5\end{array}$ & $\begin{array}{r}\text { Class } \\
6-10\end{array}$ & $\begin{array}{r}\text { Class } \\
11+\end{array}$ & (N) & $\begin{array}{r}\text { No } \\
\text { education }\end{array}$ & $\begin{array}{r}\text { Class } \\
1-5\end{array}$ & $\begin{array}{r}\text { Class } \\
6-10\end{array}$ & $\begin{array}{c}\text { Class } \\
11+\end{array}$ & (N) \\
\hline $10-14$ & 35.3 & 45.1 & 19.6 & 0.0 & 4,871 & 29.0 & 46.0 & 24.9 & 0.1 & 5,248 \\
\hline $15-19$ & 35.7 & 17.2 & 36.9 & 10.2 & 4,473 & 32.9 & 18.7 & 37.7 & 10.7 & 5,224 \\
\hline $20-24$ & 38.9 & 14.5 & 25.0 & 21.6 & 3,835 & 38.2 & 15.8 & 23.7 & 22.3 & 4,553 \\
\hline $25-29$ & 50.6 & 12.6 & 21.1 & 15.8 & 3,111 & 47.7 & 14.1 & 20.0 & 18.2 & 3,604 \\
\hline $30-34$ & 57.3 & 15.8 & 17.0 & 9.9 & 2,270 & 53.4 & 14.1 & 17.1 & 15.4 & 2,773 \\
\hline $35-39$ & 64.4 & 14.0 & 13.6 & 8.0 & 1,905 & 57.7 & 14.5 & 15.8 & 12.0 & 2,398 \\
\hline $40-44$ & 66.4 & 15.0 & 12.9 & 5.8 & 1,404 & 64.5 & 14.7 & 12.6 & 8.2 & 1,923 \\
\hline $45-49$ & 69.2 & 13.5 & 11.9 & 5.5 & 1,012 & 65.6 & 13.3 & 13.5 & 7.6 & 1,573 \\
\hline $50-54$ & 79.1 & 11.0 & 6.4 & 3.4 & 1,619 & 75.2 & 11.9 & 10.1 & 2.8 & 1,690 \\
\hline $55-59$ & 81.8 & 9.3 & 5.8 & 3.1 & 888 & 81.4 & 10.4 & 4.6 & 3.5 & 1,126 \\
\hline $60-64$ & 88.2 & 7.6 & 3.2 & 1.0 & 727 & 83.9 & 7.6 & 6.1 & 2.4 & 1,022 \\
\hline $65+$ & 91.6 & 5.1 & 3.0 & 0.2 & 1,236 & 89.9 & 5.4 & 4.1 & 0.6 & 1,692 \\
\hline Total & 52.3 & 19.3 & 19.7 & 8.7 & 27,352 & 50.0 & 19.3 & 20.5 & 10.2 & 32,824 \\
\hline
\end{tabular}


A comparison of the age pyramids also suggests that the proportion of children under age 5 years was lower than that for children ages 5-9 years in the baseline, whereas such a pattern was not visible in the endline survey. In Pakistan, surveys undertaken five years apart, show an undercut in the age group 0-4 years that is only partly explained by a fall in fertility. However, some of the deficit in children 0-4 years is likely to be caused by omission in this age group and/or by age displacements. Applying the UN Age-Sex Accuracy Index to the age-sex distribution of the baseline and endline surveys, an index score of 70.86 for the baseline and 61.40 for the endline was obtained (Shryock, Siegal and Associates, 1980). This suggests that the age reporting, as in other surveys, is highly inaccurate; however, age reporting in the endline survey is relatively better than in the baseline survey.

\section{Education}

Table 4.1 provides the distribution of the household population ages 10 years and above by sex and educational attainment for both surveys. There were only slight differences in terms of educational attainment among the populations from the two surveys. For men, there was no change in those with no education, and only 1 percentage point increases in two other educational levels. For women, there was a decline between baseline and endline in those with no education, from 52 percent to 50 percent, and correspondingly small increases at higher levels.

\section{Possessions}

The socioeconomic characteristics of the sampled households in both samples, which provide a proxy for the living standard of the population, are presented in Table 4.2 and Figure 4.2. Similar proportions of the households in both surveys reported owning agricultural land (35 percent baseline; 36 percent endline), which was an important source of livelihood for 18 percent of the households in the baseline and 16 percent in the endline. Ownership of dwellings also hardly changed. Some improvement in the living conditions of the people has also occurred during the duration of the project. The possession of items like televisions, refrigerators, air coolers, air conditioners, computers, motorcycles and cars/jeeps has increased during this time. Some improvement in sanitation facilities also occurred between the baseline and endline surveys.

Table 4.2: Percentage of households, by selected household characteristics

\begin{tabular}{lrr} 
Characteristic & Baseline survey & Endline survey \\
Household owns agriculture land & 35.5 & 36.3 \\
\hline Agriculture produce is major source of livelihood & 17.9 & 16.2 \\
\hline Dwellings owned by the household & 83.3 & 84.4 \\
\hline Electricity used as lighting source & 87.8 & 94.1 \\
\hline Type of toilet facility & & 52.4 \\
\hline Connected to sewerage/septic tank & 19.4 & 24.0 \\
\hline Rudimentary toilet facility & 28.1 & 20.8 \\
\hline No facility & (9,384) & $(11,501)$ \\
\hline (Number of households) & & 24.2 \\
\hline
\end{tabular}


Figure 4.2: Percentage of households, by selected household possessions

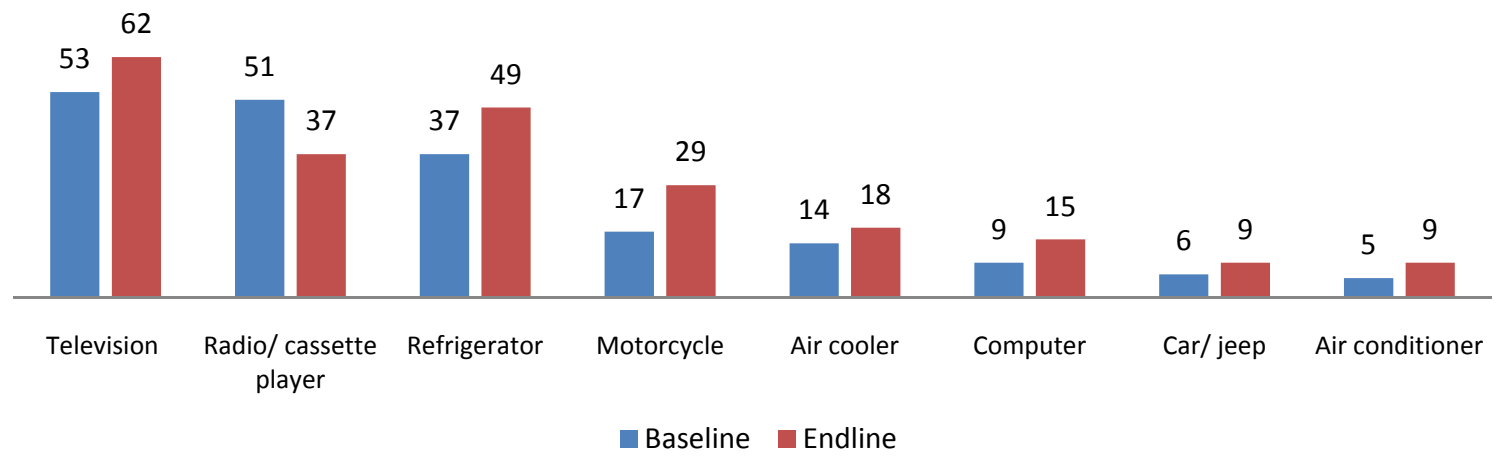

Congestion at the household level has further increased: the proportion of households with one room increased from 26 percent in the baseline to 31 percent in the endline (Figure 4.3). Similarly, the proportion of households having three or more rooms for sleeping declined from 31 percent in the baseline to 26 percent in the endline.

Figure 4.3: Percentage distribution of households, by number of bedrooms

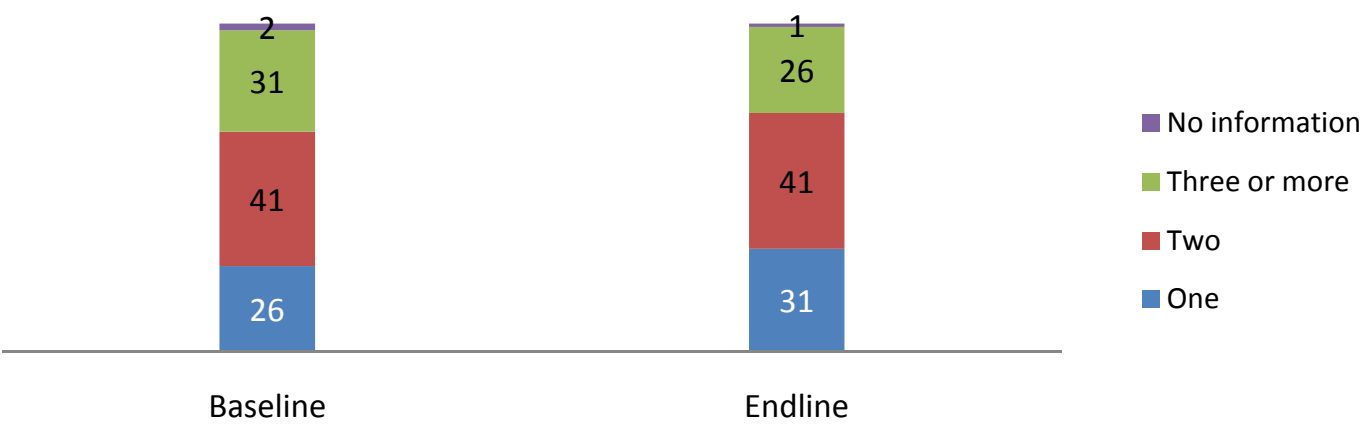

\section{Marital status}

The baseline and endline surveys collected information on the marital status of all household members aged 10 years and above. Table 4.3 shows marital status distribution of the male and female population by age and survey. Among males ages 10 years and above, nearly the same proportion were currently married (47 percent) in the two surveys. The proportions of males who were never married or were widowed/separated/divorced were also nearly identical at the time of the two surveys.

Among females, the proportions of women who were currently married, widowed/ separated/divorced and never married were almost identical in the two surveys. There were, however, some differences when comparing males and females by marital status. Higher proportions of women aged 10 years and above were currently married as compared to men in both baseline and endline surveys. Similarly, though the proportions remained almost the same in both surveys, the proportion of females who were widowed/divorced/separated was higher as compared to males (7 percent females vs. 3 percent males). The proportion of those single was higher among males than females in both surveys, signifying early marriages among females. 
Marriage is almost universal for both males and females: by age 45 years, nearly 97 percent of males were currently married, while less than 2 percent were single; for females, less than 3 percent were single by that age.

Table 4.3: Percentage distribution of household population, by age and marital status

\begin{tabular}{|c|c|c|c|c|c|c|}
\hline \multirow[b]{2}{*}{ Age group } & \multicolumn{3}{|c|}{ Male } & \multicolumn{3}{|c|}{ Female } \\
\hline & Married & $\begin{array}{r}\text { Widow/ } \\
\text { divorced/ } \\
\text { separated }\end{array}$ & Single & Married & $\begin{array}{l}\text { Widow/ } \\
\text { divorced/ } \\
\text { separated }\end{array}$ & Single \\
\hline \multicolumn{7}{|l|}{ Baseline } \\
\hline $10-14$ & 0.3 & 0.2 & 99.5 & 0.2 & 0.1 & 99.8 \\
\hline $15-19$ & 3.0 & 0.3 & 96.6 & 14.3 & 0.5 & 85.2 \\
\hline $20-24$ & 21.6 & 0.5 & 77.9 & 48.7 & 0.8 & 50.5 \\
\hline $25-29$ & 57.7 & 0.9 & 41.5 & 81.2 & 2.0 & 16.8 \\
\hline $30-34$ & 85.3 & 1.2 & 13.4 & 91.1 & 3.2 & 5.8 \\
\hline $35-39$ & 92.2 & 1.4 & 6.4 & 91.5 & 4.6 & 4.0 \\
\hline $40-44$ & 96.7 & 1.8 & 1.5 & 90.3 & 7.3 & 2.4 \\
\hline $45-49$ & 95.6 & 2.6 & 1.8 & 82.7 & 15.9 & 1.4 \\
\hline $50-54$ & 94.3 & 4.9 & 0.8 & 85.5 & 13.3 & 1.2 \\
\hline $55-59$ & 94.1 & 5.3 & 0.6 & 75.3 & 23.1 & 1.5 \\
\hline $60-64$ & 91.1 & 8.5 & 0.3 & 60.1 & 38.5 & 1.4 \\
\hline $65+$ & 79.2 & 19.4 & 1.4 & 38.9 & 59.6 & 1.5 \\
\hline Total & 47.4 & 2.5 & 50.1 & 50.9 & 7.2 & 41.9 \\
\hline (Number) & $(13,322)$ & (706) & $(14,086)$ & $(13,928)$ & $(1,976)$ & $(11,448)$ \\
\hline \multicolumn{7}{|l|}{ Endline } \\
\hline $10-14$ & 0.3 & 0.1 & 99.6 & 0.1 & 0.2 & 99.7 \\
\hline $15-19$ & 2.9 & 0.2 & 96.9 & 14.2 & 0.4 & 85.5 \\
\hline $20-24$ & 21.6 & 0.4 & 77.9 & 49.3 & 0.7 & 50.0 \\
\hline $25-29$ & 57.7 & 1.0 & 41.3 & 80.1 & 1.7 & 18.2 \\
\hline $30-34$ & 82.7 & 1.5 & 15.9 & 89.3 & 3.3 & 7.4 \\
\hline $35-39$ & 93.0 & 1.4 & 5.6 & 92.1 & 4.9 & 3.0 \\
\hline $40-44$ & 94.5 & 2.4 & 3.1 & 90.0 & 7.2 & 2.8 \\
\hline $45-49$ & 95.4 & 3.0 & 1.6 & 86.8 & 10.9 & 2.3 \\
\hline $50-54$ & 94.3 & 4.4 & 1.3 & 83.8 & 13.5 & 2.6 \\
\hline $55-59$ & 93.1 & 6.5 & 0.4 & 79.7 & 18.9 & 1.4 \\
\hline $60-64$ & 87.7 & 11.1 & 1.3 & 59.9 & 38.5 & 1.6 \\
\hline $65+$ & 78.2 & 20.7 & 1.1 & 44.0 & 53.4 & 2.6 \\
\hline Total & 47.6 & 3.0 & 49.4 & 52.8 & 7.2 & 40.0 \\
\hline (Number) & $(15,183)$ & (953) & $(15,784)$ & $(17,328)$ & $(2,375)$ & $(13,121)$ \\
\hline
\end{tabular}

\section{Socioeconomic status}

The socioeconomic status index was constructed using household asset data, including ownership of a number of consumer items (e.g., car, television, fridge, computer, motorcycle, etc.). A single asset index was developed for the whole sample; separate indices were not prepared for urban and rural populations. 
Table 4.4 shows that the medium-high and high income groups expanded between the endline and baseline surveys. Since the communities to which the populations belonged were the same in each survey, it can be construed that the social and economic conditions of the communities have improved over the period of time between the baseline and endline surveys.

Table 4.4: Distribution of households, by wealth quartiles

\begin{tabular}{lrrrrr} 
& \multicolumn{2}{c}{ Baseline } & & \multicolumn{2}{c}{ Endline } \\
\cline { 2 - 3 } \cline { 5 - 6 } Wealth index & Percent & Number & & Percent & Number \\
\cline { 5 - 6 } Low & 27.9 & 2,615 & 22.5 & 2,584 \\
\hline Medium low & 25.6 & 2,399 & 27.7 & 3,187 \\
\hline Medium high & 23.6 & 2,210 & 21.2 & 3,290 \\
\hline High & 23.0 & 2,160 & $\mathbf{1 0 0 . 0}$ & $\mathbf{1 1 , 5 0 1}$
\end{tabular}

\section{Respondent characteristics}

\section{Age}

Figure 4.4 provides information on the age composition of the currently married women of reproductive age (15-49 years) in both surveys. The proportion of women remained the same in the 15-19 and 20-24 age groups, while the proportion 25-29 and 30-34 decreased slightly, and the proportion 40-44 and 45-49 increased slightly between baseline and endline. For the women, the mean age in the baseline was 31.3 years as against 32.2 years in the endline survey, which shows the close resemblance in the distribution of currently married women of reproductive age in the two samples.

Figure 4.4: Percentage distribution of women, by age group

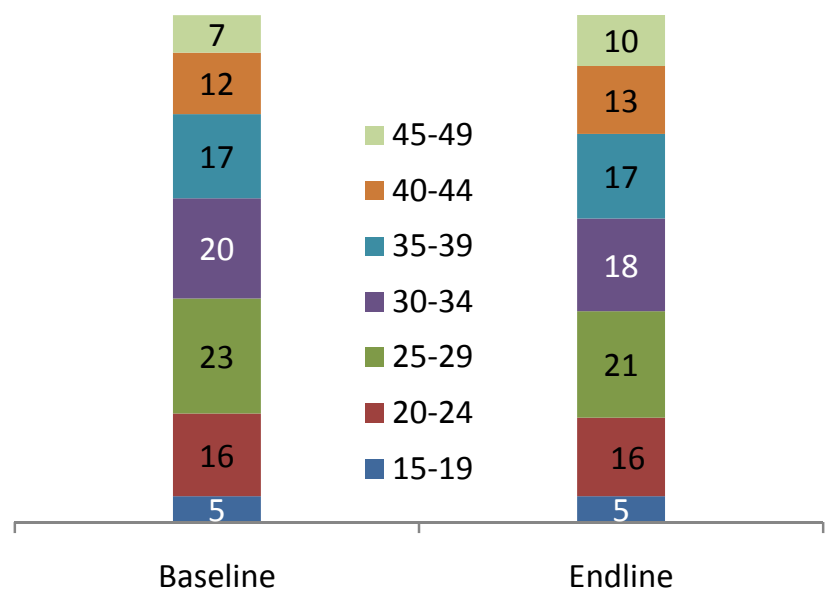

\section{Education}

Education is an important indicator reflecting the status of women in society. Women with higher education are able to make independent decisions and be part of the decisionmaking process. Education helps change attitudes and shape behavior toward improvements in the quality of life. Furthermore, 
education can lead to increased income, helping women and their families overcome poverty, and is a factor in improving health and nutrition of women and their families.

Among the women from the two surveys, a majority had no schooling (Figure 4.5). However, the proportion of such women was slightly lower in the endline (58 percent) compared to the baseline survey (61 percent). The proportions of women who had class 1-5 and class 6-10 education were almost identical, while the proportion of women who had class 11 or higher increased from 8 percent in the baseline to 10 percent in the endline.

Figure 4.5: Percentage distribution of women, by education

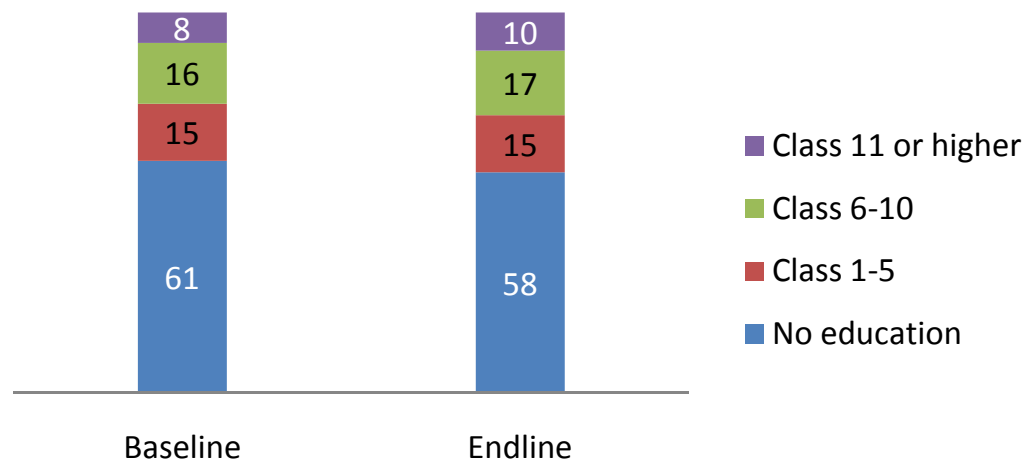

\section{Work status}

The distribution of respondents by work status was similar in the baseline and endline surveys (Table 4.5). The exceptions were for the category of agricultural workers, where the proportion has declined by 6 percentage points, and for the category of housewife, where the proportion has increased by 5 percentage points. Other professions were nearly identical in both surveys.

Table 4.5: Distribution of women, by type of work

\begin{tabular}{lrrrrr} 
& \multicolumn{2}{c}{ Baseline survey } & & \multicolumn{2}{c}{ Endline survey } \\
\cline { 5 - 6 } \cline { 5 - 6 } Type of work & Percent & Number & & Percent & Number \\
\cline { 5 - 6 } Housewife & 71.3 & 6,592 & 76.2 & 9,417 \\
\hline Agricultural work & 13.5 & 1,246 & 0.3 & 929 \\
\hline Domestic servant & 0.4 & 34 & 10.7 & 1,319 \\
\hline Embroidery/stitching/knitting & 10.5 & 972 & 0.4 & 45 \\
\hline Shopkeeper & 0.3 & 24 & 1.4 & 179 \\
\hline Tutoring (religious/formal) & 1.1 & 104 & 1.5 & 180 \\
\hline Skilled labor & 0.8 & 73 & 0.5 & 66 \\
\hline Unskilled labor & 0.2 & 20 & 1.0 & 128 \\
\hline Service & 1.1 & 99 & 0.4 & 52 \\
\hline Other & 0.9 & 79 & $\mathbf{1 0 0 . 0}$ & $\mathbf{1 2 , 3 5 7}$
\end{tabular}




\section{Exposure to mass media}

Mass media has a strong social and cultural impact upon society. It helps to form public opinion, which is often translated into action over time. Television has become a major form of mass media. Radio, once a major source of information in Pakistan, has lost some of its audience in urban and rural areas. Print medium is restricted primarily to those who are literate, which constitutes nearly half of the adult population. Besides expanding and upgrading maternal and neonatal healthcare services in the project areas, the PAIMAN project utilized mass media and interpersonal communication sources for creating awareness about maternal and neonatal health. Exposure to mass media by type of media and media habits is consolidated in Table 4.6.

\section{Television}

Information regarding exposure to television was collected in both surveys. Respondents were asked about the television channels they usually watched, along with the timings, specifics about the programs and the frequency of exposure. The findings show that among women exposure to TV increased by 14 percentage points during the project. A majority of women reported to have been exposed to Pakistan Television Corporation (PTV), the state-owned channel with the widest coverage in the country. The other preferred or frequently viewed channels in the project districts are Star Plus, followed by Geo and KTN (Figure 4.6). Though PTV had the wider viewership, the viewership of Star Plus had more than doubled in the project districts. Television was considered to be the most effective source of information by the respondents. The proportion of women who could watch television anytime, at their own will, increased from 45 percent in the baseline to 58 percent in the endline, which shows further improvement in their status (Table 4.6).

Figure 4.6: Percentage of women, by exposure to most frequently watched television channels

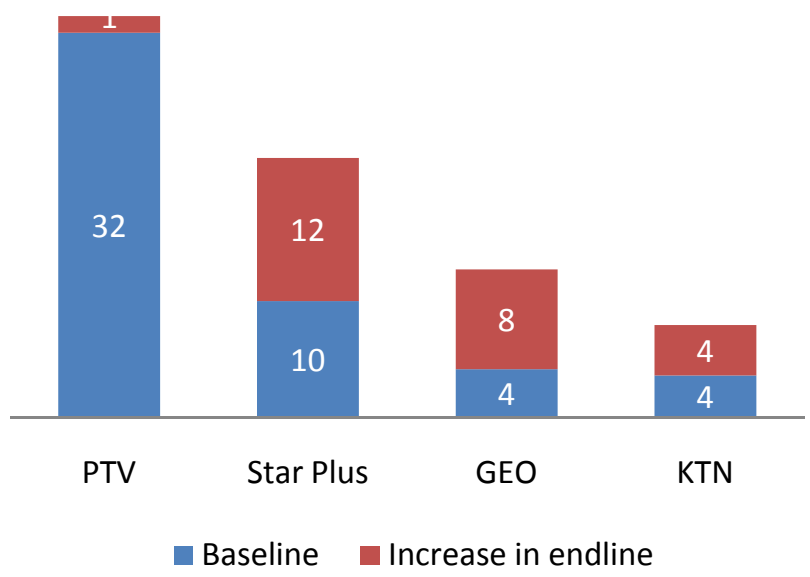


Table 4.6: Percentage of women, by variables regarding mass media

\begin{tabular}{|c|c|c|}
\hline Variable & $\begin{array}{r}\text { Baseline } \\
(N=9,242)^{a}\end{array}$ & $\begin{array}{r}\text { Endline } \\
(N=12,357)^{a}\end{array}$ \\
\hline Can watch TV anytime at her own will & 45.1 & 58.0 \\
\hline \multicolumn{3}{|l|}{ Frequency of TV watching } \\
\hline Regularly & 30.7 & 41.3 \\
\hline At least once in a week & 2.5 & 1.5 \\
\hline At least once in a month & 0.2 & 0.1 \\
\hline Once in a while & 12.9 & 17.0 \\
\hline Don't watch TV & 53.7 & 40.0 \\
\hline Listen to radio & 12.0 & 9.4 \\
\hline Frequency of listening among listeners & $(N=1,105)$ & $(N=1,166)$ \\
\hline Almost daily & 40.9 & 38.4 \\
\hline At least once a week & 6.0 & 4.2 \\
\hline At least once a month & 0.5 & 0.9 \\
\hline Once in a while & 52.3 & 56.5 \\
\hline \multicolumn{3}{|l|}{ Frequency of reading newspapers } \\
\hline Never (respondent was illiterate) & 78.4 & 76.2 \\
\hline Regularly & 2.8 & 2.1 \\
\hline Once in a while & 18.8 & 21.7 \\
\hline \multicolumn{3}{|l|}{ Most effective communication medium } \\
\hline Television & 51.7 & 68.1 \\
\hline Radio & 7.8 & 5.6 \\
\hline Newspaper & 4.1 & 3.9 \\
\hline Magazines & 0.7 & 0.4 \\
\hline Other & 0.1 & 0.1 \\
\hline Don't know/missing & 35.6 & 21.9 \\
\hline
\end{tabular}

${ }^{a}$ All percents are calculated on the basis of the $\mathrm{N}$ shown unless otherwise indicated.

\section{Radio}

The percent of radio listeners was low in both surveys (12 percent baseline; 9 percent endline). Among those exposed to radio, a majority reported that they rarely listened to radio ( 52 percent baseline; 57 percent endline) (Table 4.6). Regular listeners of radio appeared to be on the decline (41 percent baseline; 38 percent endline). Among those who listened to radio, more were tuning in to listen to songs (59 percent baseline; 70 percent endline), while listeners of news programs increased from 30 percent to 33 percent. The proportion of those listening to religious programs declined somewhat (from 24 to 18 percent), while health program listeners increased by about the same percent (from 14 to 19 percent) (Figure 4.7). 
Figure 4.7: Percentage of women who listened to the radio, by type of program

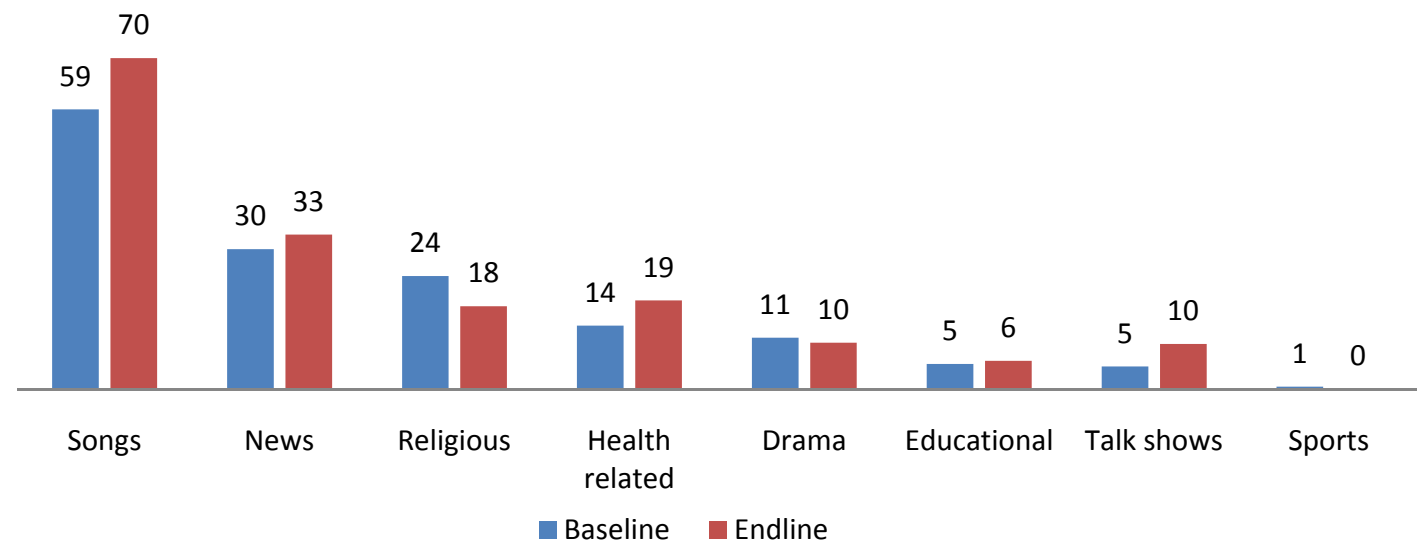

Newspapers

A majority of the women were illiterate, so it is not surprising that over three-fourths reported never reading a newspaper, while only 19 percent in the baseline and 22 percent in the endline reported reading newspapers once in a while (Figure 4.8). Only a tiny fraction reported that they read newspapers regularly (3 percent baseline; 2 percent endline).

Figure 4.8: Percentage distribution of women, by how often they read newspapers

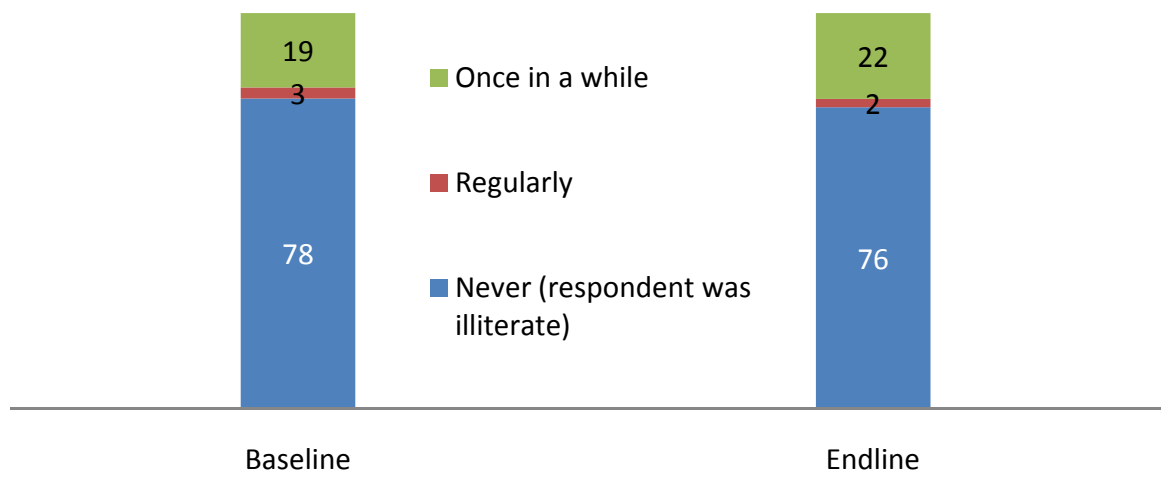

\section{Exposure to maternal and neonatal health issues through mass media}

Respondents were asked whether they had heard/watched/read, from any source, about maternal and newborn health in the three months prior to each of the surveys. Questions were also asked about whether they had heard a religious leader, scholar, representative of any NGO, or any member of the community talking about maternal and newborn health. Figure 4.9 shows that the proportion of women who recalled having watched, heard or read about maternal health issues in the three months prior to the baseline and endline surveys doubled, from 19 to 38 percent, during the duration of the project. Similarly, higher proportions of respondents reported to have heard/watched/read about newborn health issues at the end of the project (from 15 to 34 percent). 
Figure 4.9: Percentage of women who watched/read/heard a maternal/newborn health-related program in the three months preceding the survey

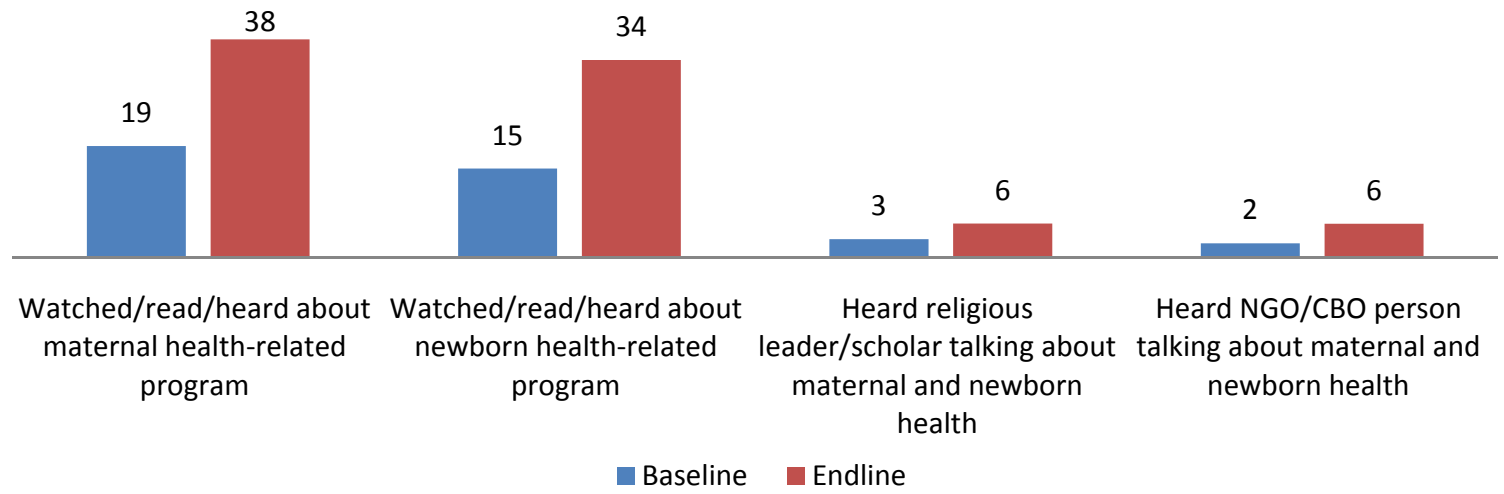

Results also show that only a small proportion of women heard about maternal and newborn health issues from religious leaders/scholars or from CBO and NGO representatives. Although the proportion of women who could recollect such talks doubled between the two surveys, from 3 percent to 6 percent, the overall level remained very low (Figure 4.9). 



\section{Chapter 5. Antenatal Care}

Maternal healthcare services received during pregnancy, delivery and postpartum period are important for the health of a mother and her child. Complications during pregnancy and childbirth are the leading causes of death among women of reproductive age. More than half a million women die around the world every year because of pregnancy-related complications and 99 percent of these deaths occur in developing countries (WHO, 2005). Any woman can experience sudden and unexpected complications during pregnancy, childbirth, and just after delivery. However, accessing and using high-quality maternal health services has made maternal death a rare event in developed countries, while these complications can often be fatal in the developing world. In Pakistan, like in many developing countries, a majority of births occur at home, assisted by untrained helpers who are not capable of handling complications during delivery.

The convention for normal pregnancies is that antenatal checkups should be scheduled at four-week intervals during the first seven months, then every two weeks up to the last month, and weekly thereafter. WHO recommends that women have a minimum of one checkup during the third, sixth, eighth and ninth months of pregnancy (WHO, 2003). Research shows that even if the first antenatal checkup is initiated as late as the third trimester, chances of antenatal mortality are substantially reduced (Ramachandran, 1992).

\section{Knowledge of danger signs during pregnancy}

Currently married women of reproductive age were asked about danger signs that may occur during the reproductive process that would indicate the need for consultation or treatment from a healthcare provider. Figure 5.1 shows that the proportion of women having knowledge of three or more danger signs during pregnancy increased from 31 percent to nearly 38 percent between the baseline and endline surveys. The proportion of women who had no knowledge of any danger sign during pregnancy declined from 23 percent to 19 percent during the project period. With regard to specific danger signs during pregnancy, awareness increased for most of the danger signs, including severe abdominal pain, heavy bleeding, high blood pressure, and spotting (Figure 5.2). However, these results are based on spontaneous answers; awareness increased substantially when a danger sign was named by the interviewer (data not shown). 
Figure 5.1: Percentage distribution of women, by knowledge of danger signs during pregnancy

\begin{tabular}{c|l|l}
31 & $\square$ Three or more signs & 38 \\
23 & $\square$ Two signs & \\
22 & $\square$ One sign & 22 \\
23 & & 20 \\
Baseline knowledge & 19 \\
\hline
\end{tabular}

Figure 5.2: Percentage of women, by knowledge of specific danger signs during pregnancy

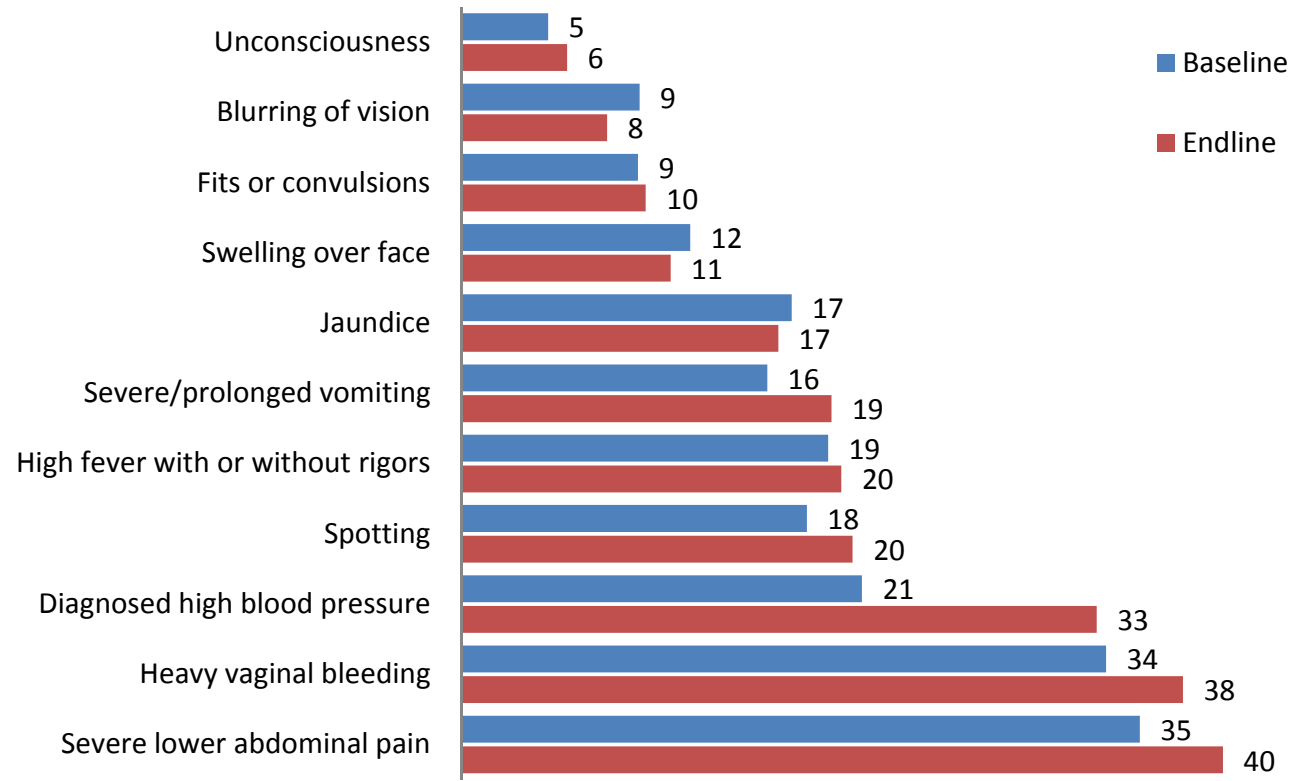




\section{KNOWLEDGE OF AT LEAST THREE DANGER SIGNS DURING PREGNANCY by selected characteristics of women}
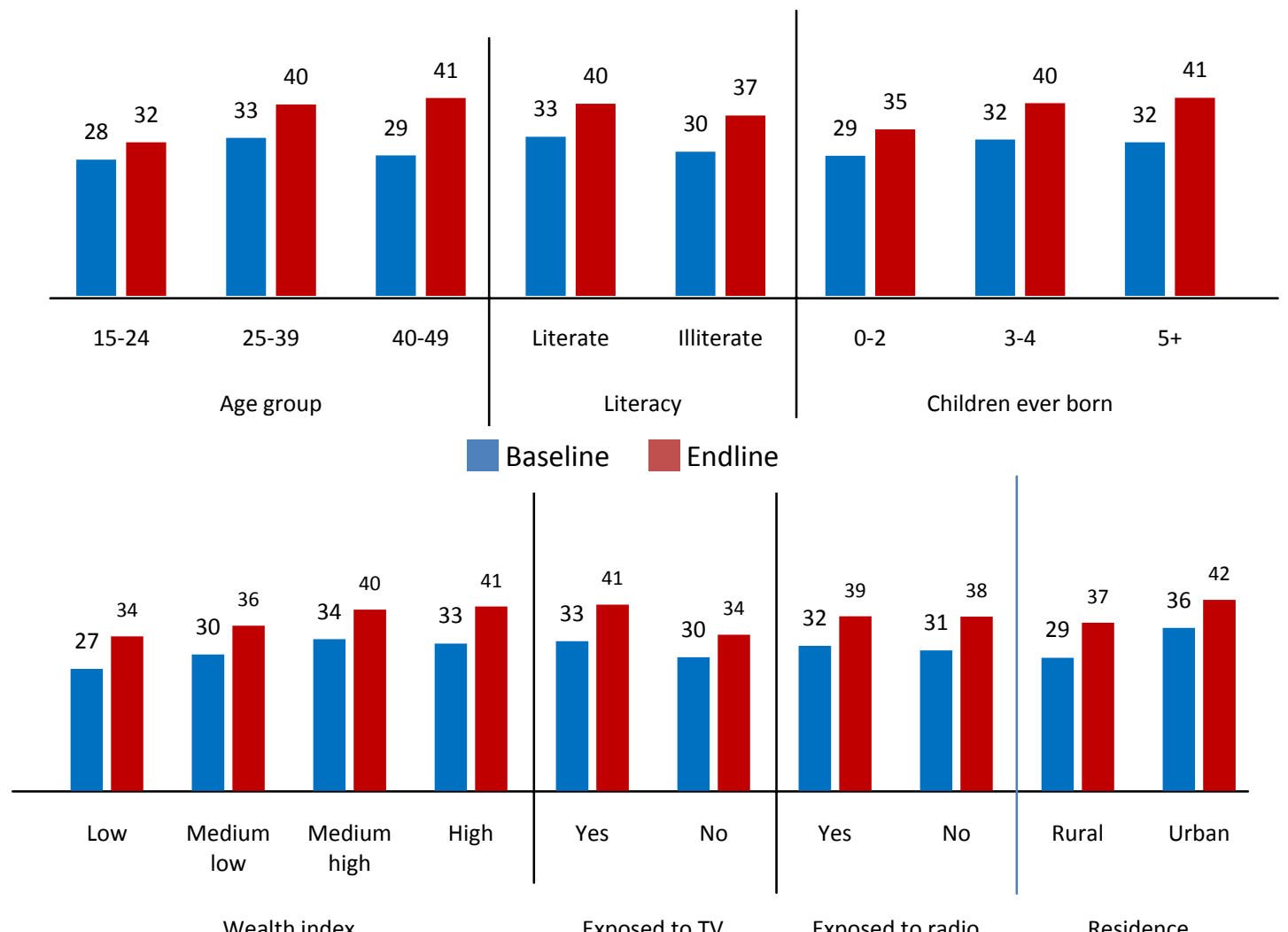

These figures show the percentage of currently married women of reproductive age who knew at least three danger signs during pregnancy by their background characteristics. The endline survey findings show an overall improvement of 7 percentage points (baseline 31 percent vs. endline 38 percent) in at least 3 danger signs during pregnancy. Findings also show that the increase is slightly higher in rural areas compared to urban areas (8 percentage points vs. 6 percentage points). Moreover, the increase is also higher among older women (12 percentage points), women with more than 4 children (9 percentage points), and women who watch TV (8 percentage points). 


\section{Attitude about and use of antenatal care}

Table 5.1 and Figure 5.3 show the status of antenatal care indicators during the project duration. The majority of the women in the baseline and endline surveys ( 85 and 94 percent, respectively) were of the opinion that women should get antenatal care during their pregnancy. Though the proportion of women who actually received antenatal care was smaller than the proportion who said that women should get antenatal care, nevertheless, the proportion of women who reported at least one antenatal care visit was 14 percentage points higher in the endline (from 58 to 72 percent), indicating a significant increase in women who were able to obtain antenatal care.

Table 5.1: Percentage of women, by attitude toward ANC and use of ANC during last pregnancy

\begin{tabular}{lrr} 
Indicator & Baseline survey & Endline survey \\
\hline Is it necessary to have ANC checkup(s) & $(N=9,242)$ & $(N=12,357)$ \\
\hline Yes & 84.8 & 94.2 \\
\hline No/Don't know & 15.2 & 5.8 \\
\hline Had ANC checkup(s) & $(N=4,854)$ & $(N=6,610)$ \\
\hline Yes & 57.8 & 71.8 \\
\hline No & 42.2 & 28.2 \\
\hline Place/person seen for ANC checkup(s)* & $(N=2,806)$ & $(N=4,742)$ \\
\hline LHW & 1.2 & 1.3 \\
\hline TBA/Dai & 5.7 & 2.7 \\
\hline CMW/CMW home & 0.0 & 0.1 \\
\hline BHU/RHC/dispensary/MCH & 13.3 & 9.1 \\
\hline DHQ/THQ & 29.8 & 24.6 \\
\hline Private clinic/hospital & 51.9 & 71.2 \\
\hline Midwife & 0.4 & 0.1 \\
\hline Nurse/LHV & 3.8 & 3.1 \\
\hline FWC/RHSC (A) & 0.8 & 1.1 \\
\hline Lady doctor/doctor & 2.9 & 0.6 \\
\hline Other & 2.0 & 1.3 \\
\hline Multiplerponse & & \\
\hline
\end{tabular}

*Multiple response variable.

Figure 5.3: Percentage of women, by attitude toward ANC and use of ANC during last pregnancy

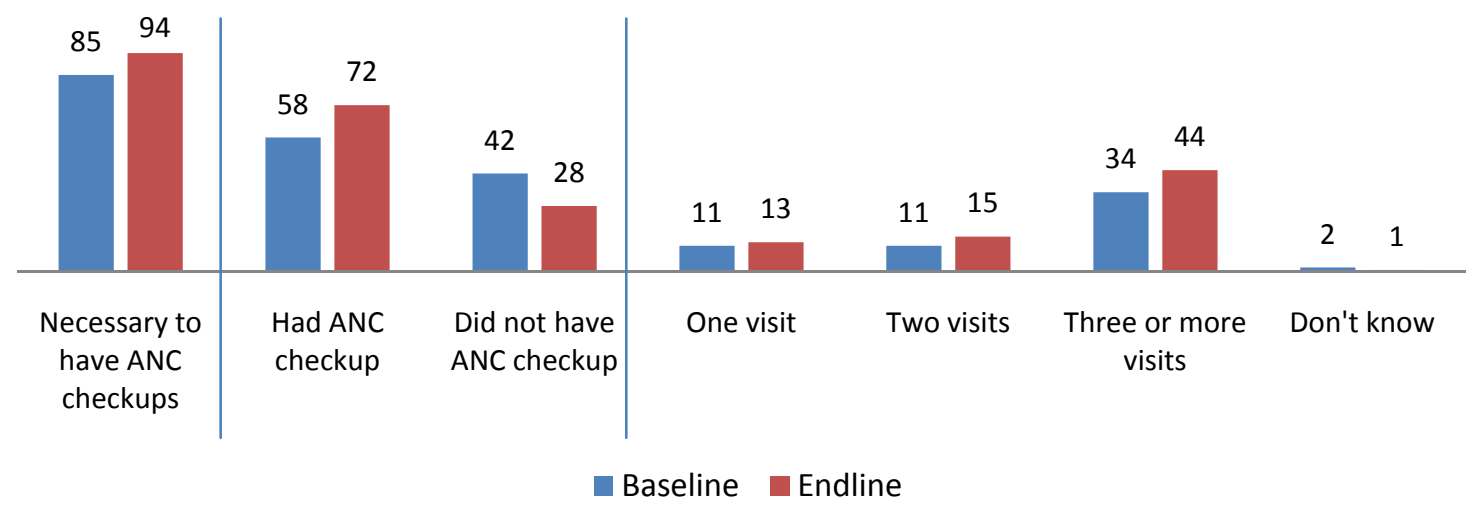




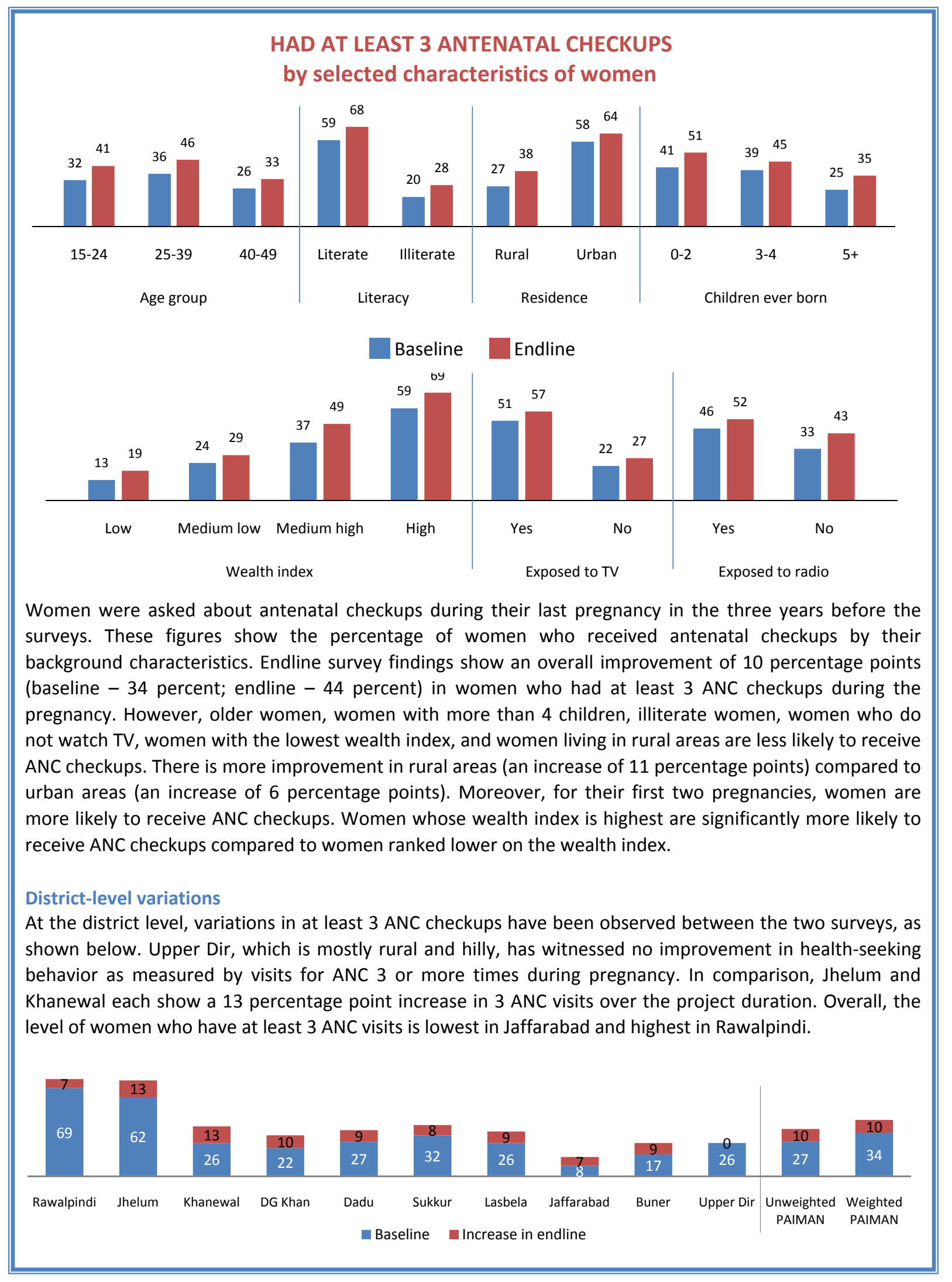




\section{Frequency and timing of antenatal care checkups}

Women who had ANC checkups during their last pregnancy were also asked about the frequency of their visits. The endline survey showed an increase in the percentage of women who had three or more antenatal visits during their last pregnancy as compared to the baseline survey (34 percent baseline; 44 percent endline) (Figure 5.3). Though more women visited a service provider for antenatal care during the first trimester than other trimesters, this percentage increased from 47 percent to 52 percent between baseline and endline (Figure 5.4).

Figure 5.4: Percentage distribution of women, by timing of first ANC checkup during last pregnancy

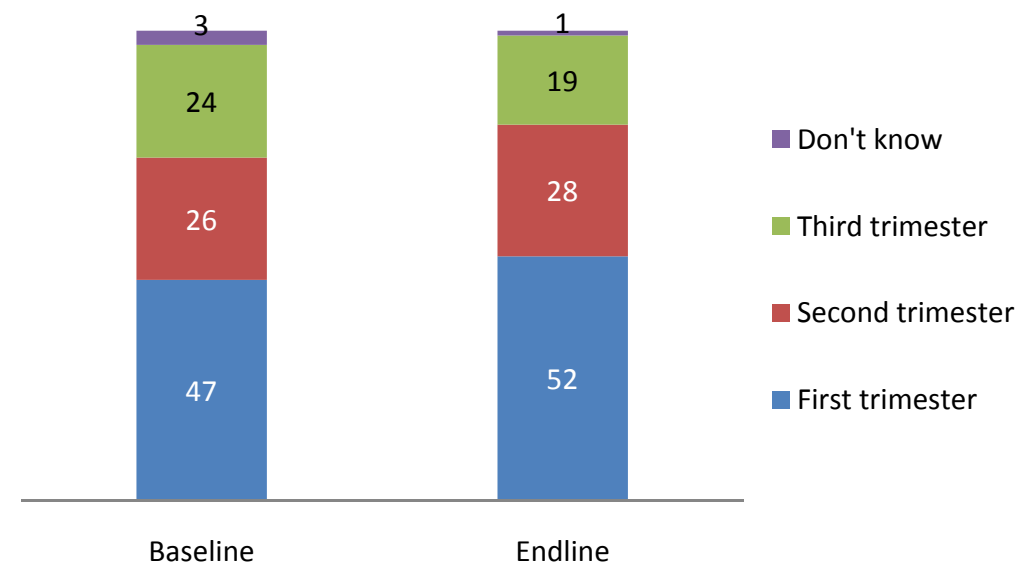

\section{Source for antenatal care}

During the course of pregnancy, a woman may opt to go to different health providers depending on her satisfaction with the providers that she sees. Her actions may also depend on the nature and severity of any complication experienced during her pregnancy. During this survey, women were encouraged to report all of the health providers they went to for antenatal care services (Table 5.1). The results show that a majority of women in both surveys who went for antenatal checkups visited private clinics/hospitals, followed by DHQs/THQs and primary healthcare facilities staffed by trained health professionals. The percentage of women who sought healthcare from private hospitals or clinics increased substantially between baseline and endline, from 52 to 71 percent. However, a decline in the proportion of those who went to publicsector facilities was observed: from 30 to 25 percent for DHQ/THQ hospitals and from 13 to 9 percent for $\mathrm{BHUs} / \mathrm{RHCs} / \mathrm{MCH}$ centers. Traditional healthcare providers, like TBA/dais, were visited by very few women for antenatal care in both surveys, and these percents declined by half between the two surveys (Table 5.1). The four main sources of antenatal checkups observed in the endline survey are shown in Figure 5.5. 
Figure 5.5: Percentage of women, by place or provider of ANC checkups during last pregnancy (for four main reported sources)

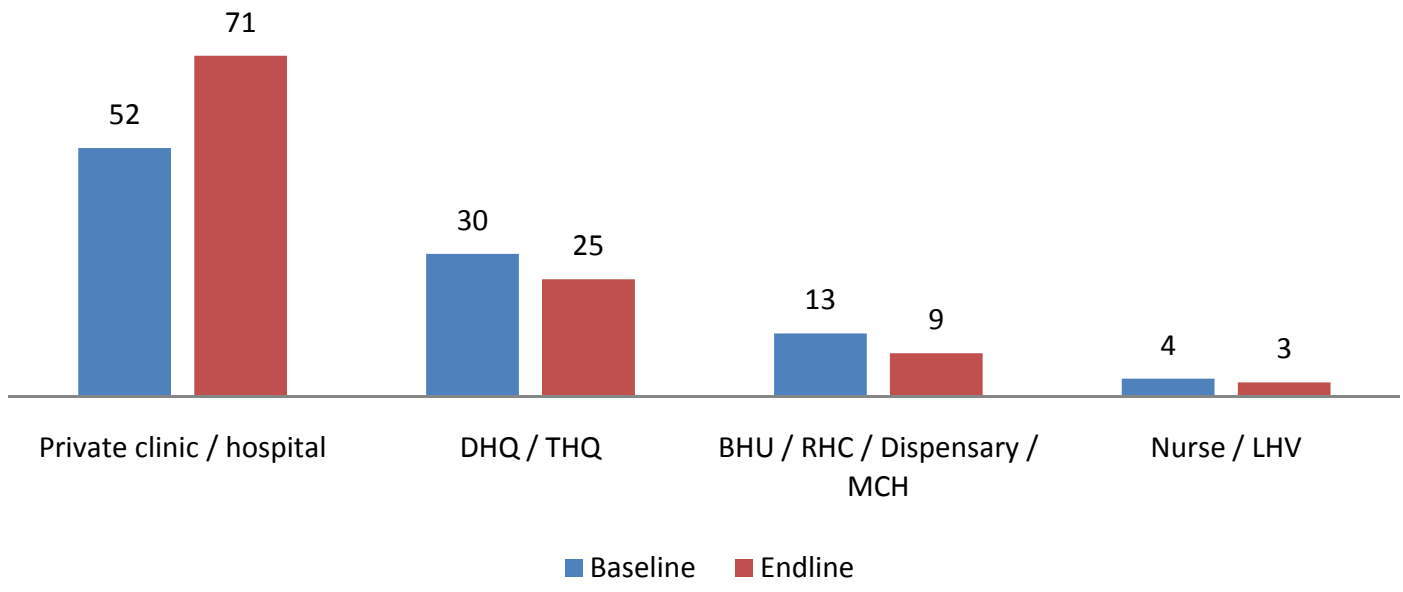

\section{Services and advice received during antenatal checkups}

A majority of the women reported that they had undergone various tests and examinations (e.g., anemia, blood and urine tests, hypertension, ultrasound, weight, measurement, and heart beat and positioning of the fetus) during their visits for ANC. The proportion of women undergoing such tests/examinations increased significantly between baseline and endline. However, a high proportion of women who visited a healthcare provider for antenatal care were not given a complete checkup (Figure 5.6).

Figure 5.6: Percentage of women, by specific services given by healthcare provider during last pregnancy

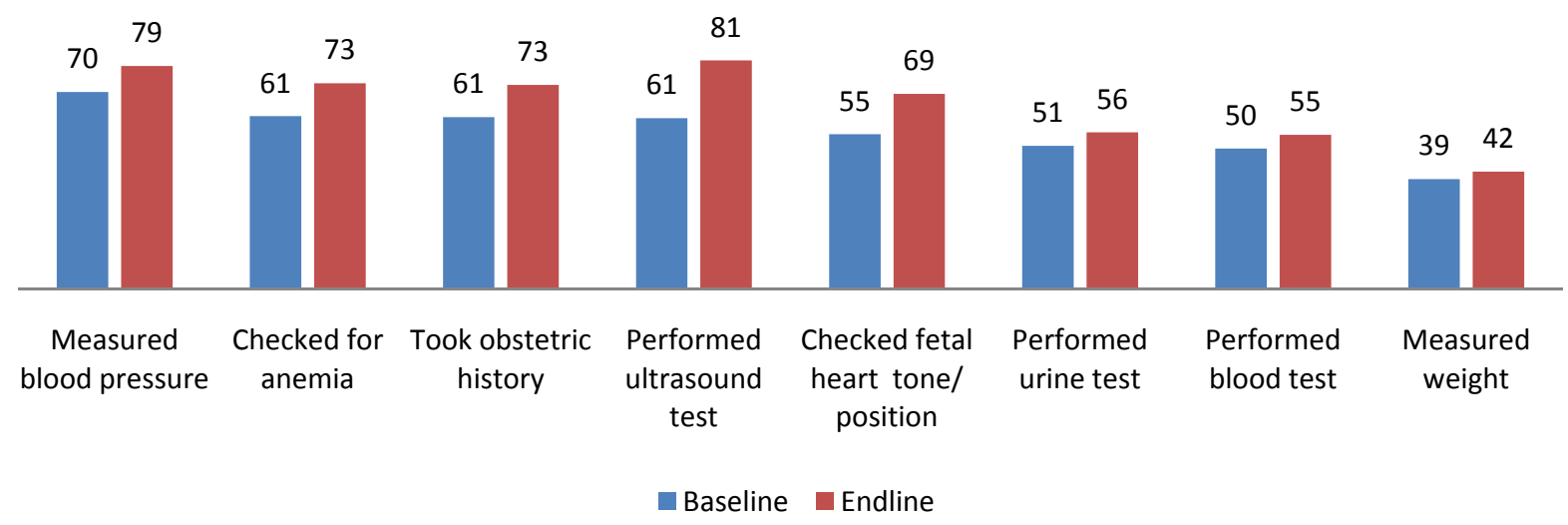

The proportion of women reporting that they were given advice by a health practitioner on nutrition; TT injections; breastfeeding; awareness about danger signs; and preparation for birth increased during the project period (Figure 5.7). Still, however, in the endline survey, a majority of women reported not being given advice about birth preparedness (71 percent), breastfeeding (61 percent), or danger signs during pregnancy (63 percent). 
Figure 5.7: Percentage of women, by type of advice given by healthcare provider during last pregnancy

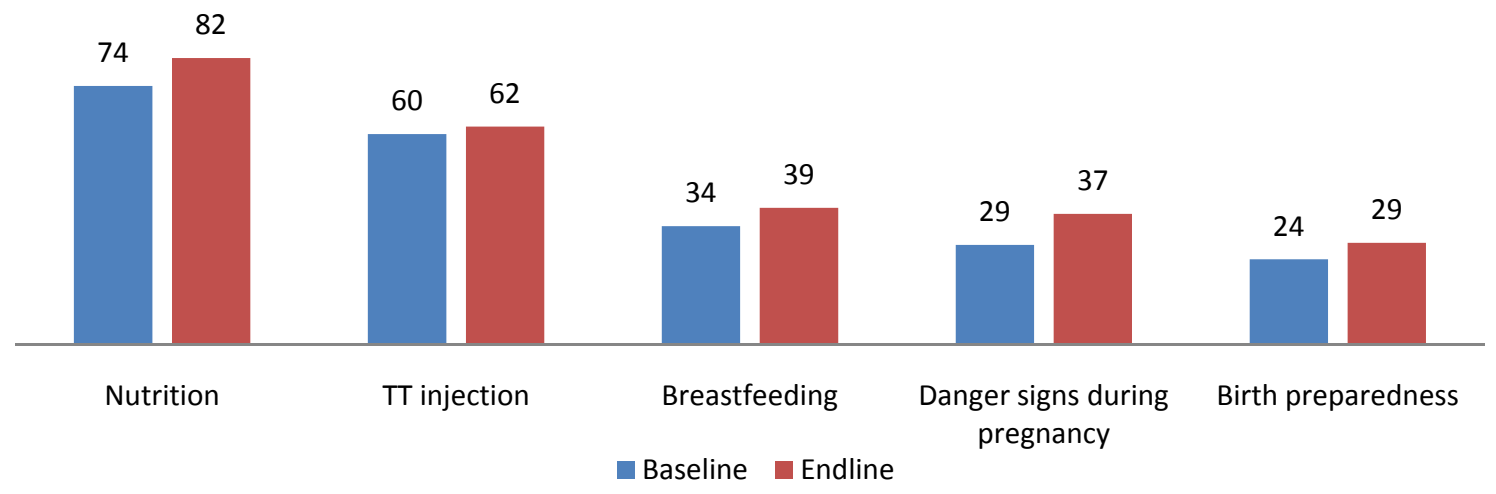

\section{Iron supplementation}

The use of iron tablets has remained stagnant during the project duration (Figure 5.8). Over half of the women reported to have never used iron supplements during their last pregnancy ( 57 percent baseline; 53 percent endline). The proportion of those who took iron supplements for three or more months during their last pregnancy increased from 24 to 27 percent between baseline and endline.

Figure 5.8: Percentage of women, by duration of use of iron supplements during last pregnancy

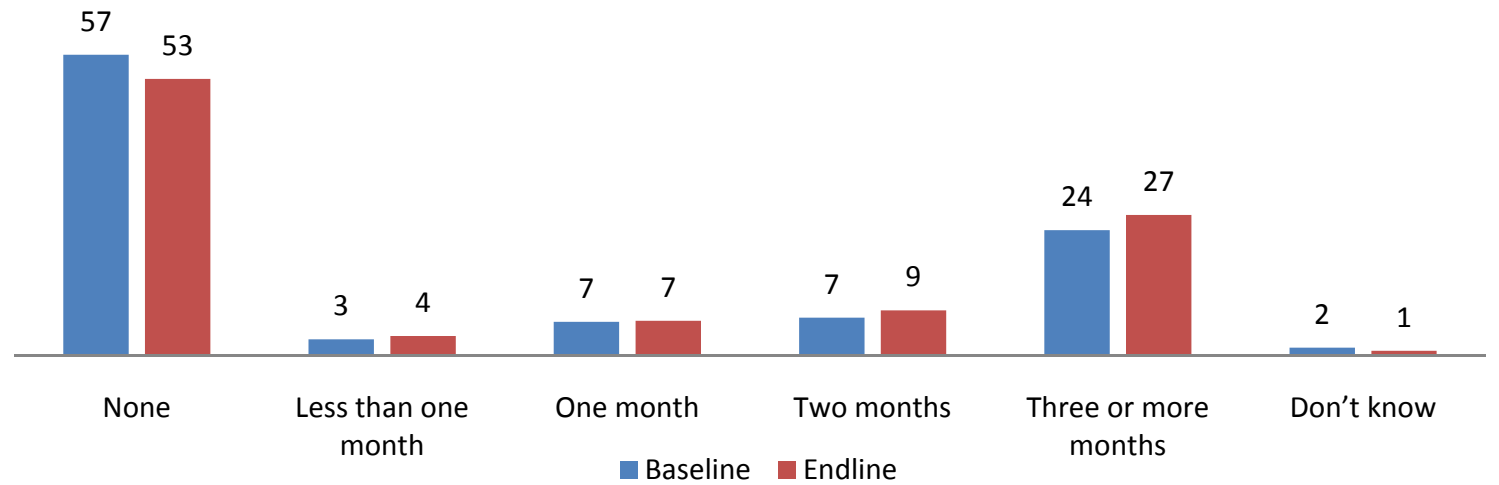

\section{Tetanus toxoid injections}

Tetanus toxoid (TT) injections are an important component of antenatal care. TT injections are given during pregnancy primarily for the prevention of neonatal tetanus. In Pakistan, one percent of neonates die because of tetanus (PDHS, 2008). For full protection, it is recommended that a pregnant woman receive at least two doses of tetanus toxoid during her first pregnancy, administered one month apart, and a booster shot during each subsequent pregnancy. Five doses of tetanus toxoid injections are considered to provide lifetime protection.

Figure 5.9 shows that although 87 percent of the women in the baseline and 92 percent in the endline survey reported that they were aware of the TT vaccine, fewer used TT injections during their last pregnancy (53 percent baseline; 62 percent endline). Of the women who were pregnant in the three years prior to each of the surveys, 48 percent and 56 percent (baseline and endline respectively) reported to have 
taken two or more doses of tetanus toxoid. The analysis shows an increase in the use of two or more TT injections. However, there is no information that women who reported to be already immunized had in fact completed their TT immunization course.

Figure 5.9: Percentage of women, by awareness and use of $T T$ injections during last pregnancy

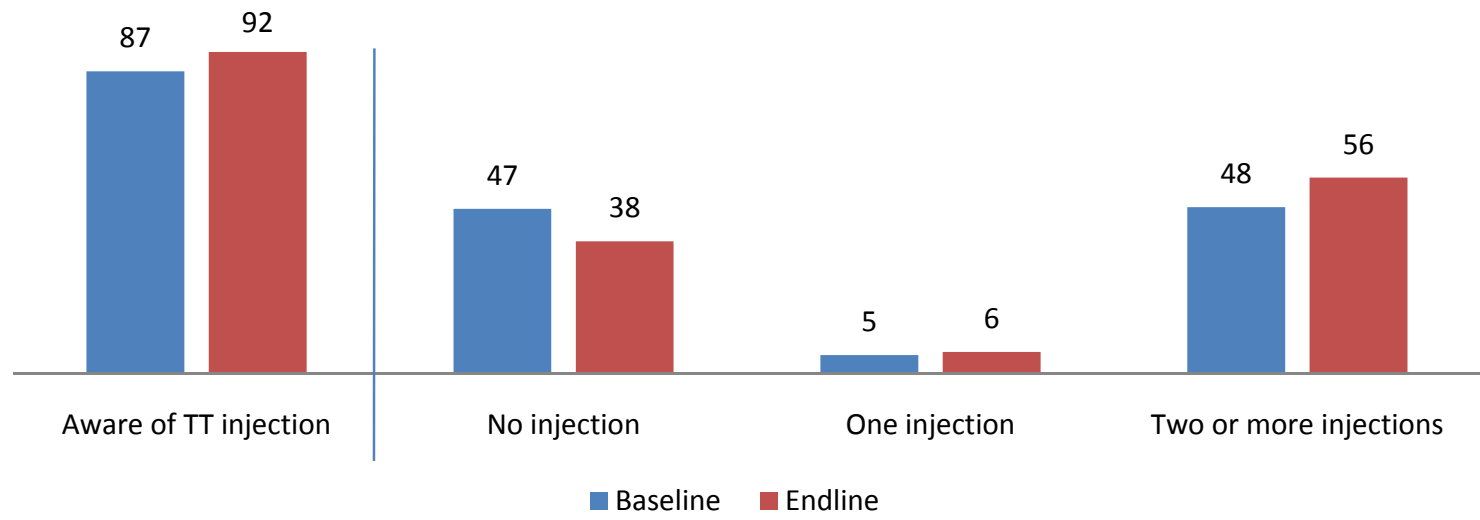

\section{Pregnancy complications and treatment}

Pregnancy complications are directly related to maternal and child morbidity and mortality. It is, therefore, important for healthcare practitioners to provide proper information to expectant mothers regarding danger signs during pregnancy. However, this has not been fully practiced, as seen earlier in the report (Figure 5.7): in the endline survey, only 37 percent of the women were given advice about the danger signs of pregnancy during antenatal visits in their last pregnancy. The complications faced during pregnancy at the time of the baseline and endline surveys were almost identical but with varying degree of incidence (Figure 5.10). Among those women who experienced any complications during pregnancy, severe abdominal pain, severe headache, shortness of breath, prolonged vomiting, and high fever were more commonly reported.

Figure 5.10: Percentage of women who experienced complications during last pregnancy, by specific complications

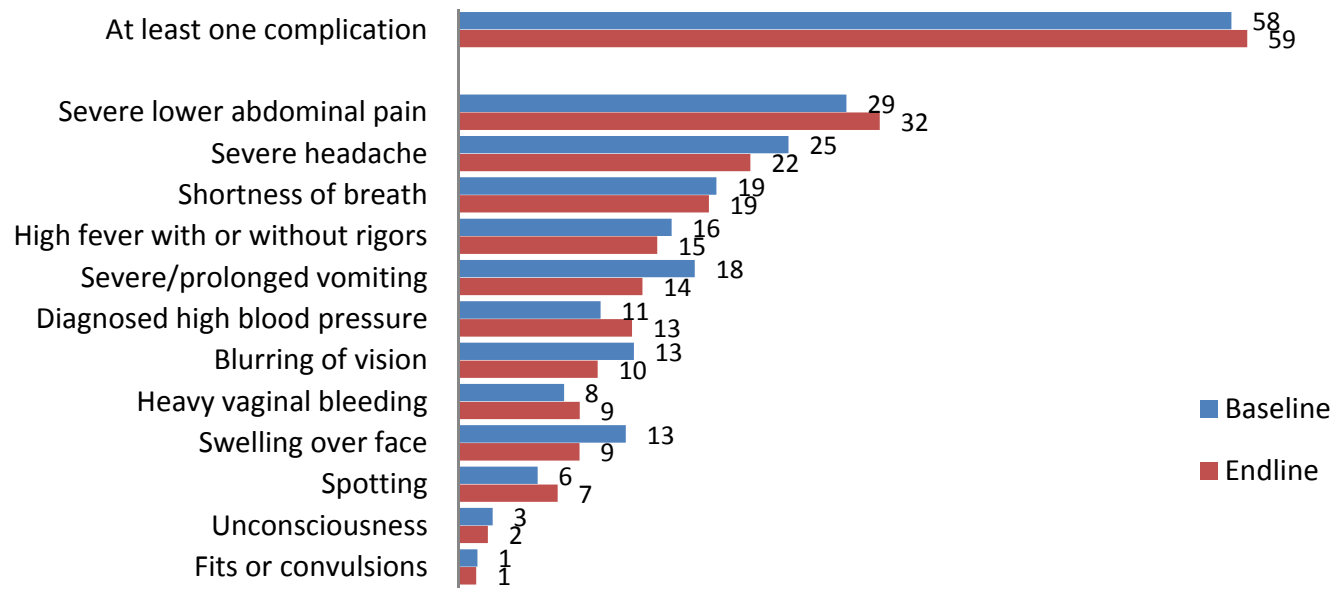




\section{RECEIVED AT LEAST 2 TETANUS TOXOID INJECTIONS}

by selected characteristics of women

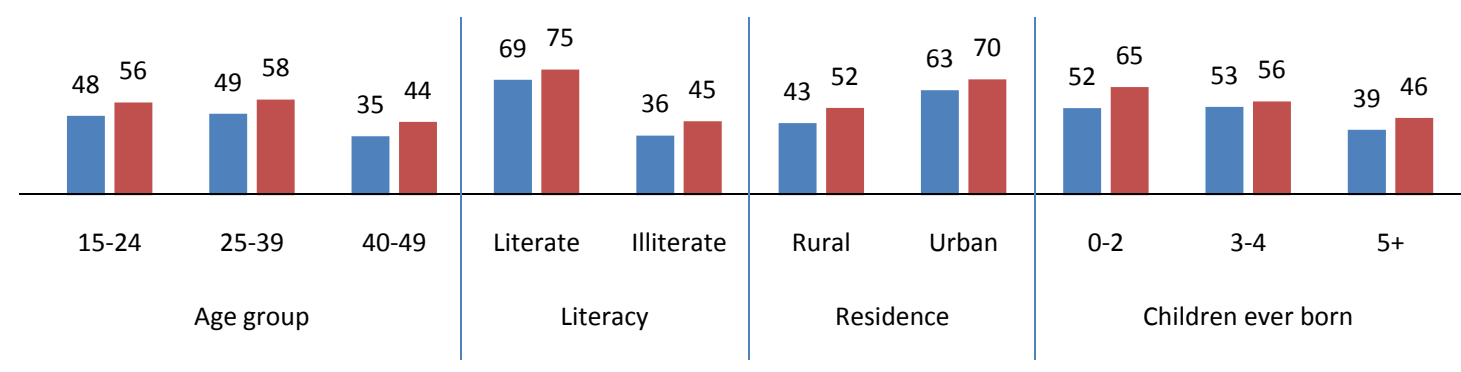

Baseline Endline

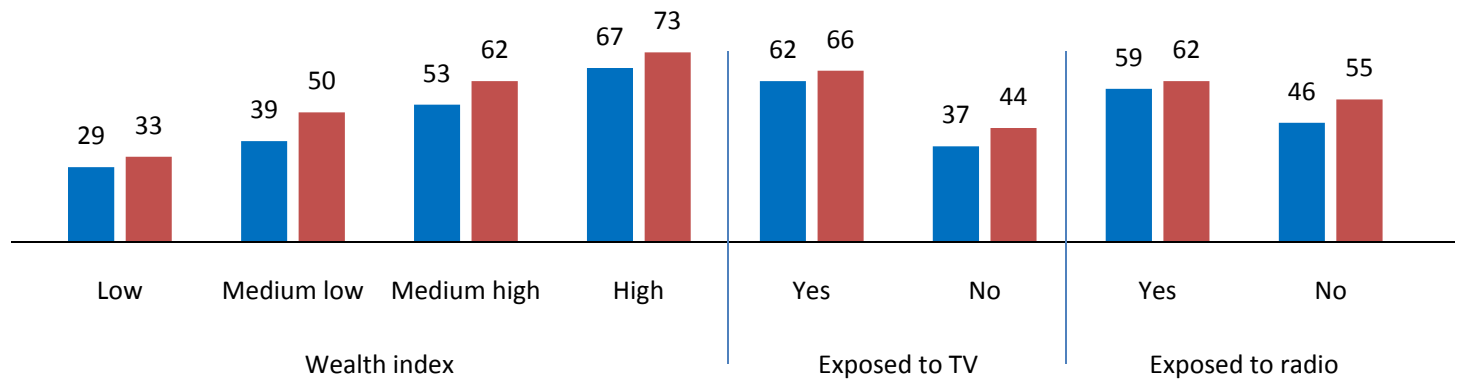

The above figures show percentages of women who had TT injections during their last pregnancy by their background characteristics. Endline survey findings show an overall increase of 8 percentage points (baseline 48 percent vs. endline 56 percent) in TT injections in PAIMAN districts (Figure 5.9). Overall, endline findings show improvement in obtaining at least 2 TT injections in all segments of the population in PAIMAN districts. However, older women, mothers with more than 4 children, illiterate women, women who do not watch TV, women living in rural areas and women with the lowest wealth index are less likely to have received 2 doses of TT injections during their last pregnancy.

\section{District-level variations}

Variations in women having TT injections during pregnancy have been observed among project districts (see below). Jhelum and Rawalpindi, the two developed and urbanized districts in the PAIMAN area, have a higher level of 2 TT injections, with an increase of 12 and 8 percentage points respectively, during the project period. However, the highest increase during the interval between baseline and endline surveys has been observed in Khanewal district, with an increase of 18 percentage points.

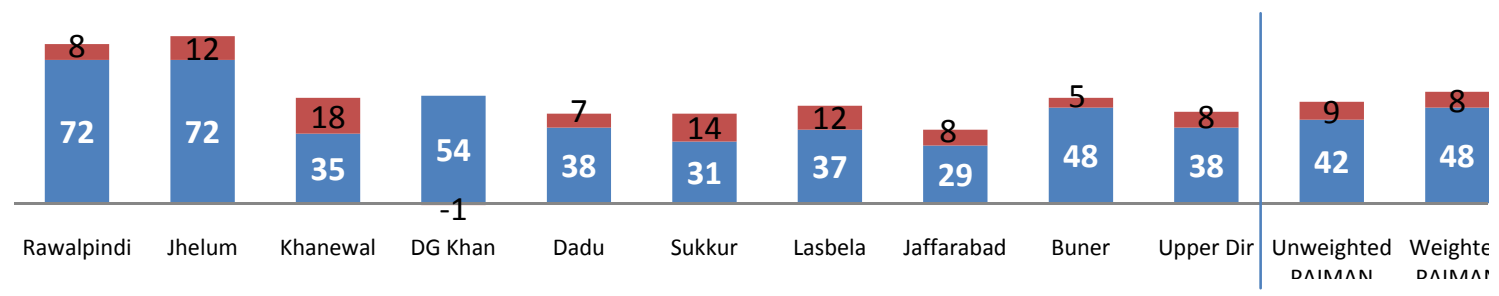


A relatively higher proportion of women who experienced a complication received treatment in the endline as compared to the baseline survey (75 percent baseline; 83 percent endline), which shows some improvement in the health-seeking behavior of women. The percentage of women seeking treatment from private hospitals/clinics rather than from the public sector has grown over the project period (from 42 percent in the baseline to 61 percent in the endline), indicating growing confidence in private-sector services (Figure 5.11).

Figure 5.11: Percentage distribution of women who had complications during their last pregnancy, by source of treatment

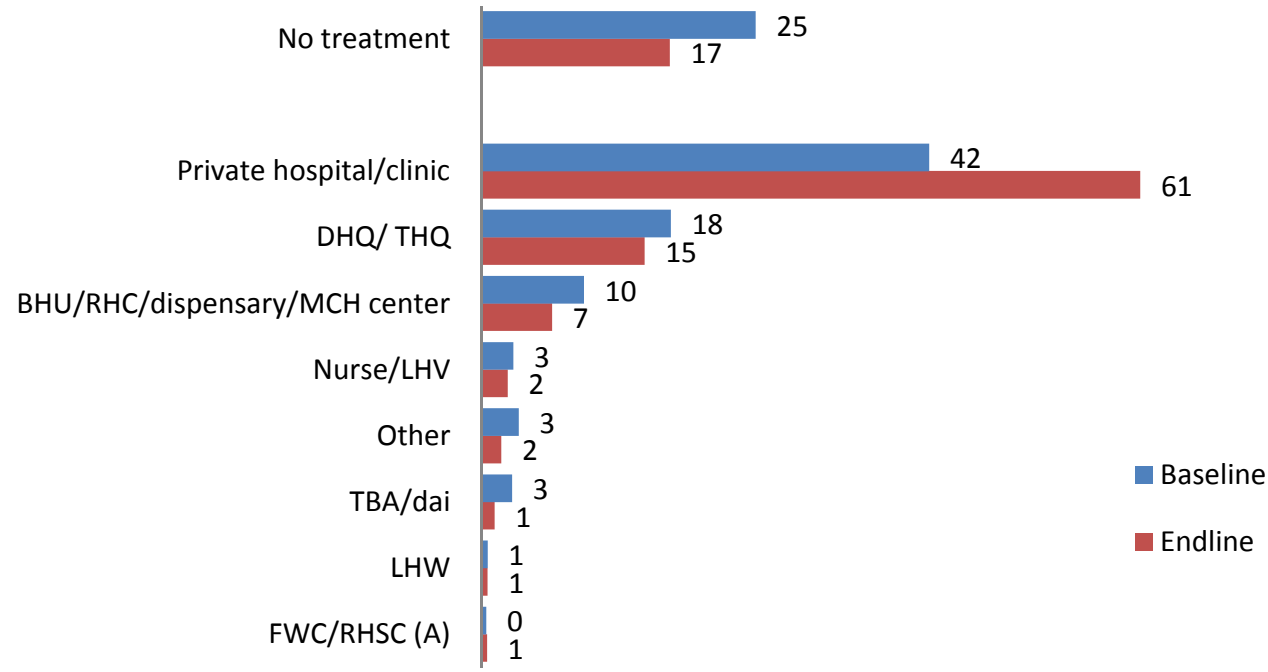

\section{Reasons for not seeking treatment}

As shown in Figure 5.11, 25 percent of the women in the baseline and 17 percent in the endline survey reported to have received no treatment for the complications they experienced during pregnancy. When these women were further probed for the reasons they did not get treatment, a majority (37 percent baseline; 42 percent endline) reported poverty as a main constraint (Figure 5.12). Distance to a facility was the main hindrance for only 5 to 8 percent, while 7 to 8 percent used traditional herbs to cure their complications. Around 30 percent (29 percent baseline; 31 percent endline) were of the view that treatment was not needed; these women perhaps also belonged to the category who could not afford to get treatment. 
Figure 5.12: Percentage distribution of women who did not seek treatment for complications during last pregnancy, by reason

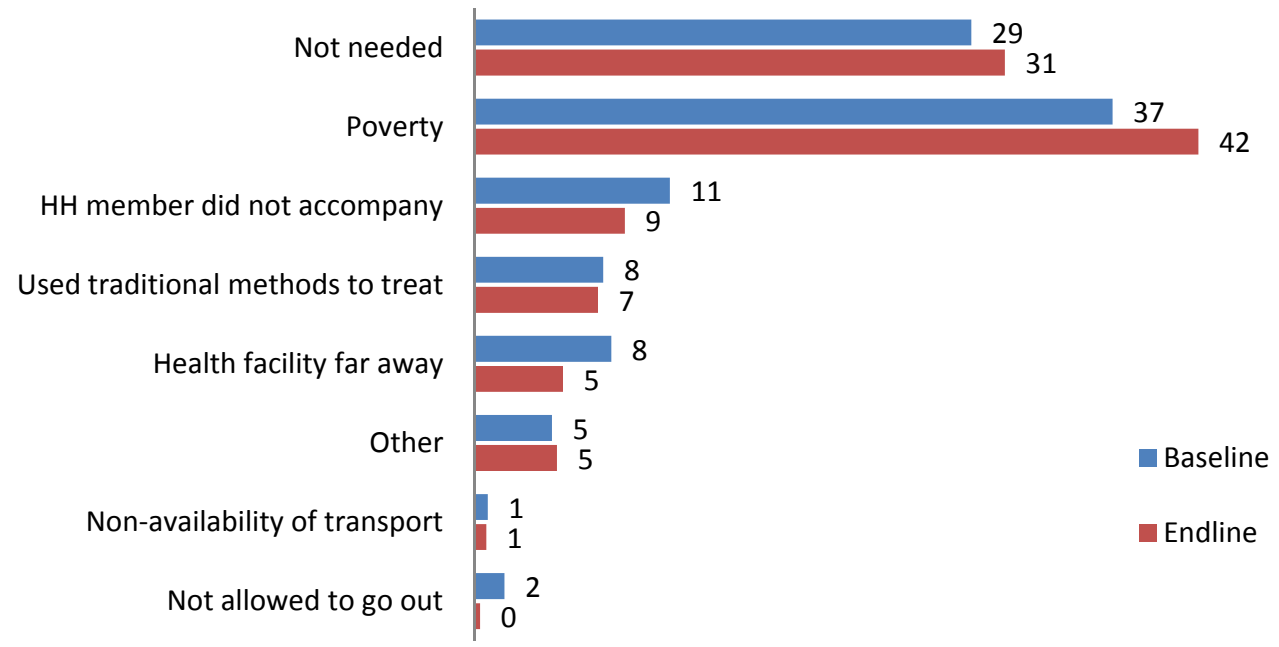

\section{Birth preparedness and complication readiness}

Birth preparedness refers to advance planning and preparation for delivery by setting aside personal funds to meet normal delivery as well as emergency delivery costs; locating the nearest hospital where complications could be treated; identifying and contacting a birth attendant, whether traditional or skilled; arranging for suitable transport, in case it is needed, for carrying the expectant mother, especially during odd hours or at night; arranging for blood, especially when the RH factor is incompatible; preparing proper clothes for the newborn; etc.

Figure 5.13 shows that all indicators of birth preparedness improved in the project areas between the baseline and endline surveys. In both surveys, most women reported preparing clothes for the newborn (73 percent baseline; 85 percent endline). In the endline survey, a higher proportion of women, nearly seven out of ten (71 percent), gathered information about the nearest hospital where obstetric complications could be treated compared to 51 percent in the baseline survey. Similarly, a higher proportion of women in the endline survey arranged money for a normal delivery (from 60 percent to 74 percent). The endline survey also shows that higher proportions of women knew about costs of care, consulted a birth attendant and arranged transport. 
Figure 5.13: Percentage of women who made preparations for last delivery, by type of preparations

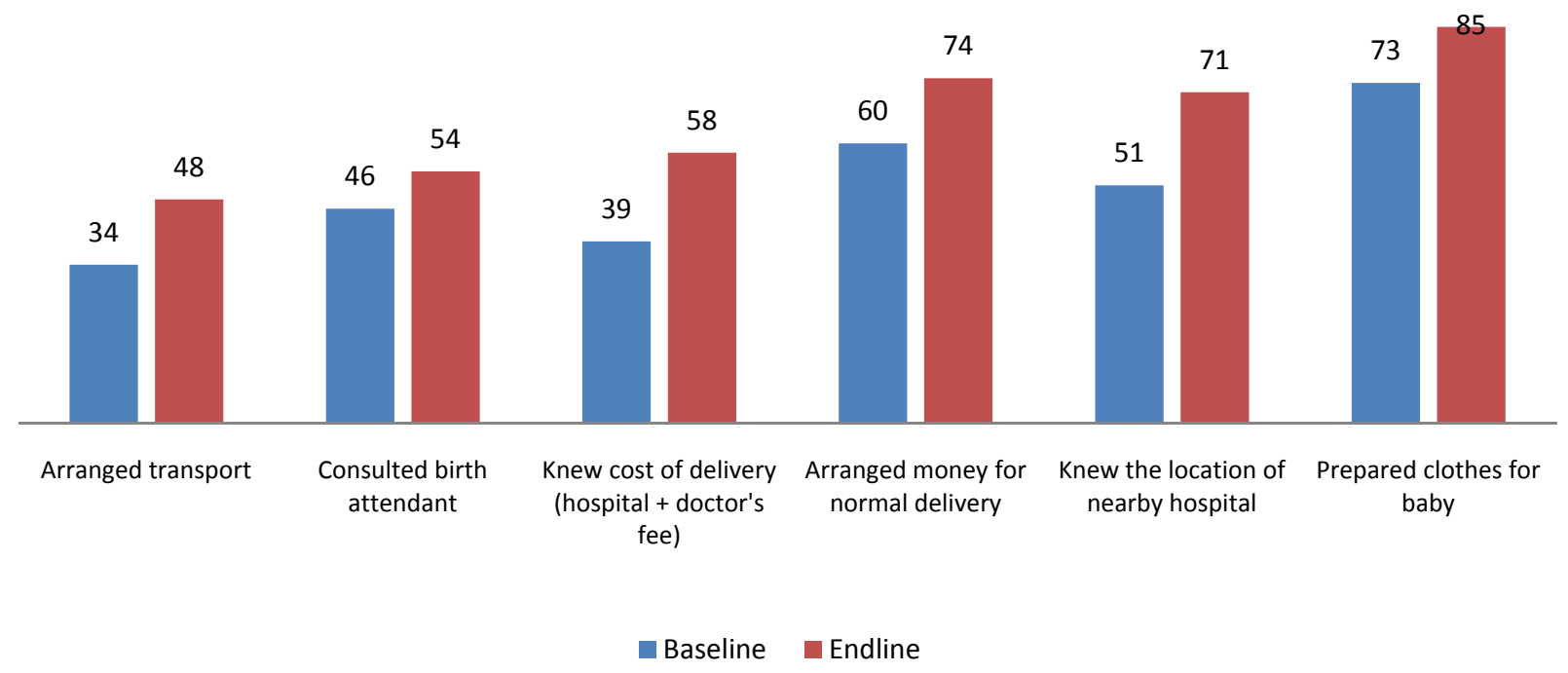





\section{Chapter 6. Delivery Care}

The objective of providing safe delivery services is to protect the life and health of the mother and her newborn. This involves proper medical attention under hygienic conditions during delivery to reduce the risk of complications and infections that may cause death or serious illness either to the mother or the newborn or both. Women who are aware of the possible complications around the time of delivery are in a better position to seek care or ask family members to take them to an appropriate facility for immediate care. During antenatal visits, health providers are also required to educate women about complications during pregnancy and delivery. Since ANC and institutional deliveries are not universal, especially in developing countries, including Pakistan, prospective mothers are not fully aware of possible complications during pregnancy, as noted in the previous chapter, nor do they have complete knowledge of the complications that may develop just before or during delivery.

\section{Knowledge of danger signs during delivery}

In the baseline and endline surveys, women were asked about their knowledge regarding complications during delivery. Figure 6.1 shows that the knowledge of three or more danger signs during delivery increased from 16 to 23 percent during the project duration. However, the proportion of women who were not aware of any danger signs remained almost static ( 28 percent baseline; 27 percent endline). Knowledge about specific danger signs, as reflected in Figure 6.2, increased for excessive bleeding before delivery (24 vs. 33 percent) and during delivery ( 21 vs. 28 percent). Awareness about prolonged obstructed labor and abnormal position of fetus, which are relatively more dangerous, especially where surgical facilities are not available, showed slight declines.

Figure 6.1: Percentage distribution of women, by knowledge of danger signs during delivery

\begin{tabular}{c|c|c}
16 & 23 \\
26 & Three or more signs & 24 \\
31 & Two signs & 26 \\
28 & No knowledge & 27 \\
\hline Baseline & Endline
\end{tabular}




\section{KNOWLEDGE OF AT LEAST THREE DANGER SIGNS DURING DELIVERY by selected characteristics of women}

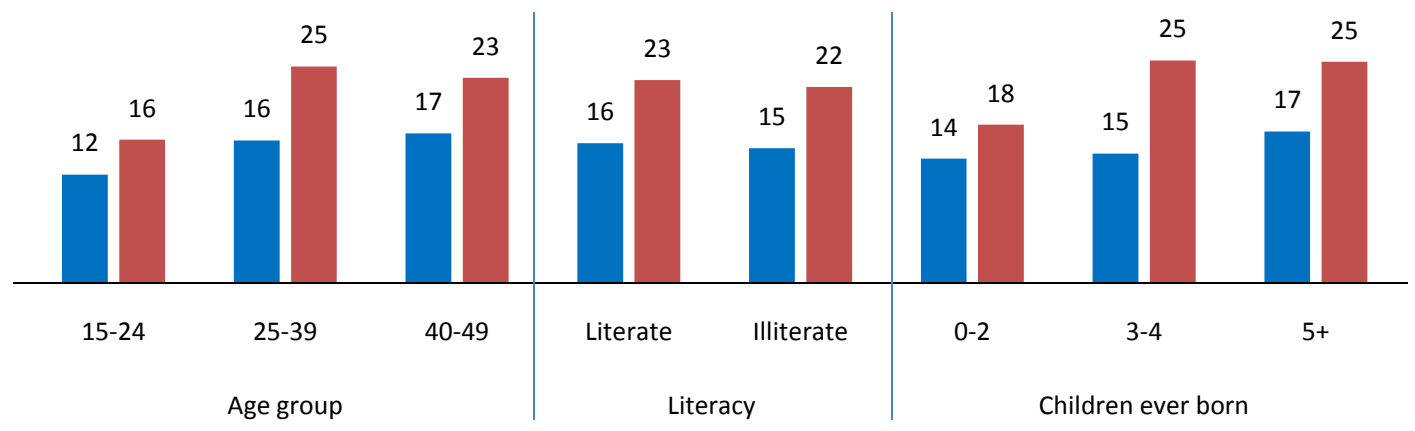

Baseline Endline

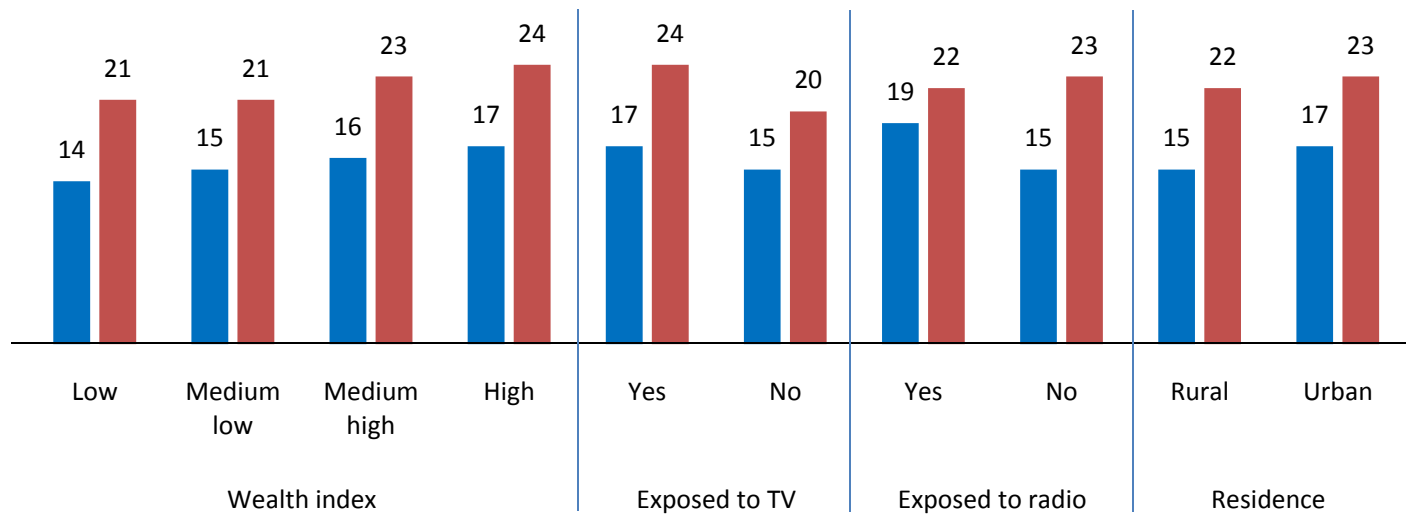

The above figures show the percentages of women who knew at least three danger signs during delivery (childbirth) by their background characteristics. Endline survey findings show an overall improvement of 7 percentage points from baseline, from 16 to 23 percent, in knowledge of at least three danger signs during delivery. Findings also show that the increase is slightly higher in rural areas compared to urban areas: the increase is 7 percentage points in rural areas and 6 percentage points in urban areas of PAIMAN districts. Moreover, the observed increase is also higher among women 25-39 years (9 percentage points), women with 3-4 children (10 percentage points), and women who watch TV (7 percentage points). The increase in knowledge of at least three danger signs during delivery is close to identical for all socioeconomic groups of women in the 10 PAIMAN districts. 
Figure 6.2: Percentage distribution of women, by knowledge of specific danger signs during delivery

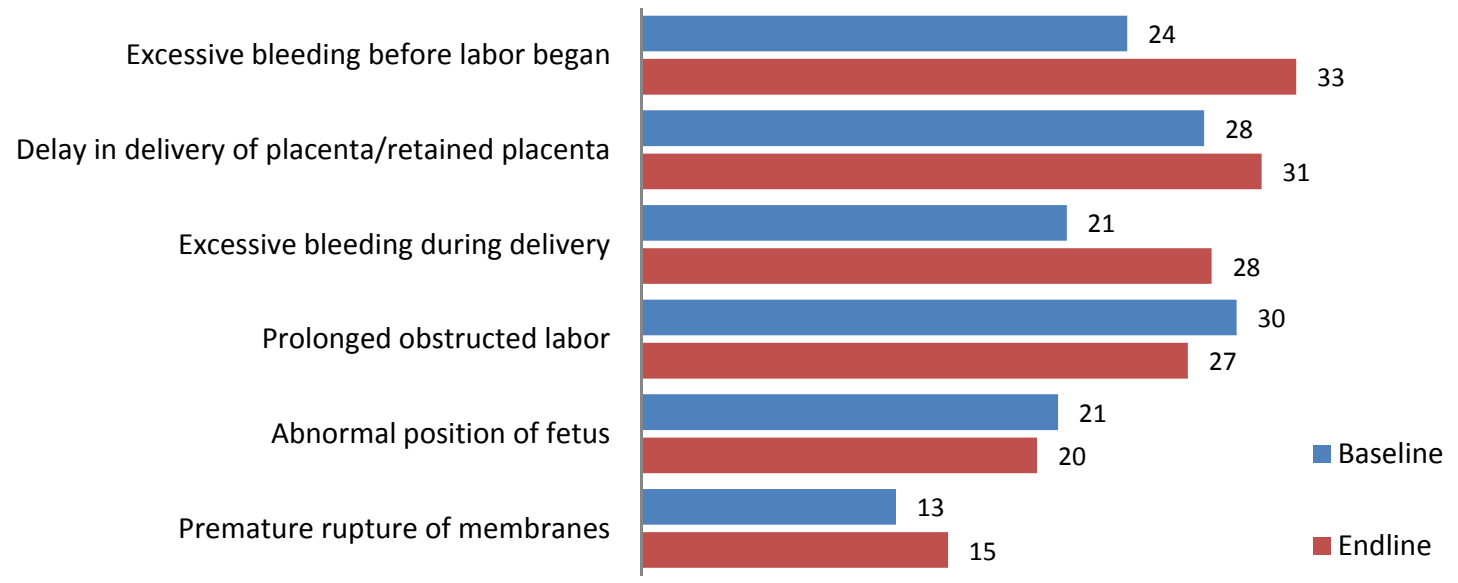

\section{Type and place of delivery}

Traditionally, Pakistani women deliver at home either without any assistance or with the assistance of TBAs or relatives and friends. Many women do not think it is necessary to deliver at a health facility, while others are constrained due to the higher cost for care at a facility (NIPS, 2008). Figure 6.3 provides a comparison of delivery care assistance reported in the baseline and endline surveys. A majority of the deliveries in the baseline ( 88 percent) and the endline ( 82 percent) surveys were normal, while some were assisted deliveries ( 6 percent baseline; 7 percent endline). Deliveries by Caesarean section are increasing and almost doubled between the baseline and endline surveys ( 6 and 11 percent respectively).

Figure 6.3: Percentage of women, by type of delivery and presence of skilled birth attendant at last delivery

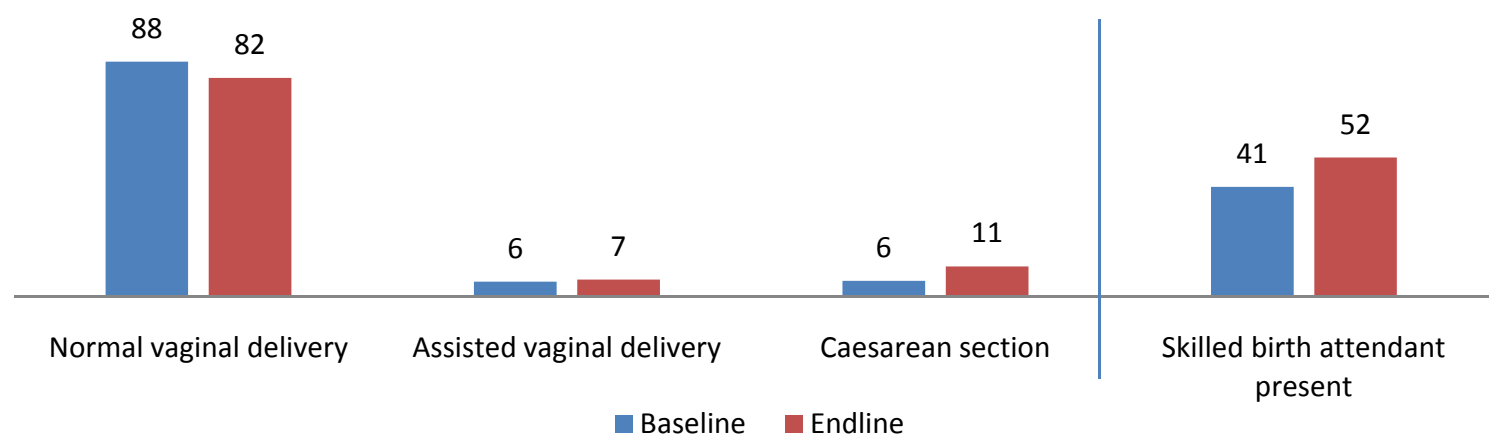

Deliveries at home declined by 11 percentage points (from 62 to 50 percent) between the baseline and endline surveys; still, half of all births were delivered at home, as shown in Figure 6.4. Overall, half of the deliveries were attended by skilled health personnel, including doctors, LHVs/nurses and midwives. Though more expensive, many women (22 percent baseline; 35 percent endline) used private hospitals/clinics for their deliveries as against those who chose public-sector facilities (16 percent baseline; 15 percent endline). The Caesarean section deliveries increased to 11 percent in the endline from 6 percent in the baseline. Findings show that a majority of the Caesarean section deliveries were carried out by private-sector providers (Figure 6.4). 
Figure 6.4: Percentage distribution of women, by place of last delivery

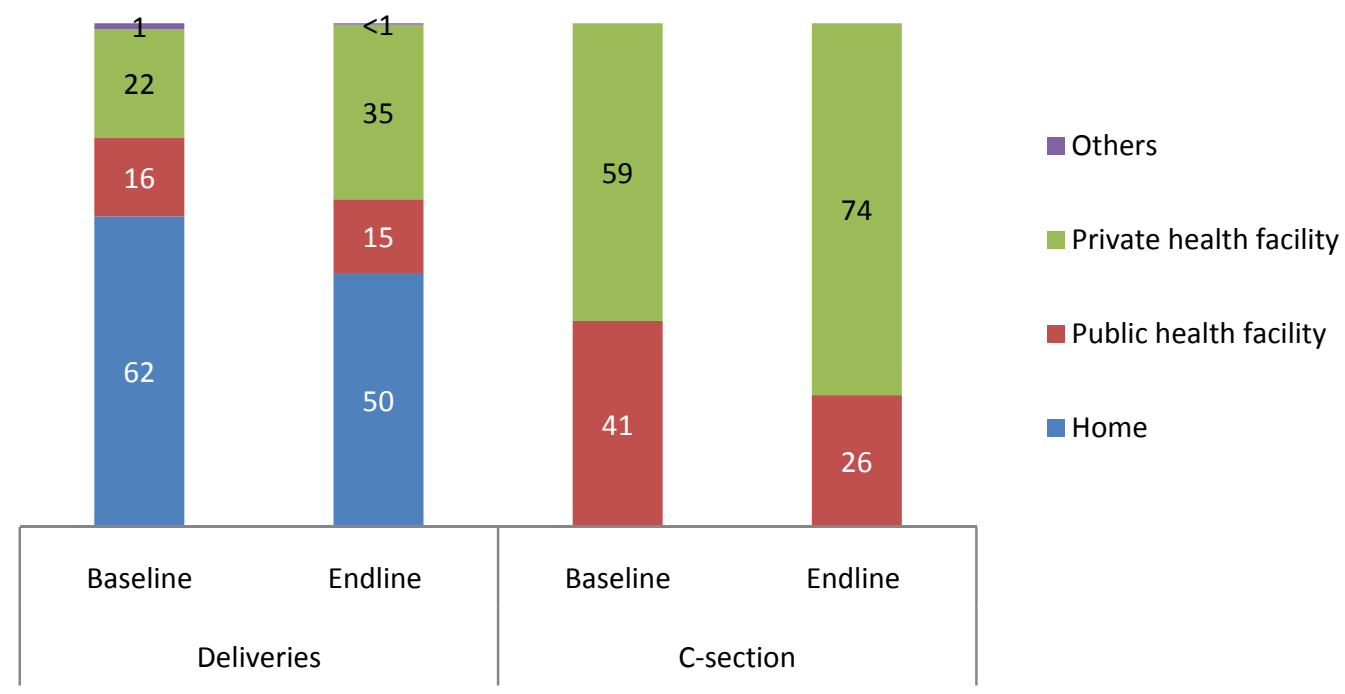

\section{Home delivery attendant}

Deliveries at home were mostly assisted by unskilled birth attendants and this increased very slightly between the two surveys (Figures 6.5 and 6.6). Figure 6.6 shows that among the home deliveries, 77 percent were assisted by TBAs in the endline compared to 75 percent in the baseline. With the exception of the use of new clean delivery kits, the attendants at home deliveries used more clean delivery practices at endline in comparison with baseline findings (see Figure 8.4).

\section{Figuer 6.5: Percentage distribution of women who delivered at home, by skill of birth attendant}

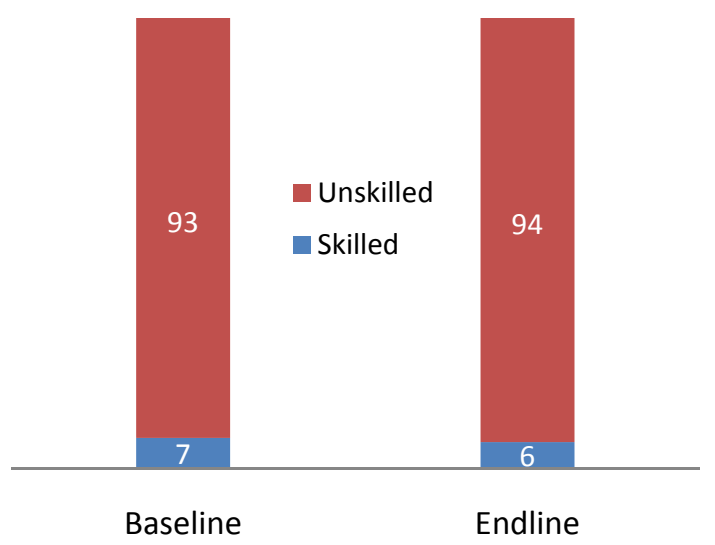

Figure 6.6: Percentage distribution of women who delivered at home, by type of birth attendant

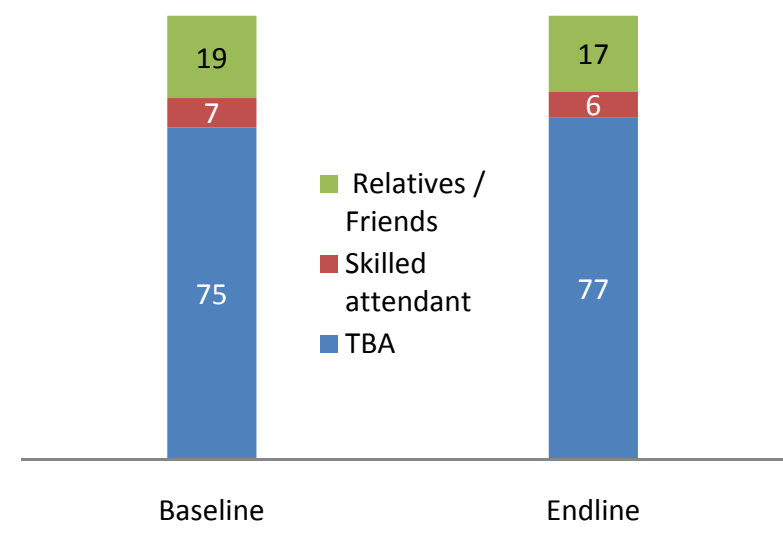




\section{Delivery complications and treatment}

Overall, 37 percent of the women in the baseline survey and 32 percent in the endline reported to have had a complication during their last delivery in the three years prior to the survey. Among those who experienced complications, the most reported complication for women in both the baseline and the endline surveys was excruciating abdominal pain, followed by prolonged obstructed labor on the day of delivery (Figure 6.7). It is worth mentioning that the proportion of women reporting specific problems during delivery declined in the endline as compared to the baseline survey. Of those who experienced a complication, a majority visited a private hospital/clinic for treatment (Figure 6.8). The proportion of women who did not seek any treatment for their complications has declined from 29 to 23 percent between baseline and endline, which shows some improvement in health-seeking behavior over time.

Figure 6.7: Percentage of women who experienced complications on the day of last delivery, by specific complications

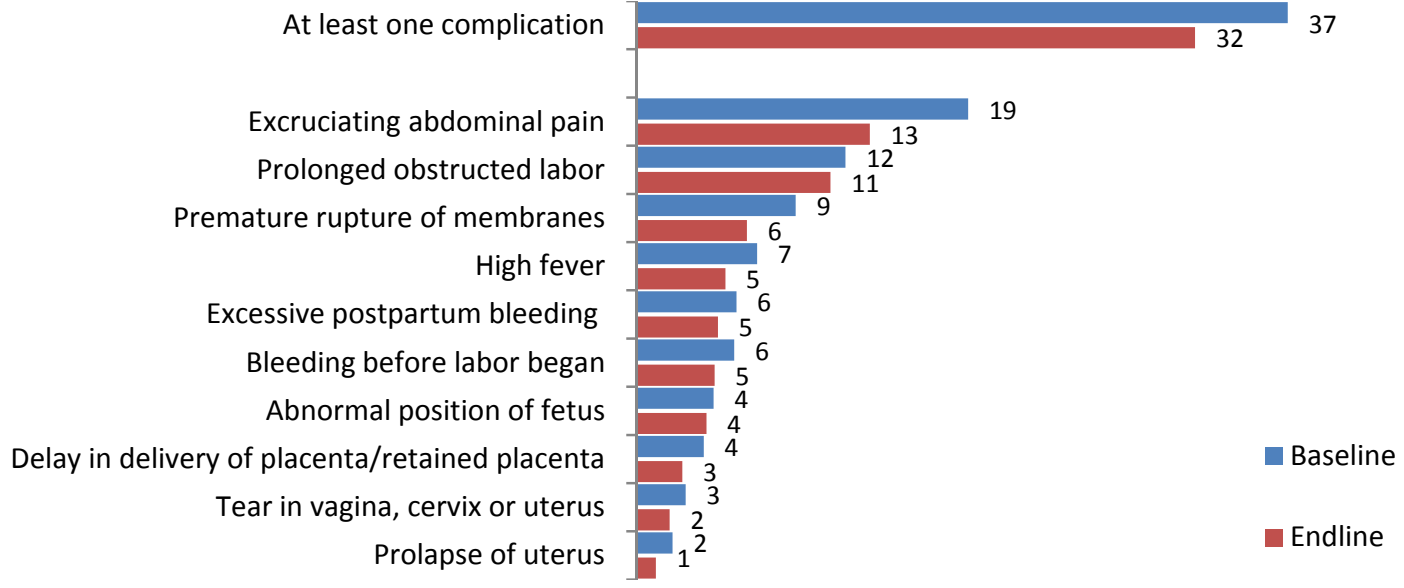

Figure 6.8: Percentage of women who sought treatment for complications on the day of last delivery, by source of treatment

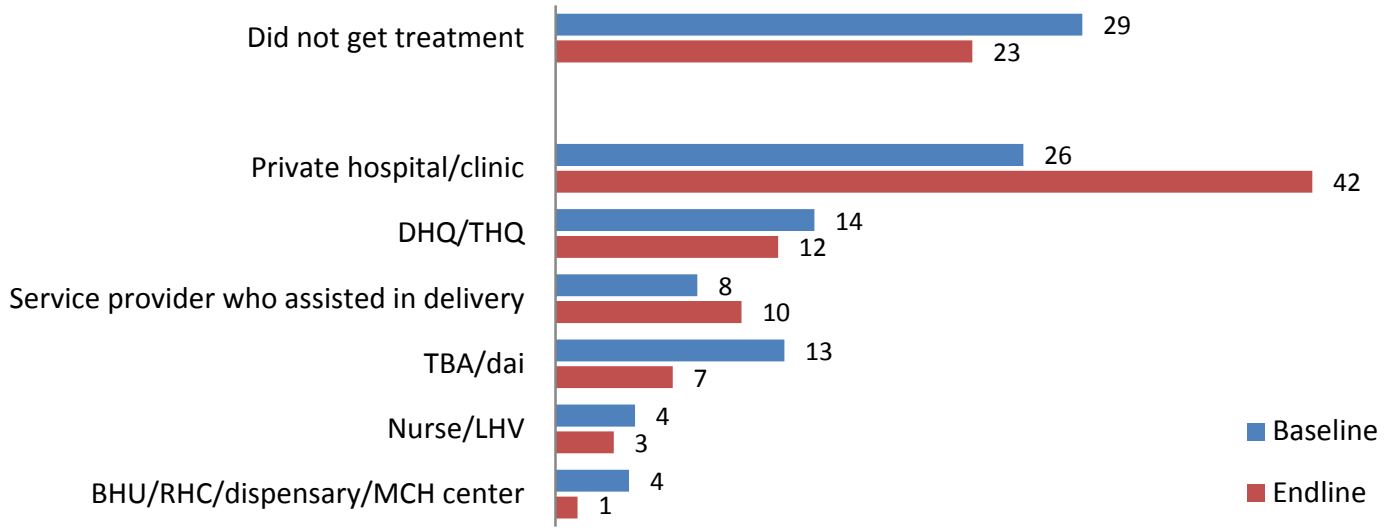




\section{SKILLED BIRTH ATTENDANCE}

by selected characteristics of women

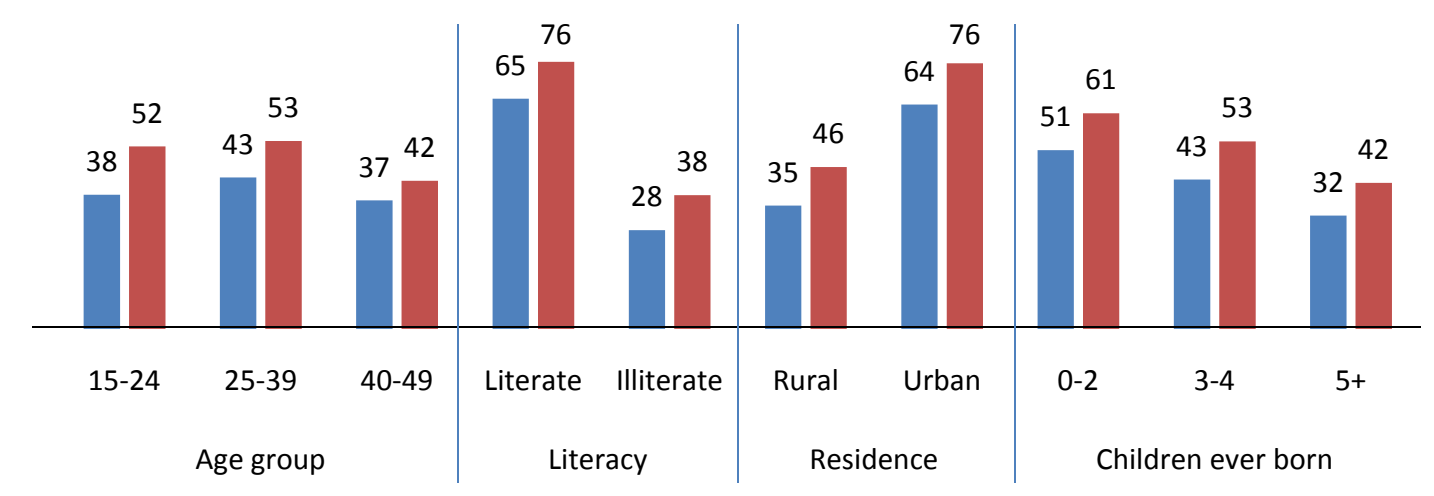

Baseline Endline

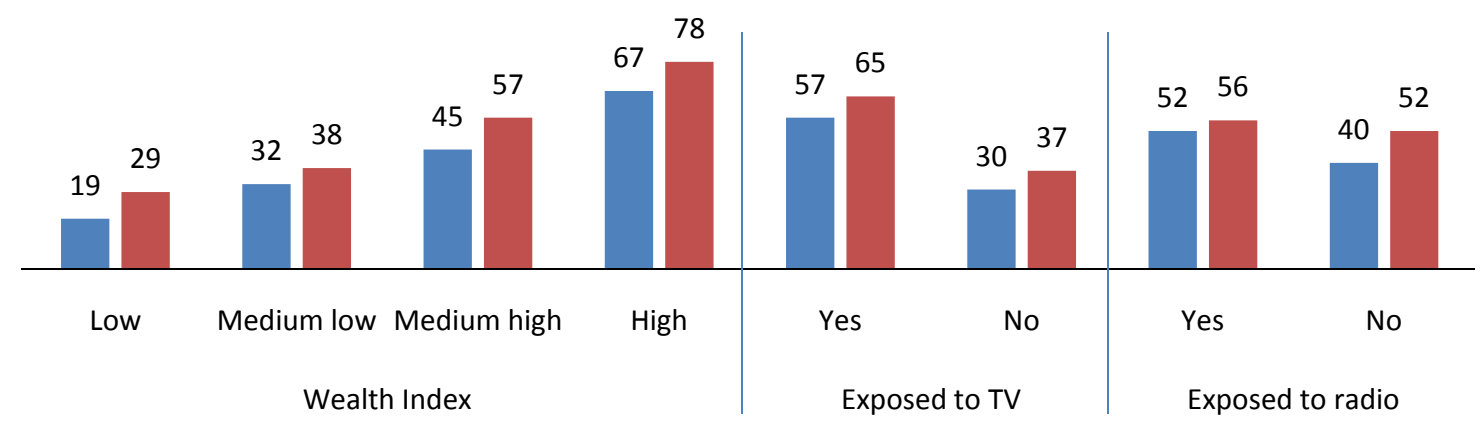

The above figures show the percentage of women whose last delivery was conducted by a skilled birth attendant by background characteristics of the respondents. Endline survey findings show an increase of 11 percentage points (from 41 to 52 percent) in the deliveries conducted by skilled birth attendants (Figure 6.3). The increase in skilled birth attendance is statistically significant $(p<0.05)$. Overall, the increase is observed in the deliveries conducted by skilled birth attendants in all segments of the population. However, mothers having more than 4 children, illiterate women, women who do not watch TV, women with the lowest wealth index, and women living in rural areas are less likely to utilize the services of a skilled delivery attendant for their deliveries.

\section{District-level variations}

Inter-survey increase in skilled birth attendance is highest in Jhelum (by 22 percentage points), followed by Khanewal (17), Jaffarabad (14), Rawalpindi and Lasbela (both at 13), as shown in the figure below. The lowest increase was observed in Upper Dir (with a 5 percentage point increase). Overall, SBA is highest in Rawalpindi (82 percent), followed by Jhelum (77 percent).

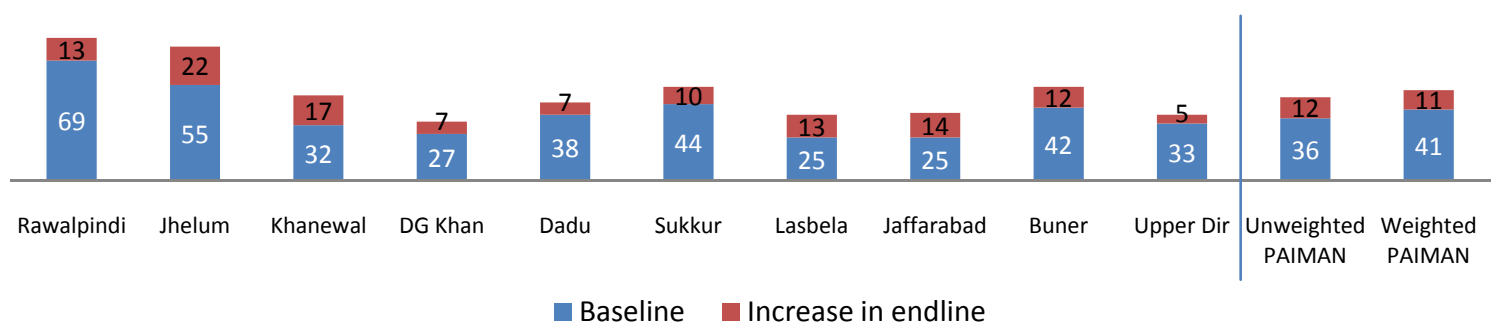




\section{Reasons for not seeking treatment}

Twenty-three percent of the women in the baseline survey and 29 percent in the endline (Figure 6.8) reported that they had not received any treatment for complications during their last delivery in the three years preceding the two surveys. Figure 6.9 shows the reasons that they reported for not getting treatment. A majority of the women stated that treatment was not necessary for their complications. One-quarter of the women in both surveys (27 percent) stated that the reason for not getting treatment for their complications was poverty. However, there was no further probing of those who said that treatment was not necessary to determine if, in fact, their reasons were because their complications were not severe or because they could not afford to get treatment and, therefore, said it was not needed. In both surveys, one in eight women (12 percent) used traditional medicines or herbs to treat their complications, while for 6 to 8 percent distance to a facility was a hindrance to seeking treatment. Availability of transport did not appear to be a problem. There was little change in women reporting that a household member(s) did not think treatment was needed (12 percent baseline; 11 percent endline).

Figure 6.9: Percentage distribution of women who did not seek treatment for their complication(s) during last delivery, by reason

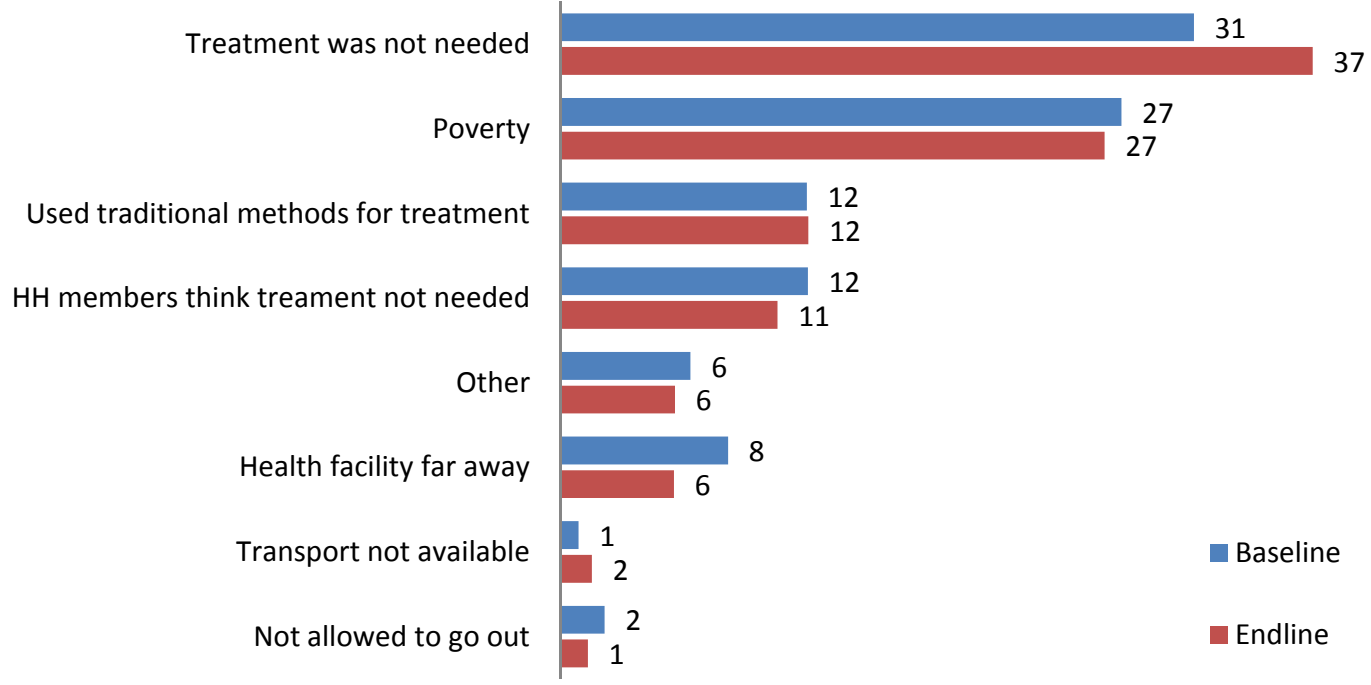




\section{INSTITUTIONAL DELIVERIES}

by selected characteristics of women

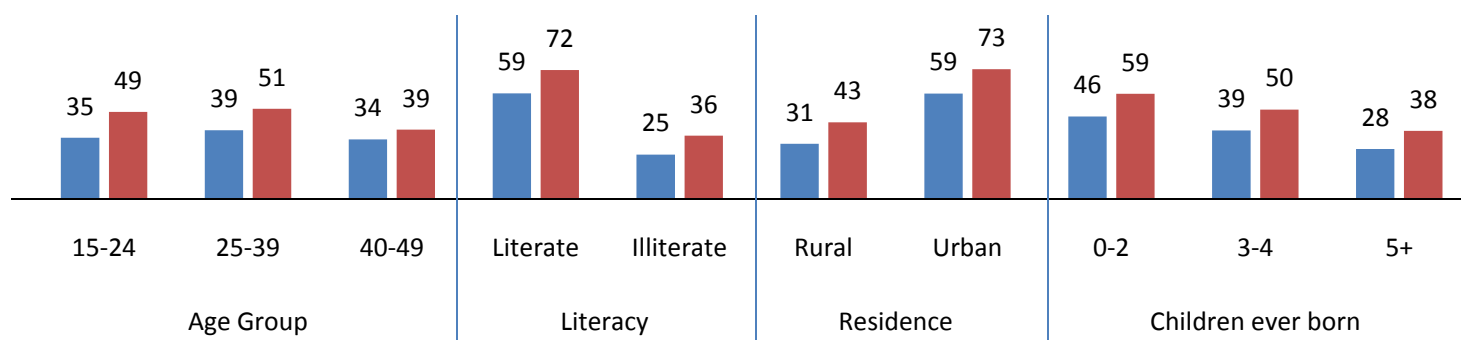

Baseline Endline

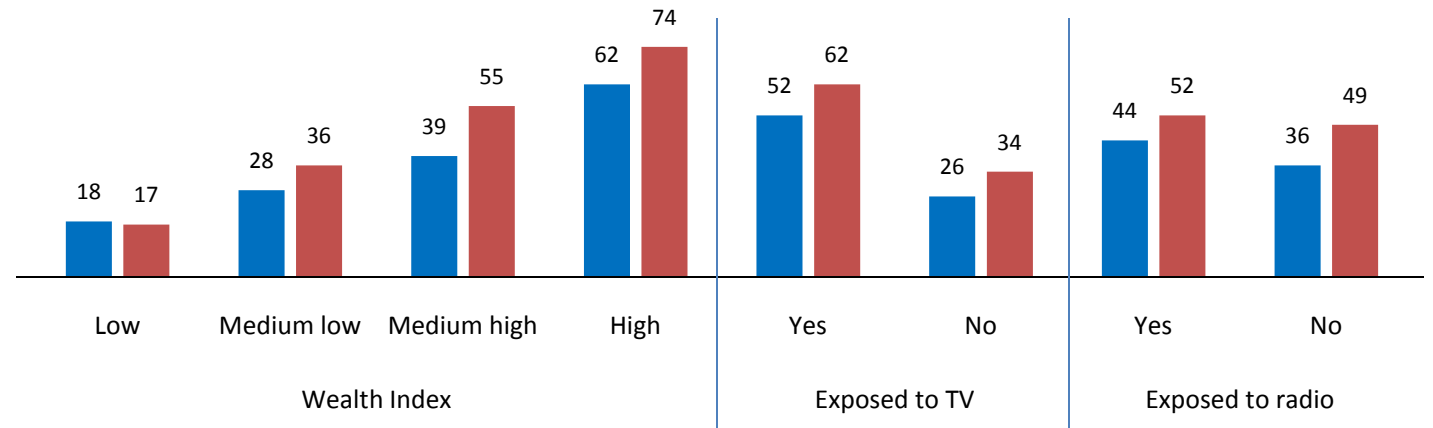

The above figures show the percentage of women whose last delivery was conducted at a health facility by background characteristics of the respondents. Endline survey findings show an increase of 12 percentage points (37 percent baseline vs. 49 percent endline) in the deliveries conducted at health facilities. The increase in institutional deliveries is statistically significant $(p<0.05)$. Overall, the increase is observed in the deliveries conducted at health facilities in all segments of the population. However, mothers having more than 4 children, illiterate women, women who do not watch TV, women with the lowest standard of living, and women living in rural areas are less likely to deliver at the health facilities for their deliveries.

\section{District-level variations}

Inter-survey increase in institutional deliveries is highest for Jhelum (by 20 percentage points), followed by Khanewal and Rawalpindi (17 percentage points each) and Buner (16) as shown in the figure below. The lowest increase was observed in DG Khan and Dadu (6 percentage points each). Overall, institutional deliveries are highest in Rawalpindi (80 percent), followed by Jhelum (69 percent).

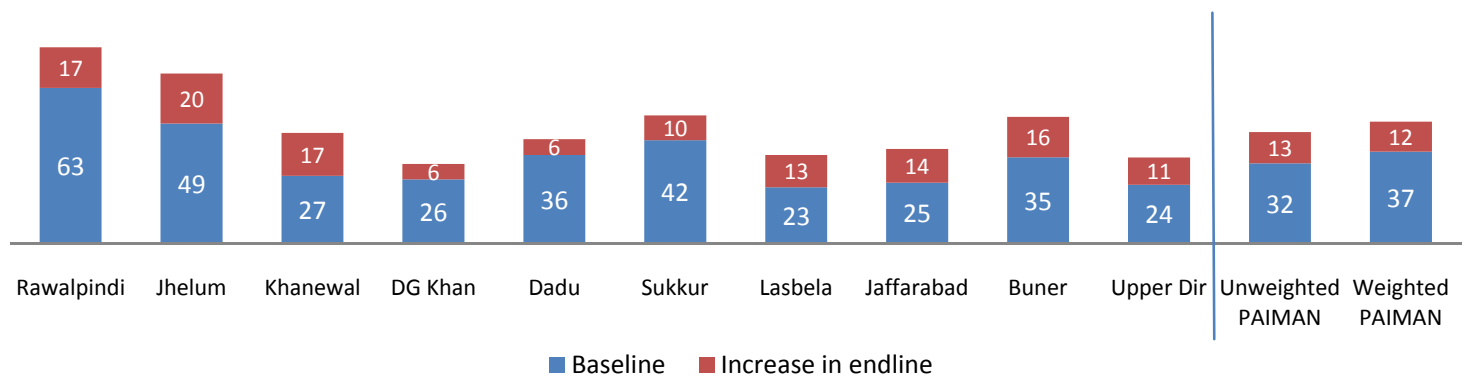




\section{DECISIONMAKING AND THE THREE DELAYS IN OBSTETRIC EMERGENCIES}

Addressing the first two delays in the "three-delay" model for obstetric emergencies has a significant impact on the outcomes of obstetric complications. These two delays - having to do with the timeliness of (1) deciding to seek care and (2) identifying and reaching a medical facility - were the focus of the birth preparedness and complication readiness components of all PAIMAN community mobilization activities. Birth preparedness and complication readiness are designed to encourage women, households and communities to make arrangements that will facilitate swift decisionmaking about seeking and reaching care once a problem arises. Arrangements include such things as identifying available transport, setting aside money to pay for service fees and transport, identifying a skilled birth attendant, identifying blood donors, and identifying the health facility.

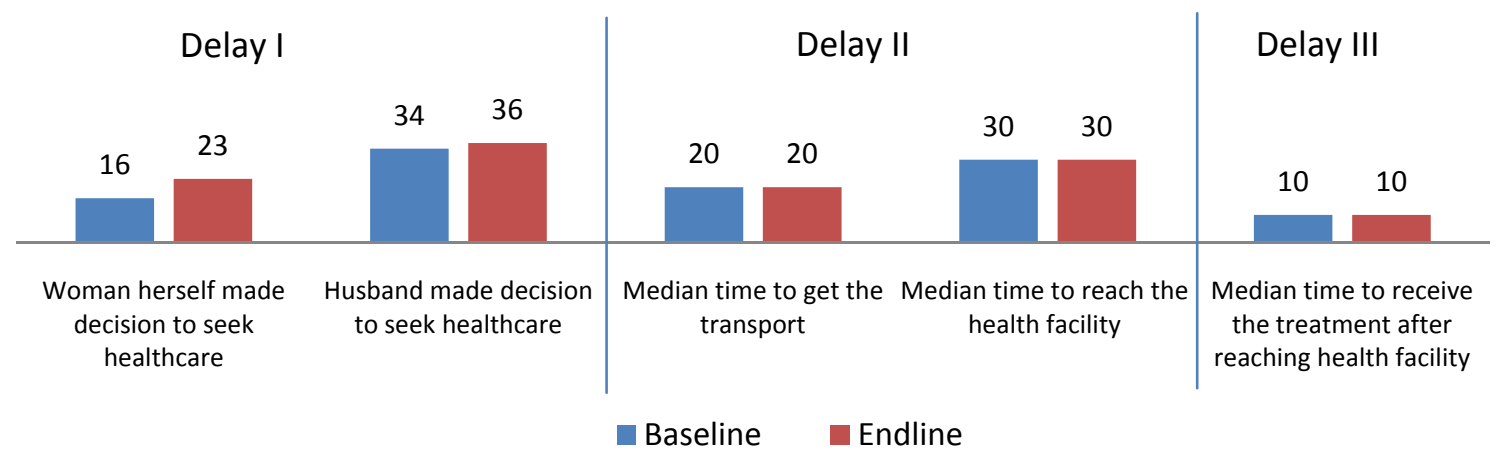

This figure (above) shows the percentage of women who had complications during their delivery and sought emergency healthcare by their decisionmaking status for seeking healthcare and the median times it took to get transport, reach a health facility and get treatment once there. Endline survey findings show an overall improvement in only one aspect of seeking and receiving timely emergency healthcare, and that is the increase in the percent of women who reported that they could make the decision to seek emergency healthcare on their own (reducing the first delay). The median time to get transport, to reach the health facility and to receive treatment once there did not change. 



\section{Chapter 7. Postpartum Care and Contraceptive Knowledge and Use}

Safe motherhood programs recommend that mothers should have postpartum checkups within 24 hours after delivery. This recommendation is based on the fact that a large number of maternal and neonatal deaths occur during the first 24 hours after delivery, making it critical to monitor complications arising from the delivery during this period of time. Mothers who deliver at home and have a complication are more likely to visit a healthcare provider immediately after delivery if they are aware of complications that can occur during the postpartum period. In addition to monitoring and checking for any complications, a postpartum care visit is also an ideal time to educate a new mother on how to care for herself and her newborn. It is also provides a good opportunity to inform women about birth spacing methods.

\section{Knowledge of postpartum danger signs}

Figure 7.1 shows that there has been a marginal increase in health-seeking behavior during the postpartum period in the PAIMAN districts. The proportion of women who had no knowledge of any danger sign during the postpartum period remained stagnant at 28 percent during the project duration. A marginal increase was noted in the proportion of women who had knowledge of three or more danger signs during postpartum (from 11 percent in the baseline to nearly 14 percent in the endline survey). With regard to specific danger signs during postpartum, an increase was noted in the proportion of women identifying 'excessive bleeding,' 'fits or convulsions' and 'unconsciousness' by 7, 2 and nearly 3 percentage points respectively (Figure 7.2).

Figure 7.1: Percentage distribution of women, by knowledge of danger signs during postpartum period

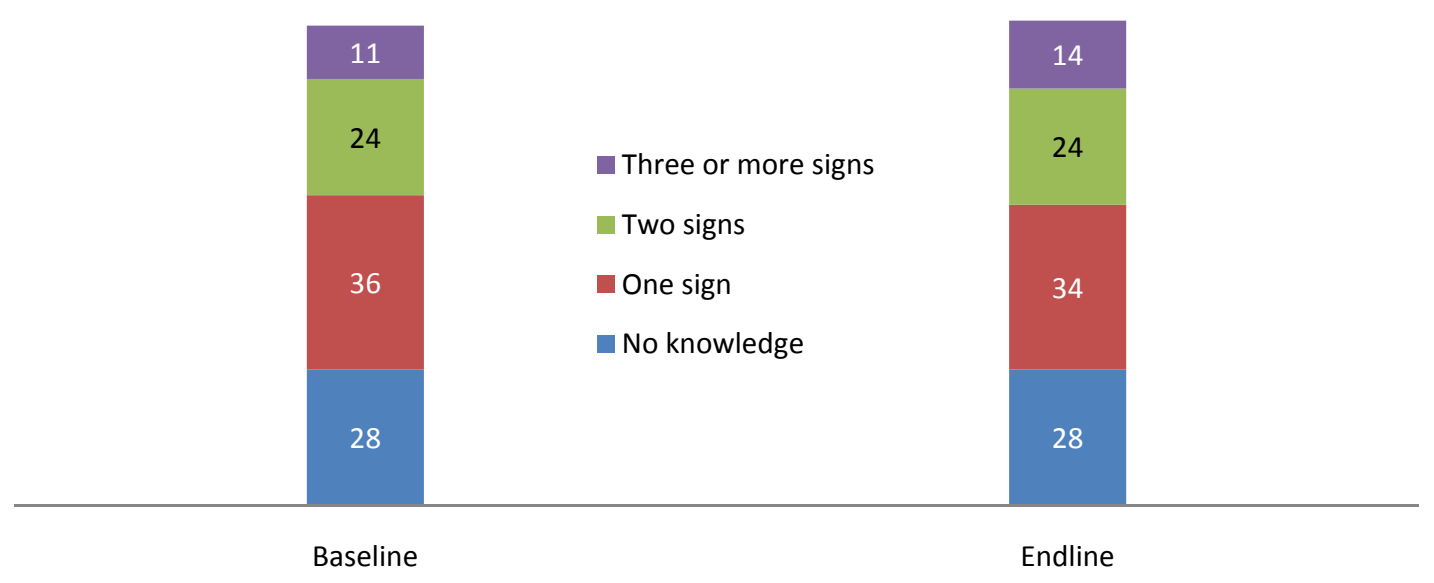


Figure 7.2: Percentage of women, by knowledge of specific danger signs during postpartum period

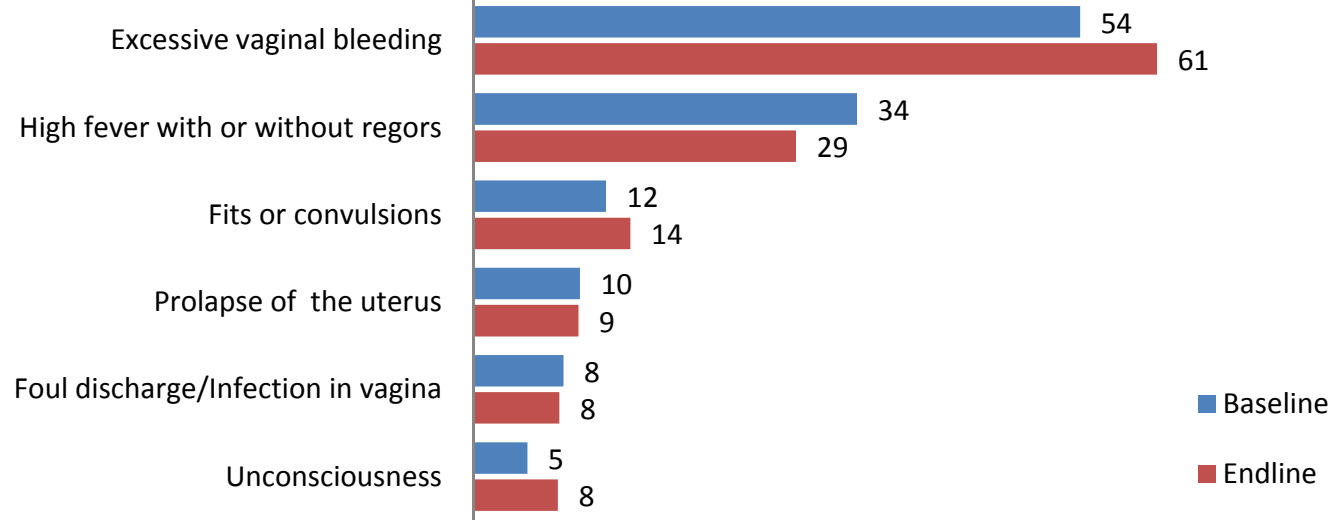

\section{Postpartum checkups}

To assess the extent of postpartum care utilization, respondents were asked whether they received postpartum checkups after their most recent delivery in the three years preceding the survey.

The national-level data collected through various sources indicate that seeking postpartum care is not common in Pakistan. The PDHS shows that 57 percent of women had no checkups after giving birth (NIPS, 2008). However, in the PAIMAN districts, the proportion of women who had a postpartum checkup has increased from 45 percent in the baseline to 56 percent in the endline survey. This, however, is still low in light of the 64 percent of women in the endline survey who thought that a woman should have a postpartum checkup after birth (Table 7.1). As discussed earlier, it is critical that a woman have a postpartum checkup within 24 hours of childbirth. The proportion of women who had a postpartum checkup within 24 hours after delivery increased from 40 to 53 percent between baseline and endline (Figure 7.3), indicating that most of the women who were getting postpartum care were getting that care within the first 24 hours.

Table 7.1: Percentage distribution of women, by attitude toward and use of postpartum services after last delivery

\begin{tabular}{lrr} 
Variable & Baseline & Endline \\
Is postpartum care necessary & $(N=9,242)$ & $(N=12,357)$ \\
\hline Yes & 46.5 & 63.7 \\
\hline No & 46.0 & 29.5 \\
\hline Don't know & 7.4 & 6.7 \\
\hline Was postpartum care received & $(N=4,511)$ & $(N=5,884)$ \\
\hline Received within 40 days of delivery & 44.7 & 56.4 \\
\hline Received within 24 hours of delivery & 39.6 & 52.8 \\
\hline No & 55.3 & 43.6 \\
\hline
\end{tabular}


Figure 7.3: Percentage of women, by attitude toward and use of postpartum services after last delivery

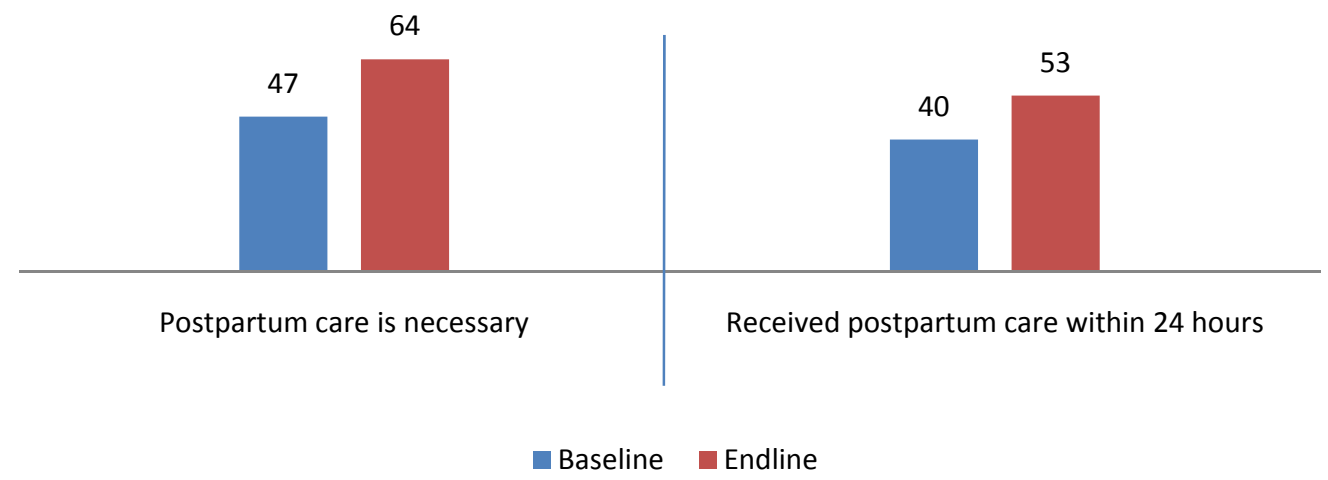

\section{Postpartum complications and treatment}

The incidence of complications during the postpartum period was reported by nearly the same proportion of women in the baseline and endline surveys (20 and 21 percent respectively) (Figure 7.4). Among those who experienced complications during the postpartum period, high fever and lower abdominal pain were reported by relatively higher proportions of women. Among those in both surveys who reported having complications and sought treatment, a majority visited a private health facility for treatment or did not get any treatment at all (Figure 7.5).

Figure 7.4: Percentage of women who experienced complications during postpartum period after last delivery, by specific complications

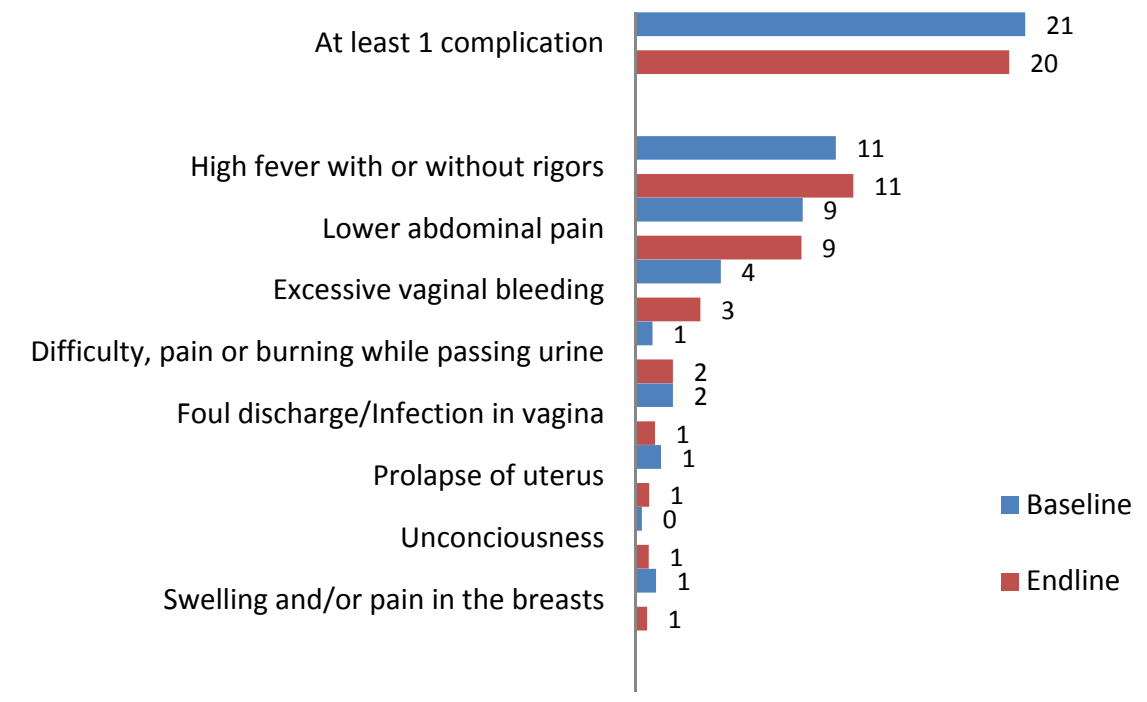


Figure 7.5: Percentage distribution of women who experienced complication in postpartum period after last delivery, by source of treatment

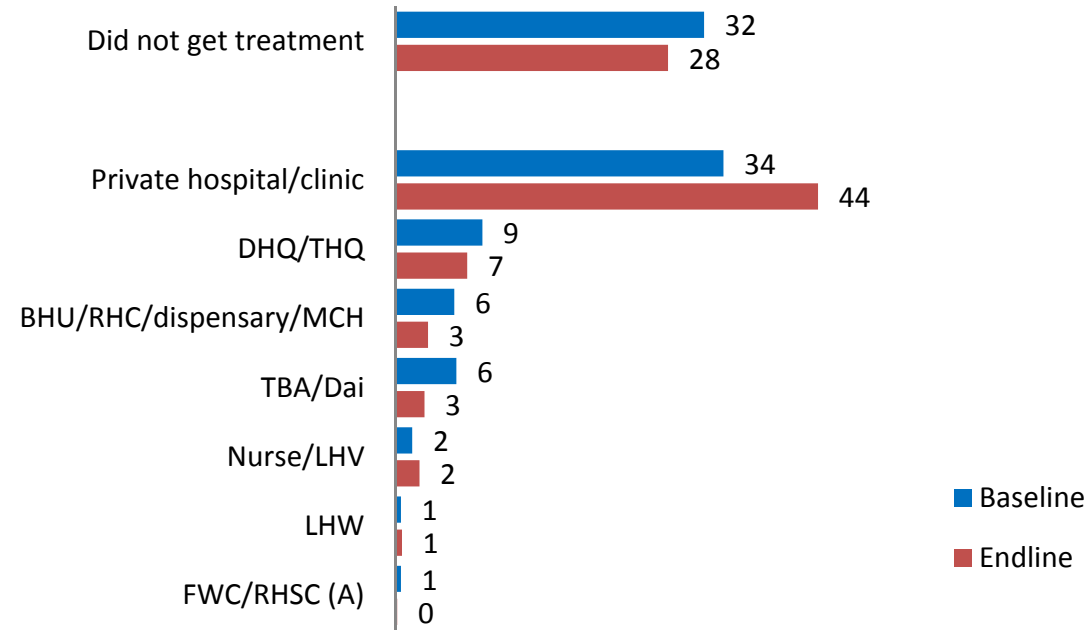

\section{Reasons for not seeking treatment}

Women who did not seek treatment for complications during postpartum were either too poor to afford treatment (39 percent baseline; 36 percent endline) or they used some traditional medicine to treat their complication (Figure 7.6). The proportion of women who used traditional methods increased in the endline (30 percent) compared to the baseline (19 percent). Distance to health facility was reported in both surveys to be another hindrance for 7 to 8 percent of the women who had complications.

Figure 7.6: Percentage distribution of women who did not seek treatment for complications in postpartum period during last delivery, by reasons

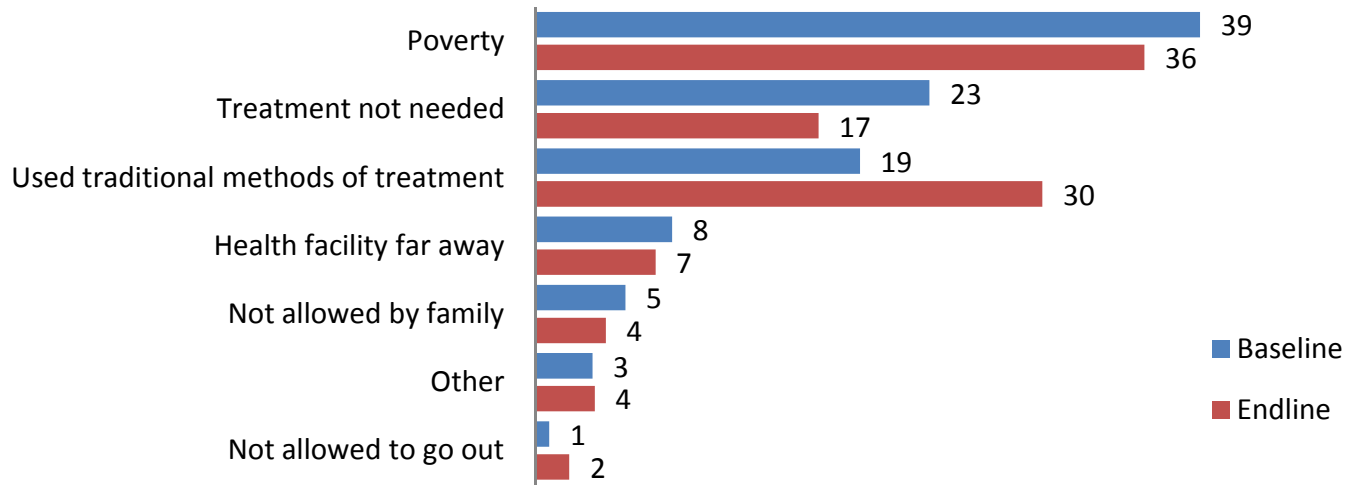




\section{POSTPARTUM CARE WITHIN 24 HOURS OF DELIVERY}

by selected characteristics of women

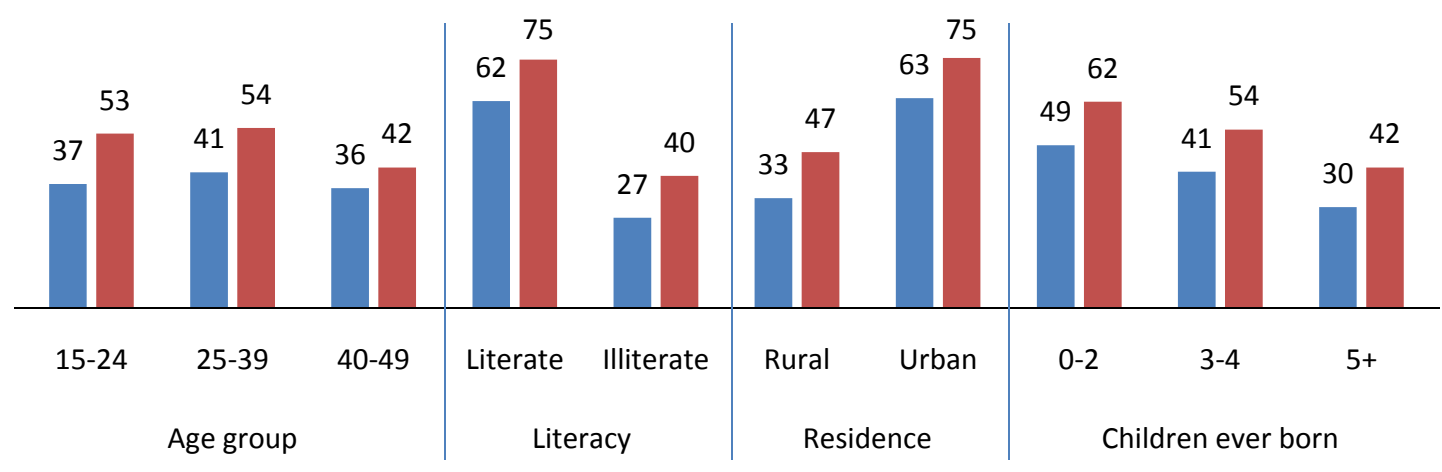

Baseline Endline

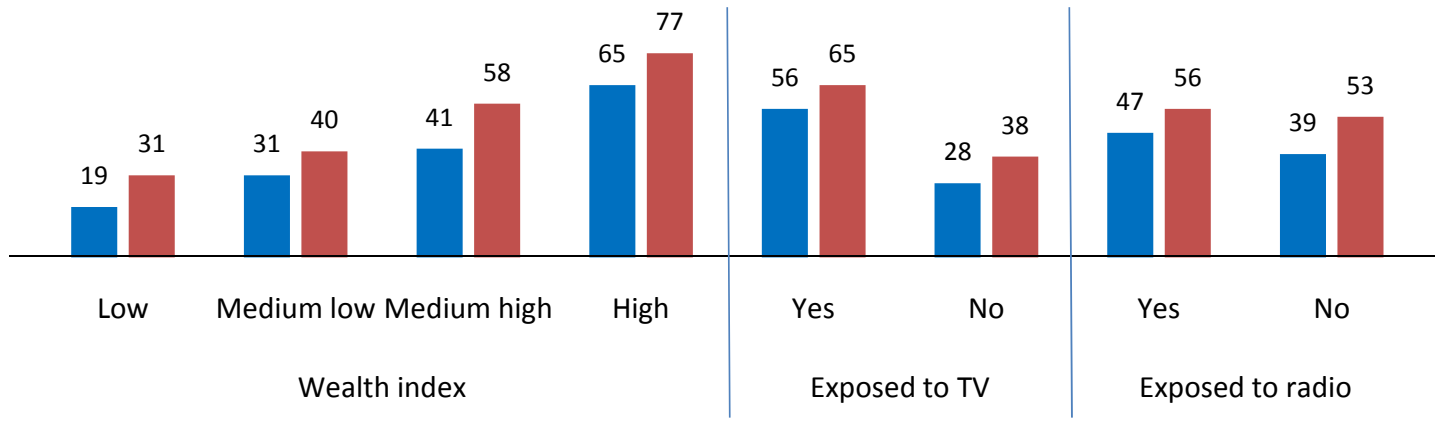

The above figures show percentage of women who had postpartum care within 24 hours after their last delivery by selected characteristics of respondents. Endline survey findings show an overall improvement of 13 percentage points (baseline 40 percent vs. endline 53 percent) in receiving postpartum care within 24 hours after delivery (Table 7.1). Overall, the improvement in receiving postpartum care within 24 hours is observed in all segments of the population. However, mothers with more than 4 children, illiterate women, women who do not watch TV, women with the lowest wealth index and women living in rural are less likely to get postpartum care within 24 hours of their last delivery. Improvements in receiving postpartum care within 24 hours are observed in women of all socioeconomic status.

\section{District-level variations}

Variation in postpartum care within 24 hours has been observed among the project districts. The highest increase between baseline and endline was observed in Lasbela (31 percentage points) and the lowest in DG Khan (5 percentage points). On the basis of the current level of postpartum care utilization in the first 24 hours, Rawalpindi ranks highest ( 81 percent), followed by Jhelum (75 percent). DG Khan ranks lowest among the project districts with 34 percent at the end of the project.

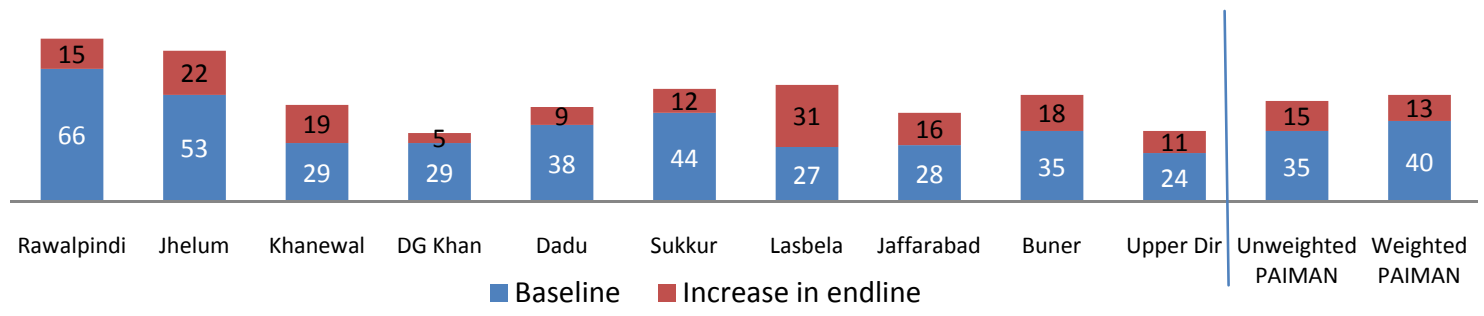




\section{Contraceptive knowledge and use}

As part of the PAIMAN project interventions, use of contraceptive methods was also promoted to avoid mistimed and unwanted pregnancies, which often lead to abortions resulting in further complications, maternal morbidities and maternal and infant deaths. Research shows that couples who space their children 3 to 5 years apart increase their children's chances of survival, and mothers are also more likely to survive. In both the baseline and the endline surveys, all currently married women of reproductive age were asked whether they had heard of any method to avoid or delay conception. Those who had knowledge of contraceptive methods were further asked whether they had ever used a method of family planning. Women who were not pregnant at the time of the survey were asked if they were currently using a contraceptive method. Women who had used a contraceptive method in the past but were not currently using any method were asked about their reasons for discontinuation. All women who were not current users were asked about their intention of using a method in the future.

\section{Knowledge}

The results show that spontaneous knowledge of any method, modern methods and traditional methods has increased in the endline as compared to the baseline survey (Table 7.2). However, there are inconsistencies with respect to some specific methods (IUD and female and male sterilization) where knowledge has reportedly declined.

Table 7.2: Percentage of women reporting spontaneous knowledge, ever use and current use of family planning methods, by method

\begin{tabular}{|c|c|c|c|c|c|c|}
\hline \multirow[b]{2}{*}{ Method } & \multicolumn{2}{|c|}{ Knowledge } & \multicolumn{2}{|c|}{ Ever use } & \multicolumn{2}{|c|}{ Current use } \\
\hline & Baseline & Endline & Baseline & Endline & Baseline & Endline \\
\hline Any FP method & 91.9 & 95.0 & 41.1 & 49.2 & 24.8 & 29.7 \\
\hline Any modern FP method & 91.7 & 94.7 & 37.0 & 43.6 & 19.9 & 23.0 \\
\hline Any traditional FP method & 13.2 & 20.4 & 11.2 & 17.9 & 4.9 & 6.7 \\
\hline \multicolumn{7}{|l|}{ Specific method } \\
\hline Condom & 36.7 & 49.2 & 14.7 & 19.8 & 5.6 & 7.4 \\
\hline Pill & 83.1 & 85.8 & 11.0 & 12.4 & 1.9 & 1.6 \\
\hline Injection & 82.7 & 84.3 & 12.5 & 15.0 & 2.8 & 3.3 \\
\hline IUD & 62.1 & 61.5 & 10.3 & 10.4 & 2.9 & 2.8 \\
\hline Female sterilization & 44.3 & 39.1 & 6.7 & 8.1 & 6.4 & 7.7 \\
\hline Male sterilization & 11.6 & 10.9 & 0.5 & 0.2 & 0.2 & 0.1 \\
\hline Withdrawal & 8.6 & 14.6 & 8.7 & 14.6 & 4.0 & 5.6 \\
\hline Rhythm & 5.2 & 7.5 & 3.6 & 5.8 & 0.8 & 0.8 \\
\hline Other & 4.1 & 5.9 & 0.7 & 1.0 & 0.1 & 0.3 \\
\hline$(N)$ & $(9,242)$ & $(12,357)$ & $(9,242)$ & $(12,357)$ & $(9,242)$ & $(12,357)$ \\
\hline
\end{tabular}

\section{Ever use}

Nearly half of the women (49 percent) reported to have ever used a contraceptive method in the endline as compared to 41 percent in the baseline survey (Table 7.2). Ever use of both modern and traditional methods has increased from 37 percent to 44 percent and from 11 percent to 18 percent, respectively, 
between the two surveys. Higher increases in ever use have been noted for withdrawal (6 percentage points) and condom (5 percentage points), while for other methods the increase has been relatively small.

\section{Current use}

Current use of modern contraception has increased by nearly 3 percentage points -- nearly half a percentage point per year (Table 7.2). Higher use was reported for female sterilization, followed by condom and the traditional method of withdrawal. Similar patterns were observed in the baseline survey and the national-level PDHS and other surveys. Use of IUDs and pills at endline was slightly lower than at baseline.

\section{Reasons for discontinuation}

The differences between ever use and current use of contraceptives appears to be high but are in close agreement with other district-level surveys conducted in PAIMAN and FALAH project areas and even at the national level (Population Council, 2006; Population Council, 2007). The widening gap between ever use and current use is a major concern shared by policymakers in the Population Welfare Program.

Table 7.3: Percentage of women who discontinued contraceptive use, by reasons*

\begin{tabular}{lrr} 
Reason & Baseline $(N=1,508)$ & Endline $(N=2,409)$ \\
Want more children & 22.2 & 32.5 \\
\hline Infrequent sex & 6.1 & 6.8 \\
\hline Husband away & 8.2 & 14.6 \\
\hline Natural spacing & 8.3 & 9.9 \\
\hline Husband opposes & 3.2 & 3.0 \\
\hline In-laws oppose & 0.5 & 0.7 \\
\hline Against religion & 0.9 & 0.8 \\
\hline Fear of side effects & 4.1 & 3.1 \\
\hline Side effects experienced & 29.9 & 25.2 \\
\hline Accidental pregnancy & 11.3 & 8.8 \\
\hline Lack of access/unavailability & 0.6 & 0.5 \\
\hline Costs too much & 1.0 & 0.3 \\
\hline Inconvenient to use & 1.9 & 1.0 \\
\hline Menopause & 5.9 & 5.1 \\
\hline
\end{tabular}

*Multiple response variable

Women who had ever used a contraceptive method but were not using any method currently were asked about the reasons for their discontinuation (Table 7.3). Two major reasons for discontinuation have emerged. The first reason may be a genuine demand for additional children, reported by 22 percent in the baseline and nearly 33 percent in the endline survey. However, the second most common reason was side effects experienced by the respondents ( 30 percent in the baseline and 25 percent in the endline), which more conspicuously relates to the quality of services and the counseling provided at the service delivery points. Another reason for discontinuation was accidental pregnancy (11 percent baseline; 9 percent endline), which also relates to lack of quality of care and counseling: counseling needs to adequately cover the proper way to use contraceptive methods and adoption of emergency contraception in case of any failure. 



\section{Chapter 8. Newborn Care}

In Pakistan, around 270,000 children die every year in the first month after birth. Deaths during the neonatal period are almost entirely due to birth asphyxia, sepsis and prematurity (NIPS, 2008). The majority of these deaths are preventable if pregnant women seek antenatal care, get $T T$ injections, take iron supplements, deliver at hospitals and get checkups after delivery for their newborns and themselves. Those who deliver at home must seek skilled birth assistance and adopt clean delivery practices (e.g., using a clean instrument to cut the cord and new thread or clamp to tie the cord; wiping the newborn clean; initiating breastfeeding early; and waiting for at least 6 hours after the birth to give the newborn a bath). These are some of the low-cost, evidence-based interventions that can prevent maternal and neonatal deaths.

As mentioned in an earlier chapter, a majority of the last births reported by women in both surveys ( 88 percent baseline; 82 percent endline) took place using normal delivery procedures, while the rest were assisted deliveries ( 6 and 7 percent, baseline and endline respectively) and Caesarean sections ( 6 and 11 percent, baseline and endline respectively). The decline of 12 percentage points (from 62 to 50 percent) in deliveries at home in the project period is expected to have positively influenced the health of neonates in the project districts. An increase in the proportions of mothers seeking antenatal care and using TT injections would have also improved the health of the newborns. However, bad household practices may contribute to high incidence of neonatal mortality (e.g., using unclean instruments to cut the cord; application of surma on the cord; first bath of the newborn within 2-4 hours after birth; massage of mustard oil; universal use of ghutti; delay in initiating breastfeeding; etc.).

The PAIMAN project's primary focus was on maternal and neonatal health. Initiatives targeting improvements in maternal and neonatal health issues (such as those listed above) were implemented in PAIMAN districts. This chapter examines whether any change occurred in attitudes and practices of mothers, especially during and after delivery, that would impact the health of their newborns. Women were asked about the children delivered during the three years prior to the baseline and endline surveys.

\section{Knowledge of danger signs in newborns}

A mother who is aware of the danger signs in newborns is more likely to seek timely treatment from an appropriate source, which may save the life of the newborn. Ideally, the service provider examining the newborn after birth should brief the mother about the danger signs and advise her about what to do under certain conditions. Figure 8.1 shows that the knowledge level of women about danger signs in newborns within one hour of birth slightly improved over the project period. The proportion of women who could identify three or more danger signs in newborns during the first hour of their lives increased by nearly 6 percentage points, averaging one percentage point increase per year. Overall, one in five women was not aware of any danger sign in infants during the first hour of their life, with slight improvement noted in the endline survey (from 19 to 22 percent). Between baseline and endline, relatively higher proportions of women reported yellow skin color, a condition of jaundice, as a danger sign (40 vs. 44 percent), followed by difficult breathing (24 vs. 35 percent) (Figure 8.2). The condition of yellow skin color was also reported by a higher proportion of women as a danger sign in the newborn's first week (46 percent baseline; 51 percent endline), followed by frequent watery stools with blood or mucus ( 25 percent baseline; 28 percent endline)

(Figure 8.3). 
Figure 8.1: Percentage distribution of women, by knowledge of danger signs in newborns within one hour after birth

\begin{tabular}{cl|c}
\hline 34 & Three or more signs & 40 \\
24 & Two signs & 23 \\
21 & One sign & 18 \\
22 & No knowledge & 19 \\
\hline & & Endline
\end{tabular}

Figure 8.2: Percentage of women, by knowledge of specific danger signs in newborns within one hour after birth

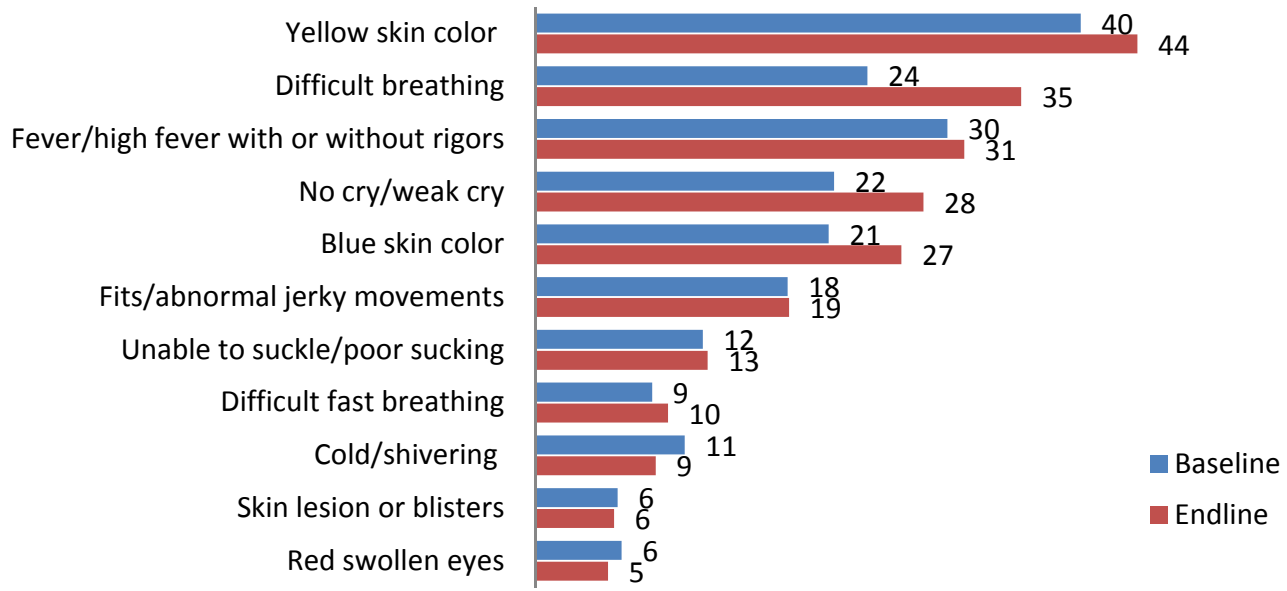

Figure 8.3: Percentage of women, by knowledge of specific danger signs in newborns within the first week after birth

Yellow skin color

Frequent watery stools/stools with blood or mucus

Difficult fast breathing Blue skin color

Unable to suckle/poor sucking

Fits/abnormal jerky movements Cold shivering

Failure to pass urine/stoo

Skin lesion or blisters

Red swollen eyes with discharge

Rigidity

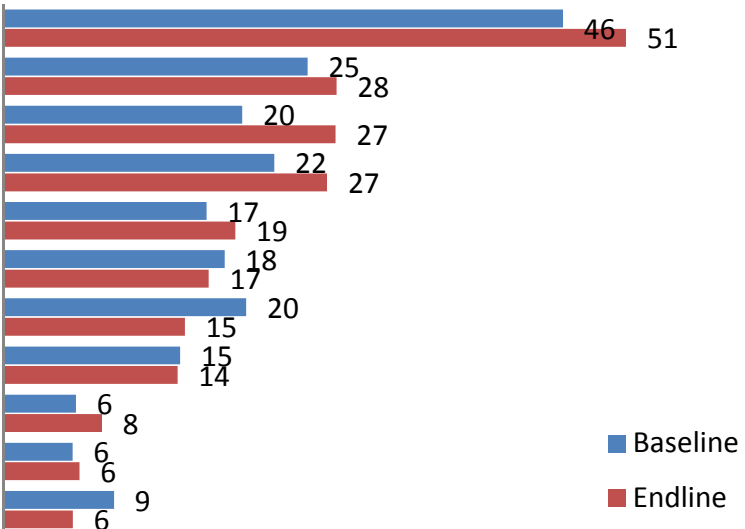




\section{Clean delivery practices}

For both the baseline and endline surveys, it was assumed that in institutional deliveries clean delivery practices were observed. Mothers who had delivered at home were asked about a number of clean delivery practices. Clean delivery practices are important for mother and newborn; for example, unsterilized instruments used during delivery can cause a dangerous infection in either or both the mother and newborn.

Figure 8.4 shows the improvement in almost all clean delivery practices used by birth attendants at home deliveries between baseline and endline. This includes hand washing (79 percent baseline; 84 percent endline); use of clean cloth or plastic sheet (36 percent baseline; 58 percent endline); use of new blade to cut the cord (67 percent baseline; 76 percent endline); and use of new thread or clip to tie the cord (86 percent baseline; 89 percent endline). The practice of using scissors or a knife to cut the cord, which is not a clean delivery practice, showed some decline (from 23 to 19 percent).

Figure 8.4: Percentage of women, by clean delivery practices used by attendant during last home delivery

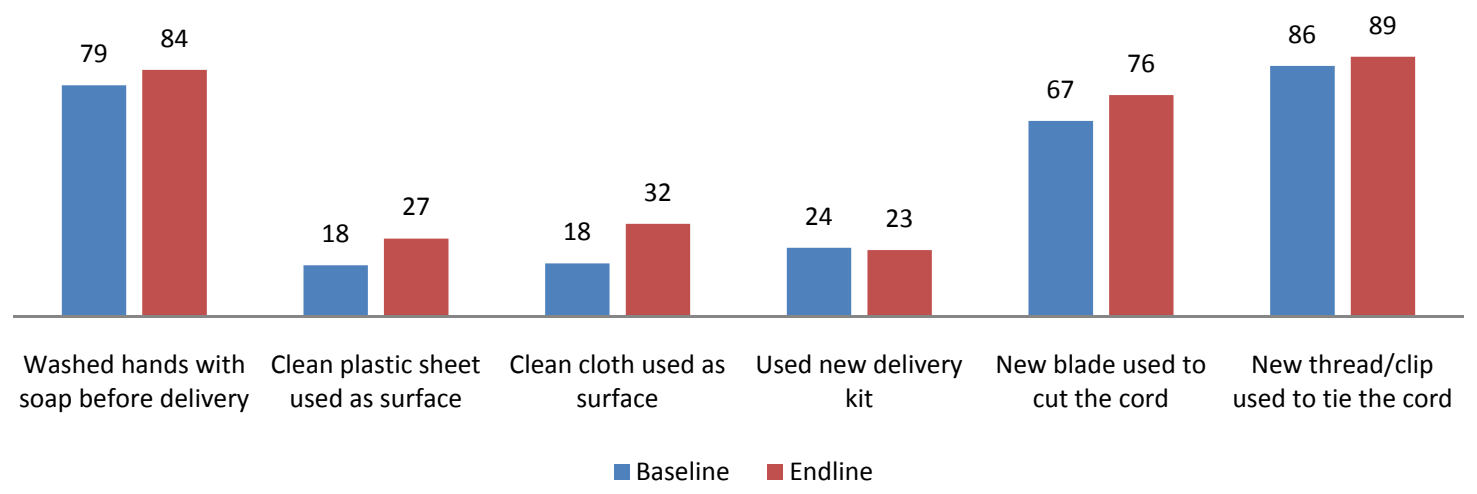

\section{Immediate newborn care practices}

The PAIMAN project, through its various interventions, focused on promoting specific care practices that have been shown to reduce the risks of infection and hypothermia, which included: cutting the umbilical cord with a blade that is new and tying it with new thread; drying and wrapping the newborn immediately after delivery; delaying the newborn's first bath for six or more hours; and initiating breastfeeding immediately (within one hour) after delivery.

Figure 8.5 shows that relative to the baseline, the endline survey results show improvement in all indicators of best practices. A significant improvement has been observed for bathing the newborn after 6 hours from birth -- from a low of 23 percent in the baseline to 53 percent in the endline. Similarly, physical/medical examination of the newborn within three days of birth, though low, has significantly improved over the duration of the project -- from 36 percent at baseline to 55 percent at endline. In Pakistani society, the practice of feeding colostrum, which is high in nutrients and antibodies, still needs to be encouraged. In the PAIMAN districts, around two-thirds of the newborns were fed colostrum, both in the baseline (66 percent) and the endline (67 percent), which is slightly higher compared to the national average of 63 percent (NIPS, 2008). 
Figure 8.5: Percentage of women whose last delivery was at home, by safe delivery practices used by birth attendant

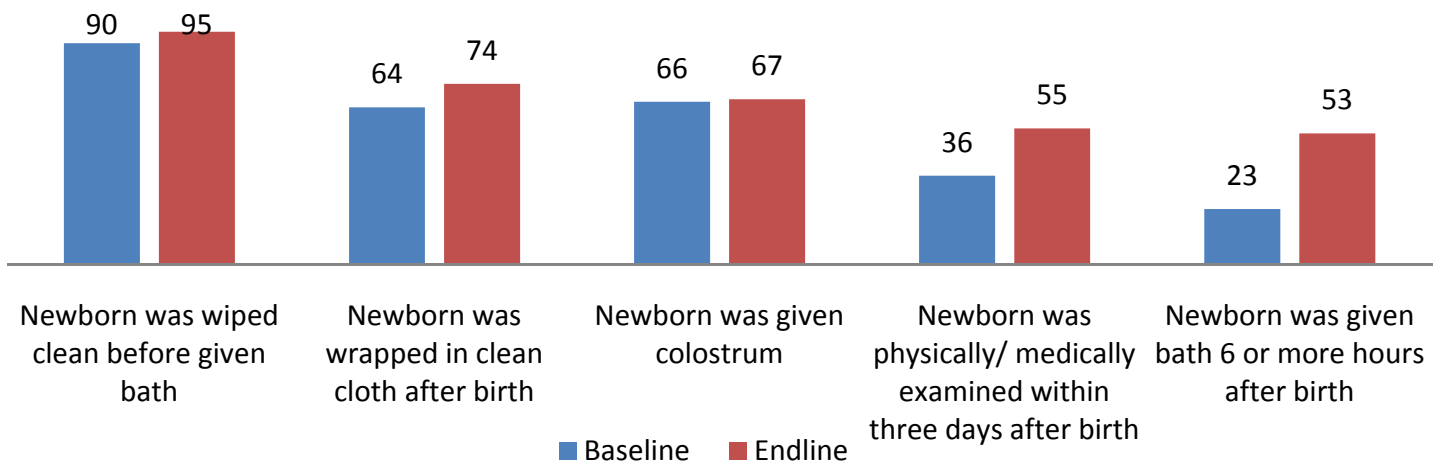

\section{Newborn examination}

Health practices require that a newborn be medically and physically examined by the birth attendant or a physician within three days of delivery. Mothers were asked if their last newborn had undergone any such examination, and, if yes, who did the examination and what kind of advice was provided. Table 8.1 shows that the practice of examining a baby after birth has improved by 18 percentage points (39 percent baseline; 57 percent endline). The majority of these newborns were examined by health professionals, including doctors, nurses/LHVs and midwives (68 percent baseline; 71 percent endline). Traditional birth attendants were also reported to have had examined the newborns and their proportion has also increased (20 percent baseline; 25 percent endline). A majority of the service providers advised mothers about keeping the newborn warm, breastfeeding (especially colostrum) and immunization. However, only 33 percent of the mothers were informed about danger signs in newborns in the endline, though this was even lower in the baseline (30 percent).

Table 8.1: Percentage of women whose newborns were examined after birth, by selected variables

\begin{tabular}{|c|c|c|}
\hline Variable & $\begin{array}{r}\text { Baseline } \\
(N=4,388)\end{array}$ & $\begin{array}{r}\text { Endline } \\
(N=5,691)\end{array}$ \\
\hline Was newborn examined after birth? & $(N=4,388)$ & $(N=5,691)$ \\
\hline Yes & 39.0 & 57.3 \\
\hline No & 61.0 & 42.7 \\
\hline Who examined newborn? & $(N=1,714)$ & $(N=3,263)$ \\
\hline LHW & 1.5 & 0.5 \\
\hline TBA/dai & 20.0 & 24.9 \\
\hline CMW & 0.0 & 0.1 \\
\hline Midwife & 1.1 & 0.2 \\
\hline Nurse/LHV & 6.1 & 7.4 \\
\hline Doctor (male or female) & 61.2 & 62.9 \\
\hline Other family member & 6.6 & 2.9 \\
\hline Friend/neighbor & 0.3 & 0.0 \\
\hline Other & 2.2 & 0.8 \\
\hline Don't know & 1.0 & 0.5 \\
\hline What advice was given? & $(N=1,714)$ & $(N=3,263)$ \\
\hline Keep newborn warm & 60.5 & 60.1 \\
\hline Breastfeeding & 67.2 & 63.4 \\
\hline Feed colostrum & 51.2 & 48.5 \\
\hline Newborn danger signs & 29.7 & 33.2 \\
\hline Immunization & 52.3 & 51.6 \\
\hline
\end{tabular}




\section{Newborn danger signs and treatment}

Mothers were read two lists of danger signs/symptoms, one for danger signs/symptoms that might occur within one hour of birth and the other for danger signs/symptoms that might occur within one week of birth. The mothers were then asked what signs/symptoms they saw in their newborn. Figures 8.6 and 8.7 show the percentage of women who reported danger sign/symptoms in their newborns for each period. Overall, about the same percentage of newborns were reported to have the problems of difficult breathing and not crying (each accounting for 6 to 7 percent in baseline and endline) in the first hour after birth, which are symptoms of birth asphyxia. Reports of symptoms of jaundice within the first week of life were relatively high (11 percent baseline; 9 percent endline).

Figure 8.6: Percentage of women who reported at least one danger sign/symptom in newborns within one hour of birth, by specific signs/symptoms

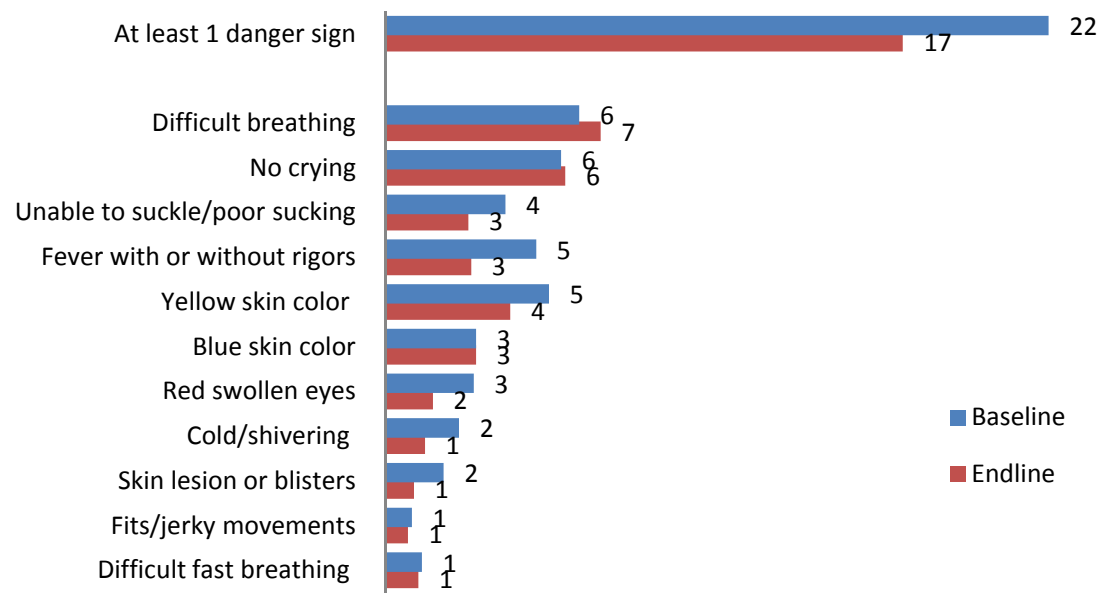

Figure 8.7: Percentage of women who reported at least one danger sign/symptom in newborns within one week of birth, by specific danger signs/symptoms

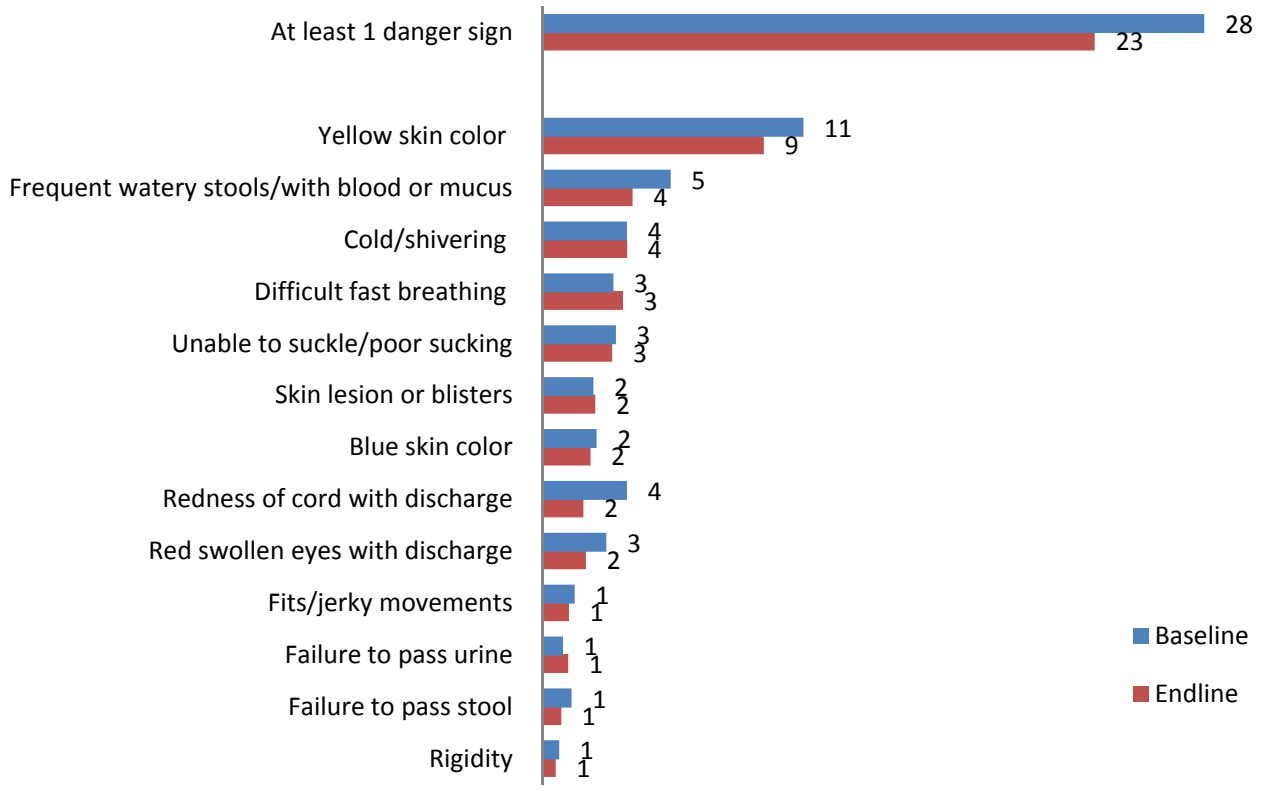


Mothers who reported that their newborns had one or more danger signs within an hour or within a week of delivery were asked where they first went for treatment. Findings from the endline survey show that a majority of the women went to a private clinic or hospital for treatment over a public facility (55 percent private; 20 percent public), a much greater difference than seen in the baseline findings (Figure 8.8). Figure 8.9 shows that the proportion of women who went for treatment for danger signs in their newborn in the first week of life was also higher for private-sector facilities over public-sector facilities. The proportion of women who did not seek treatment for their newborn who developed a dangerous symptom within an hour of birth declined from 26 to 20 percent between baseline and endline, while the proportion of those who did not seek treatment for their newborns with complications within a week of delivery declined about the same amount, going from 20 to 13 percent.

Figure 8.8: Percentage of women who sought treatment for their newborns with danger signs/symptoms within one hour of birth at last home delivery, by source of treatment

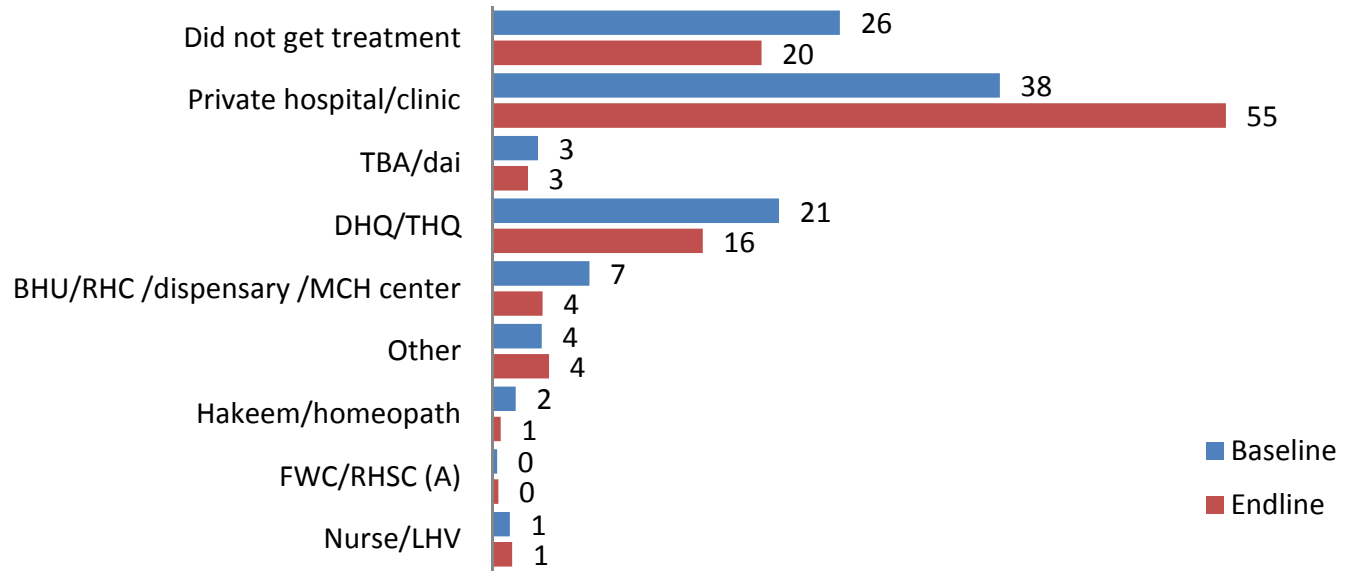

Figure 8.9: Percentage of women who sought treatment for their newborns with danger signs/symptoms within the first week of life after last home delivery, by source of treatment

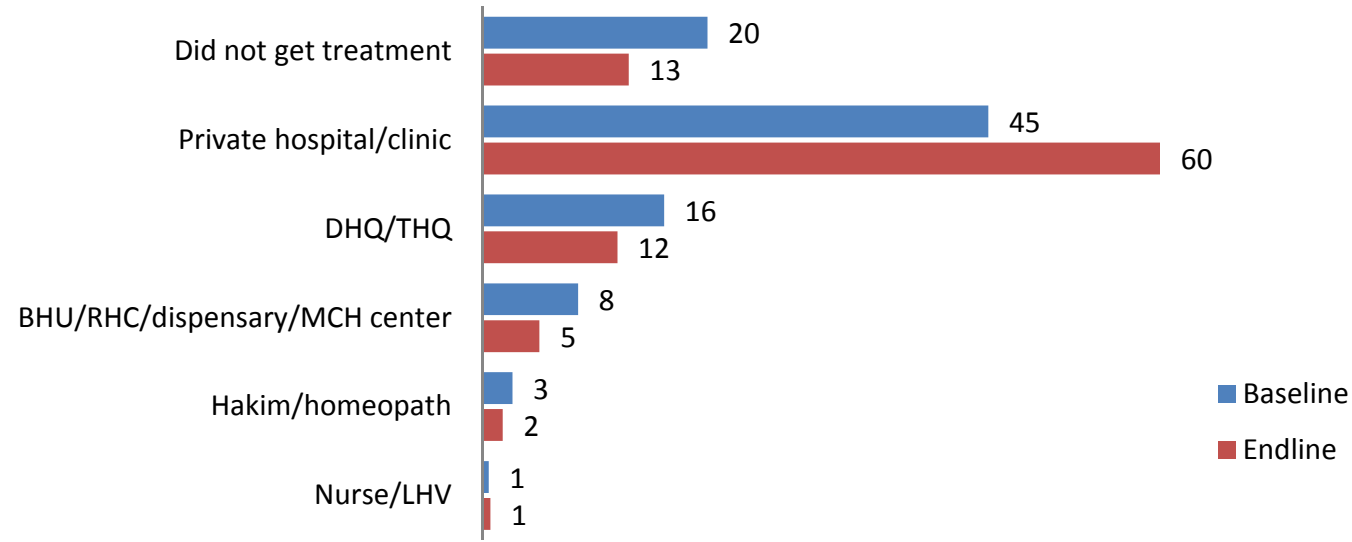

\section{Prevalence and treatment of diarrhea}

Diarrhea is one of the major causes of death among infants in Pakistan. It is higher in the post-neonatal period compared to neonatal or childhood. The PDHS 2006-07 reported that 27 percent of post-neonatal deaths were caused by diarrhea, while among children aged 1-4 years the fatality rate was around 18 
percent. Diarrhea can be fatal unless the fluids and electrolytes lost during diarrhea are replaced promptly. It is, therefore, important to increase the intake of fluid through some form of oral rehydration therapy (ORT) or a homemade solution that is usually prepared from sugar, salt and water.

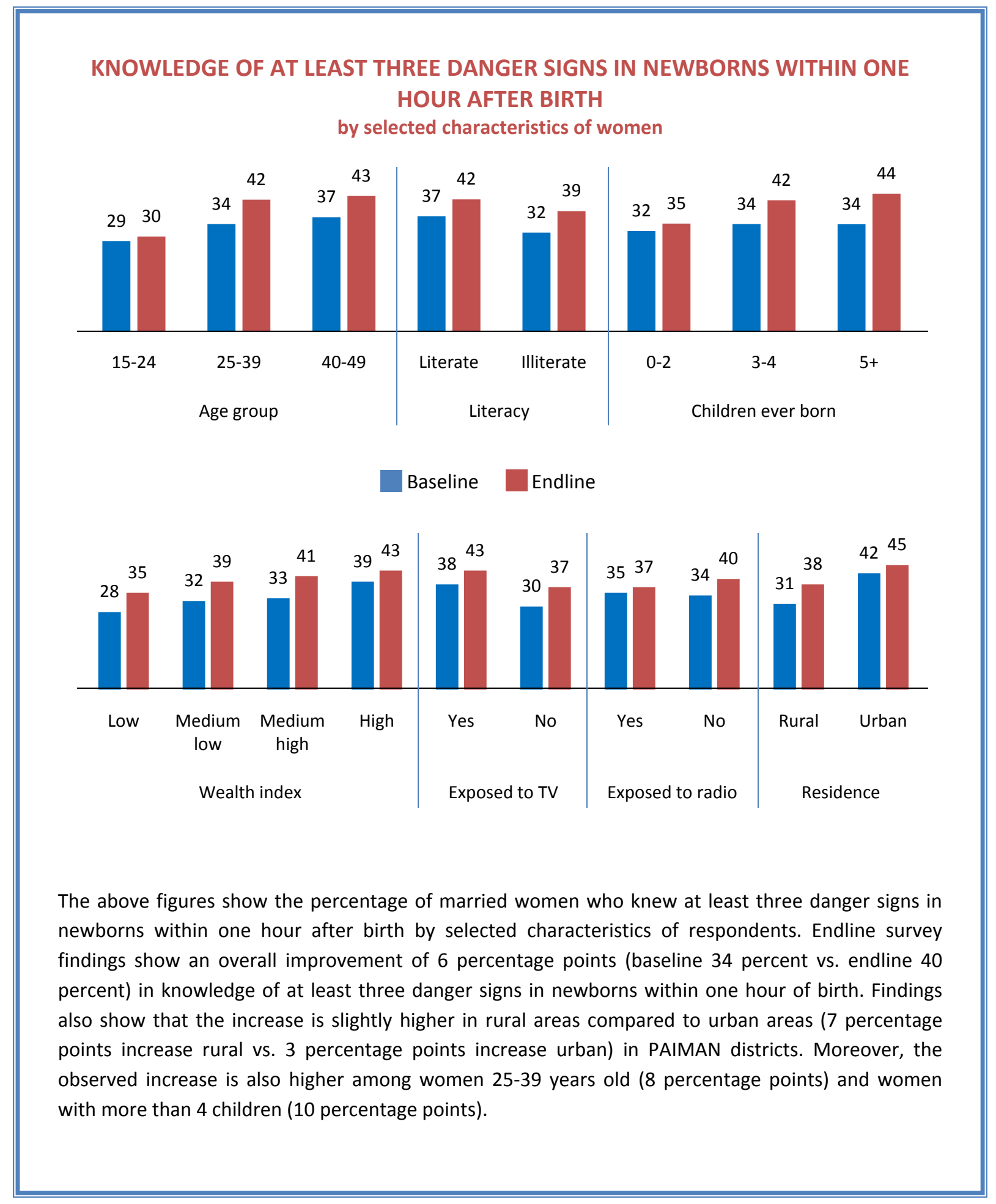


Women in the baseline and endline surveys were asked if their children under three years of age had diarrhea in the two weeks before the survey. Twenty-two percent of the children in the baseline and 32 percent in the endline had diarrhea during the reference period. Nearly half of the children were given something at home to cure diarrhea. Use of oral rehydration solution (ORS), which is available in packaged form and can be prepared at home, was higher at endline compared to baseline by 9 percentage points (Figure 8.10).

Figure 8.10: Percentage of women whose children under 3 years of age had diarrhea in the two weeks prior to the survey, by treatment given at home

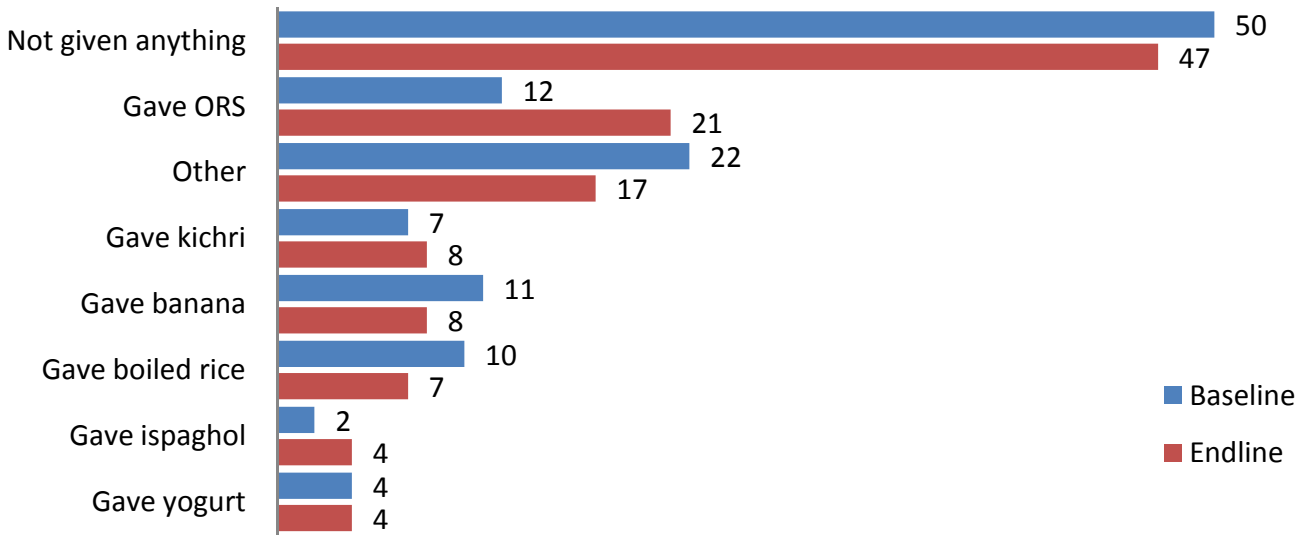

A majority of the children who had diarrhea were taken to a service provider for treatment (73 percent baseline; 79 percent endline) (Figure 8.11). Most of them were taken to private hospitals/clinics (65 percent baseline; 75 percent endline), and a much smaller proportion were taken to public-sector facilities (20 percent baseline; 16 percent endline).

Figure 8.11: Percentage of women whose children under 3 years of age were treated for diarrhea in the two weeks prior to the survey, by treatment facility

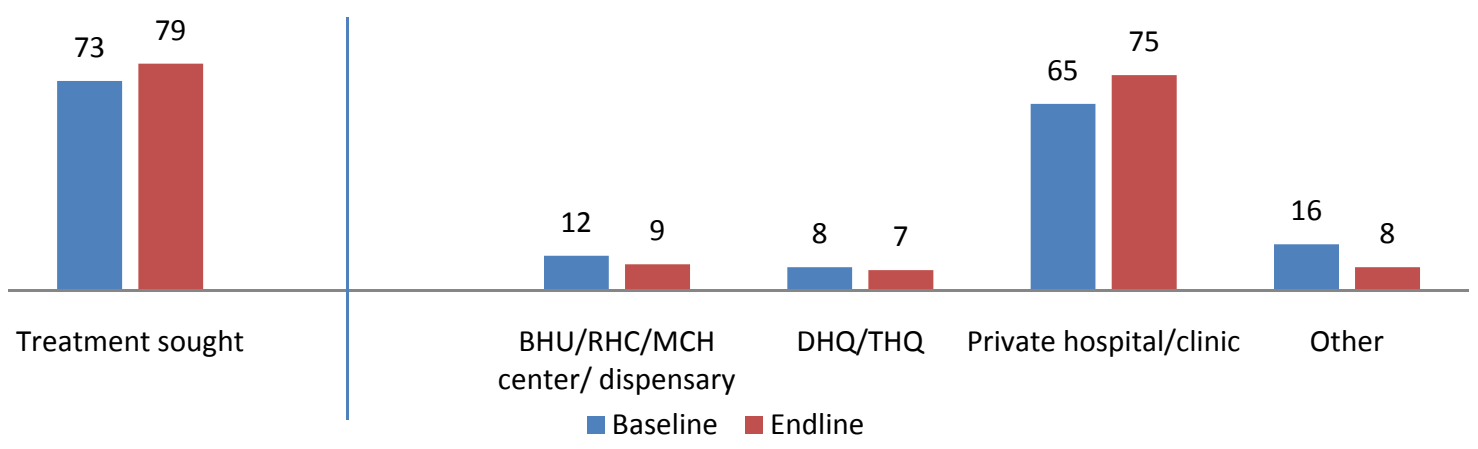

\section{Prevalence and treatment of acute respiratory infection}

Women were asked whether their children less than three years of age had had pneumonia in the two weeks prior to the survey and, if yes, what type of pneumonia it was. The two options provided were cough with fever and difficult breathing related to chest congestion. Figure 8.12 shows that 6 percent of the children were reported to have had at least one of the two conditions in the baseline and 9 percent in the endline. A majority of the sick children were not given anything at home (51 percent baseline; 63 percent 
endline), but they were presumably taken to a health care provider. Home remedies included tea or warm water, honey, yolk of egg, soup, etc. (Figure 8.13). A majority of the children with acute respiratory infection (ARI) symptoms were taken to a health service provider or facility ( 74 percent baseline vs. 86 percent endline). These children were mostly taken to private-sector facilities ( 62 percent baseline; 75 percent endline). Relatively lower proportions (30 percent baseline; 19 percent endline) were taken to public-sector facilities, showing a declining trend over time (Figure 8.14).

Figure 8.12: Percentage of women whose children under 3 years of age had symptoms of ARI, by symptoms

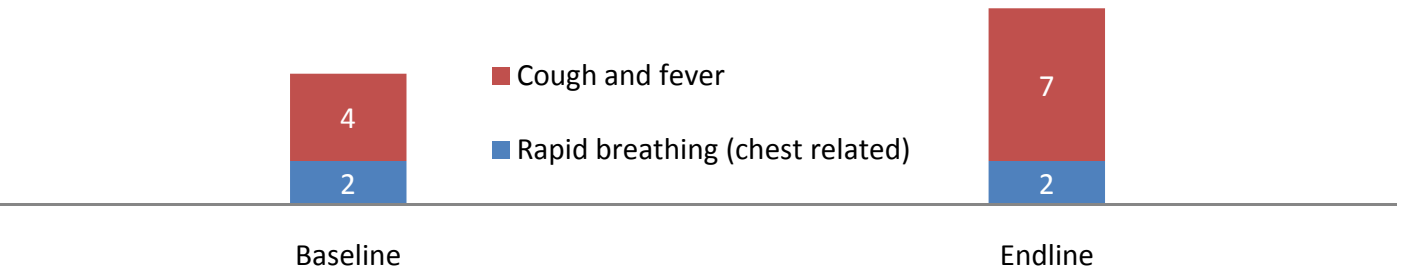

Figure 8.13: Percentage of women whose children under 3 years of age had ARI symptoms in the two weeks prior to the survey and were given something at home, by treatment

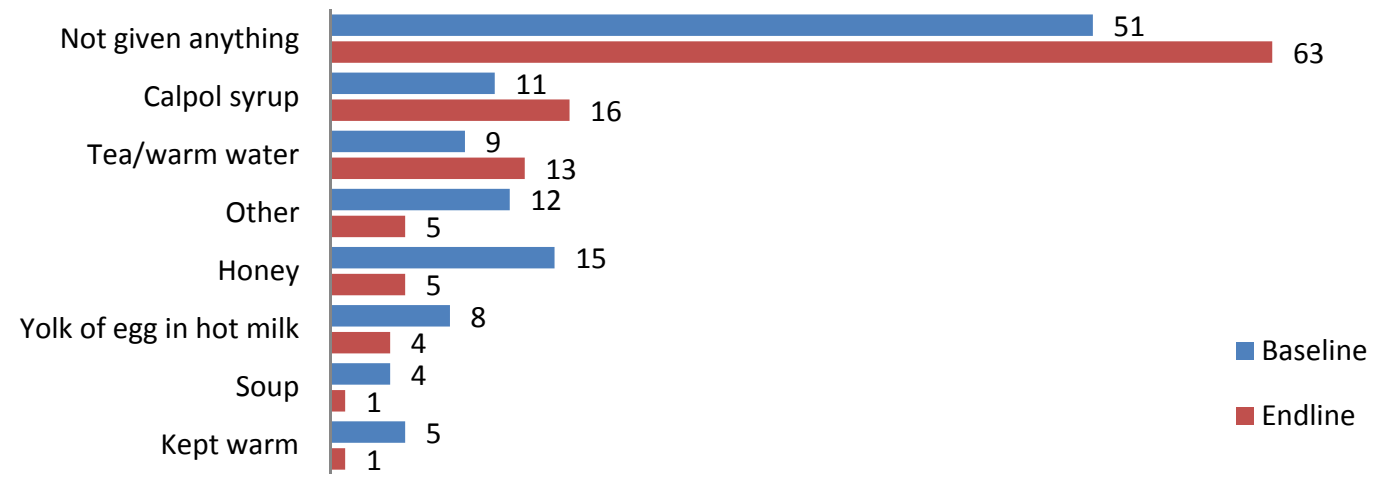

Figure 8.14: Percentage of women whose children under 3 years of age had symptoms of ARI in the two weeks prior to the survey and were taken for treatment, by treatment facility

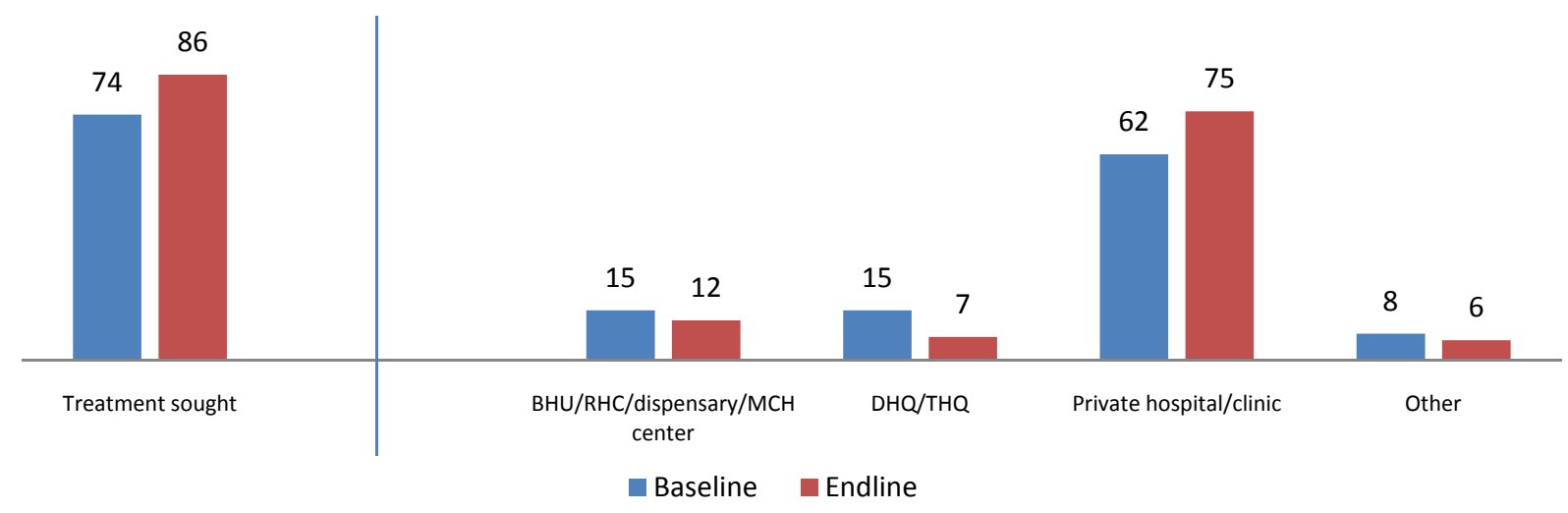




\section{Perinatal and neonatal mortality}

Neonatal mortality and perinatal mortality were considered the major outcome indicators for PAIMAN. A reduction in neonatal mortality was expected through the different PAIMAN interventions in the ten PAIMAN districts. The findings show a decline in both perinatal mortality and in neonatal mortality when comparing the estimates obtained from the endline survey with the baseline estimates. Figure 8.15 illustrates the decline in PNMR, NNMR and ENNMR. Most notable is the reduction in NNMR, which is mainly due to the decline in early neonatal mortality, an indicator highly sensitive to improvements in delivery practices.

Figure 8.15: Changes in perinatal, neonatal and early neonatal mortality rates (2005-2010)

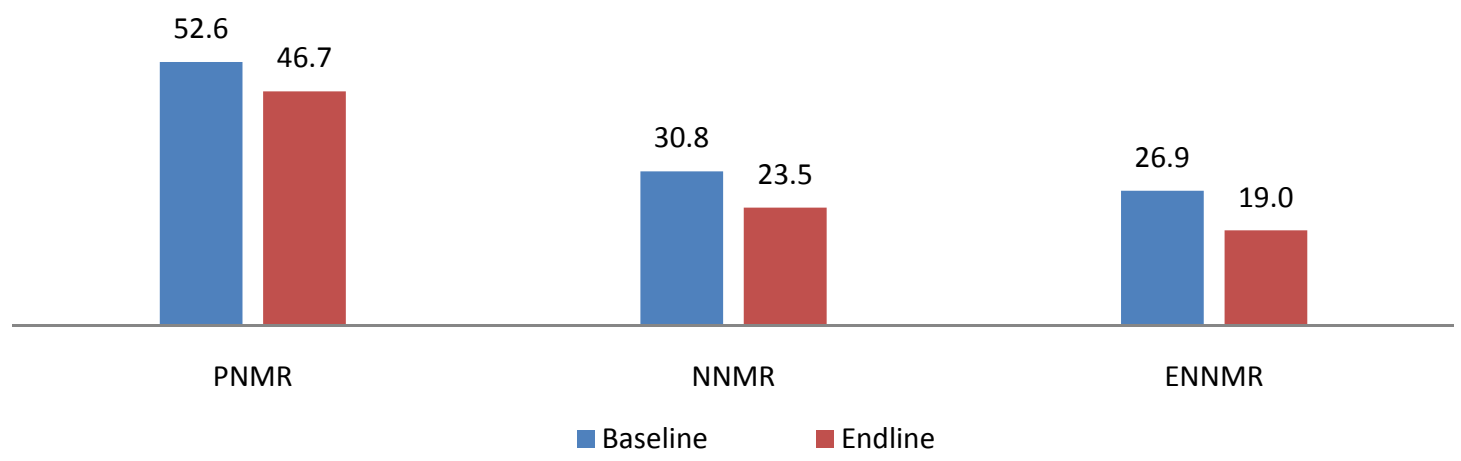

The endline survey findings show a decline in the neonatal mortality rate, from 31 deaths to 24 deaths per 1,000 live births (24 percent decline), whereas the early neonatal mortality rate has declined from 27 deaths at the time of baseline to 19 deaths per 1,000 live births (29 percent decline) in the endline survey. It is observed that the reduction in NNMR is mainly due to the decline in early neonatal mortality. The results of the endline survey are very encouraging and reinforce the positive impact of PAIMAN overall on reducing neonatal mortality.

It should be pointed out that perinatal mortality is probably the most sensitive indicator of improvements in pregnancy and delivery care, and most closely related to maternal mortality as well. A further encouraging result is the reduction in the perinatal mortality rate (stillbirths and early neonatal mortality per 1,000 births), which is estimated to be 47 in the endline compared to 53 deaths per 1,000 births in the baseline (Table 8.2).

Table 8.2: Estimates of perinatal, neonatal and early neonatal mortality rates at baseline and endline, with $95 \%$ confidence intervals

\begin{tabular}{|c|c|c|c|c|}
\hline \multirow[b]{2}{*}{ Mortality rate } & \multicolumn{2}{|c|}{ 95\% confidence } & \multicolumn{2}{|r|}{$95 \%$ confidence } \\
\hline & Baseline & interval & Endline & interval \\
\hline $\begin{array}{l}\text { Perinatal mortality } \\
\text { rate }\end{array}$ & 52.6 & [46.0--59.1] & 46.7 & [41.3--52.1] \\
\hline $\begin{array}{l}\text { Neonatal mortality } \\
\text { rate }\end{array}$ & 30.8 & [25.6--35.9] & 23.5 & [19.6--27.5] \\
\hline $\begin{array}{l}\text { Early neonatal } \\
\text { mortality rate }\end{array}$ & 26.9 & [22.1--31.7] & 19.0 & [15.5--22.9] \\
\hline
\end{tabular}




\section{Chapter 9. Husbands}

A subsample of one out of every four households interviewed in the PAIMAN baseline and endline surveys was created to obtain information from the husbands of the currently married women of reproductive age on $\mathrm{MNCH}$ topics. The topics covered in these interviews with husbands were: background characteristics; media habits; attitude toward pregnancy, delivery and postpartum care; and knowledge and attitude about safe motherhood, birth preparedness and availability and utilization of community resources for maternal and neonatal health. In addition, the endline survey included questions for husbands about particular PAIMAN interventions that targeted husbands. The questionnaire consisted of a subset of the questions used in the women's questionnaire. Altogether, 3,017 and 3,203 husbands were successfully interviewed in the baseline and endline surveys respectively.

The information presented in this chapter provides a comparison of the PAIMAN baseline and endline survey findings on the issues related to the attitude, behavior and role of husbands with respect to maternal and neonatal health issues. In a patriarchal society, such as that in Pakistan, there tend to be established roles and areas for men and women, and maternal and neonatal health are usually considered to be the domain of women; however, men have significant influence on these "female issues" because decisionmaking power usually rests with them.

\section{Characteristics}

The background characteristics of the husbands help in understanding how similar and dissimilar the baseline and endline sample populations are. Figure 9.1 shows the distribution of husbands by age according to the baseline and endline surveys. In both of the surveys, nearly eight out of ten husbands ( 80 percent baseline; 78 percent endline) were between ages 25-49 years. Figure 9.2 shows that 71 percent of husbands in the baseline survey were literate compared to 76 percent in the endline survey, indicating an improvement in the education of husbands between the baseline and endline surveys. In both surveys, nearly three out of ten (31 percent) husbands said that they were skilled laborers. The percent of husbands in various kinds of businesses rose from 16 percent in the baseline to 19 in the endline survey (Table 9.1).

Figure 9.1: Percentage distribution of husbands of currently married women of reproductive age, by age group

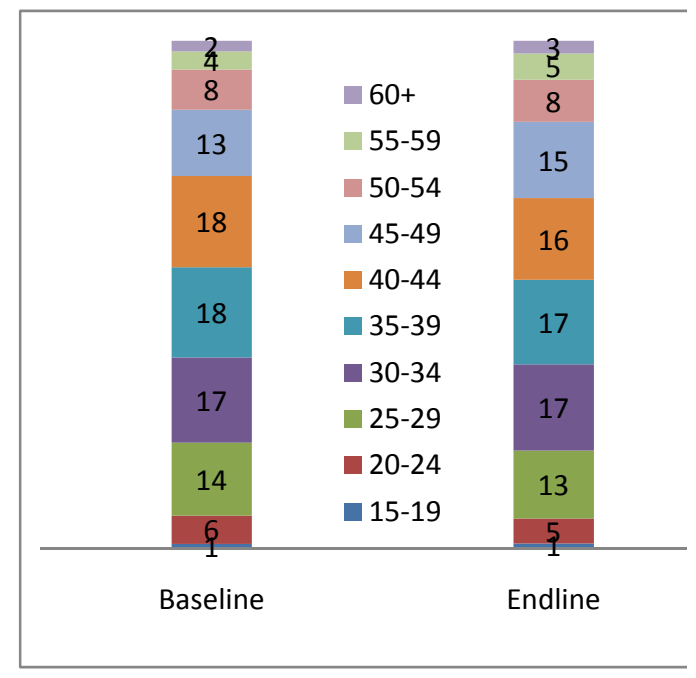

Figure 9.2: Percentage distribution of husbands of currently married women of reproductive age, by education

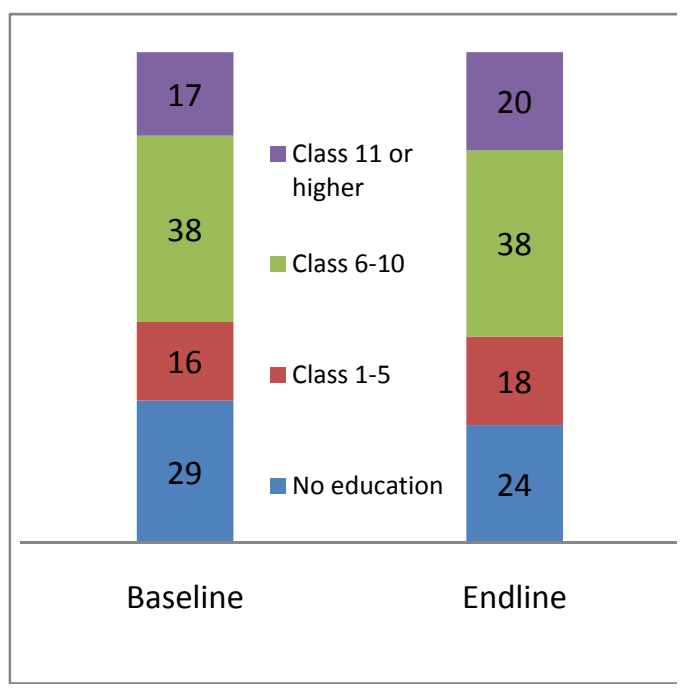


Table 9.1: Percentage distribution of husbands of currently married women of reproductive age, by occupation

\begin{tabular}{lrr} 
Occupation & Baseline & Endline \\
Agriculture & 25.4 & 24.4 \\
\hline Unskilled labor & 14.4 & 12.4 \\
\hline Skilled labor & 30.5 & 30.6 \\
\hline Professional/administrator & 2.3 & 4.7 \\
\hline Business & 16.4 & 19.1 \\
\hline Retired & 2.1 & 1.4 \\
\hline Unemployed & 2.9 & 3.9 \\
\hline Other & 6.0 & 3.5 \\
\hline (N) & 3,017 & 3,203 \\
\hline
\end{tabular}

\section{Mass media}

\section{Media habits}

Mass media is a major avenue for creating awareness about maternal and neonatal health and influencing attitudes and behaviors about this important topic. In the endline survey, 79 percent of the husbands were exposed to at least one of the three major sources of mass media -- TV, radio and newspapers -- compared to 73 percent in the baseline survey (Figure 9.3). The endline survey shows that a higher number of husbands watched TV and read newspapers as compared to the baseline survey, but the percent of those listening to the radio has gone down over the course of the project, from 30 percent to 19 percent. With the advancement of technology, television has become a major means of exposing viewers to information on a host of subjects. Viewership of TV has risen from slightly more than one-half in the baseline survey to more than two-thirds in the endline survey.

Figure 9.3: Percentage of husbands of currently married women of reproductive age, by exposure to mass media

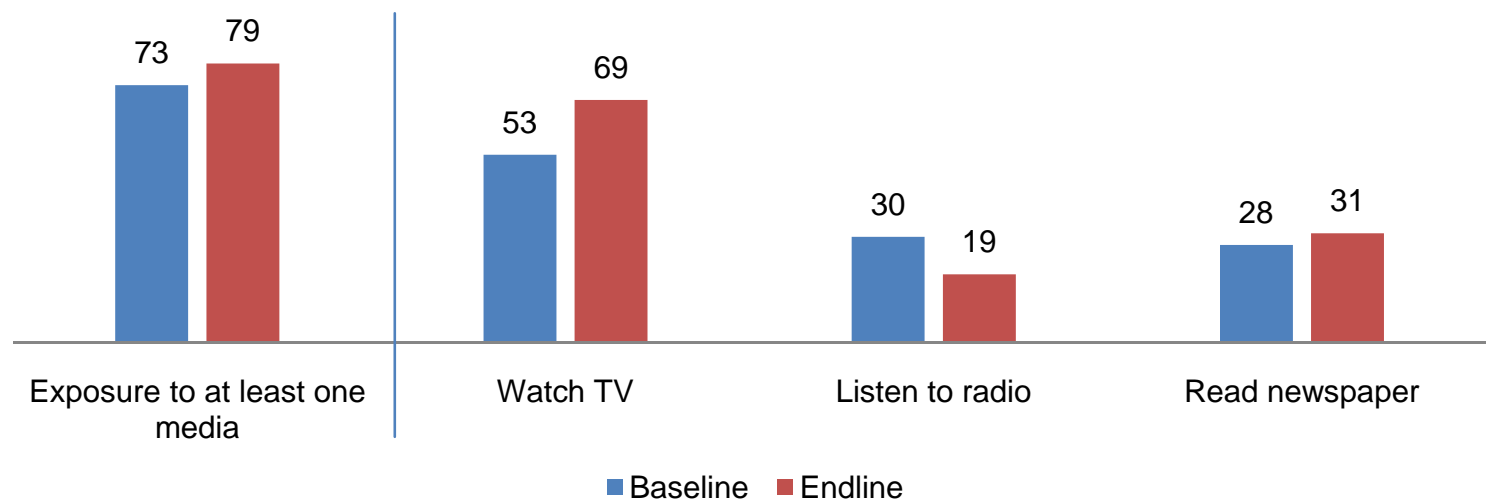




\section{Information/education through media}

The husbands were asked whether they had heard, read or watched anything related to maternal and child health from either mass media sources or through interpersonal communication channels during the three months prior to the survey. Figure 9.4 shows that a higher percentage of husbands had heard, read or watched programs about health of newborns and maternal health in the endline survey when compared to the baseline survey. There was little change over time in the percent of husbands who received information from religious leaders or representatives from $\mathrm{CBO}$ s or NGOs.

Figure 9.4: Percentage of husbands of currently married women of reproductive age, by hearing/seeing/ reading maternal and newborn health messages and the source of interpersonal communication

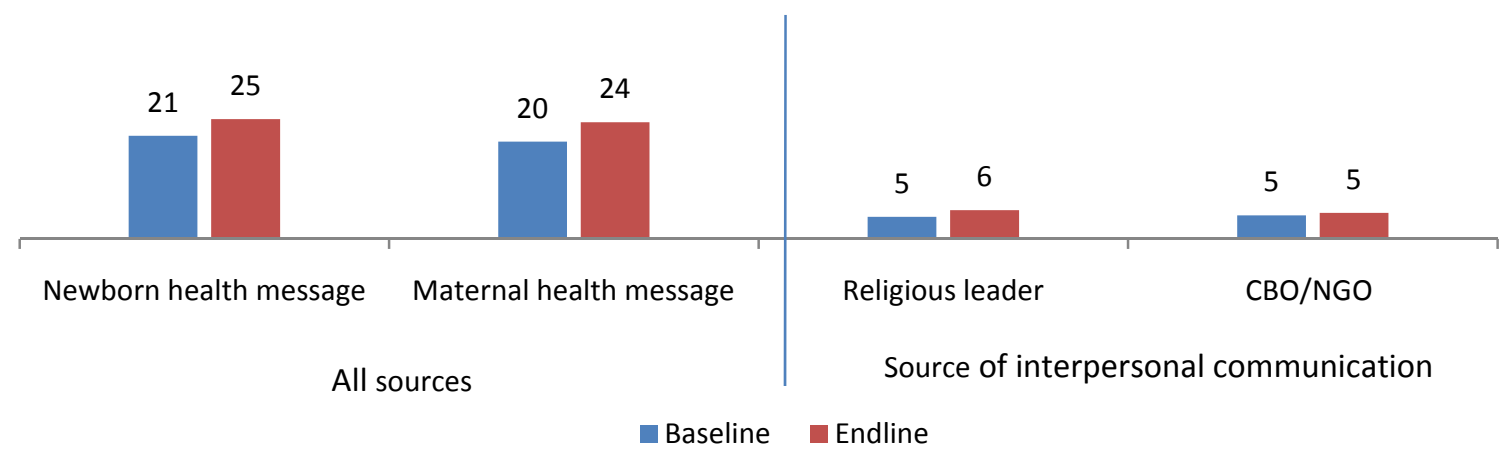

\section{Attitude toward safe motherhood issues}

\section{Prenatal care}

Both mother and infant benefit when a woman receives proper care during pregnancy and childbirth. Ensuring adequate maternity care for women was one of the fundamental goals of the PAIMAN project. It is important that husbands are aware of the importance of prenatal care and are supportive of the use of proper healthcare during pregnancy and delivery. The endline survey shows that there has been a significant increase in the proportion of husbands who think that prenatal checkups during pregnancy are required (82 percent baseline; 94 percent endline) (Table 9.2). However, only 41 percent of the husbands in the baseline survey and 61 percent in the endline survey believed that the first antenatal visit should occur during the first trimester.

\section{Knowledge of tetanus toxoid injections and iron supplements}

Tetanus toxoid injections are given to women during pregnancy in order to prevent neonatal tetanus, a frequent cause of death in young infants when sterile conditions are not observed during delivery. Data show that the percentage of husbands who knew that pregnant women should be given TT injections during pregnancy declined from 64 percent baseline to 61 percent endline (Table 9.2).

Iron supplements help pregnant women reduce iron deficiency. Since anemic women are at higher risk of experiencing life-threatening complications, putting themselves and their unborn child at higher risk of dying, it is essential for pregnant women and their husbands to know the importance of iron supplements. PAIMAN baseline and endline surveys show that the percent of husbands who knew that iron tablets are given to women during pregnancy dropped from 49 percent baseline to 44 percent endline (Table 9.2). 
Table 9.2: Percentage of husbands of currently married women of reproductive age, by attitude toward ANC, skilled birth attendance and postpartum care

\begin{tabular}{lrr} 
Topic & Baseline & Endline \\
ANC is necessary & 81.7 & 94.1 \\
\hline First ANC visit should be in first trimester & 40.9 & 60.8 \\
\hline Knowledge about TT injections during pregnancy & 64.3 & 61.2 \\
\hline Knowledge about iron tablets & 49.0 & 44.0 \\
\hline Delivery should be done by a skilled birth attendant & 90.3 & 95.7 \\
\hline Postpartum care should be obtained & 57.4 & 64.9 \\
\hline
\end{tabular}

\section{Assistance during delivery}

Hygienic conditions and proper medical attention during delivery can reduce the risk of complications and infections for both the mother and the newborn. A majority of husbands who were interviewed believed that a woman should get assistance from a skilled birth attendant during delivery (90 percent baseline; 96 percent endline) (Table 9.2).

\section{Postpartum checkup}

Postpartum checkups are often not regarded as important, but more than 60 percent of maternal deaths occur during the postnatal period (Li et al., 1996). When the husbands were asked about the importance of postpartum checkups, there was an increase between baseline and endline in those who thought that women should have a postpartum checkup (from 57 percent to 65 percent) (Table 9.2).

\section{Responsibilities of husband during child birth}

Husbands were not fully aware of what responsibilities they should have at the time of delivery. However, a majority recognized that husbands should arrange for transport, if needed, and make financial arrangements to pay for the delivery. When compared with the baseline survey, more husbands in the endline survey knew that they should be available at the time of the delivery (from 22 to 38 percent), make the financial arrangements in the event of an emergency (from 23 to 32 percent), discuss arrangements with their wives (from 7 to 15 percent), and discuss arrangements with other family members (from 7 to 9 percent) (Figure 9.5). 
Figure 9.5: Percentage of husbands of currently married women of reproductive age, by their perceptions of their responsibilities during childbirth

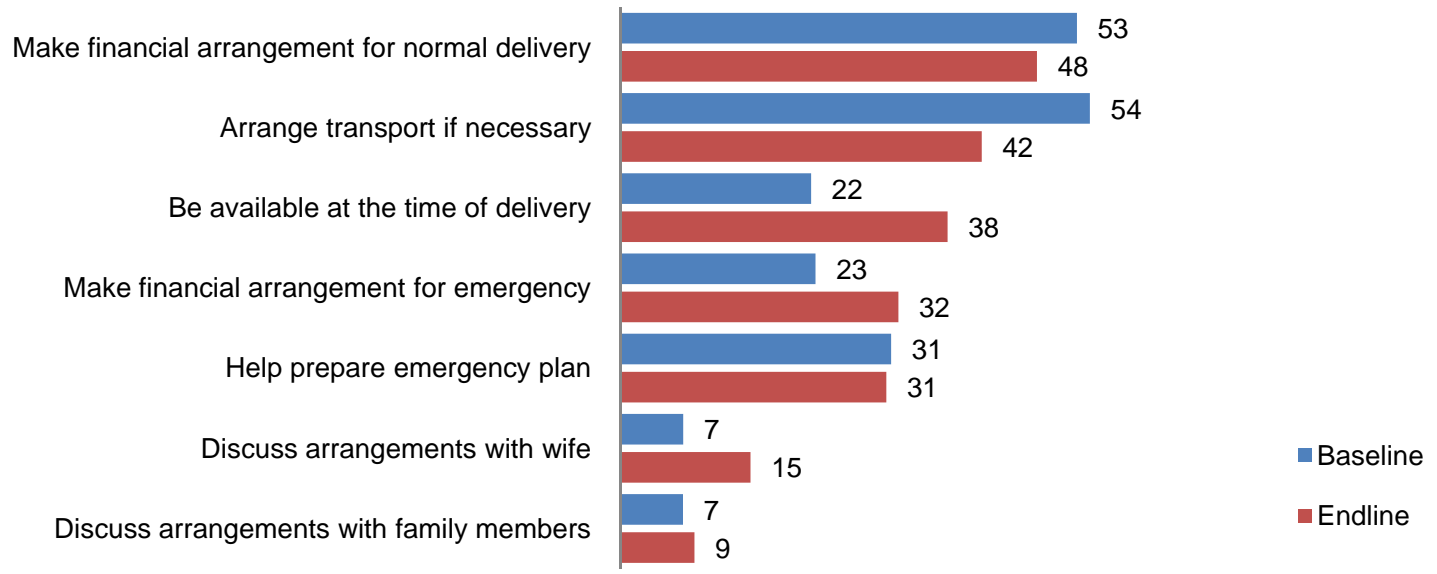

\section{Knowledge of danger signs}

Though childbirth is a female domain and complications experienced can best be described by the woman herself, it is important to know whether husbands also realize the severity of possible problems and their repercussions on the health of women and infants.

\section{Danger signs during pregnancy}

The husbands were asked whether they knew the signs during pregnancy that could be dangerous and require immediate attention and treatment. Figure 9.6 presents the knowledge of husbands of danger signs during pregnancy. Only the spontaneous responses of the husbands are included in this analysis. In the baseline survey, only 13 percent of the husbands could mention at least three danger signs during pregnancy; however, in the endline survey, 25 percent of them could mention three or more danger signs.

Figure 9.6: Percentage of husbands of currently married women of reproductive age, by knowledge of specific danger signs during pregnancy

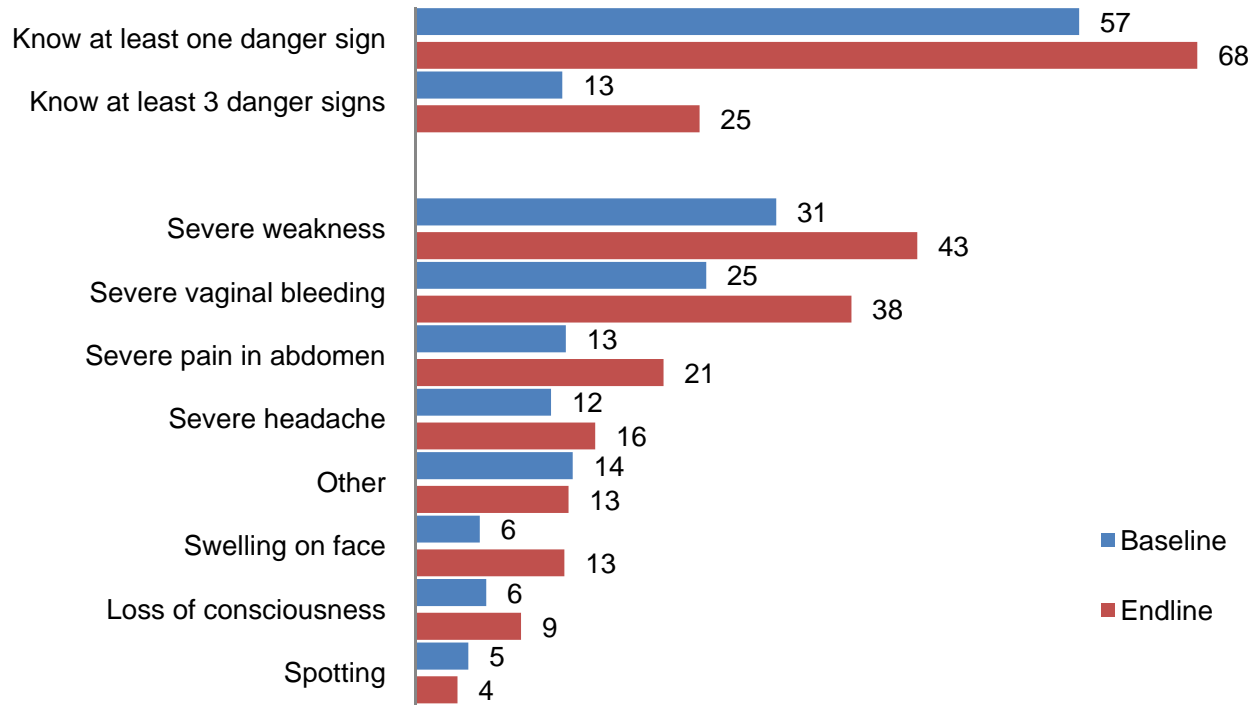




\section{Danger signs during delivery}

Figure 9.7 shows that only 13 percent of husbands in the baseline survey knew about the danger signs during delivery; however, this has increased to 20 percent according to the endline survey. In the endline survey, 43 percent of the husbands mentioned severe vaginal bleeding as a danger sign compared to only 28 percent in the baseline survey.

Figure 9.7: Percentage of husbands of currently married women of reproductive age, by knowledge of specific danger signs during delivery

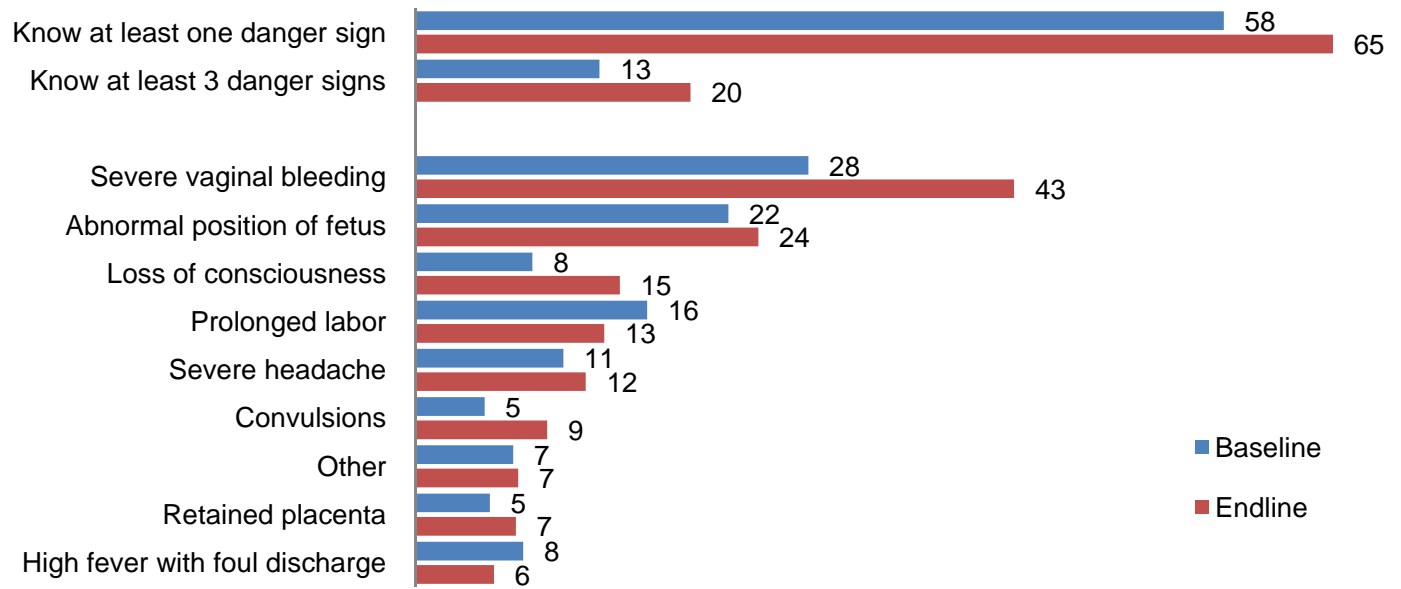

\section{Danger signs during postpartum period}

Forty-seven percent of the husbands in the endline survey could not spontaneously name even a single danger sign during the postpartum period that would require immediate treatment, and slightly more than a quarter (28 percent) could name only one danger sign. Only 7 percent of the husbands knew at least three danger signs in the endline survey compared to 6 percent in the baseline. According to the baseline survey, only 22 percent of the husbands mentioned severe vaginal bleeding as a danger sign during the postpartum period, while 37 percent of the husbands mentioned the same in the endline survey.

Figure 9.8: Percentage of husbands of currently married women of reproductive age, by knowledge of specific danger signs during postpartum period

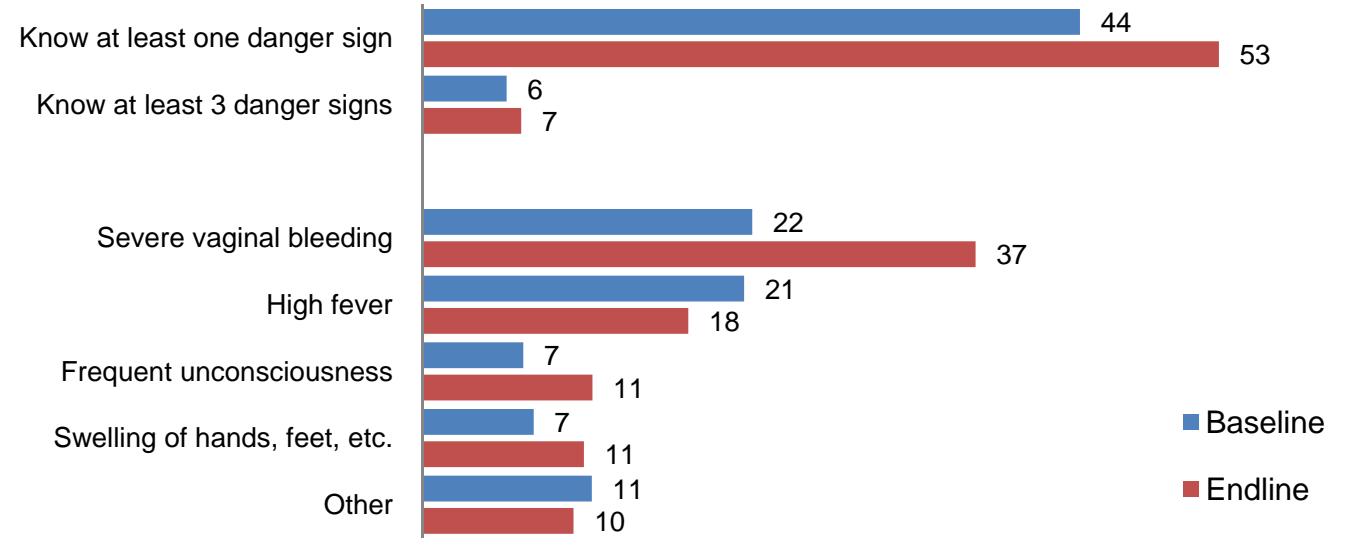




\section{Danger signs in newborns}

Spontaneous knowledge of danger signs in newborns was also limited among husbands. In the endline, 31 percent of the husbands could not spontaneously name any danger signs in newborns. Also in the endline, knowledge of one danger sign was reported by 21 percent of husbands and knowledge of three or more danger signs was reported by 18 percent (Figure 9.9). In the baseline survey, only 11 percent of the husbands could name at least three danger signs in the newborn. According to the endline survey, 43 percent of the husbands mentioned pale/blue complexion of the newborn as a danger sign compared to the baseline survey where the same danger sign was mentioned by only 23 percent of the husbands.

Figure 9.9: Percentage of husbands of currently married women of reproductive age, by knowledge of specific danger signs in newborns

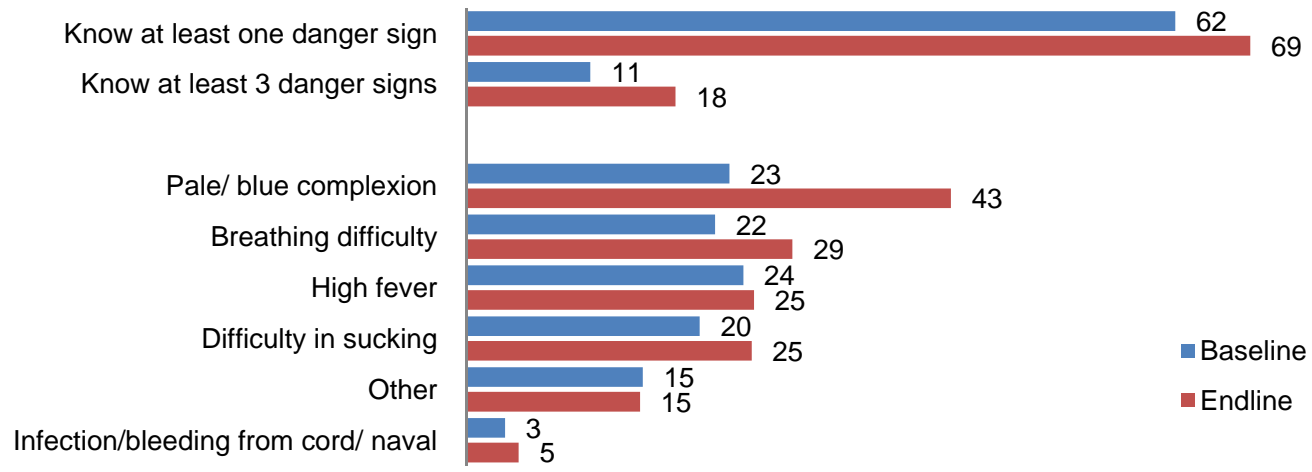

\section{Source of knowledge of danger signs}

The endline survey findings show almost 100 percent increases from baseline findings in husbands' sources of knowledge of danger signs during pregnancy from private hospitals, government hospitals, TV and LHWs (Table 9.3). Interestingly, according to the PAIMAN baseline survey, wives were the major source of information for husbands regarding danger signs during pregnancy (42 percent), followed by friends, neighbors and relatives (23 percent); whereas, according to the endline survey, private hospitals/clinics and wives were the major sources of knowledge for husbands (39 percent and 38 percent respectively). Other important sources included TV (14 percent baseline; 26 percent endline) and LHWs ( 8 percent baseline; 19 percent endline). The source of knowledge for husbands about danger signs during delivery, postpartum and in neonates show a similar pattern to those for pregnancy danger signs (Table 9.3).

Table 9.3: Percentage of husbands, by source of knowledge about danger signs in pregnancy, delivery, postpartum and newborn

\begin{tabular}{|c|c|c|c|c|c|c|c|c|}
\hline \multirow[b]{2}{*}{ Source } & \multicolumn{2}{|c|}{ Pregnancy } & \multicolumn{2}{|c|}{ Delivery } & \multicolumn{2}{|c|}{ Postpartum } & \multicolumn{2}{|c|}{ Newborn } \\
\hline & Baseline & Endline & Baseline & Endline & Baseline & Endline & Baseline & Endline \\
\hline Private hospital/clinic & 16.8 & 39.3 & 16.8 & 39.2 & 13.6 & 37.1 & 17.1 & 39.0 \\
\hline Wife & 41.6 & 36.7 & 35.6 & 35.5 & 36.0 & 36.0 & 34.7 & 30.8 \\
\hline Friends/neighbors/relatives & 22.8 & 29.2 & 22.6 & 29.0 & 21.8 & 26.7 & 23.0 & 29.1 \\
\hline $\mathrm{DHQ} / \mathrm{THQ}$ & 14.8 & 28.9 & 14.3 & 28.6 & 11.8 & 25.3 & 13.3 & 28.0 \\
\hline Television & 13.9 & 25.5 & 13.5 & 24.1 & 13.6 & 21.1 & 14.0 & 24.3 \\
\hline LHW & 8.2 & 18.6 & 7.1 & 16.5 & 6.8 & 15.2 & 7.3 & 16.2 \\
\hline TBA/dai & 11.1 & 11.0 & 12.0 & 10.9 & 11.3 & 10.4 & 10.5 & 10.0 \\
\hline $\mathrm{BHU} / \mathrm{RHC} /$ dispensary/MCH center & 4.7 & 9.3 & 4.2 & 9.1 & 4.1 & 8.5 & 4.5 & 8.8 \\
\hline
\end{tabular}




\section{Community birth preparedness}

Both surveys asked husbands about existing community-run arrangements for transport, blood and financial resources for facility-based safe deliveries. The findings show that the husbands reported hardly any community arrangements in either survey. Though there was a slight increase between baseline and endline of the husbands' reports of these community arrangements, even at endline no arrangement was reported by more than 3 percent of the husbands.

\section{PAIMAN interventions}

The PAIMAN project implemented many interventions to improve the knowledge, behavior and attitudes of husbands toward maternal and neonatal health (details are given in the next chapter). The endline survey asked the husbands if they had been exposed to any of these interventions. Findings show that almost onethird of the husbands reported that they had heard maternal and neonatal health messages through at least one of the PAIMAN interventions.

Figure 9.10: Percentage distribution of husbands of currently married women of reproductive age, by attitudes about antenatal care, skilled birth assistance and postpartum care, according to exposure to PAIMAN interventions

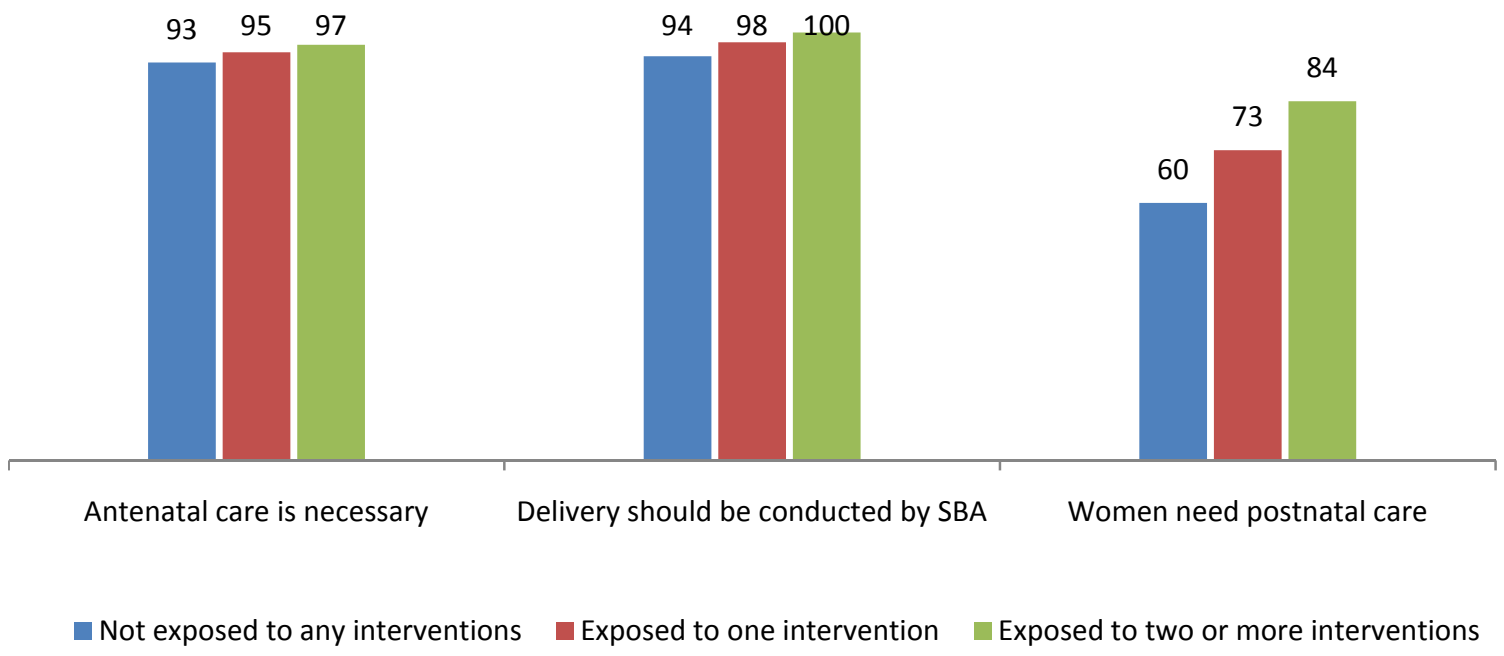

Figure 9.10 shows the attitudes of husbands toward antenatal care, delivery by skilled birth attendants and postpartum care by their exposure to PAIMAN communication and behavior change interventions. For all of the components of $\mathrm{MNCH}$ care, husbands exposed to at least one intervention had a better attitude about critical $\mathrm{MNCH}$ care practices compared to husbands who did not have exposure to any of these interventions. 


\section{Chapter 10. Impact of PAIMAN Interventions}

In Chapter 1, the PAIMAN key interventions are described. In Chapters 5 through 8, the baseline and endline findings are compared regarding different stages of maternal and newborn care. In this chapter, the coverage and impact of PAIMAN interventions are analyzed. At the end of this chapter, the effect of exposure to one or more PAIMAN communication and behavior change interventions is also presented.

It should be noted that in order to enable the project goals to be mapped, key indicators were set to assess the impact of the interventions over the project's duration. The effects of specific interventions -- the effects that could be measured using these key indicators, basically the demand generation/communication and behavior change interventions -- are presented here in light of these key indicators. The key indicators were:

- percentage of births assisted by skilled attendants;

- percentage of women with 3 or more ANC visits;

- $\quad$ percentage of women receiving at least $2 \mathrm{TT}$ injections; and

- percentage of women receiving postpartum care.

Not all of the PAIMAN interventions were measureable by the endline household surveys. This is especially true for the interventions that fall within the "upgrading the healthcare system" interventions, which involved improvements in both facility and human resources. While these upgradation improvements can be measured in terms of so many people trained, so many facilities upgraded and so many people exposed to media messages, their impact on maternal and newborn healthcare is less quantifiable. Available documentation about the number of people reached through media and facility upgradation are presented in Chapter 1 in order to describe the sphere of influence of the PAIMAN project in reducing maternal and neonatal mortality and improving maternal and neonatal healthcare in the 10 original PAIMAN districts. This sphere of influence will inform the debate regarding national applicability of the PAIMAN interventions.

The focus here is on the impact of the communication and behavior change interventions that can be analyzed through the baseline and endline surveys. The impact of the women's support groups, which were formed by lady health workers, is presented extensively because of the impact that this intervention had on spreading $\mathrm{MNCH}$ messages and on changing behavior. The same depth of analysis for ulama involvement, puppet shows, video on wheels or CMWs is not possible because of their limited geographical coverage.

Changes between baseline and endline findings on knowledge and behavior regarding maternal and neonatal health are given here for women who did and did not have exposure to any PAIMAN communication and behavior change intervention to demonstrate the effect of PAIMAN interventions, even to some degree those with limited geographical reach. The focus of some of the PAIMAN mass media interventions was national. To assess the impact of these mass media interventions, they are combined with other PAIMAN local-level interventions in the 10 original PAIMAN districts. 


\section{Methodology}

To measure the effect of the PAIMAN interventions on the knowledge, attitudes and behavior of women regarding maternal and neonatal health, the endline survey results of maternal health indicators are compared with the baseline survey findings. The difference between the two shows the overall increase in each indicator during the PAIMAN project period. We then estimate the effect of individual PAIMAN interventions on maternal health indicators by assuming the indicator at endline is estimated separately for those who were and were not exposed to that intervention. Changes that occurred over the five-year period between baseline and endline that were due to other healthcare system related interventions or to events independent of the project are estimated by the difference between the value of the indicator at endline for women who were not exposed to the intervention and the value of the indicator at baseline. The gross effect of the intervention is estimated by the difference between the value of the indicator for women who were exposed to the intervention and women who were not exposed to the intervention. The net effect of the intervention is estimated by subtracting the endline estimates from the estimates of women who were not exposed to the intervention. (Details of methodology are provided in Appendix 1.)

It is important to note when discussing coverage and impact of interventions that the survey does not allow for controlling or measuring some aspects of the interventions. For example, in the following discussion, when talking about the importance of women's participation in women's group meetings formed by LHWs, there is no way of knowing or accounting for factors that made certain women choose to participate. The factors that make some people choose to participate might make them more likely to benefit from participation; therefore, when assumptions are put forward about the benefit such an intervention might have if only more women were given an opportunity to participate, we cannot, in fact, say with certainty that the same percentage of women in a larger context would benefit because of the self-selection factor that we have not measured.

\section{Coverage of interventions}

\section{Overall coverage}

Figure 10.1 and 10.2 provided information on the coverage of any PAIMAN interventions, including mass media and geographically limited activities, in the ten original PAIMAN districts, though these primarily reflect exposure to communication and behavior change interventions. Overall, 49 percent of the women in rural areas and 60 percent in urban areas were aware of one or more interventions. Knowledge (or awareness) of any PAIMAN intervention means simply that the woman had heard about the intervention, but the question does not address the issue of whether or not she participated in the PAIMAN intervention activity. On the other hand, exposure (or participation or coverage) refers to women who actually participated in an intervention (participation here includes those who attended, watched or listened). Overall, 29 percent of the women were exposed to only one intervention, 8 percent were exposed to two interventions, and 3 percent to more than two interventions. Figure 10.2 shows the percent of women who were exposed to one or more PAIMAN interventions by district. 
Figure 10.1: Percentage distribution of women, by awareness of and exposure to PAIMAN interventions according to number of interventions

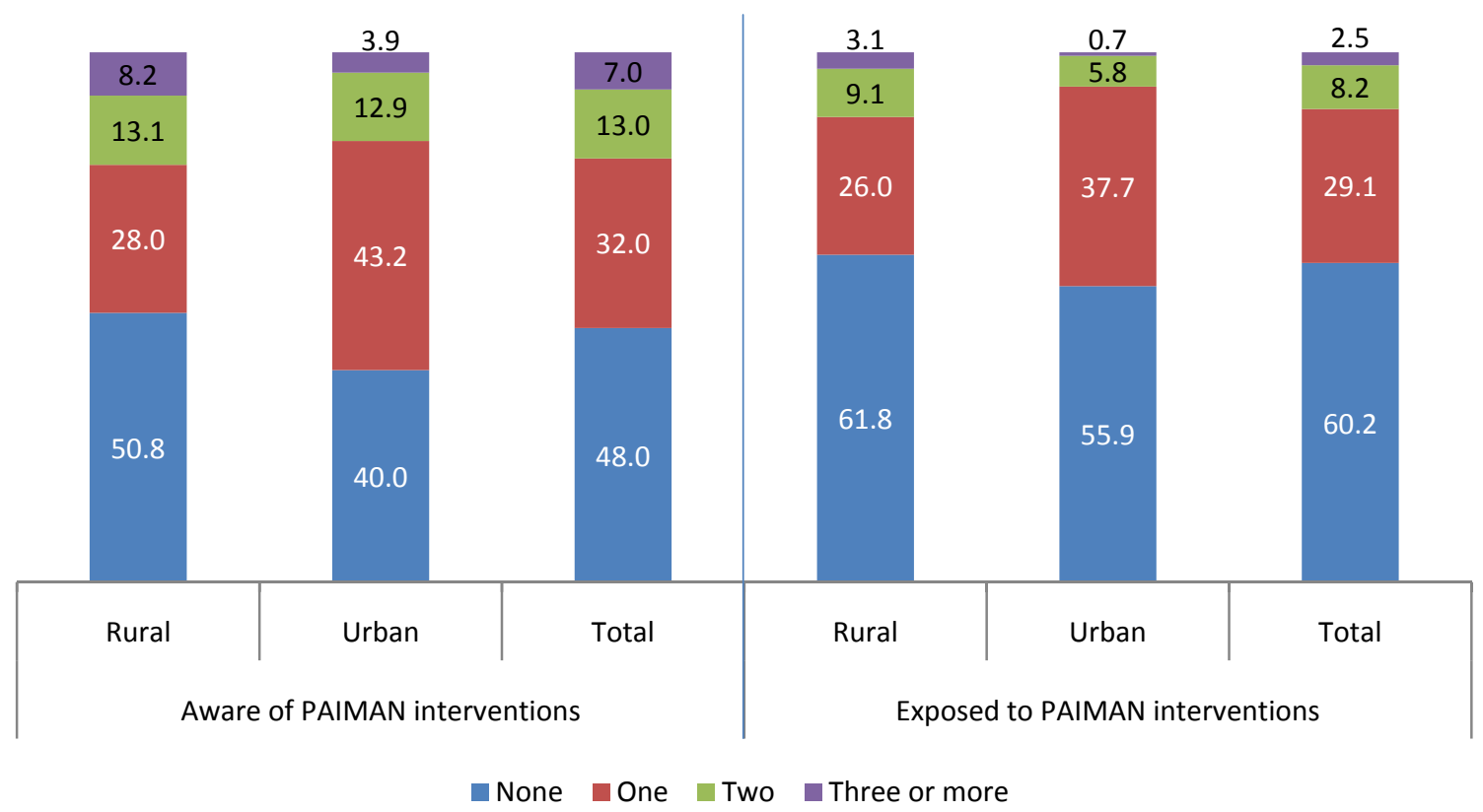

Figure 10.2: Percentage of women who were exposed to at least one PAIMAN intervention, by district

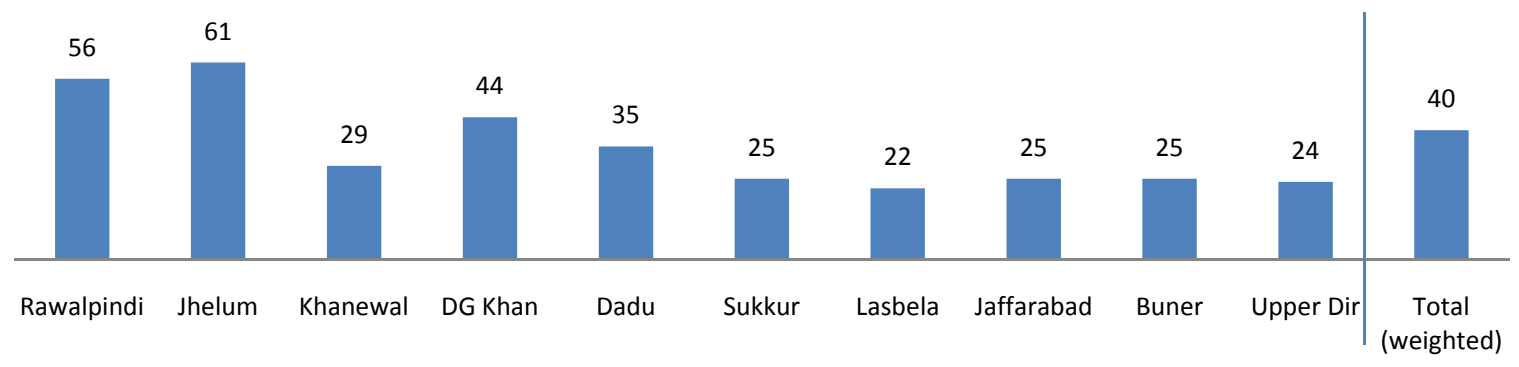

\section{Coverage of specific communication and behavior change interventions}

An overview of exposure to PAIMAN interventions from the endline survey findings is presented here as a preview of the discussion on the impact of communication and behavior change intervention activities (Table 10.1 and Figure 10.3). Only one intervention that came under the "upgrading of health facilities" interventions is included in the table and figure below and that has to do with community midwives. Because this cadre of skilled birth attendants was still quite new to the districts, and to the women interviewed in the endline survey, women were asked only if they were aware of the role that CMWs could play in their communities (services they would provide). The plan is for CMWs to play a significant role in reducing maternal and neonatal mortality as they become fully trained and deployed.

The findings show that, overall, 52 percent of the women in the endline survey knew about PAIMAN communication and behavior change interventions and 40 percent participated in intervention activities 
(weighted average) in their districts. Coverage varied from 62 percent in Jhelum district to 22 percent in Lasbela. The coverage of individual interventions also varied across districts.

Table 10.1: Percentage of women who were exposed to any PAIMAN communication and behavior change intervention, by district and specific intervention

\begin{tabular}{lrrrrrrrr} 
District & TV/radio & $\begin{array}{r}\text { WSG } \\
\text { meeting }\end{array}$ & $\begin{array}{r}\text { NGO/CBO } \\
\text { activity }\end{array}$ & $\begin{array}{r}\text { Aware of } \\
\text { role of } \\
\text { CMWs* }\end{array}$ & $\begin{array}{r}\text { Ulama } \\
\text { inter- } \\
\text { vention }\end{array}$ & $\begin{array}{r}\text { Video on } \\
\text { wheels }\end{array}$ & $\begin{array}{r}\text { Puppet } \\
\text { (drama/film) }\end{array}$ & $\begin{array}{r}\text { Any inter- } \\
\text { vention }\end{array}$ \\
Rawalpindi & 45.7 & 11.3 & 6.6 & 5.2 & 6.7 & 0.0 & 0.4 & 56.6 \\
\hline Jhelum & 42.3 & 30.7 & 3.6 & 6.1 & 3.3 & 0.0 & 0.7 & 61.8 \\
\hline Khanewal & 11.0 & 16.6 & 7.2 & 5.4 & 0.8 & 0.4 & 0.6 & 29.9 \\
\hline DG Khan & 30.8 & 12.3 & 6.2 & 7.5 & 1.8 & 2.3 & 1.6 & 44.4 \\
\hline Dadu & 24.6 & 8.2 & 3.7 & 3.5 & na & 6.3 & 0.7 & 35.5 \\
\hline Sukkur & 11.0 & 8.3 & 5.5 & 4.5 & na & 2.8 & 2.1 & 25.0 \\
\hline Lasbela & 11.3 & 10.7 & 2.3 & 3.0 & na & na & na & 22.2 \\
\hline Jaffarabad & 20.0 & 5.7 & 2.7 & 0.7 & na & na & na & 24.9 \\
\hline Buner & 12.1 & 3.6 & 15.6 & 0.1 & 0.5 & na & na & 24.9 \\
\hline Upper Dir & 7.8 & 9.1 & 1.1 & 1.3 & 7.9 & na & na & 23.9
\end{tabular}

* Women were asked about their awareness of the services CMWs could provide.

na $=$ not applicable: these specific interventions were not held in these districts.

Figure 10.3 shows that dramas and advertisements on TV/radio were the most known intervention (26 percent), followed by WSG meetings formed by LHWs (12 percent) and NGO/CBO engagement in $\mathrm{MNH}$ educational activities (6 percent). The rest of the individual interventions reached 5 percent or less of the women in the communities. Table 10.1 shows the district-wise coverage of PAIMAN individual interventions: it can be seen that MNCH dramas/ads on TV/radio accounted for the highest exposure in Rawalpindi (46 percent), followed by 42 percent in Jhelum and 31 percent in DG Khan. Exposure to PAIMAN interventions through WSG meetings was highest in Jhelum (31 percent), followed by 17 percent in Khanewal and 12 percent in DG Khan. Ulama intervention was implemented in 6 districts of Punjab and Khyber Pakhtunkhwa with coverage of 8 percent in Upper Dir, followed by 7 percent in Rawalpindi and 3 percent in Jhelum. The other PAIMAN interventions show very little exposure by district.

Figure 10.3: Percentage of women, by exposure to specific interventions

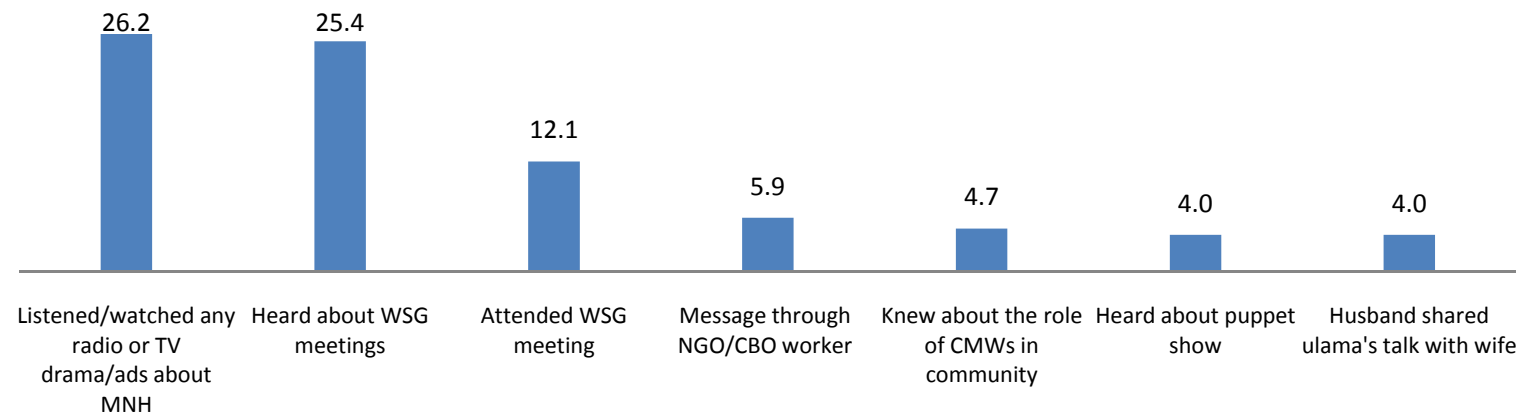

Note: For puppet shows and ulama activities, only women in Punjab and Sindh were asked about these geographically-limited interventions. Other interventions were carried out in all districts, though, even then, their reach was also limited geographically within the districts. 


\section{A. Support groups for women formed by trained lady health workers}

If women reported in the endline survey that they had attended a WSG meeting, they were asked what messages they had received about maternal and neonatal healthcare. The findings reveal that 25 percent of the women in the endline survey had heard of the women's support group meetings; of those who had heard of the WSG meetings, 12 percent had attended a meeting (Figure 10.3). In areas that had an LHW, 18 percent of the women reported attending a women's support group meeting.

Figure 10.4 shows that those who had attended the WSG meetings could recall a number of maternal health messages, especially for nutrition and adequate food (61 percent each), followed by adequate rest (54 percent). However, recall for some important maternal health messages was quite low, particularly tetanus toxoid injections, danger signs during pregnancy, and iron supplements.

Figure 10.4: Percentage of women who had attended WSG meetings, by recall of specific message received about maternal health

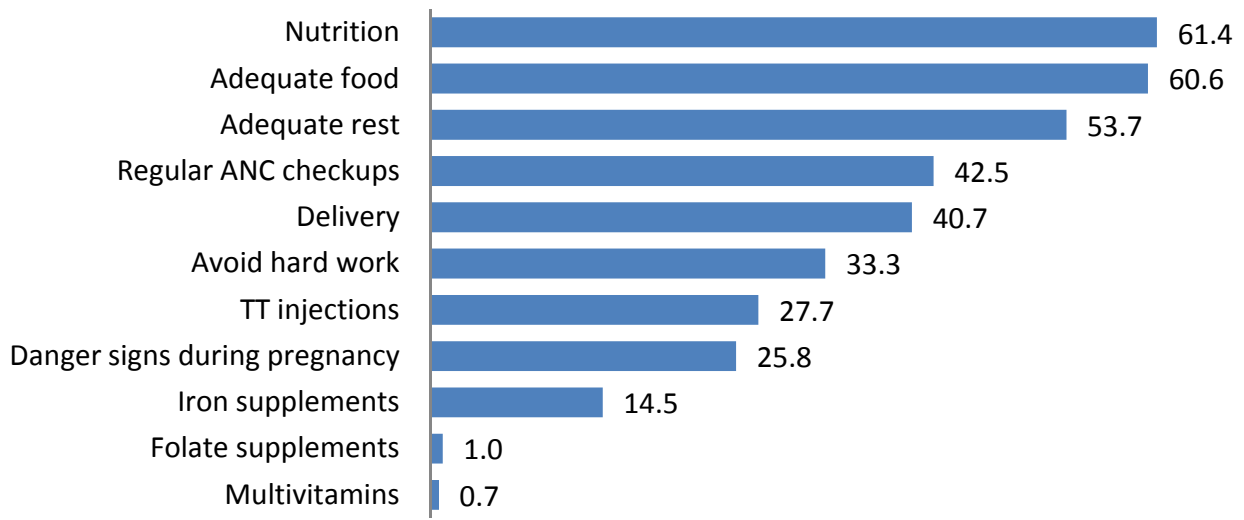

As can be seen in Figure 10.5, recall for messages regarding neonatal health was highest for keeping the newborn clean ( 60 percent), followed by feeding the newborn colostrum ( 42 percent), but was low for other important newborn care messages.

Figure 10.5: Percentage of women who attended WSG meetings, by recall of specific messages given on newborn care

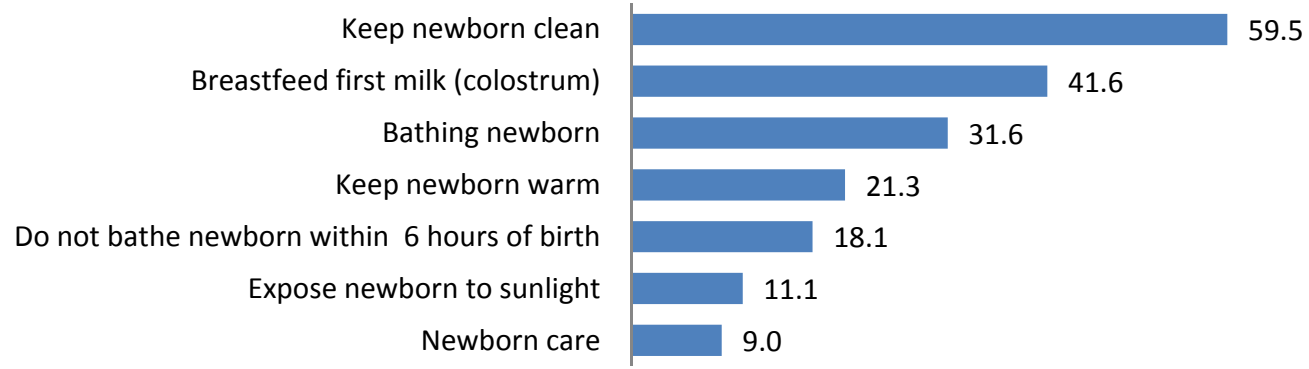

\section{B. Media interventions (radio/TV)}

Of the currently married women of reproductive age interviewed for the endline survey, 26 percent acknowledged that they had watched TV dramas and advertisements that involved maternal and newborn health messages. As shown in Figure 10.6, for those who had watched such dramas or advertisements, the 
most-remembered messages were about adequate food (59 percent) and nutrition (57 percent) during pregnancy. Except for adequate rest (52 percent), less than half of the women reported learning about other important maternal health messages.

Figure 10.6: Percentage of women who watched TV drama/advertisements about maternal health, by recall of specific messages

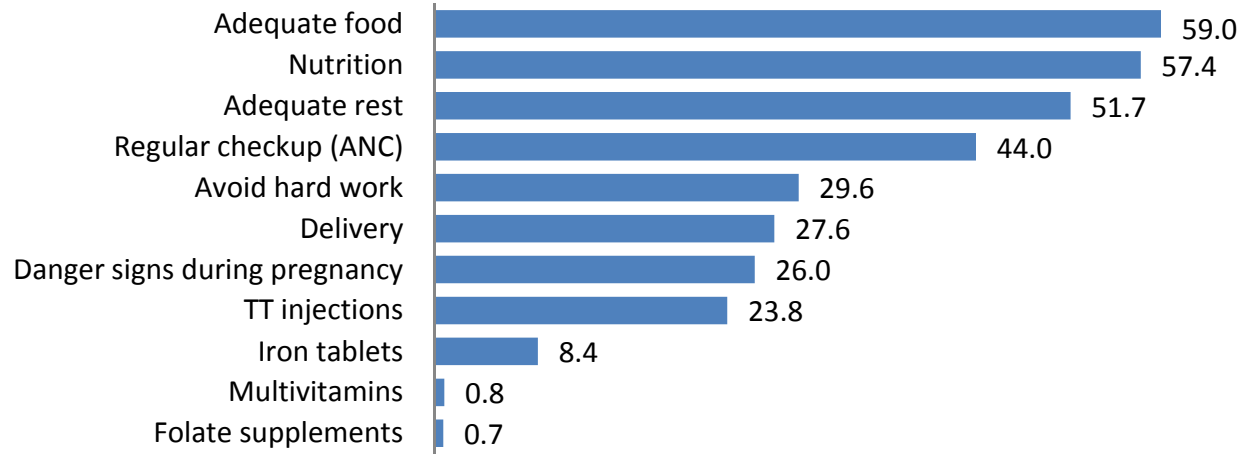

Messages regarding newborn care generally were recalled by 72 percent of the women, while keeping the newborn clean was the specific message most cited (57 percent) (Figure 10.7). Other newborn care messages were recalled by smaller percentages of women.

Figure 10.7: Percentage of women who watched TV drama/advertisements about newborn care, by recall of specific messages received

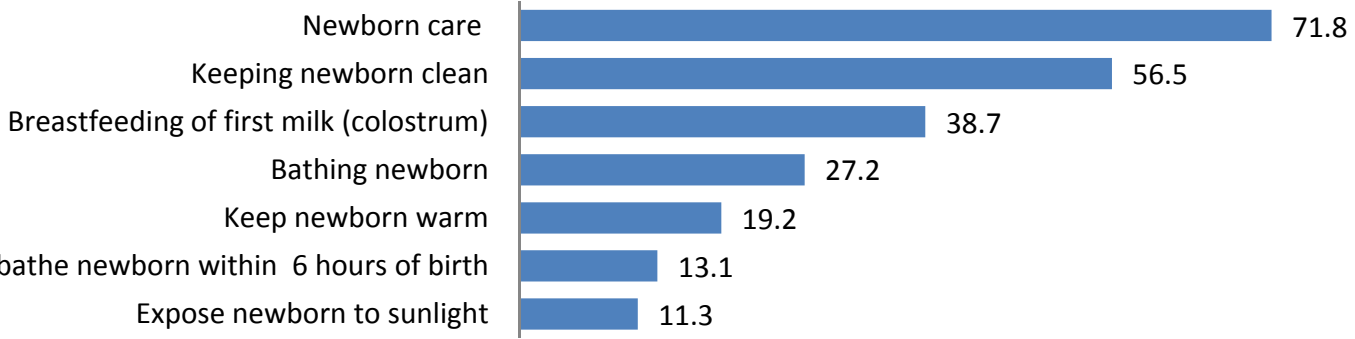

It is not possible to use the endline survey results to quantify the full extent of the impact of this intervention on behavioral change. However, because of the extensive coverage of television and radio dramas, advertisements and other programming and the training of journalists on $\mathrm{MNCH}$ reporting, it is believed that this intervention will have a long-term effect on awareness, knowledge and behavior change regarding $\mathrm{MNCH}$, and is one more tool to use in spreading the messages about behaviors that will reduce maternal and neonatal mortality.

\section{Video on wheels}

The dramas and films shown through the video-on-wheels intervention were seen by 2.7 percent of the women interviewed in the endline survey (Table 10.1), though the intervention was only carried out in a limited number of remote districts in Sindh and Punjab provinces that had little other media coverage. This is an intervention whose impact is difficult to measure. Yet, as with other geographically limited interventions, its impact might well be part of a cumulative effect of the scope of coverage of PAIMAN interventions, raising awareness and knowledge of $\mathrm{MNCH}$ issues that will gradually change behaviors. 


\section{Puppet shows}

In the endline survey, women from Punjab and Sindh were asked if any puppet show was organized in their community. If the reply was in the affirmative, subsequent questions related to their attendance at such a show and their recall of messages conveyed through this intervention.

The findings show that about 4 percent of the respondents in the districts in Punjab and Sindh provinces reported having heard of a puppet show in their community (Figure 10.3). Of the respondents who had heard of a puppet show, 27 percent had also watched a puppet show. A majority of these women remembered that the puppet show emphasized that a woman should take adequate food during pregnancy (74 percent) and, similarly, take care about their nutrition during pregnancy (66 percent), and also take adequate rest. Fewer, about one-third, recalled messages about danger signs during pregnancy and ANC checkups. With regard to care of newborns, a majority of the women recalled that the puppet show focused on "taking care of the baby" (81 percent), keeping the newborn clean, and the importance of breastfeeding.

While the overall response of women from Sindh and Punjab provinces in the endline survey indicate very limited exposure to the puppetry intervention (Table 10.1), that is not unexpected, given its limited geographical scope. It is hoped that this intervention can be explored further because of the potential this kind of indigenous activity has for reaching those in areas that are not accessible by other means. The numbers of women reached within the specific targeted areas (see Chapter 1) speaks to the potential of this intervention to make a difference, as does the recall of women who did see a puppet show.

\section{E. Ulama intervention}

When the endline survey was being carried out, the currently married women of reproductive age were asked whether their husbands had shared the information received from ulamas during Friday gatherings (or from other announcements). In the ten original PAIMAN districts, only a small percentage of husbands (4 percent) had shared the information given by the ulama with their wives (Figure 10.3). However, of the 11 districts in which the ulama intervention was carried out, 6 were in the 10 original PAIMAN districts where the endline was conducted, and in no district was the intervention district-wide. Therefore, the lower response by women in the endline survey is not surprising. Further, when the women were also asked if they thought that $\mathrm{MNCH}$ messages delivered by ulama could be instrumental in changing the behavior of people regarding maternal and child healthcare, a majority (67 percent) of the women, whose husbands had shared this information with them, were of the opinion that the talks of the ulama were helpful in changing attitudes of people toward maternal and child healthcare.

\section{F. Involvement of NGOs/CBOs}

The work of the NGOs/CBOs who received grants from PAIMAN to carry out specific project-related activities was important in reaching populations that were not covered through other interventions. Table 10.1 and Figure 10.3 show that 6 percent of all women in the endline survey reported having been exposed to an activity conducted by one of the PAIMAN NGO/CBO grantees. Exposure ranged, by district, from a low of 1 percent in Upper Dir to a high of 16 percent in Buner. Again, the exact impact of the NGO/CBO activities are hard to separate out; however, they are included in later discussions about exposure to "any" PAIMAN intervention. As with other interventions of a limited scale, it is the full panel of interventions that allowed for greater project impact on behavior change, and change that might continue to grow over time after multiple types of exposure to $\mathrm{MNCH}$ messages. 


\section{Coverage from other interventions}

\section{A. Facility upgradation}

Upgrading of public health facilities was seen as one step toward encouraging women to use these facilities, particularly as an alternative to home deliveries. However, as shown in Chapter 6, though home deliveries declined from 62 percent to 50 percent over the course of the project, the percentage of deliveries in public health facilities did not increase. Instead, the percentage of deliveries in private facilities increased from 22 percent to 35 percent.

Although one DHQ was upgraded in each district headquarters and one THQ was upgraded in one selected tehsil headquarters of each PAIMAN district in order to provide $24 / 7$ services, it was assumed that all of the women living in these districts and selected tehsils were benefitting from these upgraded facilities. This was assumed because, in theory, all of women living in these districts and tehsils could reach these upgraded health facilities for health services. Therefore, it was not possible to observe the impact of these upgraded DHQS/THQs on health indicators through the household surveys. The findings show that the overall proportion of women utilizing the services from the public sector declined in the endline compared to the baseline survey. However, the impact of upgraded RHCs (one RHC was upgraded in each of the PAIMAN districts) was observed by looking into the change in the public-sector institutional deliveries performed among the women living in communities within a radius of $15 \mathrm{kms}$. of these facilities and comparing this with the change in institutional deliveries performed among the women living in communities within a radius of $15 \mathrm{kms}$. of non-upgraded RHCs.

Table 10.2 and Figures 10.8, 10.9 and 10.10 illustrate the estimates observed in the baseline and endline survey findings on the normal, assisted vaginal deliveries and Caesarean section deliveries within $15 \mathrm{kms}$ of the upgraded and non-upgraded RHCs, as well as overall, in the public-sector health facilities. It is interesting to note, when comparing baseline findings in Figures 10.9 and 10.10, that the RHCs that were chosen for upgradation were facilities that were already functioning better than facilities that were not chosen for upgradation (as per baseline findings). Facilities that were under-performing were facilities that, among other problems, may not have had adequate staff available to provide coverage and services $24 / 7$. PAIMAN had no control over hiring and staffing and, therefore, needed to choose RHCs that were better staffed by people who they could then train to manage the upgraded facilities and services. Overall, it can be observed that there is a decline in the normal deliveries performed in the endline survey compared to the baseline survey in the public-sector facilities (16 percent vs. 15 percent). This decline in institutional deliveries is observed in both upgraded and non-upgraded public-sector facilities. However, for women living within $15 \mathrm{kms}$. of the upgraded RHCs, there was a noticeable increase in Caesarean section deliveries between baseline and endline ( $<1$ percent to 4 percent).

The PAIMAN findings are clear that an increase in facility-based deliveries (as well as in other facility-based pregnancy and postpartum care) is underway. It is important to fully understand what factors are behind women's choices regarding public vs. private facility care, and the role that upgradation will play in enhancing the use of public-sector facilities. 
Table 10.2: Percentage of different types of deliveries conducted in within $15 \mathrm{kms}$. of upgraded and nonupgraded RHCs

\begin{tabular}{lrr} 
Distance and type of delivery & Baseline & Endline \\
Within $\mathbf{1 5}$ kms. of upgraded RHCs & & 12.3 \\
\hline Normal vaginal delivery & 15.0 & 3.3 \\
\hline Assisted vaginal delivery & 3.3 & 4.1 \\
\hline Caesarean section & 0.2 & 19.7 \\
Total & 18.5 & 6.6 \\
\hline Within 15 kms. of non-upgraded RHCs & & 0.2 \\
\hline Normal vaginal delivery & 6.8 & 2.4 \\
\hline Assisted vaginal delivery & 1.3 & 9.2
\end{tabular}

Figure 10.8: Percentage of deliveries conducted in public-sector health facilities, by type of delivery

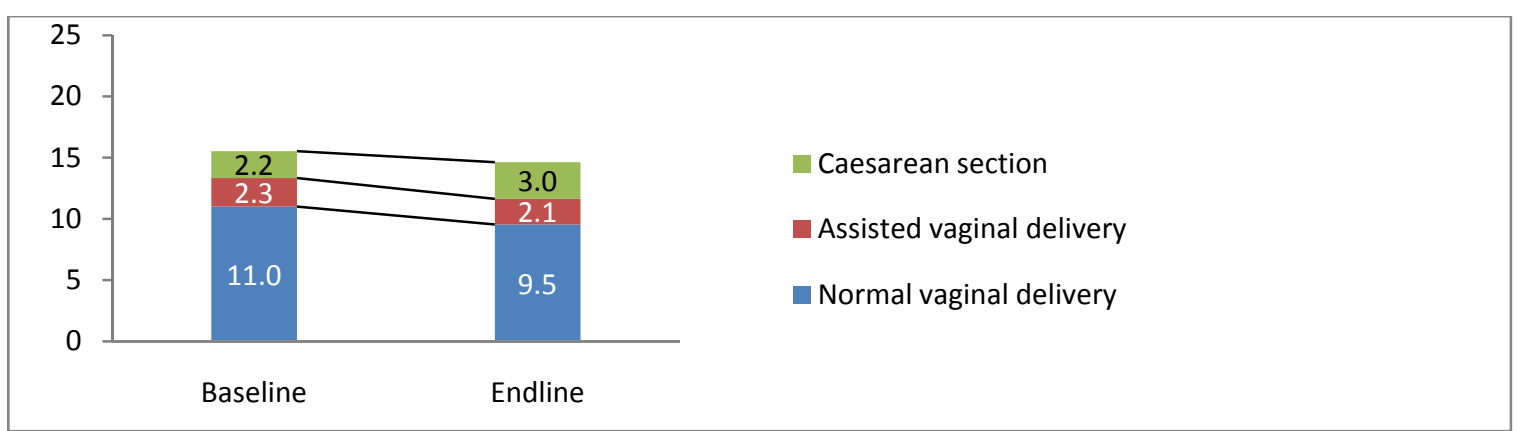

Figure 10.9: Percentage of deliveries conducted in public sector health facilities among women living within $15 \mathrm{kms}$. of upgraded RHCs

$\left.\begin{array}{rr}25 \\ 20 \\ 15 \\ 10 \\ 5 \\ 5 \\ 0\end{array}\right] \begin{array}{rr}0.1 \\ 3.3 \\ 15.0\end{array}$

Figure 10.10: Percentage of deliveries conducted in public health sector facilities among women living within $15 \mathrm{kms}$. of non-upgraded RHCs

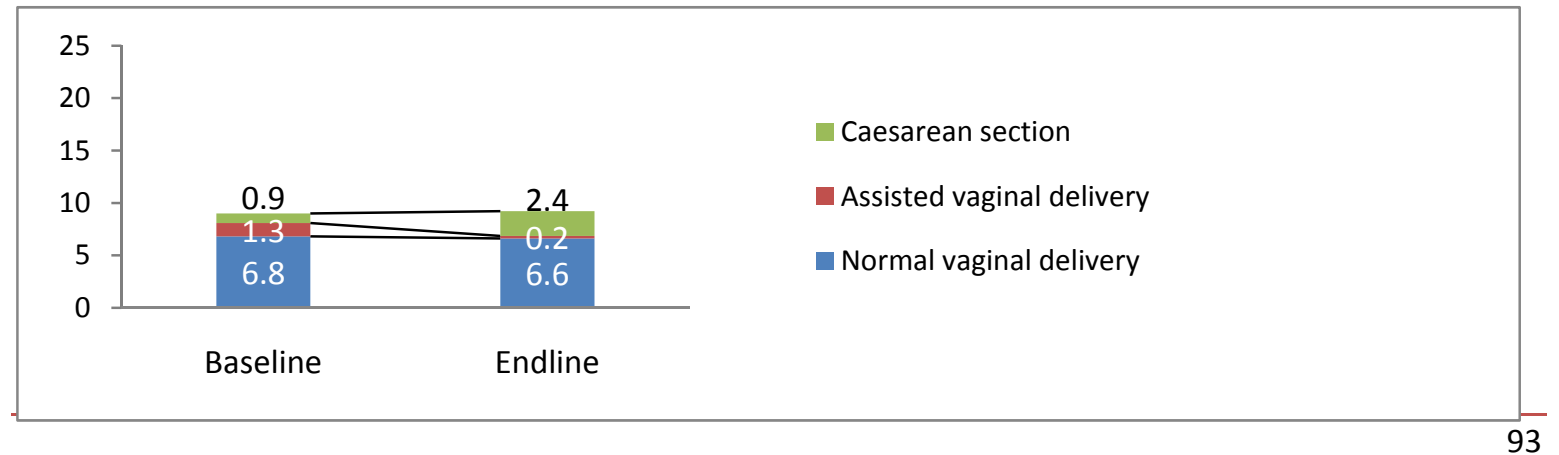




\section{B. Training of community midwives}

In the endline survey, women were asked if a community midwife was available in their locality and, if yes, if the women aware of the kinds of services the CMW was supposed to provide. Efforts at the time of the endline survey were still being made to train and deploy these health workers; therefore, it is difficult to assess the short or long-term impact of this program.

As noted (Table 10.1 and Figure 10.3), nearly 5 percent of all of the women in the endline survey were aware of a CMW in their community. Figure 10.11 shows that 58 percent of the women who were aware of the presence of a CMW reported that CMWs provide assistance during delivery, and around half said that CMWs provide antenatal care and advice on maternal health. Not many women were aware that CMWs provide postpartum care and newborn checkups, though nearly a quarter knew that CMWs provide family planning information.

Figure 10.11: Percentage of women who were of aware of a CMW in their community, by knowledge of the tasks a CMW can perform

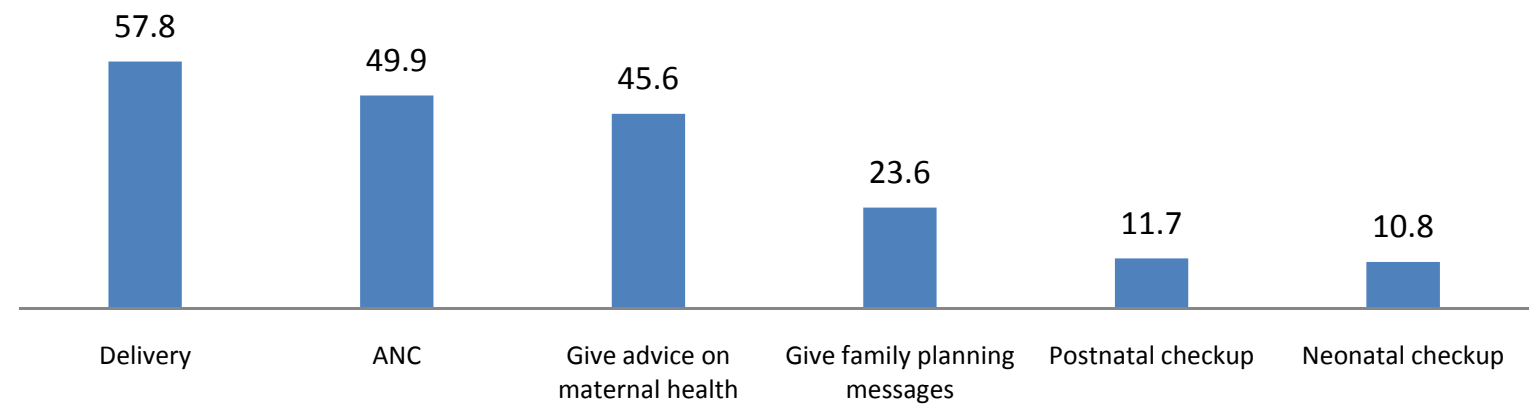

\section{Training of traditional birth attendants}

Traditional birth attendants are important in Pakistan. Between baseline and endline surveys, as shown in Chapter 6 , the number of home births that were attended by traditional birth attendants went up slightly, from 75 to 77 percent. The training of TBAs in clean delivery practices may well have played an important role in the improvement in clean delivery practices of TBAs reported by the women in the endline survey, as shown in Figure 10.12 and Table 10.3.

Figure 10.12: Percentage of women, by clean delivery practices used by TBAs during last home delivery

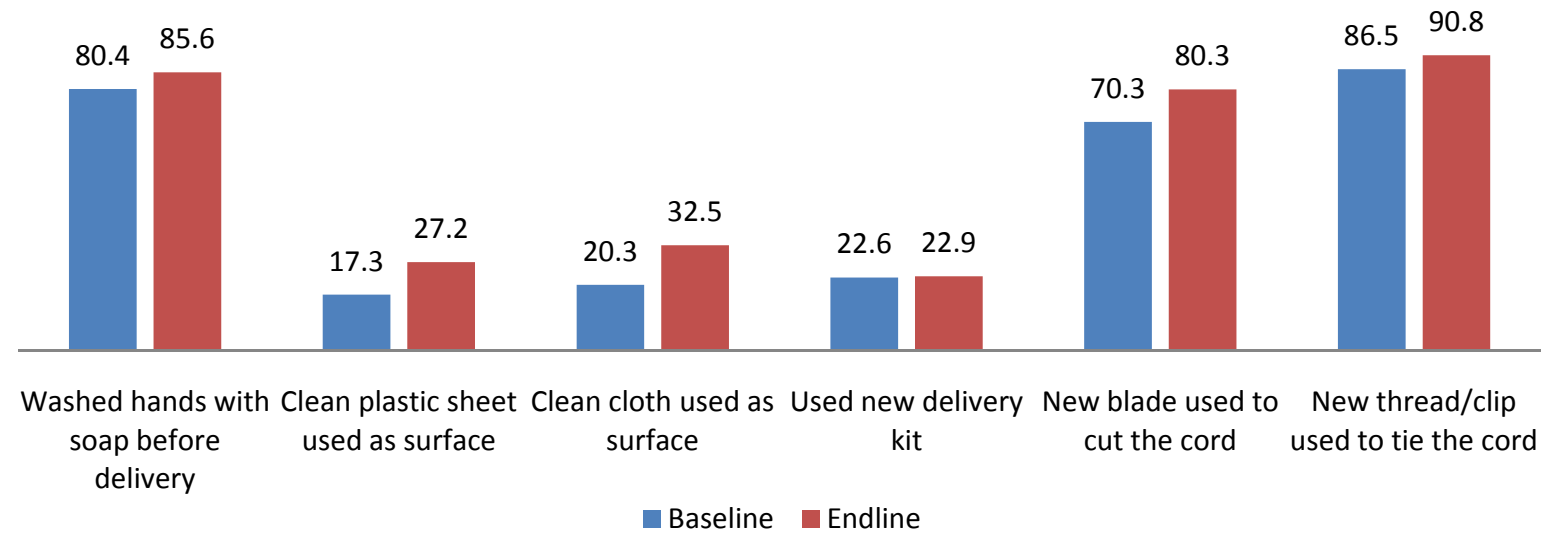


As can be seen in Table 10.3, all clean delivery practices reported by the women as having been used by the traditional birth attendant at the woman's last home delivery showed significant improvement between baseline and endline, except for the use of a new clean delivery kit. It should be noted that these improved clean delivery practices are consistent with the kind of supplies provided in a clean delivery kit and the training that is provided in the proper use of a CDK.

Table 10.3: Percentage of women, by clean delivery practices used by TBAs during last home delivery, with 95 percent confidence intervals and $p$-values, baseline and endline

\begin{tabular}{|c|c|c|c|}
\hline \multirow[b]{2}{*}{ Clean delivery practices and survey } & \multirow[b]{2}{*}{ Indicator } & \multirow{2}{*}{$\begin{array}{c}95 \text { percent confidence interval } \\
\text { Lower -- Upper }\end{array}$} & \multirow[b]{2}{*}{ p-value } \\
\hline & & & \\
\hline \multicolumn{4}{|c|}{ Washed hands with soap before delivery } \\
\hline Baseline & 80.4 & $78.7--82.1$ & \multirow{2}{*}{$p<.05$} \\
\hline Endline & 85.6 & $84.1--87.0$ & \\
\hline \multicolumn{4}{|l|}{ Clean plastic sheet used as surface } \\
\hline Baseline & 17.3 & $15.7--18.9$ & \multirow{2}{*}{$\mathrm{p}<.05$} \\
\hline Endline & 27.2 & $25.4--29.1$ & \\
\hline \multicolumn{4}{|l|}{ Clean cloth used as surface } \\
\hline Baseline & 20.3 & $18.6--22.1$ & \multirow{2}{*}{$p<.05$} \\
\hline Endline & 32.5 & $30.5--34.4$ & \\
\hline \multicolumn{4}{|l|}{ Used new delivery kit } \\
\hline Baseline & 22.5 & $20.8--24.3$ & \multirow{2}{*}{$p>.05$} \\
\hline Endline & 22.9 & $21.2--24.6$ & \\
\hline \multicolumn{4}{|l|}{ New blade used to cut cord } \\
\hline Baseline & 70.3 & $68.4--72.3$ & \multirow{2}{*}{$\mathrm{p}<.05$} \\
\hline Endline & 80.3 & $78.7--82.0$ & \\
\hline \multicolumn{4}{|l|}{ New thread/clip used to tie cord } \\
\hline Baseline & 86.5 & $85.0--88.0$ & \multirow{2}{*}{$p<.05$} \\
\hline Endline & 90.8 & $89.6--92.0$ & \\
\hline
\end{tabular}

\section{Training of healthcare providers and managers}

The major strategy of investing in managers and providers resulted in training and supervision of several thousand healthcare providers and managers in $\mathrm{MNCH}$ services and in health system support areas, such as district planning and district health information systems (DHIS). While it is almost impossible to measure the exact impact of these capacity-building interventions on the $\mathrm{MNCH}$ service indicators based on the available household data, the training of this large cadre of healthcare providers certainly impacted the PAIMAN project areas, influencing changes between baseline and endline, as substantiated by changes noted in the indicators for women who were not exposed to BCC interventions. 


\section{Impact of PAIMAN communication and behavior change interventions}

\section{Impact of women's support groups}

\section{Impact of WSGs on women's knowledge of danger signs}

The impact of WSG meetings on women's knowledge of at least three danger signs during pregnancy, delivery and postpartum is statistically significant (Table 10.4). Women who attended the WSG meetings had significantly greater awareness of at least 3 danger signs during pregnancy, delivery and postpartum period compared to women who did not attend the WSG meeting in rural areas.

Table 10.4: Percentage of women in rural areas who had knowledge of at least 3 danger signs during pregnancy, delivery and postpartum period, with 95 percent confidence intervals and p-values, by exposure to WSG meeting

\begin{tabular}{|c|c|c|c|c|}
\hline \multirow[b]{2}{*}{ Specified period } & \multirow{2}{*}{$\begin{array}{l}\text { Attendance at WSG } \\
\text { meeting }\end{array}$} & \multirow{2}{*}{$\begin{array}{l}\text { Indicator } \\
\text { estimate }\end{array}$} & $95 \% \mathrm{Cl}$ & \multirow[b]{2}{*}{ p-value } \\
\hline & & & Lower -- Upper & \\
\hline \multirow{2}{*}{ Pregnancy } & Attended & 44.3 & $41.6--47.1$ & \multirow{2}{*}{$p<.05$} \\
\hline & Did not attend & 36.1 & $34.7--37.4$ & \\
\hline \multirow{2}{*}{ Delivery } & Attended & 26.3 & $23.9--28.8$ & \multirow{2}{*}{$\mathrm{p}<.05$} \\
\hline & Did not attend & 22.7 & $21.5-23.8$ & \\
\hline \multirow{2}{*}{ Postpartum } & Attended & 18.2 & $16.1--20.4$ & \multirow{2}{*}{$p<.05$} \\
\hline & Did not attend & 12.8 & $11.9--13.7$ & \\
\hline
\end{tabular}

Impact of WSGs on health-seeking behavior as measured by four maternal health indicators

The findings show that the women's support group meetings formed by the LHWs in their areas of the 10 PAIMAN districts had a definite impact on women's health-seeking behavior. The basis for the calculations of impact is provided in Appendix 1.

The following discussion shows the impact of women's support group meetings on four key maternal indicators. Information for urban and rural areas is provided separately because LHWs are employed in relatively developed areas within rural domains and relatively underdeveloped areas in urban domains, so separating residence provides a better picture of the impact of women's support groups on maternal health indicators. Areas with LHWs are expected to start at a higher base on all indicators and to perform better because of the outreach services and contacts provided by this cadre of healthcare providers. This is borne out by the findings presented below.

\section{i) Impact of WSGs on antenatal care visits}

PAIMAN interventions were based on the assumption that the maternal health care services that a mother receives during her pregnancy and at the time of delivery are important for the wellbeing of the mother and her newborn. Antenatal care can be more effective in avoiding adverse pregnancy outcomes when it is sought early in the pregnancy and is continued through to delivery. The LHWs in the support group meetings provided information about benefits, timing and frequency of ANC checkups. It was assumed that women who attended WSG meetings would be more likely to utilize ANC checkups than women who did not attend these meetings. 
The percentage of women who received at least three ANC checkups in rural LHW-covered areas was much higher as compared to women in non-LHW rural areas. Figure 10.13 shows that in rural non-LHW areas, the proportion of those who received at least three ANC checkups increased from 18.5 percent at baseline to 24.7 percent at endline. In rural LHW-covered areas, the proportion of women who received at least three ANC checkups increased from 33.7 to 45.5 percent between baseline and endline. In other words, for those having at least three ANC checkups, an overall increase of 6.2 percentage points (24.7-18.5) was observed in non-LHW areas, while an increase of 10.8 percentage points $(44.5-33.7)$ was observed in LHW areas.

Survey findings show that women who had attended WSG meetings were more likely to have at least three ANC checkups in rural areas than those who did not attend WSG meetings ( 57.6 vs. 41.2 ); this was also true in urban areas (65.2 vs. 60.1).

The gross effect of WSG meetings in rural areas could be estimated as an increase of 16.4 percentage points $(57.6-41.2)$. However, the net effect of participation in WSG meetings was about 3.3 percentage points (44.5 - 41.2). Thus, the increase of 10.8 percentage points (44.5 - 33.7) in ANC coverage among those living in rural LHW-covered areas is made up of 3.3 percentage points due to WSG meetings and 7.5 percentage points increase due to factors other than WSG meetings (Figure 10.17).

Figure 10.13: Percentage of women who had at least 3 ANC checkups, by residence, presence of LHW and WSG attendance
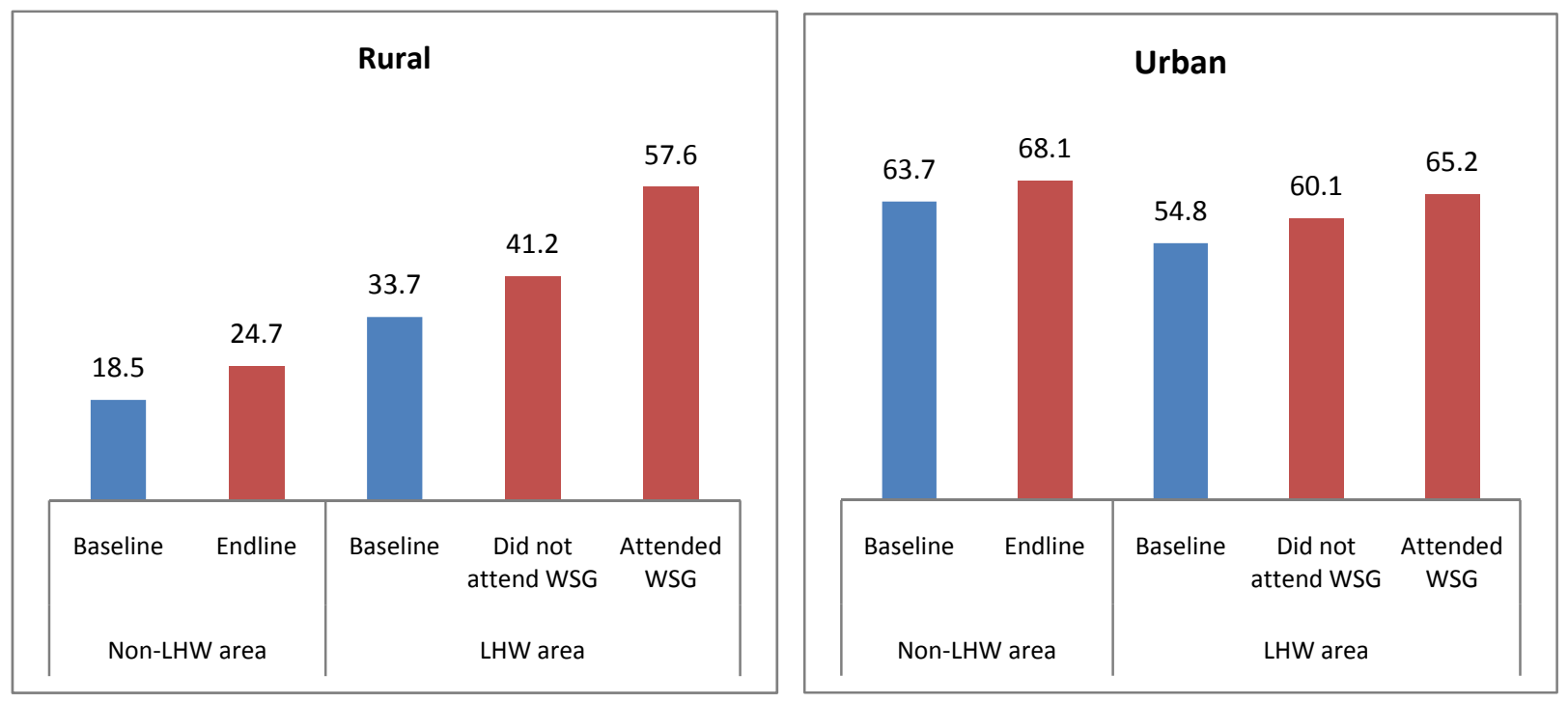

The differences in receiving at least three ANC checkups are presented in Table 10.5, with tests of significance. The analysis in Table 10.5 shows that the improvement in receiving three ANC checkups is statistically significant when comparing the baseline and endline survey findings both in rural and urban areas of ten PAIMAN districts. It is observed that the positive impact of WSG meetings is highly significant for women who attended them compared to the women who did not attend them in LHW-covered rural areas. Urban women in non-LHW areas are significantly more likely to receive at least three ANC checkups compared to the LHW-covered areas. In urban areas, there are other effective modes of communication available to mothers about antenatal care; however, women's support groups are a very important tool to use in communicating messages about antenatal care in rural communities. 
Table 10.5: Percentage of women who had at least 3 ANC checkups, with 95 percent confidence intervals and $p$-values, by residence, for survey, presence of LHW and WSG attendance

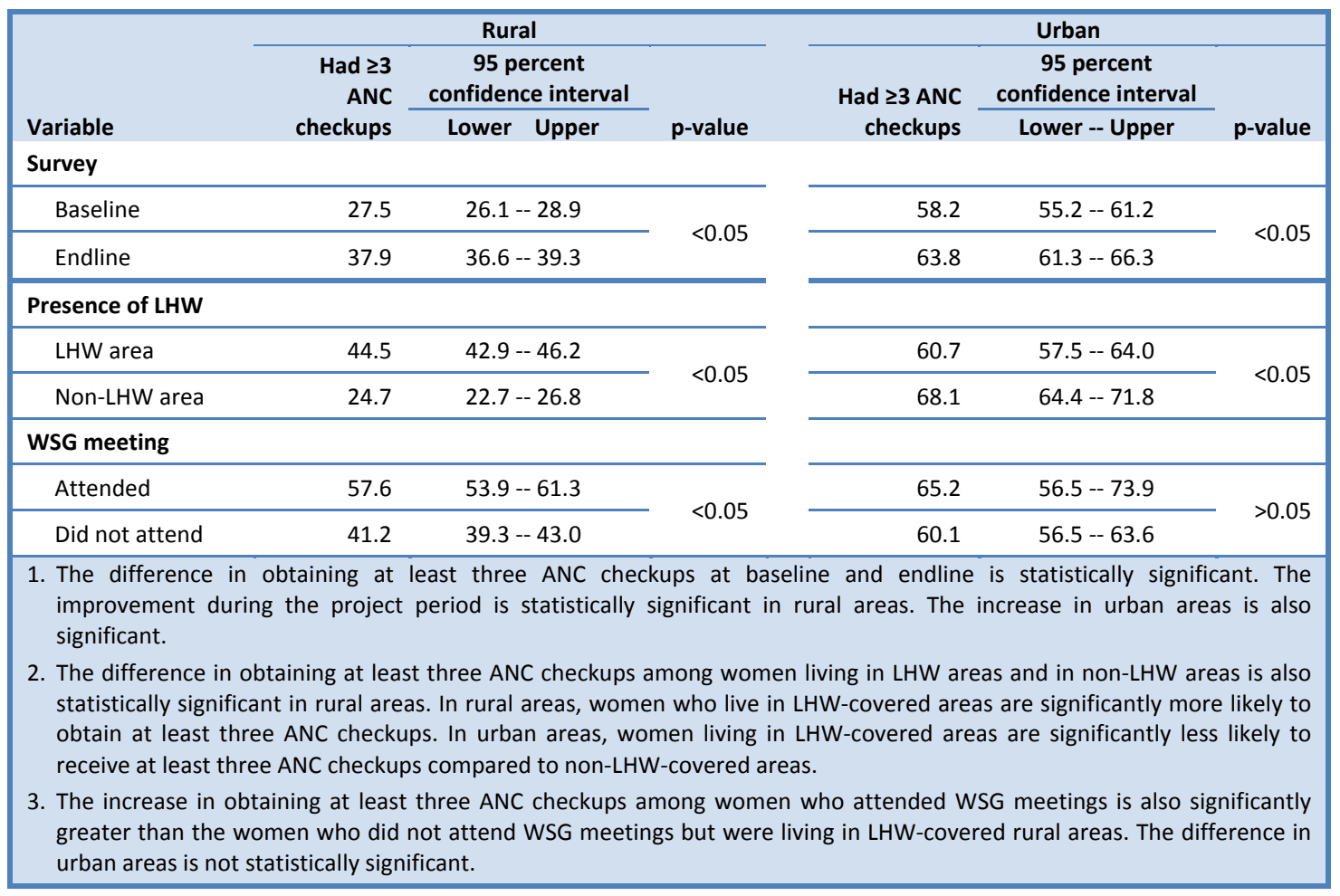

\section{ii) Impact of WSGs on tetanus toxoid injections}

There was a clear improvement in pregnant women obtaining TT injections in the PAIMAN districts. Figure 10.14 shows that in non-LHW areas, 35.2 percent of women received at least two TT injections during their last pregnancy in the endline survey compared to 29.8 percent in the baseline survey. In LHW areas, 61.2 percent of women received at least two TT injections during their last pregnancy in the endline survey, an increase of 8.4 percentage points from the baseline of 52.8 percent. Women who had attended WSG meetings were more likely to have TT injections in both rural (77.7 vs. 57.0 percent) and urban areas (90.7 vs. 67.6 percent).

The gross effect of WSG meetings on TT coverage in rural areas was 20.7 points $(77.7-57.0)$. An improvement of 5.4 percentage points was observed in non-LHW areas $(35.2-29.8)$ compared to 8.4 percentage points $(61.2-52.8)$ in LHW areas. The increase of 8.4 percentage points in at least two TT injections in LHW areas is made up of about 4.2 percentage points due to participation in WSG meetings and 4.2 percentage points due to factors other than WSG meetings (Figure 10.17). 
Figure 10.14: Percentage of women who received at least 2 TT injections, by residence, presence of LHW and WSG attendance
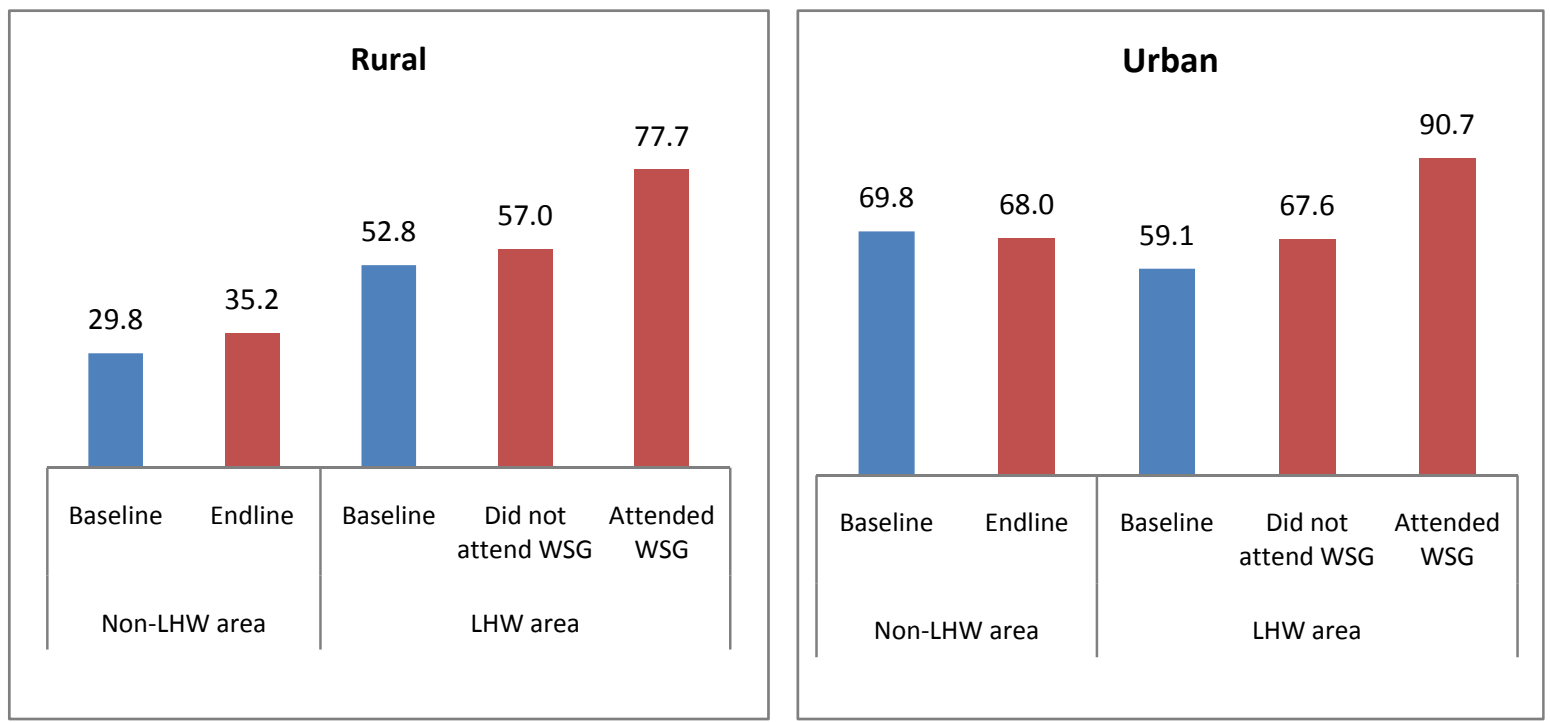

The differences in receiving at least two TT injections are shown in Table 10.6, with tests of significance. Significant improvement in both urban and rural areas is observed in obtaining two TT injections. The positive impact of WSG meetings is highly significant for women who attended WSG meetings compared to the women who did not attend in LHW-covered rural areas. In urban areas, the behavior of women in obtaining at least two TT injections is not significantly different among LHW covered and uncovered areas. However, the impact of WSG meetings is statistically significant in urban areas. Therefore, participation in WSG meetings both in urban and rural communities improves the behavior of women in obtaining at least two TT injections.

Table 10.6: Percentage of women who had at least $2 \mathrm{TT}$ injections, with 95 percent confidence intervals and p-values, by residence, for survey, presence of LHW and WSG attendance

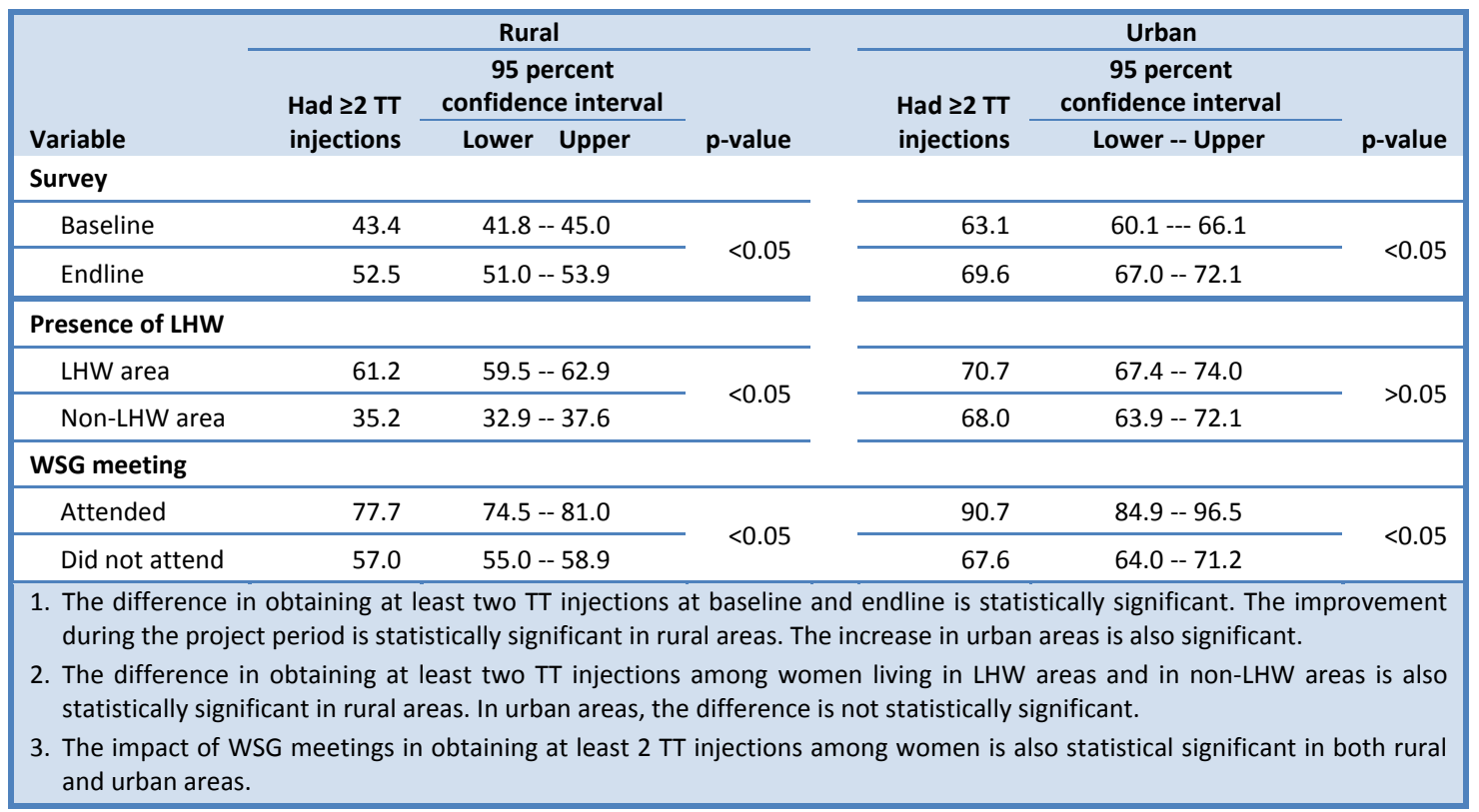




\section{iii) Impact of WSGs on skilled birth assistance}

Skilled birth attendance is considered to be an effective means of reducing maternal and neonatal mortality. Deliveries at home are usually more likely to take place without the assistance of a skilled health provider, whereas deliveries at health facilities are more likely to be conducted by health personnel with at least minimal training in the provision of normal delivery services. The communities were informed through different mediums about the benefits of institutional deliveries. The findings show that deliveries assisted by skilled health providers have substantially increased during the project's duration in the PAIMAN districts.

Skilled birth assistance has increased in urban as well as rural areas, as shown in Figure 10.15. The increase was 9.0 percentage points $(37.8-28.8)$ in non-LHW areas and 10.8 percentage points $(50.2-39.4)$ in LHW covered areas, in the rural domain. An appreciable increase in SBA was noted in the endline survey for women who had attended WSG meetings in rural areas (14.2 percent) over those who had not attended. However, the difference was moderate in urban areas ( 2.5 percent) between those who had attended WSG meetings and those who had not.

The gross effect of WSG meetings on skilled birth assistance in rural areas was 14.2 points and the net effect was 2.9 percentage points. The increase of 10.8 percentage points in SBA coverage in rural LHW areas is made up of about 2.9 percentage points due to participation in WSG meetings and 7.9 percentage points due to factors other than WSG meetings (Figure 10.17).

Figure 10.15: Percentage of women who utilized skilled birth assistance, by residence, presence of LHW and WSG attendance
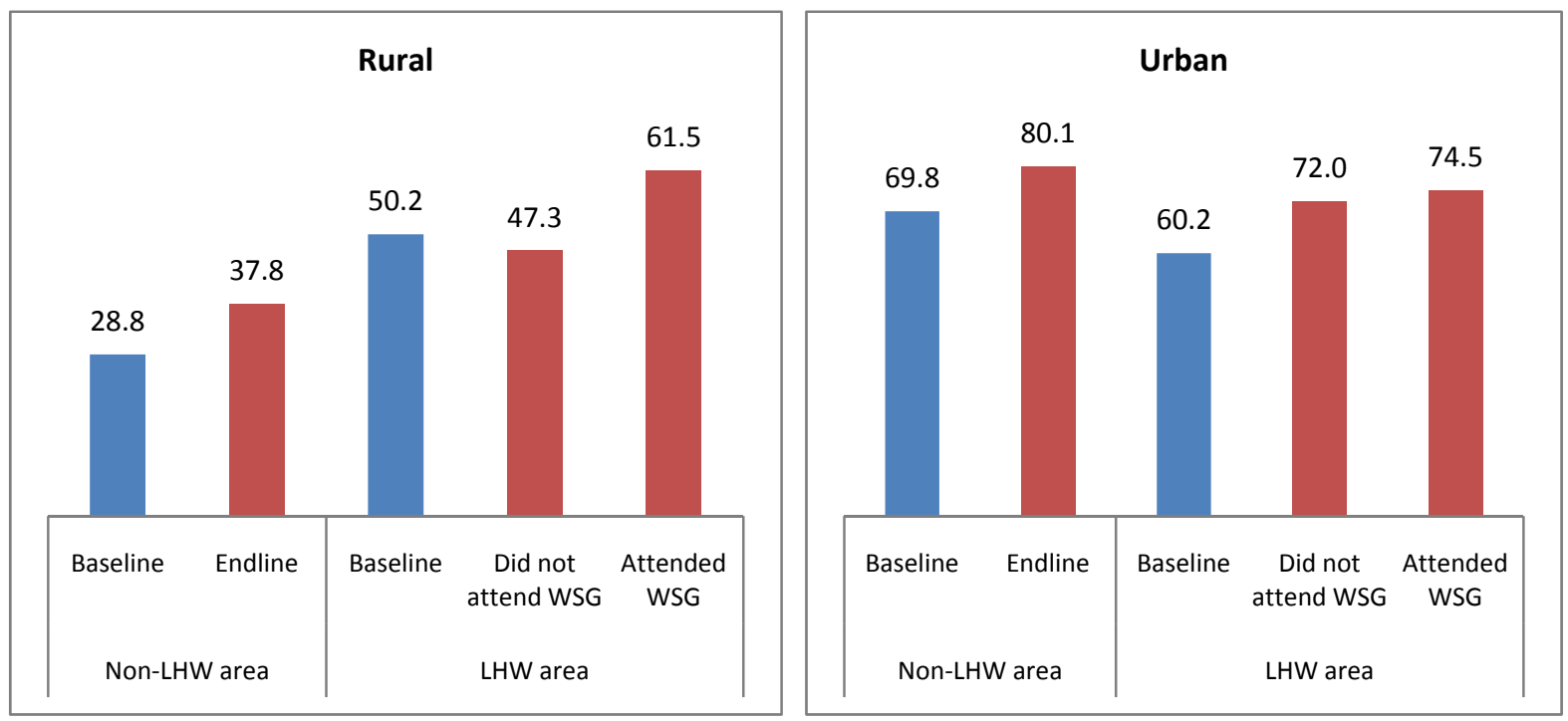

The differences in using skilled birth assistance are presented in Table 10.7, with tests of significance. The analysis shows that there is a statistically significant improvement in women using the assistance of a skilled birth attendant in PAIMAN districts. It is observed that the positive impact of WSG meetings is highly significant for women who attended compared to women who did not attend in LHW-covered rural areas. In urban areas, women in non-LHW areas are significantly more likely to use the assistance of a skilled birth attendant compared to the LHW-covered areas. Even the impact of WSG meetings is not significant in 
- 36.8) in the LHW areas. The gross effect of WSG meetings in rural areas could be estimated as a 14.5 percentage points $(61.8-47.3)$ increase in PNC coverage among those living in LHW areas.

The increase of 13.4 percentage points in obtaining postpartum checkups within 24 hours after delivery in rural LHW areas is made up of about 2.9 percentage points due to participation in WSG meetings and 10.5 percentage points due to factors other than WSG meetings (Figure 10.17).

Figure 10.16: Percentage of women who received postpartum care within 24 hours after delivery, by residence, presence of LHW and WSG attendance
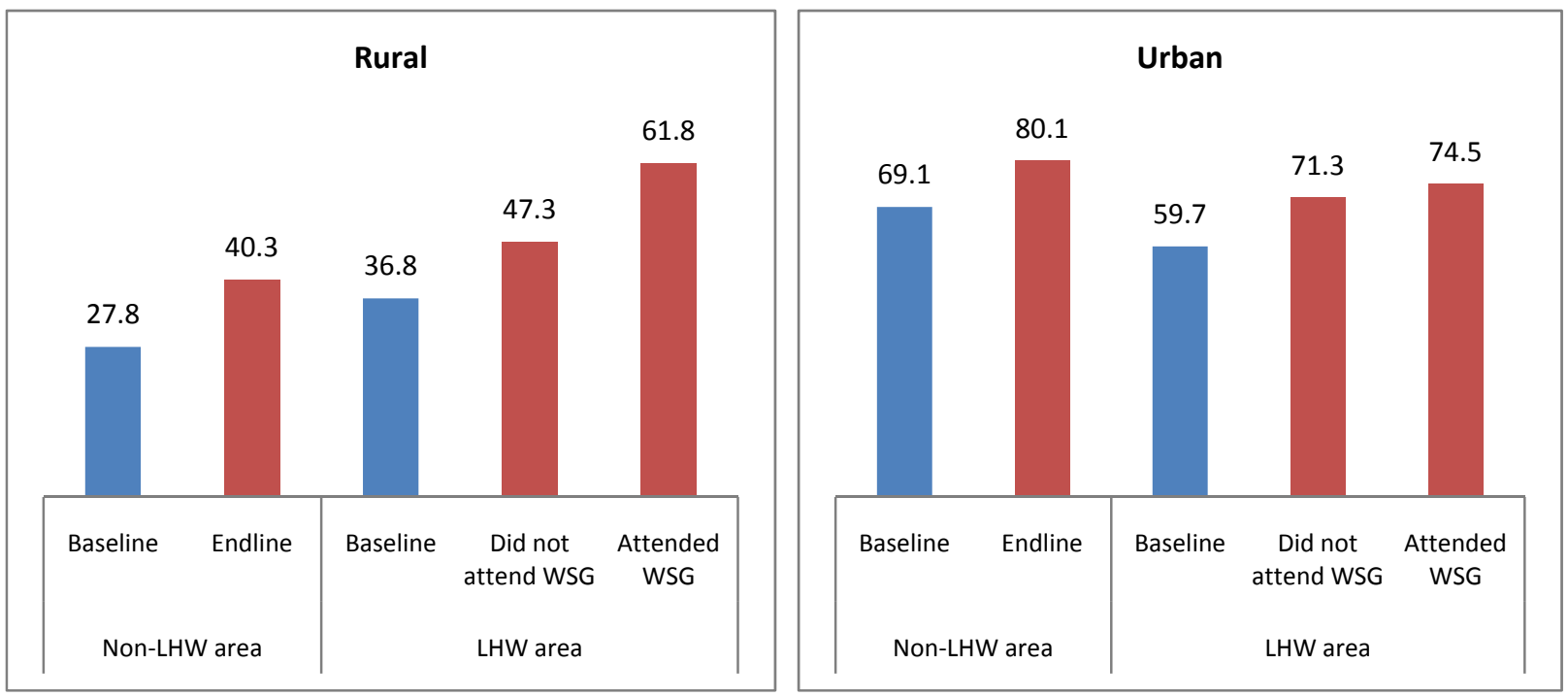

The differences in receiving postpartum care within 24 hours after delivery are presented in Table 10.8, with tests of significance. The analysis shows that the improvement in receiving postpartum checkup within 24 hours after delivery when comparing the endline and baseline survey is statistically significant. In urban areas, women in non-LHW areas are significantly more likely to get postpartum care compared to the LHWcovered areas. Further, the impact of WSG meetings on postpartum care is not significant in urban areas. However, for rural areas, the impact of WSG meetings on receiving postpartum care within 24 hours is significant. 
Table 10.8: Percentage of women who received postpartum care within 24 hours after delivery, 95 percent confidence intervals and p-values, by residence, presence of LHW and WSG attendance

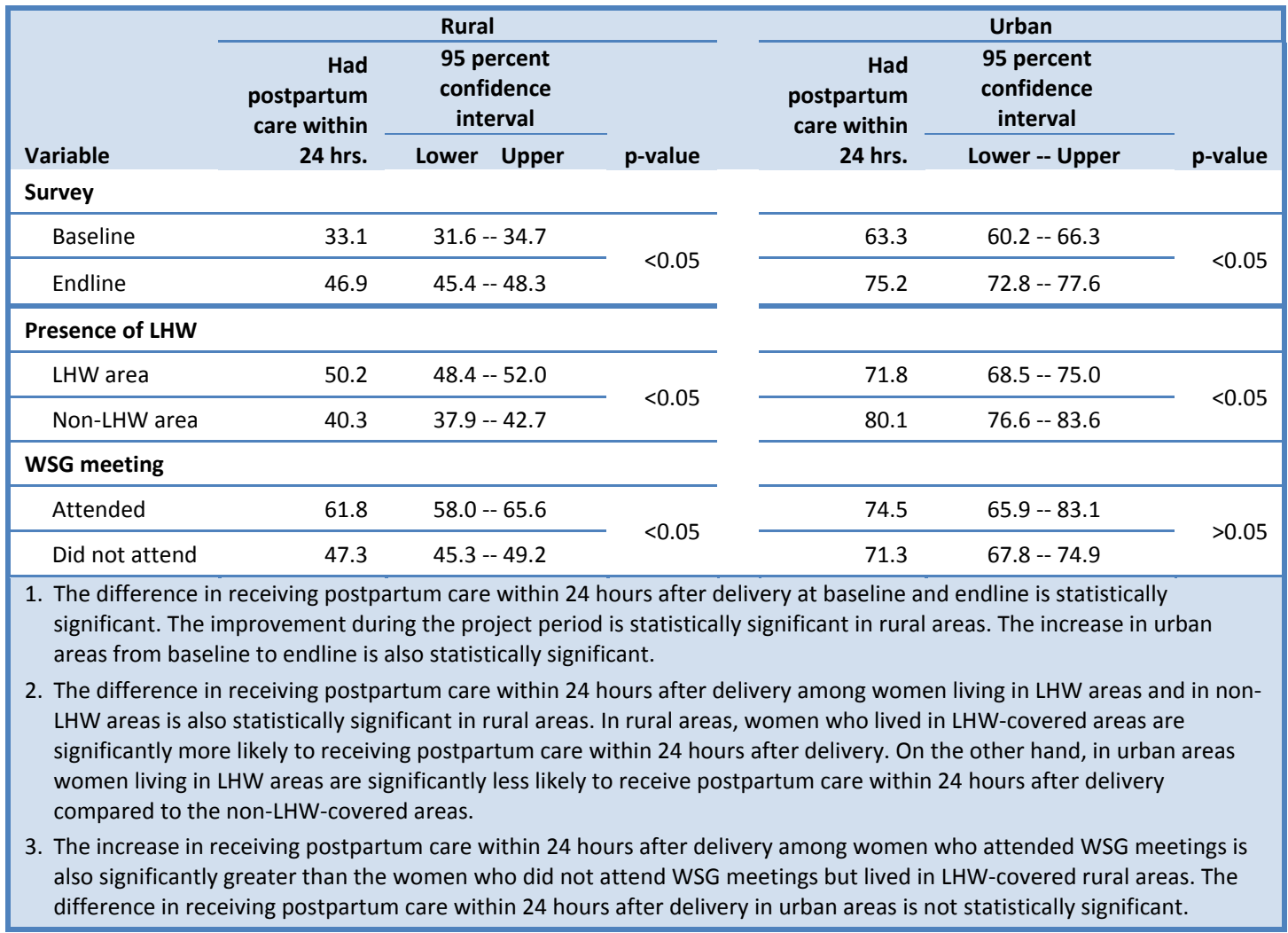

\section{Overall impact of women's support groups}

The analysis shows that the PAIMAN communication and behavior change intervention of women's support group meetings had a positive impact on women receiving maternal and newborn health services during their last pregnancy, especially in rural areas.

Overall, the impact of WSG meetings was higher on TT injections, followed by antenatal care visits and skilled birth attendance in 10 PAIMAN districts, as presented in Figure 10.17. This may partially be due to the fact that LHWs provide TT injections to women, while for antenatal care, skilled birth assistance and postpartum care LHWs refer women to health facilities for services. The impact on TT injection coverage is significantly higher even in urban areas for women who attended WSG meetings compared to women who did not attend WSG meetings in LHW areas. 
Figure 10.17: Percentage of women in rural areas, by impact of PAIMAN communication and behavioral change intervention of women's support groups on four maternal health indicators

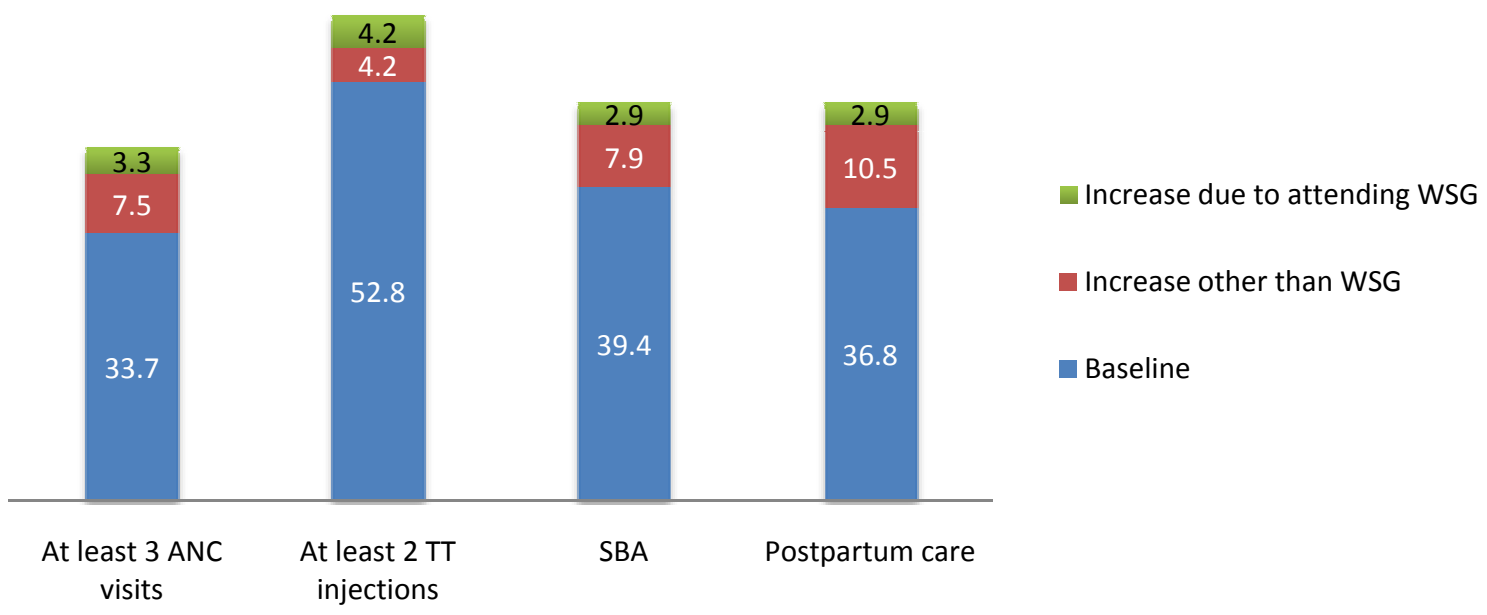

Since the coverage by LHWs in these project districts was less than 60 percent, not all of the women in the project districts were exposed to support group meetings. Those who did attend WSG meetings reported significantly higher utilization of health services during their pregnancy, delivery and postpartum period. Even in LHW-covered areas, only 18 percent of women participated in these meetings; for this reason, the impact of this intervention was limited. However, it seems safe to suggest that if all women had attended these meetings, the proportion of women who utilized maternal health services would have been much higher.

\section{Impact of at least one PAIMAN communication and BCC interventions}

\section{Impact of at least one PAIMAN BCC intervention on women's knowledge of danger signs}

The impact of exposure to PAIMAN interventions on women's knowledge of at least three danger signs during pregnancy, delivery and postpartum is statistically significant. Women exposed to PAIMAN interventions showed significantly greater awareness of these danger signs in both rural and urban areas Table 10.9. For women who were exposed to at least one PAIMAN intervention, there was a significantly greater awareness of at least three danger signs during pregnancy, delivery and postpartum period compared to women who were not exposed to PAIMAN interventions. This was true in both urban and rural areas. In addition, there was a significant increase overall for rural women who knew at least three danger signs for pregnancy, delivery and postpartum period. 
Table 10.9: Percentage of women in rural and urban areas who had knowledge of at least 3 danger signs of pregnancy, delivery and postpartum period, with 95 percent confidence intervals and $p$-values, by exposure to PAIMAN interventions

\begin{tabular}{|c|c|c|c|c|c|c|c|}
\hline \multirow{3}{*}{$\begin{array}{l}\text { Specified } \\
\text { period }\end{array}$} & \multirow{3}{*}{$\begin{array}{l}\text { PAIMAN } \\
\text { exposure } \\
\text { status }\end{array}$} & \multicolumn{3}{|c|}{ Rural areas } & \multicolumn{3}{|c|}{ Urban areas } \\
\hline & & \multirow{2}{*}{$\begin{array}{l}\text { Indicator } \\
\text { estimate }\end{array}$} & $\begin{array}{l}\text { 95\% confidence } \\
\text { interval }\end{array}$ & \multirow[b]{2}{*}{$p$ value } & \multirow{2}{*}{$\begin{array}{l}\text { Indicator } \\
\text { estimate }\end{array}$} & \multirow{2}{*}{$\begin{array}{c}\text { 95\% confidence } \\
\text { interval } \\
\text { Lower -- Upper }\end{array}$} & \multirow[b]{2}{*}{$p$ value } \\
\hline & & & Lower --Upper & & & & \\
\hline \multirow{2}{*}{ Pregnancy } & Exposed & 44.2 & $42.5--45.8$ & \multirow{2}{*}{$p<.05$} & 47.2 & $44.6--49.7$ & \multirow{2}{*}{$p<.05$} \\
\hline & Not exposed & 32.8 & $31.6--34.0$ & & 38.3 & $36.1--40.5$ & \\
\hline \multirow{2}{*}{ Delivery } & Exposed & 28.3 & $26.8--29.8$ & \multirow{2}{*}{$p<.05$} & 26.3 & $24.1--28.6$ & \multirow{2}{*}{$p<.05$} \\
\hline & Not exposed & 18.8 & $17.8--19.8$ & & 20.4 & $18.6--22.3$ & \\
\hline \multirow{2}{*}{ Postpartum } & Exposed & 18.6 & $17.3-19.9$ & \multirow{2}{*}{$p<.05$} & 17.0 & $15.1--19.0$ & \multirow{2}{*}{$\mathrm{p}<.05$} \\
\hline & Not exposed & 10.3 & $9.5--1.0$ & & 11.8 & $10.3--13.3$ & \\
\hline
\end{tabular}

Impact of at least one PAIMAN BCC intervention on four maternal and newborn health indicators

The indicators of exposure to the intervention and maternal health-seeking behavior were based on women's' own reports. Intervention coverage was considered as the proportion of women who reported that they had participated in any of the PAIMAN interventions or watched any TV or radio drama/advertisements on $\mathrm{MNH}$ issues. The communication and behavior-change interventions are presented in Table 10.1 for reference. The indicators on maternal health-seeking behavior were also reported by the women based on the experience of their last delivery within the three years before the surveys. The PAIMAN communication and behavior change interventions were combined to create a variable with two categories, exposed to PAIMAN interventions and not exposed to interventions, and then the impact on maternal health indicators of PAIMAN interventions and non-PAIMAN factors was estimated.

\section{Impact of at least one PAIMAN BCC intervention on women having at least 3 ANC visits}

Figure 10.18 shows the effect of at least one PAIMAN intervention on ANC coverage by residence. In the endline survey, for women who were not exposed to PAIMAN interventions, ANC checkups increased to 30.1 percent compared to 50.6 percent for women exposed to PAIMAN interventions. The increase in ANC among women with at least three ANC checkups is only 2.6 percentage points $(30.1-27.5)$ for women not exposed to PAIMAN interventions compared to an increase of 23.1 percentage points for women exposed to interventions $(50.6-27.5)$.

The gross increase in the rural areas during the 6-year project period is 10.4 percentage points $(37.9-27.5)$. The impact of PAIMAN interventions in the improvement of at least three ANC checkups in rural areas is 7.8 points, while the remaining increase of 2.6 percentage points is contributed by other factors (Figure 10.22).

The gross increase in at least 3 ANC visits in urban areas during the project period is 5.6 percentage points, which includes 5.3 percentage points due to PAIMAN interventions and 0.3 percentage points contributed by other factors (Figure 10.23). 
Figure 10.18: Percentage of women who had at least 3 ANC checkups, by residence, survey and exposure to at least one PAIMAN communication and behavior change intervention

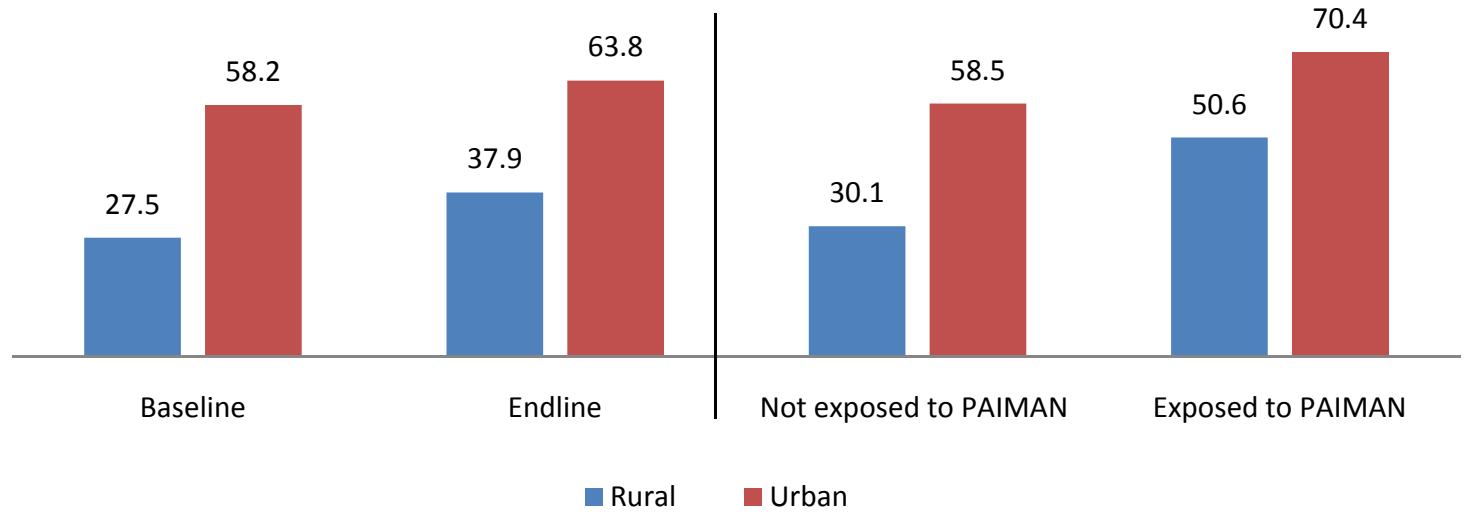

The analysis shows that the impact of PAIMAN interventions on receiving at least three ANC checkups is much higher in rural areas than the impact in urban areas (Figures 10.22 and 10.23). In rural areas, the contribution of PAIMAN interventions is 7.8 points compared to 5.3 points increase in urban areas. The effect may be largely attributed to attending WSG meetings in rural areas.

Table 10.10 shows the comparison of women who received at least three ANC checkups during their last pregnancies, by exposure to PAIMAN interventions. The statistical test shows that the women who were exposed to PAIMAN interventions were significantly more likely to obtain at least three ANC checkups in both urban and rural areas of PAIMAN districts $(p<0.05)$.

Table 10.10: Percentage of women who had at least 3 ANC checkups, with 95 percent confidence intervals and p-values, by residence and exposure to at least one PAIMAN communication and behavior change intervention

\begin{tabular}{|c|c|c|c|}
\hline \multirow{2}{*}{$\begin{array}{l}\text { Residence and exposure to } \\
\text { PAIMAN intervention(s) }\end{array}$} & \multirow{2}{*}{$\begin{array}{r}\text { Had at least } 3 \text { ANC } \\
\text { checkups }\end{array}$} & 95 percent confidence interval & \multirow[b]{2}{*}{ p-value } \\
\hline & & Lower -- Upper & \\
\hline \multicolumn{4}{|l|}{ Rural } \\
\hline Exposed & 50.6 & $49.0--52.3$ & \multirow{2}{*}{$<0.05$} \\
\hline Not exposed & 30.1 & $28.9--31.3$ & \\
\hline \multicolumn{4}{|l|}{ Urban } \\
\hline Exposed & 70.4 & $68.0--72.7$ & \multirow{2}{*}{$<0.05$} \\
\hline Not exposed & 58.5 & $56.2--60.8$ & \\
\hline
\end{tabular}

\section{Impact of at least one PAIMAN BCC intervention on women having at least 2 TT injections}

Figure 10.19 shows the women who had at least 2 TT injections during their last pregnancy. The coverage of $2 \mathrm{TT}$ injections was lowest (43.4 percent) in rural areas at the time of baseline; at endline, rural coverage of 2 TT injections increased to 52.5 percent. The coverage was 45.1 percent among rural women who had not been exposed to PAIMAN interventions compared to 64.8 percent among women who had been exposed to at least one PAIMAN intervention. The increase in at least 2 TT injections is only 1.7 percentage points among women not exposed to PAIMAN interventions compared to 21.4 percentage points increase among those who were exposed to at least one PAIMAN intervention. 
Figure 10.19: Percentage of women who had at least 2 TT injections, by residence, according to survey and exposure to at least one PAIMAN communication and behavior change intervention

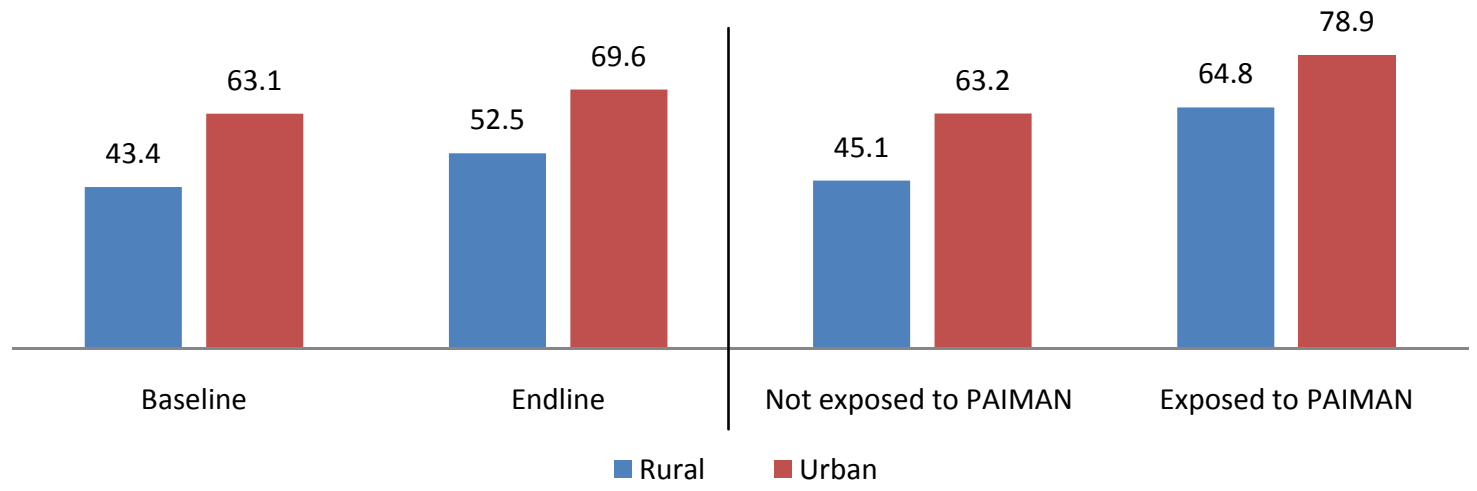

The gross increase in the rural areas during the project period of 9.1 percentage points is made up of 7.4 points due to PAIMAN interventions and 1.7 percent contributed by other factors (Figure 10.22). Similarly, the gross increase in the urban areas during the 6-year period is 5.6 percentage points (Figure 10.23). The increase of 5.6 points in at least 2 TT injections is made up of about 5.3 points due to PAIMAN interventions, while 0.3 percent is contributed by other factors.

The overall increase of 9.1 percentage points in receiving at least $2 \mathrm{TT}$ injections in rural areas is significantly higher compared to the increase of 6.5 percentage points in urban areas (63.1 - 69.6). The analysis shows that the higher increase in rural areas is due to the PAIMAN interventions. The contribution of PAIMAN interventions in rural areas is 7.4 percentage points compared to 6.4 percentage points in urban areas.

Table 10.11 shows the comparison of women who received at least two TT injections during their last pregnancies, by exposure to PAIMAN interventions. The statistical test shows that the women who were exposed to PAIMAN communication and behavior change interventions were significantly more likely to obtain at least two TT injections both in urban and rural areas of PAIMAN districts $(p<0.05)$.

Table 10.11: Percentage of women who had at least $2 \mathrm{TT}$ injections, with 95 percent confidence intervals and $p$-values, by residence and exposure to at least one PAIMAN communication and behavior change intervention

\begin{tabular}{|c|c|c|c|}
\hline \multirow{2}{*}{$\begin{array}{l}\text { Residence and exposure to } \\
\text { PAIMAN intervention(s) }\end{array}$} & \multirow{2}{*}{$\begin{array}{r}\text { Had at least } 2 \text { TT } \\
\text { injections }\end{array}$} & 95 percent confidence interval & \multirow[b]{2}{*}{ p-value } \\
\hline & & Upper & \\
\hline \multicolumn{4}{|l|}{ Rural } \\
\hline Exposed & 64.8 & $63.2--66.4$ & \multirow{2}{*}{$<0.05$} \\
\hline Not exposed & 45.1 & $43.8--46.4$ & \\
\hline \multicolumn{4}{|l|}{ Urban } \\
\hline Exposed & 78.9 & $76.7--81.0$ & \multirow{2}{*}{$<0.05$} \\
\hline Not exposed & 63.2 & $60.2--64.7$ & \\
\hline
\end{tabular}

\section{Impact of at least one PAIMAN BCC intervention on women using skilled birth assistance}

Figure 10.20 shows percentages of women who had delivered their last child with the assistance of a skilled birth attendant by exposure to PAIMAN interventions and residence. The lowest use of SBAs was 35.1 percent in rural areas at the time of the baseline survey. In the endline survey, skilled birth assistance increased to 40.4 percent among women who were not exposed to PAIMAN interventions compared to 55.3 percent among women who had such exposure. The increase in SBA coverage in rural areas of PAIMAN 
districts is only 5.3 percentage point among women not exposed to PAIMAN interventions compared to an increase of 20.2 percentage points among women who were exposed to such interventions.

Figure 10.20: Percentage of women who used skilled birth assistance, by residence and exposure to at least one PAIMAN communication and behavior change intervention

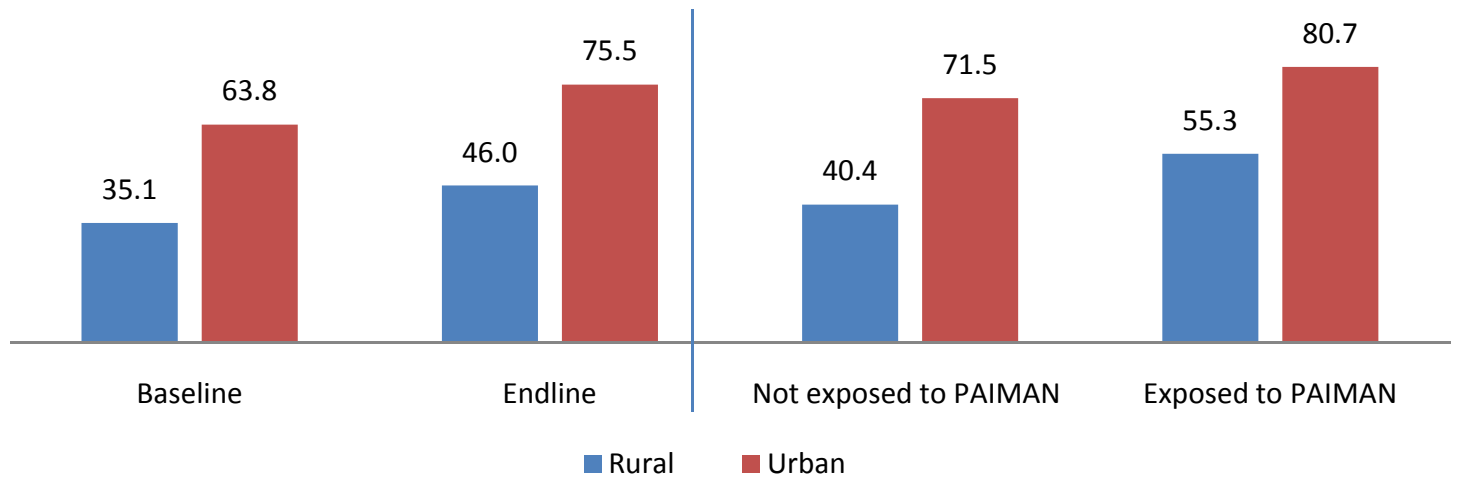

The gross increase in the rural areas during the project period is estimated to be 10.9 percentage points. The increase of 10.9 points in SBA assistance in rural areas is made up of about 5.6 points due to PAIMAN interventions and 5.3 percent contributed by other factors (Figure 10.22).

In urban areas, the gross increase of the PAIMAN districts during the project period is 11.7 percentage points, which is made up of about 4.0 points due to PAIMAN interventions and 7.7 percent contributed by other factors (Figure 10.23).

The overall increase of 10.9 percentage points in using a skilled birth assistant in rural areas is slightly lower than the increase in urban areas, which is 11.7 percentage points. Analysis shows that although the overall increase in rural areas is slightly lower than the increase in urban areas, the percentage increase (31.2 percent) in rural areas is significantly higher than in urban areas (18.4 percent).

Table 10.12 shows the comparison of women who used the assistance of a SBA for their last delivery, by exposure to PAIMAN interventions. One of the main objectives of the PAIMAN project was to increase the use of skilled care at birth. The proportion of women who reported giving birth with the assistance of a skilled provider increased significantly $(p<0.05)$ from baseline to endline. At endline, women who were exposed to PAIMAN communication and behavior change intervention were significantly more likely $(p<0.05)$ than those who were not exposed to report giving birth with the assistance of a skilled provider both in rural and urban areas of PAIMAN districts.

Table 10.12: Percentage of women who used skilled birth assistance, with 95 percent confidence intervals and $p$-values, by residence and exposure to at least one PAIMAN communication and behavior change intervention

\begin{tabular}{|c|c|c|c|}
\hline \multirow{2}{*}{$\begin{array}{l}\text { Residence and exposure to } \\
\text { PAIMAN intervention(s) }\end{array}$} & \multirow[b]{2}{*}{ Used skilled birth assistance } & 95 percent confidence interval & \multirow[b]{2}{*}{ p-value } \\
\hline & & Upper & \\
\hline \multicolumn{4}{|l|}{ Rural } \\
\hline Exposed & 55.3 & $53.6--56.9$ & \multirow{2}{*}{$<0.05$} \\
\hline Not exposed & 40.4 & $39.2--41.7$ & \\
\hline \multicolumn{4}{|l|}{ Urban } \\
\hline Exposed & 80.7 & $78.7--82.7$ & \multirow{2}{*}{$<0.05$} \\
\hline Not exposed & 71.5 & $69.5-73.6$ & \\
\hline
\end{tabular}




\section{Impact of at least one PAIMAN BCC intervention on women utilizing postpartum care within 24 hours}

Figure 10.21 shows women who received postpartum care within 24 hours by exposure to PAIMAN intervention(s) and place of residence. It is observed that postpartum coverage within 24 hours was lowest (33.1 percent) in rural areas at baseline, increasing by endline to 39.9 percent among women who were not exposed to PAIMAN interventions and to 49.2 percent for women who were exposed to such interventions. This increase in postpartum care within 24 hours is only 6.8 percentage points among women who were not exposed to PAIMAN interventions compared to the increase of 16.1 percentage points among exposed women in the rural areas.

Figure 10.21: Percentage of women who utilized postpartum care within 24 hours, by residence and exposure to at least one PAIMAN intervention

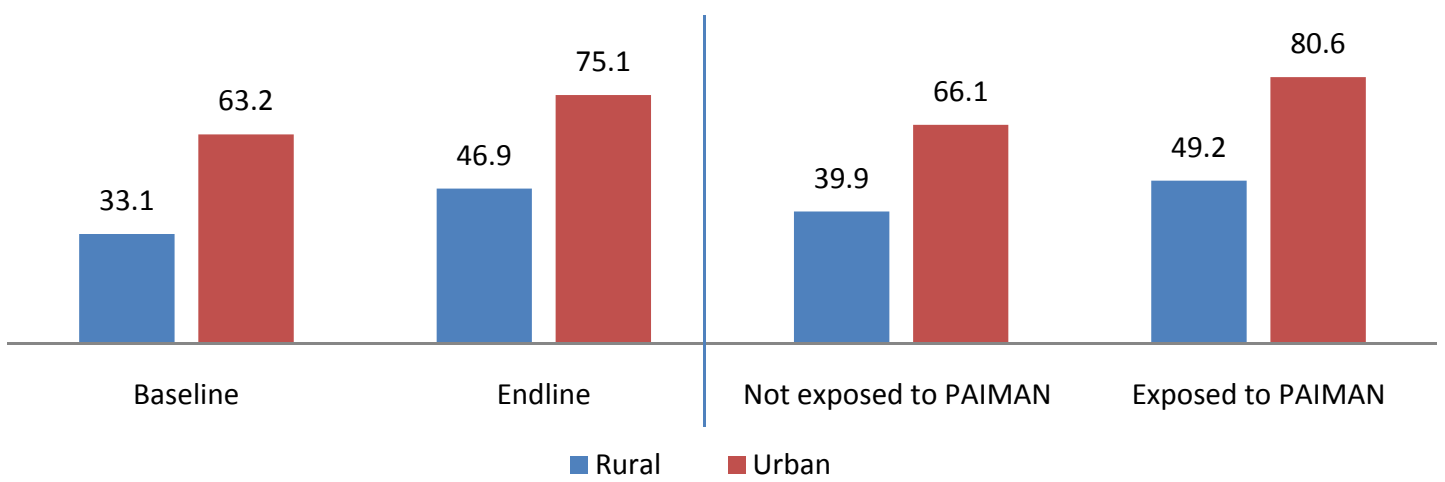

The gross increase in rural areas of 13.8 percentage points is made up of 6.9 points due to PAIMAN interventions and 6.8 points due to other factors (Figure 10.22).

In urban areas, for the increase of 11.9 percentage points in receiving postpartum care within 24 hours after delivery, 9.0 percentage points are due to the PAIMAN interventions and 2.9 percentage points are due to other factors (Figure 10.23).

The overall increase of 13.8 percentage points in receiving postpartum care within 24 hours in rural areas is slightly higher than the increase in urban areas, which is 11.9 percentage points.

Table 10.13 shows the comparison of women who received postpartum care within 24 hours of delivery, by exposure to PAIMAN interventions. The statistical test shows that the women who were exposed to PAIMAN interventions were significantly more likely to receive postpartum care within 24 hours after giving birth both in urban and rural areas of PAIMAN districts $(p<0.05)$.

Table 10.13: Percentage of women who received postpartum care within 24 hours after delivery, with 95 percent confidence intervals and $p$-values, by residence and exposure to at least one PAIMAN communication and behavior change intervention

\begin{tabular}{|c|c|c|c|}
\hline \multirow{2}{*}{$\begin{array}{l}\text { Residence and exposure to } \\
\text { PAIMAN intervention(s) }\end{array}$} & \multirow{2}{*}{$\begin{array}{r}\text { Received postpartum care } \\
\text { within } 24 \text { hours }\end{array}$} & 95 percent confidence interval & \multirow[b]{2}{*}{ p-value } \\
\hline & & Upper & \\
\hline \multicolumn{4}{|l|}{ Rural } \\
\hline Exposed & 49.2 & $46.8--51.7$ & \multirow{2}{*}{$<0.05$} \\
\hline Not exposed & 39.9 & $38.6--41.3$ & \\
\hline \multicolumn{4}{|l|}{ Urban } \\
\hline Exposed & 80.6 & $76.6--84.5$ & \multirow{2}{*}{$<0.05$} \\
\hline Not exposed & 66.1 & $63.5--68.6$ & \\
\hline
\end{tabular}




\section{Overall impact of at least one PAIMAN BCC intervention}

Figures 10.22 and 10.23 illustrate the impact of PAIMAN communication and behavior change interventions on the selected maternal health indicators in rural and urban areas. The analysis shows that exposure to PAIMAN interventions appears to have had a significantly positive impact on receiving ANC checkups, TT injections, utilization of skilled providers for delivery, and obtaining postpartum care within 24 hours after delivery in rural areas. In urban areas, the impact of these interventions also holds true. In rural areas, the highest impact of PAIMAN interventions is observed in receiving ANC checkups (7.8 percentage points) followed by TT injections (7.4 percentage points), postpartum care within 24 hours after delivery (6.9 percentage points) and in obtaining the assistance of skilled providers for delivery ( 5.6 percentage points) in rural areas. In urban areas the highest impact is recorded in receiving postpartum care within 24 hours ( 9 percentage points) followed by TT injections ( 6.4 percentage points) ANC checkups (5.3 percentage points), and in obtaining the assistance of skilled providers (4 percentage points).

Figure 10.22: Percentage of women in rural areas by exposure to at least one PAIMAN communication and behavior change intervention, by change over time in selected maternal health indicators

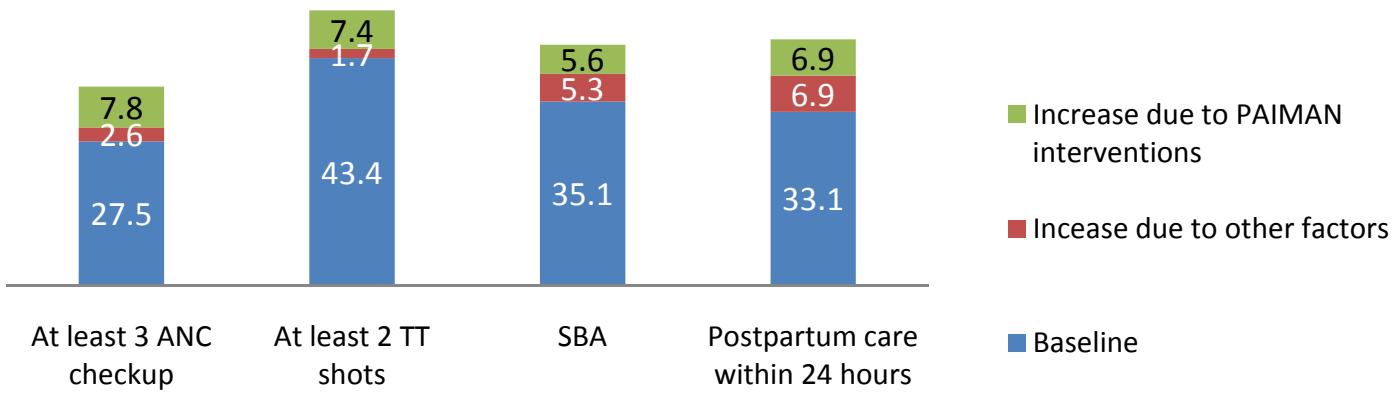

Figure 10.23: Percentage of women in urban areas by exposure to at least one PAIMAN communication and behavior change intervention, by change over time in selected maternal health indicators

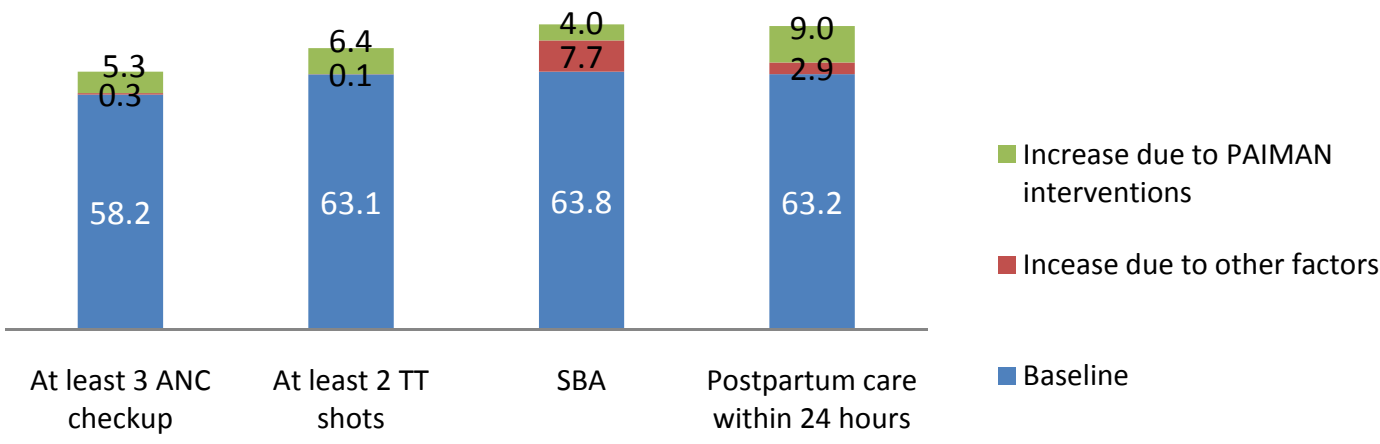

As mentioned in the methodology, the effect over time is also estimated by the difference between estimates for the women who were not exposed to any PAIMAN interventions and the baseline estimates. Figures 10.22 and 10.23 illustrate the estimated effect over time of the four maternal health indicators. The 
estimated effect of other factors is highest in obtaining postpartum care within 24 hours followed by SBA, ANC and TT injections in rural areas; whereas, in urban areas, the effect of other factors is highest for SBA, followed by postpartum care within 24 hours.

\section{Impact of PAIMAN communication and behavior change interventions on perinatal and neonatal mortality}

Table 10.14 shows the impact of communication and behavior change interventions on stillbirths, early neonatal and neonatal mortality rates. It shows that only these interventions have been significant in reducing perinatal mortality. Perinatal mortality has declined from baseline estimates of 53 deaths per 1,000 births to 37 deaths per 1000 births for women who had exposure to at least one PAIMAN communication or BCC intervention but remained unchaned at 53 for women with no exposure (Figure 10.24). The observed reduction in early neonatal and neonatal mortality rates is not statistically significant among women who had exposure to at least one PAIMAN communication and behavior change intervention.

Table 10.14: Estimated neonatal, early neonatal and perinatal mortality rates, with 95 percent confidence intervals and $p$-values, by exposure to at least one PAIMAN communication and behavior change interventions

\begin{tabular}{|c|c|c|c|}
\hline $\begin{array}{l}\text { Type of mortality and exposure } \\
\text { status }\end{array}$ & Mortality rate & $\begin{array}{l}\text { confidence interval } \\
\text { Lower -- Upper }\end{array}$ & $p$ value \\
\hline \multicolumn{4}{|l|}{ Neonatal mortality } \\
\hline Exposed & 21.1 & $15.2-26.2$ & \multirow{2}{*}{$p>.05$} \\
\hline Not exposed & 25.0 & $19.8--29.7$ & \\
\hline \multicolumn{4}{|l|}{ Early neonatal mortality } \\
\hline Exposed & 15.1 & $10.0--20.2$ & \multirow{2}{*}{$p>.05$} \\
\hline Not exposed & 21.5 & $16.7--26.4$ & \\
\hline \multicolumn{4}{|l|}{ Perinatal mortality } \\
\hline Exposed & 36.6 & $28.9--44.3$ & \multirow{2}{*}{$p<.05$} \\
\hline Not exposed & 53.2 & $45.9--60.6$ & \\
\hline
\end{tabular}

Figure 10.24: Perinatal mortality, by exposure status of women to at least one PAIMAN communication and behavior change intervention

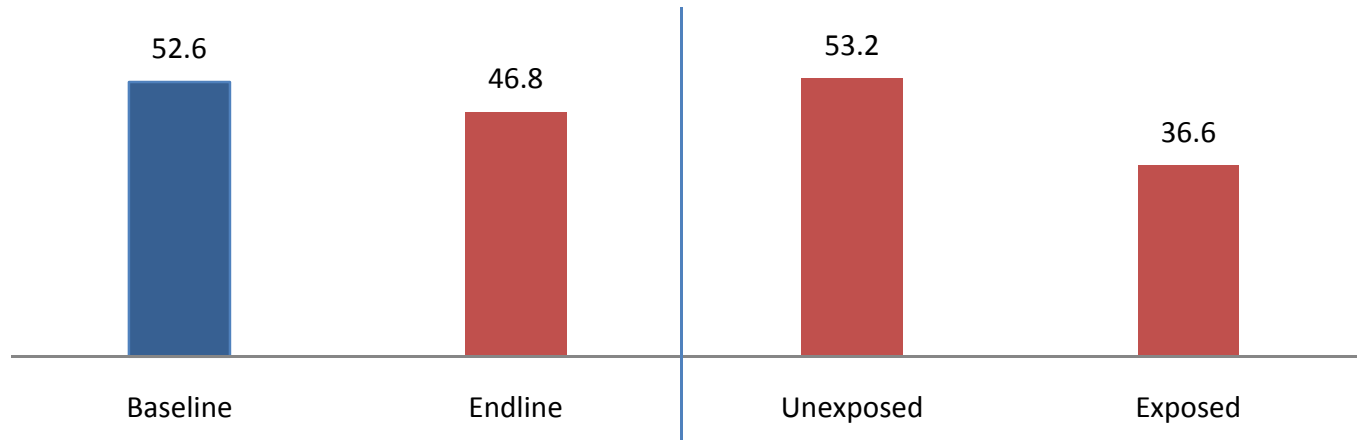




\section{Conclusion}

In keeping with the strategic objectives, key interventions were implemented to achieve PAIMAN project goals within the PAIMAN districts. The interventions fell into two broad areas: 1) health systems upgradation and 2) behavior change communication/community mobilization.

The thrust of PAIMAN efforts were aimed at reducing the health risk to mothers and newborns by increasing the proportion of deliveries under the supervision of health professionals. It is very significant that there were notable improvements in SBA during the project period. The majority of the increase in institutional deliveries occurred in private institutions, not surprisingly, given the spurt of growth of the private sector in the past decade. The proportion of those reporting to have had postpartum checkups within 24 hours, as reflected by the endline survey, also improved.

In general, women who had the exposure to PAIMAN interventions were significantly more likely to obtain maternal health services during pregnancy, delivery and postpartum period compared than women who were not exposed to PAIMAN interventions. Thus, the project succeeded in implementing some key interventions that have the potential for upscaling because of their strong impact on maternal health indicators.

A communication and behavior change intervention that had the greatest impact on women's knowledge and practices was attendance at a women's support group meeting formed by LHWs. This single BCC intervention was linked to significant improvements in maternal health indicators.

Other interventions, such as TV airing of maternal and neonatal care messages, had a widespread influence, but were intermingled with other TV-related influences, making them difficult to disentangle. However, just as PAIMAN used many approaches to reach people with important MNCH messages, it is safe to assume that the impact of some approaches will be long term and will be built on by new programs and methods that will reinforce PAIMAN messages. The next generation of efforts to reduce maternal and neonatal mortality and improve maternal and neonatal care will build on the platform that PAIMAN has laid down, especially in rural areas of Pakistan.

PAIMAN interventions had greater impact in rural areas compared to urban areas. This is not surprising since the room for improvement of delivery practices was also greater in rural areas, where opportunities for getting information and for accessing services are scarcer. It is important that the focus of the major interventions was in rural areas, where women were more likely to be exposed to the PAIMAN initiated women's support groups formed by LHWs and mobilization of the local NGOs/CBOs for safe deliveries by training dais and informing women of lowering risks during pregnancy and delivery. Maternal health did improve in the urban areas also but the major impact was mainly due to mass media campaign initiated by PAIMAN. Furthermore, urban women are more likely to have benefitted from the upgradation of public facilities and the expansion of choices of maternal care in the private sector. However, for women in rural areas, the upgradation of facilities, such as RHCs, did contribute to greater use of such facilities by women who required Caesarean section services.

The most definitive finding of the endline is the decline in perinatal as well as early neonatal mortality in the PAIMAN districts during the project period. As Pakistan continues to struggle with stagnant neonatal mortality rates in the last decade and more, PAIMAN findings when analyzed further can offer real solutions to this national challenge. PAIMAN has succeeded in reducing perinatal mortality significantly in a period of 
six years in the project districts through a combination of improved knowledge of pregnant women on maternal and newborn health issues, increased ANC checkups, TT injections, skilled delivery attendance, and postpartum care utilization.

There are still many obstetrical and complications that are not detected or not treated, and the overall coverage of at least three ANC checkups, postpartum care within 24 hours and institutional deliveries are still far from satisfactory despite the tremendous improvements achieved. More needs to be done with TBAs and CMWs to make their services better since they serve on the frontlines of maternal and neonatal delivery care in Pakistan. The clean delivery practices of TBAs greatly improved between baseline and endline, according to women's reports of clean delivery practices at their home deliveries. The extensive training of TBAs both through PAIMAN and other programs has raised their awareness and use of healthy practices.

While the government needs to continue to provide the resources to maintain the upgraded facilities and personnel, and to expand this to non-PAIMAN districts, the challenge for communities and organizations is how best to scale up those communication and behavior change interventions, such as women's support groups, clean delivery practices, and coverage of TT injections, in a sustainable framework. 



\section{Bibliography}

Caldwell J. 1986. Routes to Low Mortality in Poor Countries. Population and Development Review 12(2) (June): 171-220.

Center for Global Development. 2006. When Will We Ever Learn? Improving Lives Through Impact Evaluation. Report of the Evaluation Gap Working Group. Washington, DC: Center for Global Development

Hollander D. 2004. Antenatal Education Helps Turkish Women Adopt Health-Promoting Behaviour. International Family Planning Perspectives 30(1) (March): 45-46.

JHPIEGO/Maternal and Neonatal Health Program. 2004. "Monitoring Birth Preparedness and Complication Readiness: Tools and Indicators for Maternal and Newborn Health."

Johns Hopkins Bloomberg School of Public Health. 2010. Ulama - Agents for Social Change: Muslim Scholars Speak for Mothers Rights. Islamabad, Pakistan: Johns Hopkins Bloomberg School of Public Health.

Li XF, Fortney JA, Kotelchuck M and Glover LH. 1996. The postpartum period: the key to maternal mortality. International journal of gynecology and obstetrics 54(1): 1-10.

Mahmood A. 2002. Determinants of Neonatal and Post-Neonatal Mortality in Pakistan. The Pakistan Development Review 41(4) Part II (Winter): 723-744.

Mahmood A. 1992. Socioeconomic Factors, Personal Illness Control and Infant and Child Mortality in Pakistan. Pakistan Population Review 3(1) (1992), pp. 67-86.

Martin LG, Trussell J, Reyes Salvail F, Shah NM. 1983. Co-variates of Child Mortality in the Philippines, Indonesia, and Pakistan: An Analysis Based on Hazard Models. Population Studies 37(3) (November): 417-432.

National Institute of Population Studies (NIPS) [Pakistan] and Macro International Inc. 2008. Pakistan Demographic and Health Survey 2006-07. Islamabad, Pakistan: National Institute of Population Studies and Macro International Inc.

Nawaz S. 1983. The Mass Media and Development in Pakistan. Asian Survey 23(8) (August): 934-957.

PAIMAN. 2010. [PAIMAN project information sources from 2005-2010 -- newsletter, quarterly and annual reports -- were used.] Islamabad, Pakistan: PAIMAN Project.

Population Census Organization. Various. District Census Reports. [The reports for each of the 10 PAIMAN districts were utilized; not listed here separately.] Islamabad: Statistics Division, Government of Pakistan.

Population Council. 2006. Baseline household surveys. [There are reports for the 10 project districts of PAIMAN; not listed here separately.] Islamabad, Pakistan: Population Council.

. 2009. Baseline household surveys. [There are reports for the 20 project districts of FALAH; not listed here separately.] Islamabad, Pakistan: Population Council. 
Ramachandran P. 1992. Need of organization of antenatal and intrapartum care in India. Demography India 21(2): 179-193.

Ringheim K. 2002. When the Client is Male: Client-Provider Interaction from a Gender Perspective, International Family Planning Perspectives 28(3) (September): 170-175.

Robbins PT. 2001. Global Approaches to Development. In Sociology of Development, pp. 29-37. London: University of London.

Sathar Z, Crook N, Callum C, Kazi S. 1988. Women's Status and Fertility Change in Pakistan. Population and Development Review 14(3) (Sept.): 415-432.

Simmons, GB. 1979. Family Planning Programs or Development: How Persuasive is the New Wisdom? International Family Planning Perspectives 5(3) (Sept.): 101-110.

Syed SH. 1979. Communications Channels and Family Planning in Pakistan. Studies in Family Planning 10(2) (Feb.): 53-60.

Shryock HS, Siegal JS and Associates. 1980. The Methods and Materials of Demography, Volume 1, 1980.

UNESCO. nd. www.unesco.org.

World Health Organization (WHO). 2003. Pregnancy, Childbirth, Postpartum and Newborn Care: A Guide for Essential Practice. Geneva: World Health Organization.

2005. The World Health Report 2005: Make every mother and child count. Geneva: World Health Organization. 


\section{Appendix 1. Methodology}

To measure the effect of the PAIMAN interventions on the knowledge, attitudes and behavior of women regarding maternal and neonatal health we begin by comparing the endline survey results of maternal health indicators with the baseline survey findings. The difference between the two shows the overall increase in each indicator during the PAIMAN project period. We then estimate the effect of individual PAIMAN interventions on maternal health indicators by assuming the indicator at endline is estimated separately for those who were and were not exposed to that intervention. Temporal effects, which represent changes over the five-year project period largely independent of the project, are estimated by the difference between the value of the indicator at endline for women who were not exposed to the intervention and the value of the indicator at baseline. The gross effect of the intervention is estimated by the difference between the value of the indicator for women who were exposed to the intervention and women who were not exposed to the intervention. The net effect of the intervention is estimated by subtracting the endline estimates from the estimates of women who were not exposed to the intervention.

The value of an indicator at baseline was estimated for:

(a) women living in PSUs without LHWs and

(b) women living in PSUs with LHWs.

For the endline, the values of an indicator were estimated for:

(c) women living in PSUs without LHWs and

(d) women living in PSUs with LHWs.

The second group was then divided into two subgroups:

(e) women who attended WSG meetings and

(f) women who did not attend WSG meetings.

$\rightarrow$ The temporal effects are estimated by the difference between (c) and (a).

$\rightarrow$ The overall effect in LHW areas is estimated by the difference between (d) - (b).

$\rightarrow$ The effect of LHW at baseline is estimated by the difference between (b) and (a).

$\rightarrow$ The effect of LHW at endline is estimated by the difference between (f) and (c).

$\rightarrow$ The increase between baseline and endline among those exposed to LHWs is estimated by the difference between the two $[(f-c)-(b-a)]$.

$\rightarrow$ The gross effect of WSG meetings is estimated by the difference between (e) and (f).

$\rightarrow$ The net effect of WSG meetings is estimated by multiplying the gross effect by the proportion of women who attended WSG meetings. The net effect can also be estimated by subtracting the endline estimates from the estimates of women who were not exposed to the intervention.

\section{Statistical significance test}

The statistical test is also applied to test the significance of the differences between the following:

$\rightarrow$ the increase in the indicator between the baseline and the endline surveys;

$\rightarrow$ the difference between LHW and non-LHW areas in both rural and urban domains; and

$\rightarrow$ the difference between the women who did and did not attend WSG meetings organized in LHW areas in both rural and urban domains. 